\title{
The development and impact of computer-tailored nutrition education
}

Citation for published version (APA):

Brug, J. (1997). The development and impact of computer-tailored nutrition education. [Doctoral Thesis, Maastricht University]. Universiteit Maastricht. https://doi.org/10.26481/dis.19970313jb

Document status and date:

Published: 01/01/1997

DOI:

10.26481/dis.19970313jb

Document Version:

Publisher's PDF, also known as Version of record

\section{Please check the document version of this publication:}

- A submitted manuscript is the version of the article upon submission and before peer-review. There can be important differences between the submitted version and the official published version of record.

People interested in the research are advised to contact the author for the final version of the publication, or visit the DOI to the publisher's website.

- The final author version and the galley proof are versions of the publication after peer review.

- The final published version features the final layout of the paper including the volume, issue and page numbers.

Link to publication

\footnotetext{
General rights rights.

- You may freely distribute the URL identifying the publication in the public portal. please follow below link for the End User Agreement:

www.umlib.nl/taverne-license

Take down policy

If you believe that this document breaches copyright please contact us at:

repository@maastrichtuniversity.nl

providing details and we will investigate your claim.
}

Copyright and moral rights for the publications made accessible in the public portal are retained by the authors and/or other copyright owners and it is a condition of accessing publications that users recognise and abide by the legal requirements associated with these

- Users may download and print one copy of any publication from the public portal for the purpose of private study or research.

- You may not further distribute the material or use it for any profit-making activity or commercial gain

If the publication is distributed under the terms of Article $25 \mathrm{fa}$ of the Dutch Copyright Act, indicated by the "Taverne" license above, 
The Development and Impact of Computer-Tailored Nutrition Education 



\section{Universiteit Maastricht}

The Development and Impact of Computer-Tailored Nutrition Education

\section{Proetschrift}

ter verkrijging van de graad van doctor aan de Universiteit Maastricht, op gezag van de Rector Magnificus, prof. mr. M.J. Cohen, volgens het besluit van het College van Decanen

in het openbaar te verdedigen, op donderdag 13 maart 1997 om 14.00 uur door

Johannes Brug

geboren te Apeldoorn op 21 juni 1963 


\section{Promotores:}

Prof. dr. G.J. Kok

Prof. dr. K. Glanz (University of Hawaii, USA)

Co-promotor:

Dr. P. van Assema

Beoordelingscommissie:

Prof. dr. ir. W.H.M. Saris (voorzitter)

Dr. ir. P.A. van den Brandt

Dr. R. Knibbe

Dr. P. Sparks (Institute of Food Research, Reading, UK)

Prof. dr. V.J. Strecher (University of Michigan, USA)

Brug, Johannes

The development and impact of computer-tailored nutrition education ISBN: $90-9010160-8$

The study presented in this thesis was performed at the Mastricht Health Research Institute for Prevention and Care (HEALTH), which participates in the Netherlands School of Primary Care Research (CaRe), acknowledged in 1995 by the Royal Dutch Academy of Science (KNAW).

The studies were conducted with financial support from the Dutch Cancer Society. The study described in chapter 3 was financially supported by the Steering Committee Healthy Nutrition (Stuurgroep Goede Voeding).

The printing of this thesis was financially supported by the Dutch Cancer Society and OHRA i.s.m. Gezondheid Service Nederland. 


\section{Contents}

General Introduction

Part I:

Problem analysis

Chapter 1 Diet and primary prevention of chronic diseases

Part II:

Determinants of dietary behavior

Outline

Chapter 2:

Self-rated dietary fat intake: Association with objective assessment of fat, psychosocial factors and intention to change

Chapter 3: Misconception of fat consumption: Causes and implications

Chapter 4: Differences in psychosocial factors and fat consumption between stages of change for fat reduction

Chapter 5: Determinants of fruit and vegetable consumption: Results of focus group interviews

Chapter 6: Determinants of fruit and vegetable consumption: Telephone survey

Chapter 7: Do eating practices and psychosocial factors differ across stages of change for fruit and vegetable intake?

Part III:

Development and evaluation of computer-tailored nutrition education

Outline

Chapter 8:

A review of the application and impact of computer-tailored nutrition education

Chapter 9: The impact of a computer-tailored nutrition intervention 
Chapter 10: Differences in impact between two computer-tailored nutrition interventions

Chapter 11: Computer-tailored nutrition education: Longer term impact and the impact of ipsative feedback

General discussion

References

Summary 193

Samenvatting

201

Curriculum vitae

209

Acknowledgements

210

Appendix

211 


\section{General Introduction}

In this thesis the development and evaluation of an individual tailored nutrition education instrument is described. In planned development, implementation, and evaluation of health education interventions, different, consecutive phases should be completed. The Model for Planned Health Education Interventions (Figure 1; Green \& Kreuter, 1991) describes these different phases. The general outline of the thesis follows this model.

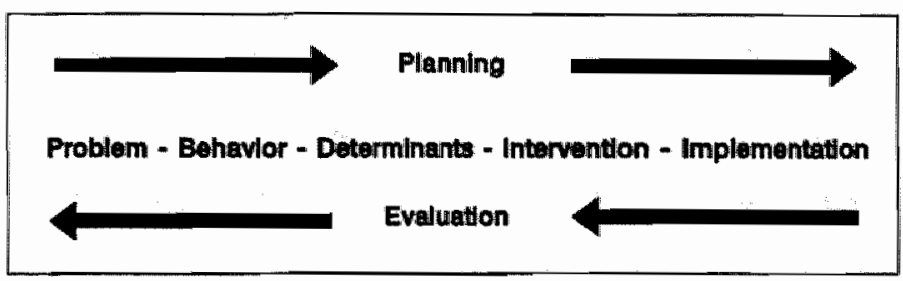

Figure 1. The model for planned health education interventions

According to the model, the first step in the development of health education is the identification of a bealth problem that is serious and important enough to be targeted with a health education intervention. During the second step the specific human behaviors that are causing the health problem of interest should be identified and it should be revealed whether there are specific population groups who take part in these risk behaviors. In Part I of this thesis the choice of the health problem and the target behaviors will be justified. The ultimate goal of the intervention that is described in this thesis is primary prevention of cardiovascular disease (CVD) and certain cancers. Two aspects of the diet were targeted by the intervention: a reduction in dietary fat consumption and an increase in consumption of fruit and vegetables. The seriousness of CVD and cancer as health problems in the Netherlands will be briefly illustrated first in Part I. Furthermore, the epidemiology of the association between diet and CVD and between diet and cancer, and the Dutch diet in relation to recommendations for a prudent diet, will be reviewed.

In the third step of health education planning, a diagnosis should be made of the (psychosocial) determinants of the behaviors that are causing the health problem. In this planning phase, which is described in Part $\Pi$, it should become as clear as possible why people 
take part in the risk behavior of interest. For the present study this meant that the question "why do people eat too much fat and too little fruit and vegetables" had to be answered as completely as possible. Therefore, a number of studies were conducted in which the psychosocial determinants of consumption of fat, and of fruit and vegetable consumption were investigated.

During the fourth step, the actual methods, strategies, materials, intermediaries, and media for the health education intervention should be selected, and the actual intervention should be developed. This actual development is idleally based on the results of the behavioral analysis from which the target population can be derived, the determinant analysis from which the intervention goals should have become clear, and on available insights in the most appropriate ways to reach the target population. During this phase the intervention should also be pretested and adjustments of the intervention should be made based on pretest results. Based on the behavioral analysis and on the determinant studies, a computer-tailored intervention was developed and pretested. Computer-tailoring is similar to person-to-person health education, be it that the expertise of the educator is programmed using computer software. The tailored intervention provided subjects with personal letters with information about their own diets in order to make them aware of their consumption patterns, and suggestions on how they could try to change their diet towards a healthier way of eating. Information about pros and cons and self-efficacy information related to less fat and more fruit and vegetables, tailored to the subjects" individual beliefs, was also provided.

The final step in the planning phase of health education is the implementation diagnosis of the intervention. In this phase, factors that might enhance or hinder actual implementation should be identified.

The model for planned health education also addresses the evaluation of the intervention. The evaluation phases are similar to the planning steps: During the evaluation it should be assessed if the intervention was implemented according to plan, whether the intervention has resulted in changes in the behavioral determinants and in the behavior of interest. The ultimate goal of health education interventions is to reduce the health problem. Eventually, the evaluation of health education interventions should focus on answering the question whether the health problem itself bas been reduced. Unfortunately, for many health problems there is a substantial time span before changing the associated risk behavior leads to a reduced health risk. Therefore, in evaluation studies of health education interventions, often changes in behavioral determinants and behavior are used as indicators of the intervention impact. This is also true for nutrition education interven- 
tions aimed at primary prevention of chronic diseases. Changes in dietary behaviors are often used to assess the impact of these interventions.

The development, implementation and evaluation of tailored nutrition education is described in Part III of this thesis. In Chapter 8 a brief review of computer-tailored nutrition interventions is given. In Chapter 9 the first version of the tailored intervention is described and the design, methods and results of the impact evaluation study of the tailored intervention are described and discussed. Changes in dietary consumption of fat, fruit and vegetables were used to assess the impact of the tailored intervention.

In order to try to improve the intervention, two additional experiments were conducted. In the first of these experiments it was investigated whether the tailored intervention could be simplified without reducing it's effectiveness. In this experiment, two tailored nutrition education interventions were compared, a comprehensive tailored intervention and a more limited tailored approach. The results are described and discussed in Chapter 10. In the third experiment the longer term effects of computer-tailored nutrition education and the additional effect of a second mutrition education letter, tailored to changes in intentions and behavior were investigated. This experiment is described in Chapter 11. Finally, in the General Discussion, the results of the different studies are discussed in an integrated way and the conclusions that can be drawn based on the studies are reported and discussed.

Most chapters were written as research articles in order to be published in scientific journals. Therefore, these chapters are self-explanatory outside the context of this thesis. Another consequence of the fact that the thesis consists of a number of research articles that have been, or will be published separately, is that some information about models or procedures that were used are described more than once. An overview of the different studies with the samples, data collection method and general study design is presented in Table 1. 
Table 1

Ovenview of the differen studies presented in the thesis

\begin{tabular}{|c|c|c|c|c|}
\hline Chapter & Sample & $\mathrm{n}$ & Study design & Data collection \\
\hline 2 & $\begin{array}{l}\text { Random sample of } \\
\text { aduit population of } \\
\text { two municipalities }\end{array}$ & 1507 & Survey & $\begin{array}{l}\text { Telephone inter- } \\
\text { views }\end{array}$ \\
\hline 3 & $\begin{array}{l}\text { Random sample of } \\
\text { Dutch adult popula- } \\
\text { tion }\end{array}$ & 989 & Survey & $\begin{array}{l}\text { Telephone inter- } \\
\text { views }\end{array}$ \\
\hline 4 & $\begin{array}{l}\text { Sample of employ- } \\
\text { ees of oil company }\end{array}$ & 507 & Survey & $\begin{array}{l}\text { Written question- } \\
\text { naires }\end{array}$ \\
\hline 5 & $\begin{array}{l}\text { Inhabitants of Zuid } \\
\text { Limburg }\end{array}$ & 29 & Focus groups & $\begin{array}{l}\text { Focus group } \\
\text { interviews }\end{array}$ \\
\hline 6 & $\begin{array}{l}\text { Random sample of } \\
\text { Dutch adult popu- } \\
\text { lation }\end{array}$ & 367 & Survey & $\begin{array}{l}\text { Telephone ques- } \\
\text { tionnaires }\end{array}$ \\
\hline 7 & Adult volunteers & 739 & Survey & $\begin{array}{l}\text { Written question- } \\
\text { naires }\end{array}$ \\
\hline 9 & $\begin{array}{l}\text { Sample of employ- } \\
\text { ees of oil company }\end{array}$ & 347 & Experiment & $\begin{array}{l}\text { Written question- } \\
\text { naires }\end{array}$ \\
\hline 10 & $\begin{array}{l}\text { Employees of re- } \\
\text { gional home care } \\
\text { organization }\end{array}$ & 315 & Experiment & $\begin{array}{l}\text { Written question- } \\
\text { naires }\end{array}$ \\
\hline 11 & Adult volunteers & 646 & Experiment & $\begin{array}{l}\text { Written question- } \\
\text { naires }\end{array}$ \\
\hline
\end{tabular}


Part I

Problem analysis 


\section{Introduction}

The major causes of death in the Netherlands as well as in most European and North American countries are chronic diseases like cardiovascular disease (CVD) and cancer (Kris-Etherton, Volz-Clarke, Clark \& Dattilo, 1990; Nederlandse Hartstichting, 1995; Stuurgroep Toekomstscenario's Gezondheidszorg, 1994). In the Netherlands, cardiovascular diseases were responsible for approximately forty percent of total mortality in 1993. A sharp rise in incidence and mortality of CVD occurred in the Netherlands after the second world war, especially in the 1960's. In 1972 CVD was responsible for $46 \%$ of total mortality. From 1973 onwards CVD mortality rates have declined in the Netherlands. It is expected that cardiovascular disease mortality rates will further decline in the next decades, but CVD is expected to remain one of the main causes of death in the Netherlands. Furthermore, although mortality rates might further decrease, the prevalence, incidence and total mortality are not expected to decline, due to a growing and aging population (Ruwaard \& Kramers, 1993).

Cancer is the second main cause of mortality in the Netherlands, responsible for approximately 25\% of annual deaths in 1993 (Stuurgroep 'Toekomstscenario's Gezondheidszorg, 1994). For people between 45 and 60 years of age, cancer is the main cause of death. The most important cancers in terms of incidence and mortality are cancer of the lung for men and cancer of the breast for women. Other cancers with relatively high incidence rates are cancers of the prostate for men and cancer of the digestive tract, especially the colon, among both men and women. Cancer mortality rates have increased since registration began in the $1950^{\prime}$ 's. In recent years this trend has levelled off and for men a slight decrease has been found (Stururgroep Toekomstscenario's Gezondheidszorg, 1994), but similar to the situation regarding CVD, total cancer mortality is not expected to diminish because of the increasing age of the Dutch population (Ruwaard \& Kramers, 1993).

Chronic diseases like CVD and cancer are associated with our 'life style'. Smoking habits, physical exercise, and dietary habits, are three examples of life style factors that are thought to be associated with risk for these diseases (Kris-Etherton et al., 1990). In order to influence these factors towards a healthier life style, various activities have been employed in the field of health education and health promotion. For example, various health education programs have been carried out to stimulate people to stop smoking, to increase their physical activities and to change their diet, in other words, to stimulate people to adopt healthier behaviors. As far as nutrition is concerned, two aspects of the 
diet have received a considerable amount of attention in relation to primary prevention of CVD and cancer: a reduction of dietary fat and, more recently, an increase in consumption of fruit and vegetables. Fat consumption as a risk factor was first studied in relation to CVD. Somewhat later, dietary fat was also suspected to play a role in the etiology of cancer. For fruit and vegetables, the attention came in the reversed order: The preventive characteristics of consumption of ample amounts of fruit and vegetables were first studied in relation to cancer. More recently, the association between CVD risk and fruit and vegetable consumption also got increased attention.

\section{Fat Consumption}

\section{Dietary Fat and Cardiovascular Disease}

The association between fat consumption and CVD has been studied extensively. Interest in the association between diet and CVD found its origin in the observation that serum cholesterol levels are positively associated with coronary heart disease (CHD) risk (Dawber, 1980; Willet, 1994). It became generally accepted that serum cholesterol levels tend to increase with higher consumption levels of cholesterol and especially with increased intake of saturated fat. Serum cholesterol tends to decrease with higher intakes of poly-unsaturated fat. The implications of these findings were that a reduction in intake of cholesterol and saturated fat could lead to lower CHD incidence and mortality (Voedingsraad, 1982). Based on the epidemiological evidence, public health authorities in different countries published recommendations for the public to reduce the amount of (saturated) fat in the diet. In the Netherlands the recommendation to reduce dietary fat intake to a level between 30 and 35 percent of calories is part of the official dietary recommendations (Voedingsraad, 1986a).

More recently, the associations between dietary fat consumption and CHD risks have been studied in more detail (Mensink, Zock \& Katan, 1994; Shrapnel, Calvert, Netsel \& Truswell, 1992; Willet, 1994). Nowadays, the ratio between high density lipoprotein (HDL) cholesterol and total cholesterol is seen as a better predictor of CHD risk than total cholesterol levels. HDL cholesterol has been found to be inversely related to CHD risk, whereas low density lipoprotein (LDL) cholesterol and very low density lipoprotein (VLDL) cholesterol have been recognized as the major risk elevating cholesterol particles (Linscheer \& Vergroesen, 1988). Therefore, the higher the HDL cholesterol / total cholesterol-ratio is, the higher the risk for CHD. Furthermore, it has been found that different fatty acids have different effects on serum cholesterol levels. Fatty acids are 
traditionally divided into three categories based on the number of double bonds between the carbon atoms that form the backbone of the fatty acid molecules: saturated fatry acids (no double bonds), mono-unsaturated fats (one double bond), and poly-unsaturated fats (wwo or more double bonds) (Davidson, Passmore, Brock \& Truswell, 1979). But currently it is argued that this popular division is too simple in relation to health issues.

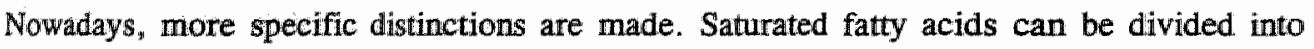
three separate categories, based on the number of carbon atoms in the fatty acid chain. The long-chain saturated fatry acids, with 12,14 or 16 carbon atoms, proved to be the LDL cholesterol raising agents. Animal fats like meat and meat products and milk products are dietary sources of these fatty acids. Saturated fatty acids with less than 12 , or more than 18 carbon atoms seem to be neutral with respect to serum cholesterol levels (Mensink et al., 1994). For poly-unsaturated fatty acids, a distinction between so-called omega-6 or N-6 and omega-3 or N-3 poly-unsaturated fatty acids is often made (Shrapnel et al. 1992). An example of N-6 poly-unsaturated fatty acids is linoleic acid. Rich sources of linoleic acids are most vegetable oils, like sunflower oill and corn oil (Linscheer \& Vergroesen; 1988). There are strong indications that linoleic acid lowers serum LDL cholesterol levels. Some claims were made that N-6 poly-unsaturated fatty acids also lower HDL cholesterol levels which would be a less desirable effect in relation to CHD prevention (Fraser, 1994; Shrapnel et al., 1992), but the HDL cholesterol lowering effect might be only temporary after increasing $N-6$ poly-unsaturated fatty acid intake (Kromhout et al., 1995). N-3 poly-unsaturated fatty acids can be found in fish oils and are also supposed to have preventive characteristics in relation to $\mathrm{CHD}$ (Kromhout, Bosschieter \& De Lezenne Coulander, 1985; Leaf, 1992). The effects of N-3 poly-unsaturated fatty acids on the various cholesterol particles are not yet clear. The supposedly protective effect of N-3 poly-unsaturated fatty acids has been attributed to their effects on thrombosis prevention, since they increase bleeding time and decrease platelet aggregability (Kromhout et al., 1985; Shrapnel et al., 1992; Willet, 1994), but the positive effects of N-3 poly-unsaturated fatty acids are not undisputed (Leaf, 1992; Linscheer \& Vergroesen, 1988).

Because poly-unsaturated fats do not only decrease LDL cholesterol levels but might also have the undesired effect of decreasing HDL cholesterol levels, and because various studies suggested that vegetable oils, especially olive oil, with high percentages of monounsaturated fats might have preventive effects in regard to CHD, mono-unsaturated fatty acids became a further subject of study: When saturated fats are replaced by mono- 


\title{
Chapter 1
}

Diet and Primary Prevention of Chronic Diseases

\begin{abstract}
Cardiovascular disease and cancer are the two most common causes of death in the Netherlands. There are strong indications that certain dietary habits might increase the risk for these diseases. Consumption of saturated fat has been found to be positively associated with cardiovascular disease risk while cancer risk has repeatedily been found to be inversely associated with fruit and vegetable consumption. There are also indicarions that consumption of larger quantities of fruit and vegetables are beneficial with respect to cardiovascular disease risk. Reduction of dietary fat intake and increasing consumption of fruit and vegetables are key elements of dietary recommendations. Consumption of fat, fruit and vegetables have been found to be far from ideal in the Netherlands. Therefore, changing dietary habits has the potential to contribute to a reduction of cardiovascular and cancer risk.
\end{abstract}


unsaturated fats in the diet they seem to lower LDL cholesterol levels with a neutral effect on HDL cholesterol (Shrapnel et al., 1992).

Because of the increased use of partially hydrogenated fats in the food industry, there has been a growing interest in the effects of so-called trans fatty acids on CVD risk (Willet \& Ascherio, 1994). Hydrogenation of liquid fats produces these trans fatty acids. Hydrogenation is used to convert liquid vegetable oils into solid fats that can be used as shortening in the production of many food products, like for example margarines, pastry, cookies, etc. During the partial hydrogenation some unsaturated bonds are converted from their natural cis position to the trans position. Research that has been published so far points to the conclusion that trans fatty acids have an elevating effect on LDL cholesterol comparable to saturated fats. Furthermore, trans fatty acids are thought to decrease HDL cholesterol levels (Willett \& Ascherio, 1994).

Because of the attention on the effects of different fatty acids on CHD risk, the effects of dietary cholesterol have been forced to the background somewhat. Nevertheless, the general accepted conclusion is that dietary cholesterol tends to increase serum levels of LDL and total cholesterol, but the effect is of a lesser extent than that of saturated fats.

A final way in which dietary fat intake might be associated with CVD risk is through body weight. Total fat consumption has been found to be positively associated with body weight; people with high fat intakes are suspected to have higher risks for obesity and obesity is thought to be a risk factor for CVD (Larsson, 1990). Obese people have elevated total cholesterol levels while inverse associations between body mass index and HDL choiesterol levels have been reported as well (Higgins \& D'Agostino, 1990). Furthermore, obesity is assaciated with hypertension and reduced physical activity. There are, however, indications that obesity is also a risk factor for CVD independent of factors like serum cholesterol, blood pressure, and exercise (Larsson, 1990).

\section{Dietary Fat and Cancer Risk}

A high fat intake, and concurrent high energy intake and high body weight, are also considered as agents that increase cancer risk (Carroll, Braden, Bell \& Kalameghan, 1986; Graham, 1986; Kritchevsky, 1995; Voedingsraad, 1986b). Fat has been studied in particular as a risk factor for two of the most common cancers: breast cancer and cancers of the digestive tract, especially the colon.

Different mechanisms have been proposed through which higher fat intakes could lead to a higher breast cancer risk (Van 't Veer, 1990). High fat intake and/or associated high. energy intake are supposed to influence hormone mediated mechanisms considered to be 
important in the etiology of breast cancer (Rose, 1986). Higher fat and energy intakes are associated with earlier menarche, and a delayed menopause. Furthermore, high fat intake may affect cancer risk by altering the fatty acid composition of the cell membrane (Welsch, 1987).

Indications for a telationship between fat consumption and breast cancer risk initially came from ecological studies. Countries with lower average fat consumption showed lower incidence and mortality rates for breast cancer (Rohan \& Bain, 1987). Additional evidence for a relation between dietary fat consumption and breast cancer risk came from migrant studies and studies using animal models (Goodwin \& Boyd, 1987). In recent years, a number of prospective cohort studies have been conducted and reported on the association between fat consumption and breast cancer and based on the results of these studies, the conclusion can be drawn that there is not enough evidence for a positive association between total fat and breast cancer risk (Ossendorp, Ypma, Van Leeuwen \& Rookus, 1993; Van den Brandt et al., 1993; Willet et al., 1992). Furthermore, an association with animal fat consumption instead of total fat could also not be supported in these studies. A potential pitfal in most prospective studies is the homogenity of the study population. Some argue that fat intake should be reduced to levels well below $30 \%$ energy from fat in order to have preventive effects on breast cancer risk. Subjects with such low fat intake levels are insufficiently represented in most samples in Western countries. Furthermore, fat intake in early life might be a more important predictor of breast cancer risk than fat intake during adulthood (Willett, 1989).

The possible association between dietary fat and colon cancer has been studied extensively with ambivalent results. The biological mechanism for the positive association between fat consumption and colon cancer is plausible. A higher fat consumption increases the secretion of bile acids (Carroll et al, 1986). These bile acids can be broken down by intestinal flora into carcinogenic compounds (Willett, 1989). Positive associations between saturated fat or animal fat intake, meat consumption and consumption of processed meat with colon cancer risk but no relation with total fat have been found in recent prospective cohort studies (Giovannucci, Rimm, Stampfer, Colditz, Ascherio \& Willett, 1994; Goldbohm, Van den Brandt, Van 't Veer et al., 1994; Willett, Stampfer, Colditz, Rosner \& Speizer, 1990; Willett et al., 1992). Based on a review of these studies, Potter (1995) concluded that the data strongly suggest that a diet high in meat, fat and protein is important in the etiology of colon cancer.

The evidence for a positive relation between total fat intake and colon cancer risk has recently been disputed by data that showed that risk for colon cancer in Europe is lowest 
in countries like Greece and Spain, the same countries that have a very high per capita fat intake (Hill, 1994). More recently a protective effect of unsaturated fat has been proposed (Giovannucci et al., 1994; Martin-Moreno et al., 1994). The low cancer incidence in Greece and Spain might be partially attributed to high intake of olive oil or high fish consumption in those countries. However, olive oil is not only a good source of monounsaturated fatty acids, but is also rich in certain anti-oxidants that are supposed to be chemopreventive against cancer. Therefore, the proposed protective effect of olive oil might be attributable to this characteristic.

A preventive effect of $\mathrm{N}-3$ poly-unsaturated fatty acids on colon cancer risk has also been suggested (Anti et all, 1992; Wargovich, 1992). Areas where fish and fish products are consumed in high quantities show lower colon cancer incidence rates. Fish oils might reduce the production of postaglandines and leukotrienes and through this mechanism improve the immune response to carcinogenisis (Wargovich, 1992).

\section{Dietary Fat Consumption and Dietary Recommendations in the Netherlands}

In the Netherlands, the recommendation for fat is as follows (Hulshof, Löwik, Kistemaker, Hermus \& Ockhuizen, 1993; Voedingsraad, 1986a):

"Reduce the amount of fat to $30-35 \%$ of calories, by especially limiting the amount of saturated fatty acids"

In comparison with other countries, this recommendation is rather conservative. In the U.S.A., for example, for more than a decade, the recommendation has been to reduce fat intake to levels below $30 \%$ energy from fat (U.S. Department of Agriculture, U.S. Department of Health and Human Services, 1985). The Dutch recommendation is considered to offer a realistic goal for the public but might not represent the most ideal fat intake levels from a health perspective.

Fat consumption is far from desirable in the Netherlands. In the most recent national food consumption survey in the Netherlands an average fat consumption of $37 \%$ of calories (or 92 grams) was found (Hulshof, Löwik \& Kistemaker, 1994; Voorlichtingsbureau voor de Voeding, 1993). Although fat consumption seems to bave declined somewhat in recent years, the amount of fat is still high and most fat - $14 \%$ of calories or 35 grams - is consumed as saturated fat (Hulshof et al., 1994; Voorlichtingsbureau voor de Voeding, 1993), which indicates that a large proportion of Dutch adults eats too much (saturated) fat. 
A reduction of fat consumption is generally accepted as the main goal for healthy diet promotion in the Netherlands. In 1987, the Dutch government initiated a Steering Group Healthy Nutrition. In this Steering Group, different organizations that are active in the field of food supply and nutrition education are represented, like the Netherlands Food and Nutrition Bureau, the Heart Foundation and Cancer Society, consumer organizations, as well als representatives from the food industry and retailers. This Steering Group Healthy Nutrition explicitly recommended that nutrition education for the general population should be primarily aimed at fat reduction because it was expected that this would lead to greater public health benefits as compared to other dietary changes. Therefore, the Steering Group initiated the so-called Fat Watch campaigns to motivate the Dutch population to reduce their fat consumption (Brug, Riedstra, Pruyn \& Löwik, 1993; Riedstra, Brug, Hardeman, Pruyn \& Löwik, 1993). The first four years of the Fat Watch campaign were not very successful in helping subjects through the process of dietary fat reduction. This lack of success was attributed to the suspicion that the campaigns were aimed especially at subjects already contemplating dietary changes. This in spite of the fact that the vast majority of Dutch subjects does not consider reducing their fat consumption since they think that their diet is healthy as far as fat is concerned (Brug \& Kok, 1995; Kok, 1994). Stimulating people to reduce their consumption of fat remains therefore a priority in the Netherlands.

\section{Fruit and Vegetable Consumption}

\section{Fruit and Vegetable Consumption and Cancer Risk}

The strongest epidemiological evidence for the assumed relation between diet and cancer has been found for the protective effect of a high consumption of fruit and vegetables on cancers at different locations, especially cancers of the respiratory and digestive tracts (Benito, 1992; Block, 1991; Block, Patterson \& Subar, 1992; Hunter \& Willett, 1989; Ziegler, 1989). Two possible explanations have been proposed for this protective effect: the high dietary fiber content, and the high concentrations of possible chemopreventive nutrients and non-nutritive compounds in fruit and vegetables.

Different mechanisms have been proposed to explain the inhibitory effect of dietary fiber on colon cancer development. Fiber can shorten the fecal transit time and thus shorten the period in which possible carcinogens are present in the colonic contents (Kritchewsky, 1986). Furthermore, dietary fiber, being a substrate for colonic fermentation, can contribute to a reduction of colonic PH. A low colonic PH is supposed to be 
inhibitory to colonic carcinogens (Thornton, 1981). Dietary fiber can also have a protective effect against colon cancer through its binding capacity for bile acids. Bile acids have been found to be promoters for colon carcinogenesis (Mariswa, Magadia, Weisburger \& Wynder, 1975). Finally, dietary fiber can contribute to a reduction in energy intake and thus comtribute to a lower cancer risk (Kritchevsky, 1986). The epidemiologic evidence for a protective effect of fiber is quite strong. However, in a review on the causes of breast and colon cancer, Willett (1989) concluded that the epidemiologic evidence only supported a protective effect from fiber from fruit and vegetables, and not from grain products.

In addition to the high fiber content, fruit and vegetables also contain high concentrations of compounds considered to be chemopreventive in initiation and promotion in carcinogenesis (Brug \& Van Poppel, 1993). Especially antioxidant nutrients like vitamin $\mathrm{C}$, vitamin $\mathrm{E}, \mathrm{B}$-carotene, and selenium are considered as promising chemopreventives for different tumors (Block, 1991; Knekt et al., 1991; Willett et al. 1983; Ziegler, 1989), but also non-nutritive food components like indoles, flavonoids, and polyphenols might be blocking agents in carcinogenesis (Hertog, 1991; Milner, 1989).

\section{Fruit and Vegetables and Cardiovascular Disease Risk}

More recently the anti-oxidant hypothesis has also been applied to prevention of CVD. Nevertheless, an inverse association between vegetable intake and risk for coronary heart disease was already reported in 1975 (Armstrong, Mann, Adelstein \& Eskin, 1975). Most indications of a possible inverse relation between CVD and fruit and vegetable intake carne from studies on the impact of particular food components on CVD risk. A number of antioxidant nutrients and non-nutritive compounds have been studied in this context.

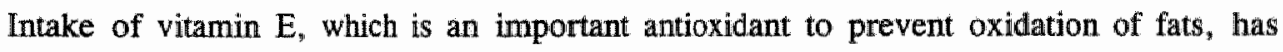
been found to be inversely related to CHD risk (Gey, Puska, Jordan \& Moser, 1991) but the epidemiological evidence for a protective effect of vitamin $E$ for $C H D$ is not yet conclusive. Other antioxidants that have been found to have preventive effects in relation to CVD risk are carotenes and flavonoids (Bolton-Smith, Woodward \& Tunstall-Pedoe, 1991; Hertog, Feskens, Hollman, Katan \& Kromhout, 1993).

\section{Consumption of Fruit and Vegetables and Dietary Recommendations in the Netherlands}

Although there are no official guidelines for fruit and vegetable consumption in the Netherlands, one of the official recommendations is strongly related to consumption of fruit and vegetables and is as follows (Voedingsraad, 1986a): 
"Increase the average relative intake of dietary fiber

(from approximately 2.4 to 3.0 grams $/ M J$ )"

Since fruit and vegetables are important providers of dietary fiber and are a important sources of (anitioxidant) mutrients and non-nutritive substances, the Netherlar Food and Nutrition Education Bureau made specific recommendations to eat am amounts of fruit and vegetables, that have been quantified as follows:

"Eat two or more pieces of fruit per day"

and

"Eat 150 to 200 grams of vegetables each day"

When the Dutch food consumption data are compared to these recommendations it clear that there are ample opportunities for improvement. The average consumption , fruit is 114 grams, which is the equivalent of one small piece of fruit (Voorlichtingsbt reau voor de Voeding, 1993). The average consumption of vegetables is 128 gram. (Voorlichtingsbureau voor de Voeding, 1993). Furthermore, consumption of fruit an vegetables has declined with about $10 \%$ between 1988 and 1993 (Hulshof et al., 1994. This has been attributed to recent changes in the Dutch food habits: the popularity $c$ meals with pasta or rice disches with little vegetables instead of the traditional potato vegetables-meat combination and the acceptance of convineance foods (Van der Weijden 1995). The result is that for both fruit and vegetables actual consumption is below th recommendations for a large proportion of the Dutch population.

\section{Conclusions}

In conclusion, there are strong indications for a relation between dietary habits and the risk for CVD and different cancers. The relation between fat consumption and CVD risk is hardly doubted anymore, although there is still some uncertainty about which fats and fat components are the main risk elevators. Still, a reduction in saturated fat consumption is generally accepted as a good means to lower CVD risk. The association between dietary fat and cancer risk is now more disputed than it was a number of years ago, especially because of the publication of prospective studies that failed to confirm that total 
fat consumption is positively associated with breast cancer risk. But in relation to cancer risk there is evidence that consumption of meat and meat products is positively associnted with colon cancer risk and that consumption of ample amounts of fruit and vegetables has a clear preventive effect for several cancers. The evidence that consumption of larger quantities of fruit and vegetables might be beneficial in relation to CVD risk too, is becoming stronger.

Consumption of fat, fruit and vegetables in the Netherlands is far from ideal. Changing dietary habits has the potential to contribute to a reduction of CVD and cancer risk. Therefore, dietary recommendations for CVD and cancer prevention have been published by different organizations in Western Europe, North America, and also in the Netherlands (Butrum, Clifford \& Lanza, 1988; Doll, 1989; Voedingsraad 1986b, 1991). The dietary recommendations for CVD and cancer prevention are in accordance with the general Dutch dietary recommendations for a healthy diet (Voedingsraad, 1986a). Reduction of dietary fat intake and increasing the consumption of fruit and vegetables are key elements of these dietary recommendations (Benito, 1992; Bierman \& Chait, 1988; Butrum et al., 1988). 
Part II

Determinants of Dietary Behaviors 


\section{Outline}

The third step in health education planning (Figure 1, page 7), a diagnosis should be made of the psychosocial determinants of the behaviors that are causing the health problem. During this planning step it should become clear which reasons people have for participating in the risk behavior. Therefore we tried to find out why people eat too much fat and too little fruit and vegetables.

Hereafter, six chapters will follow that describe the studies that were conducted in order to identify a number of psychosocial determinants of fat consumption and fat reduction and fruit and vegetable consumption. The studies are primarily based on expectancy value models that have proven to be useful in explaining and predicting human behavior. Since unrealistic self-assessment of dietary behaviors was identified as an important barrier towards dietary change and because this factor has hardly drawn attention in earlier studies on determinants of dietary behavior, a major part of the determinant studies focusses on the role of awareness of personal dietary intake in motivating people to change.

For the studies on determinants of fat consumption it was possible to derive information from studies conducted and published by others before the research described in this thesis was started. These studies are reviewed in the general discussion of this thesis. Three additional studies were conducted. The first study on determinants of fat consumption in this thesis is described in Chapter 2 and was a secondary analysis of data that were collected in the framework of the so-called 'Healthy Bergeyk' project (Van Assema, Steenbakkers, Kok, Eriksen \& De Vries, 1994). That study explored the role of awareness of dietary fat consumption as a determinant of motivation to reduce fat consumption. A preliminary study into the possible causes for misconception of personal fat intake is described in Chapter 3. Differences in psychosocial factors between subjects in different stages of change for fat reduction were also studied. The results are presented and discussed in Chapter 4. At the start of the studies described in this thesis, hardly any research had been done on psychosocial determinants of fruit and vegetable consumption. Therefore, the first study on this subject was an exploratory investigation in which a qualitative data collection method was used. This study is described in Chapter 5. The results of this qualitative study were used as the basis for a quantitative survey which is described in Chapter 6. Finally, the data of the baseline measurement of one of the tailoring experiments reported on later in this thesis, were used to get further insight in differences in psychosocial factors related to fruit and vegetable consumption between subjects in different stages of change for increasing fruit and vegetable consumption. This study is described in Chapter 7 . 


\title{
Chapter 2
}

\author{
Self-Rated Dietary Fat Intake: Association with Objective Assessment \\ of Fat, Psychosocial Factors, and Intention to Change ${ }^{1}$
}

\begin{abstract}
In order to study the role of awareness of dietary fat intake as a possible factor in the process of dietary behavior change, data on 1507 adult subjects gathered in the Netherlands were analyzed. Objective assessments of dietary fat intake were compared to selfrated, or subjective, dietary fat intake among a Dutch study population. A majority of the respondents had an unrealistic view of their own fat intake. Men were more often unrealistic than women. Underestimation of fat intake was especially prevalent. Self-rated dietary fat intake, and not objectively assessed fat intake, proved to be a significant correlate of intention to reduce fat consumption in the near future among women. Psychosocial determinants of fat intake were stronger correlates of self-rated fat intake than of objectively assessed fat intake. It was concluded that underestimation of one's own dietary fat intake could be a major barrier in healthy diet promotion aimed at reducing fat consumption in the Netherlands. Therefore, improving dietary fat intake awareness should be given priority as a first step in healthy diet promotion strategies. Personal feedback and advice could be means to improving realistic estimation of dietary fat intake.
\end{abstract}

'This chapter was published as:

Brig. J., Van Assema, P., Kok, G., Lenderink, T., \& Glanz, K. (1994). Self-rated dietary fat intake: Association with objective assessment of fat, psychosocial factors, and intention to change. Journal of Nutrition Education. 26. 218-223. 


\section{Introduction}

The growing body of epidemiological evidence of a relationship between diet: patterns and the etiology of various chronic diseases, like cardiovascular diseases a some cancers, has led governments and public health organizations to promote cert. preventive dietary recommendations (U.S. Department of Agriculture, U.S. Departm of Health and Human Services, 1985; Benito, 1992). In the Netherlands the guidelines 1 a prudent diet from the Dutch Nutrition Council were published in 1986 (Voedingsras 1986a). The Dutch Nutrition Council recommended eating a variety of foods, eati ample amounts of complex carbohydrates and reducing dietary fat intake, especially reducing intake of saturated fat, to $35 \%$ or less of total calories. Further recommendatio were to increase dietary fiber intake to at least 3 grams per MJ energy intake, to restri consumption of mono- and di-saccharides to less than $25 \%$ of total calories and to lin the intake of cholesterol to less than $33 \mathrm{mg} / \mathrm{MJ}$ energy intake. These recommendations a in accordance with dietary guidelines in other European and North American countrix (U.S. Department of Agriculture, U.S. Department of Health and Human Services, 198: Benito, 1992), although the U.S. guidelines recommend reducing fat intake to less tha $30 \%$ of total calories, and the importance of consuming five or more servings of fruit and vegetables per day is stressed.

Major discrepancies have been found between these guidelines and actual dietar behavior as measured through food consumption research in the Netherlands (Hulshot 1993). The Dutch Nutrition Council advised that healthy diet promotion activities shoul focus on a reduction in total fat intake with special attention to a reduction in saturater fat, because the largest public health gain was expected from such a reduction (Voedings raad, 1986a). This advice resulted in a nationwide campaign aimed at reducing fat intaks among the general Dutch population, called 'Fat Watch' (Riedstra et al., 1993; Brug Riedstra, Pruyn et al., 1993).

A major difference between dietary fat intake and other behaviors associated with chronic disease, such as smoking, is that individuals are often unaware of their dietary risk behavior. Dietary behavior is very complex. It involves, for example, choosing a variety of food items in different quantities and combinations that can be prepared in various ways. Dietary fat intake cannot be avoided completely and dietary fat is often hard to recognize in food items (Glanz \& Eriksen, 1993). Dutch research revealed that less than $20 \%$ of the Dutch population rate their own diet as high in fat and less than $10 \%$ rate their own dietary fat consumption as too high (Riedstra, Hardeman, Pruyn, Van 
der Feen de Lille \& Jonkers, 1992; Baranowski; 1992). This is in sharp contrast with results of nationwide food consumption research in the Netherlands (Hulshof, 1993).

The primary purpose of this study was to estimate the strength of the association of awareness of one's own dietary fat intake with the intention to reduce dietary intake of fat. It was hypothesized that a majority of the study population would be unrealistic about their dietary fat intake. Frequent underestimation of dietary fat intake was expected. Furthermore, it was expected that unrealistic self-rating of fat intake would be more prevalent among men than among women because in the Netherlands women are most often responsible for purchasing food items and preparing meals, and have shown more interest in nutrition education activities in the past (Riedstra et al., 1992).

Lack of awareness could be a major barrier to changing dietary behavior through healthy diet promotion interventions. Awareness of the relationship between behavior (diet) and outcome (health) may be important, especially in earlier stages of (dietary) behavior change (Glanz \& Eriksen, 1993; Baranowski, 1992). But awareness of performing the risk behavior itself could also be important in a complex behavior like dietary behavior. Subjects who underestimate their dietary risk behavior, that is, who mistakenly rate their personal diet as low in fat, are not likely to intend to change their diet towards less fat. Therefore, the second hypothesis in this study was that self-rated dietary fat intake is more likely to be associated with intention to change than is objectively assessed dietary fat intake.

Furthermore, it is proposed that for subjects who have a biased image of their own dietary intake, psychosocial factors that may be related to dietary behavior, are in fact associated with self-rated dietary behavior. Therefore, the third hypothesis was that correlations of selected psychosocial factors with self-rated dietary fat intake will be stronger than correlations with objectively assessed dietary intake. It was expected that these hypothesized differences in associations would be strongest among subjects who are unaware of their dietary fat intake.

\section{Methods}

\section{Subjects}

In order to test these hypotheses, data collected for the baseline measurement of the Healthy Bergeyk Project were analyzed. The Healthy Bergeyk Project was a communitybased cancer prevention intervention project. The project aimed to reduce the prevalence of four cancer related risk behaviors (high fat consumption, smoking, high alcohol intake, 
use of solaria) among the population of Bergeyk, a small municipality in the south Netherlands. More information on the intervention and the evaluation study ha reported elsewhere (Van Assema, Pieterse, Kok, Eriksen, \& De Vries, 1993). I evaluation study an experimental and a control community were randomly selecter municipalities in the south of the Netherlands with approximately 10,000 inhat From both communities a random sample of 1,000 adults selected. Response baseline survey was $75.3 \%(n=1507)$.

\section{Theoretically -based concepts}

The Healthy Bergeyk Project was based on a number of theoretical models such Theory of Planned Behavior (Ajzen, 1988; Ajzen \& Madden, 1986) and Social Lea Theory (Bandura, 1986). According to these models three determinants of $d$ behavior can be distinguished: attitude, social influence, and self-efficacy (Ajzen, De Vries, Dijkstra \& Kuhlman, 1988). These determinants are expected to have a 1 influence on behavioral intention. External variables, such as socio-demographic fai are expected to influence behavior through the behavioral determinants and intentic person's attitude towards a specific dietary behavior is determined by comparing rel pros and cons of the expected consequences of the specific behavior. Social infli consists of two components: direct and indirect social influence. Direct influence it perceived expectations of others. Indirect social influence, or modeling, appears whel behavior of others is taken as an example (Bandura, 1986). Self-efficacy refers person's expectations regarding his or her capability to realize a (desired) behavior. : efficacy is partly dependent on a person's abilities to perform a behavior and on bari that stand in the way of performing the behavior (Bandura, 1986; De Vries et al., 19 Finally, the behavior, or trying to perform the behavior, will lead to feedback that $\mathbf{n}$ in turn, influence the determinants (Kok, De Vries, Mudde \& Strecher, 1991).

\section{Measures}

Data for the evaluation study of the Healthy Bergeyk Project were collected by me of telephone interviews. The study population consisted of 1507 subjects, 751 women 756 men. For the present analysis self reported fat intake cobjectively assessed fat intal self-rated fat intake, intention to reduce dietary fat intake, and psychosocial determina of dietary fat intake were analyzed.

Objectively assessed fat intake was assessed by means of a validated 25-item $\mathrm{fc}$ frequency questionnaire (Van Assema, Brug, Kok \& Brants, 1992). The validity of $t$ 
questionnaire, assessed in relation to seven-day diet records was considered sufficient and comparable to the validity of other often-used food frequency questionnaires (Van Assema, Brug et al., 1992). With a short food frequency questionnaire, or with any other kind of self report, it is impossible to measure "true" dietary fat intake. Nevertheless, measuring fat consumption with a short food frequency questionnaire is generally recognized as a practical and acceptable way to assess food consumption in large population studies (Cameron \& Van Staveren, 1988). The food frequency questionnaire used in the present study permits a fat consumption score to be calculated, ranging from 12 to 60 . Based on this score subjects can be ranked according to dietary fat intake and changes in fat intake can be measured. However, it is not possible to express dietary fat intake in grams of fat or in percentage of total calories. Therefore no absolute comparisons between fat scores and dietary recommendations can be made. For the first and second hypothesis of the present study, subjects were divided in tertiles for objectively assessed dietary fat intake. The tertiles were defined as low, intermediate, or high fat diets. Self-rated dietary fat intake (subjective fat intake) was measured by asking respondents to evaluate their fat intake on a bipolar five-point scale (very low in fat to very high in fat). For studying the first and second hypothesis, the subjective fat intake wariable was recoded into three categories (high, intermediate, and low fat). For the present study, an awareness variable was created as follows (Figure 2:1): Subjects were classified as realistic when their subjective dietary fat intake was in the same tertile as their objectively assessed fat intake. Subjects were classified as optimistic when they underestimated dietary fat intake as compared to objectively assessed fat intake and as pessimistic when subjective intake was higher than objectively assessed intake.

Psychosocial determinants of dietary fat consumption were measured by means of a questionnaire specially developed for the Healthy Bergeyk study using a combination of qualitative and quantitative techniques. Information on the development of the psychosocial determinants questionnaire has been reported elsewhere (Van Assema, De Vries, \& Kok, 1992; De Vries, Weijts, Dijkstra, \& Kok, 1992). Two attitude constructs were measured. First, "sum of beliefs" was measured by means of five items based on the expectancy-value model of attitude (Ajzen, 1988). Respondents were asked to evaluate the five most salient beliefs (taste, skin problems, growing fat, digestive problems, heart disease risk) in relation to choosing high fat diets on a bipolar five-point scalle $(-2 / 2,3$ items) or on a unipolar three-point scale $(0 / 2,2$ items). Further, 'direct attitude' was 
measured by means of two items in which respondents were asked to rate high fat diet on a bipolar five-point $(-2 / 2)$ good-bad scale and pleasant-unpleasant scale.

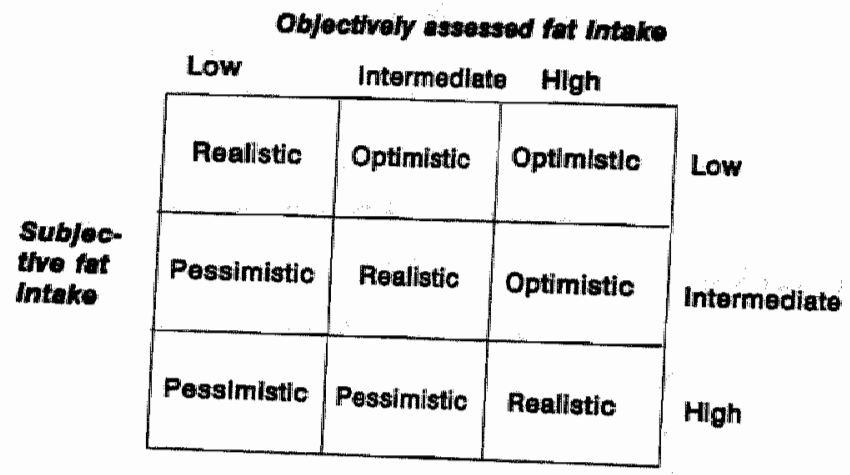

Figure 2:1. Different categories of awareness of dietary fat intake

Direct social influence was measured by means of four items asking the respondents to indicate to what extent important others (partner, close relatives, colleagues, and friends) encourage them to use low fat diets, on unipolar four-point scales $(-3 / 0)$. Indirect social influence (modeling) was measured by asking the respondents to assess the level consumption of the same significant others, on unif efficacy was measured by two items asking the unipolar five-point scales (0/4). Selfpoint scale $(-2 / 2)$, how difficult they think they respondents to indicate, on a bipolar fivecertain 'high risk' situations (during weekends, would find refusing high fat food items in that high positive scores indicated parties). All variables were coded so 
measured by asking respondents to what extent they intended to reduce their fat intake in the next month, on a unipolar four-point scale (0/3).

\section{Statistical analysis}

Chi-square tests were performed to test for differences between men and women in proportions having the intention to reduce dietary fat intake and in proportions being optimistic, realistic, or pessimistic in relation to dietary fat intake. Analysis of variance was used to detect differences between men and women in objective and subjective dietary behavior, and psychosocial determinants.

Univariate and multiple logistic regression were used, with intention to reduce dietary fat consumption as the dependent variable and self-rated dietary intake and objectively assessed fat intake as independent variables, in order to detect the strongest correlates of intention to reduce dietary fat intake. Subjects were divided in tertiles for the independent variables for the logistic regression analyses. Finally, univariate and multivariate regression analysis was used to study correlations of behavioral determinants related to fat intake with objectively assessed fat intake and with subjective dietary fat intake.

Regression and logistic regression analyses were done separately for men and women. All analyses were performed using the SPSSx statistical package (SPSS Inc., 1988).

\section{RESULTS}

\section{Hypothesis 1}

A majority ( $55 \%$ ) of the respondents proved to be unrealistic about their dietary fat intake. A large proportion $(76 \%)$ of these unrealistic subjects underestimated their dietary fat intake.

Results on mean objectively assessed fat intake scores and psychosocial determinants of dietary fat intake are presented in Table $2: 1$. Mean fat score was 29.3 and 25.7 among men and women respectively. Men had a significantly higher mean dietary fat intake and reported significantly less negative beliefs, attitudes, self-efficacy expectations and social. influences towards high fat diets compared to women. 
Table 2:1

Range and meams (S.D.) for objectively assessed fat intoke, and psychosiacial determinants of dietary fat inake omong men and women

\begin{tabular}{|c|c|c|c|}
\hline \multirow[b]{2}{*}{ Vanable } & \multirow[t]{2}{*}{ Range } & \multicolumn{2}{|c|}{ Mean } \\
\hline & & $\operatorname{Men}(n=756)$ & Women $(n=751)$ \\
\hline Objectively assessed fat intake & $(12$ to 60$)$ & $29.3(5.9)$ & $25.7(5.4)$ \\
\hline Sum of beliefs & $(-10$ to 4$)$ & $-0.7(3.4)$ & $-2.8(3.5)$ \\
\hline Direct attitude & $(-4$ to 4$)$ & $-0.8(2.5)$ & $-2.0(2.2)^{\prime \prime}$ \\
\hline Self-efficacy & $(-4$ to 4$)$ & $-1.5(2.7)$ & $-1.8(2.6)^{\circ}$ \\
\hline Soxial influence & $(-12$ to 0$)$ & $-1.6(2.1)$ & $-1.4(2.2)^{\prime}$ \\
\hline Modeling & (0 to 16$)$ & $5.1(3.4)$ & $4.7(3.5)$ \\
\hline
\end{tabular}

Significant difference between men and women $(p<.05)$

Proportions of men and women who rated their dietary fat intake as high and in the different awareness categories, and the proportions of men and women who had the intention to reduce dietary fat intake are presented in Table $2: 2$.

The percentage of subjects who rated their own dietary fat intake as high was $21.4 \%$ among men and $10.1 \%$ among women, with the difference being statistically significant. A significantly larger proportion of men was optimistic regarding dietary fat intake than were women, $47 \%$ vs. $37 \%$, respectively. Women were significantly more often realistic about their dietary fat intake. No significant difference between men and women was found in the proportion of pessimistic subjects. Among men, 9.7\% had the intention to reduce their dietary fat intake and significantly more women $(16.1 \%)$ had this intention. Pearson correlation between objectively assessed fat intake and self-rated dietary intake was .30 and .37 among men and women respectively, both correlations being statistically significant. 


\section{Table 2:2}

Proportions of men and women with high self-rated dietary fat intake, intention to reduce fat intake, and with optimistic, realistic and pessimistic self-rated dietary fat intake

\begin{tabular}{lcc}
\hline & $\begin{array}{c}\text { Men } \\
(\mathrm{n}=756)\end{array}$ & $\begin{array}{r}\text { Women } \\
(\mathrm{n}=751)\end{array}$ \\
\hline High self-rated fat intake & $21.4 \%$ & $10.1 \%^{*}$ \\
Intention to reduce fat intake & $9.7 \%$ & $16.1 \% \%^{*}$ \\
\hline Optimistic & $46.6 \%$ & $36.5 \%$ \\
Realistic & $41.0 \%$ & $49.5 \%$ \\
Pessimistic & $12.4 \%$ & $14.0 \%$ \\
\hline
\end{tabular}

- Significant difference between men and women $(p<.05)$

\section{Hypothesis 2.}

Results of univariate and multiple logistic regression analyses are presented in Table 2:3. Because of the differences between men and women in objectively assessed dietary fat intake and subjective dietary fat intake (both were higher for men) and in intention to reduce fat intake (higher for women), these analyses were done separately for men and women. For women self-rated dietary fat intake was a relatively strong predictor of intention to reduce dietary fat intake $(\mathrm{OR}=2.4)$. Objectively assessed fat intake was inversely associated with intention ( $O R=0.7)$ among women, but this association was not statistically significant. In the multiple logistic regression with subjective and objectively assessed fat intake as independent variables the association of subjective fat intake with intention was somewhat stronger among women ( $O R=3.0)$. Among men, neither selfrated dietary fat intake $(O R=0.8)$ nor objectively assessed fat intake $(O R=0.7)$ was significantly associated with intention to reduce dietary fat intake. 
Table 2:3

Odds ratios and confidence intentals for subjective fot intake and objectively assessed fat intake as predictors of intention to reduce dietary fat intake within the next month, among women and men, in univariate and multiple logistic regression analysis

\begin{tabular}{lcclc|}
\hline & Univariate & \multicolumn{3}{l}{ Multiple } \\
\hline Women $(\mathrm{n}=751)$ & & $95 \%$ C.I. & O.R. & $95 \%$ C.I. \\
\hline Subjective fat intake & 2.4 & $1.4-4.8$ & 3.0 & $1.6-5.3$ \\
Objectively assessed fat intake & 0.7 & $0.4-1.2$ & 0.7 & $0.5-1.0$ \\
\hline Men $(\mathrm{n}=756)$ & & & & \\
\hline Subjective fat intake & 0.8 & $0.4-1.6$ & 0.9 & $0.4-1.7$ \\
Objectively assessed fat intake & 0.7 & $0.4-1.2$ & 0.9 & $0.6-1.2$ \\
\hline
\end{tabular}

\section{Hypothesis 3.}

In Table 2:4 correlations between determinants and both objectively assessed and subjective dietary behavior are presented. All correlations are statistically significant. The dietary behavior determinant model explained $34 \%$ of the variance in self-rated dietary fat intake. The explained variance in objectively assessed dietary fat intake was $15 \%$. The correlations of psychosocial determinants, except for self-efficacy, are significantly stronger with subjective fat intake than with objectively assessed fat intake.

In Table 2:5 Pearson correlations between determinants and both objectively assessed and subjective dietary fat intake are presented for subjects who are unrealistic about their fat intake. The correlations with subjective dietary fat intake are still highly significant. For objectively assessed intake only the correlations with self-efficacy and direct attitude are statistically significant at the .05 level. The model explained $22 \%$ of variance in subjective dietary fat intake and only $2 \%$ of variance in objectively assessed intake of fat. 


\section{Table 2:4}

Pearson correlations between psychosocial determinants and objectively assessed far intake and subjective fat intake $(n=1507)$

\begin{tabular}{|c|c|c|}
\hline Variable & $\begin{array}{c}\text { Objectively assessed } \\
\qquad(12 \text { to } 60)\end{array}$ & $\begin{array}{l}\text { Subjective } \\
(-2 \text { to } 2)\end{array}$ \\
\hline Sum of beliefs ( -10 to 4$)$ & $.31^{*}$ & $.47^{\cdots / 4}$ \\
\hline Direct artitude $(-4$ to 4$)$ & $.33^{* *}$ & $.47^{* * *}$ \\
\hline Self-efficacy $(-4$ to 4$)$ & $.22^{*}$ & $.24^{* *}$ \\
\hline Social influence $(-12$ to 0$)$ & $.06^{\circ}$ & $.14^{-* n}$ \\
\hline Modeling (0 to 16$)$ & $.21^{\prime-}$ & $.40^{-* 4}$ \\
\hline
\end{tabular}

Significant correlation; $\mathbf{p}<.05$

"Significant correlation; $\mathrm{p}<.01$

${ }^{z}$ Significant difference between correlations for the objective and subjective assessments; $p<.01$

\section{Table $2: 5$}

Pearson correlations between psychosocial determinants and objectively assessed fat intake and subjective fat intake among subjects who are unrealistic about their dietary fat intake in $=828$ )

\begin{tabular}{|c|c|c|}
\hline Variable & $\begin{array}{l}\text { Objectively assessed } \\
(12 \text { to } 60)\end{array}$ & $\begin{array}{l}\text { Subjective } \\
(-2 \text { to } 2)\end{array}$ \\
\hline Sum of beliefs $(-10$ to 4$)$ & .04 & $.38^{-4+k}$ \\
\hline Direct atritude $(-4$ to 4$)$ & $.08^{\circ}$ & $.37^{* * *}$ \\
\hline Self-efficacy $(-4$ to 4$)$ & $.09^{*}$ & $.12^{*+*}$ \\
\hline Social influence $(-12$ to 0$)$ & -.03 & $.13^{0+40}$ \\
\hline Modeling ( 0 to 16 ) & .001 & $.34^{* \pi}$ \\
\hline
\end{tabular}

Significant correlation; $\mathrm{p}<.05$

"significant correlation; $\mathrm{p}<.01$

"Significant difference between correlations for the objective and subjective assessments; $p<.01$ 


\section{DISCUSSION}

Although food consumption research has shown that approximately $80 \%$ of the Dutch adult population has a diet that is too high in fat compared to dietary recommendations, only a relatively small percentage of the respondents in this study rated their own diets as high in fat. These data indicate that underestimation of dietary fat intake is highly prevalent in the Netherlands. Indications that Dutch subjects underestimate their fat intake have been found before (Riedstra et al., 1993; Brug, Riedstra, Van der Feen de Lille, Pruyn \& Aarnink, 1993; Riedstra et al., 1992). Correlations between actual dietary fat intake and self-rated dietary fat intake were rather low and comparable to those found in U.S. research (Glanz, Kristal, Sorensen, Palombo, Heimendinger \& Probart, 1993). The biased self-rating of dietary fat intake among the Dutch population, could be caused by lack of knowledge about fat contents of food items. In particular, the so-called 'hidden fats' in foods like pastries, snacks, and fast food are often hard to recognize for subjects without extensive nutrition education.

We hypothesized that the lack of awareness could be a major barrier in interventions aimed at reducing dietary fat intake. This study supports that hypothesis, but only among women. Female subjects who rate their personal fat intake as high were more likely to intend to reduce their fat intake than female subjects who thought their fat intake was low.

Providing objective information about individual dietary fat intake might bring about a more realistic estimation of dietary fat intake among Dutch subjects. Based on the results presented in this paper it can be argued that this kind of individualized dietary feedback might result in a larger proportion of female subjects with a high fat intake, being motivated to reduce their dietary fat intake. General information about high fat consumption is not likely to be effective. Previous research showed that a large majority of the Dutch population is convinced that the general Dutch diet is too high in fat (Riedstra et al., 1992). However, they do not think that they are eating too much fat themselves.

In this study, male subjects who rate their fat intake as high were not more likely to intend to reduce their fat intake. Male subjects had more positive feelings towards high fat diets than women. For men nutrition education should be focused on changing these determinants first. However, men are even more unrealistic about their dietary fat intake than women. Therefore, personalized feedback on dietary fat intake might be an additional healthy nutrition education strategy for men. The higher proportion of realistic women as compared to men may be associated with the fact that women are often responsible for 
food and nutrition in Dutch households leading to more acurate knowledge about the fat. content of their diet.

In the study described here, psychosocial determinants of dietary fat intake were measured, and associations between these determinants and objectively assessed behavior and self-rated behavior were assessed. The associations with self-rated behavior were quite strong and always significant. Associations of behavioral determinants with actual behavior were much weaker. Among the group of unrealistic subjects, determinants of high fat intake explained only two percent of actual dietary fat intake. Should this finding be reproduced in other studies, it will have serious consequences for psychosocial nutrition research. In nutrition education evaluation studies, positive intervention effects on attitudes and other psychosocial determinants of nutrition behavior are often found. This is seen as a successful outcome, or at least as a first step toward dietary behavior change. However, the present study suggests that only determinants of subjective dietary behavior might be changed. When, as in the Dutch situation, a large proportion of subjects tend to underestimate their personal fat intake, positive views toward low fat diets will not imply a positive prerequisite for a reduction in dietary fat consumption.

This study is based on data gathered in the Netherlands. Because associations between objective and subjective dietary intake in the U.S. are likely to be of the same magnitude as found in this study, there are indications that the awareness problem might be apparent in the U.S. as well (Glanz et al., 1993). Further Dutch-U.S. collaborative analyses will be conducted in order to study whether the situation in the U.S. is similar to that in the Netherlands.

It can be concluded that only a minority of the study population has a realistic view of their own dietary fat intake. This result is confirmed by previous studies in the Netherlands (Riedstra et al., 1992). Improving dietary fat intake awareness should be given priority as a first step in nutrition education interventions in the Netherlands. This could improve the effectiveness of nutrition education aimed at reducing dietary fat consumption, because subjects who are aware of their high fat intake might be more likely to be willing to pay attention to information on reducing fat intake.

The lack of association found between psychosocial determinants of fat intake and objectively assessed fat intake shows that what are normally considered as psychosocial determinants of dietary behavior are more likely determinants of what subjects think that their dietary behavior is like. 


\title{
Chapter 3
}

\section{Misconception of Fat Intake:}

\author{
Determinants and Implications ${ }^{t}$
}

\begin{abstract}
Misconception of personal fat consumption has been identified as an important barrier $n$ motivating people to reduce their consumption of fat. Possible determinants of nisconceptions of personal fat consumption were studied among a random sample of the Dutch population $(n=989)$, in order to propose recommendations for strategies to reduce nisconception. The possible correlates that were studied were identified through focus group interviews. Multiple regression analyses were used to identify significant correlates of misconception. The way respondents compared their fat intake to that of others was the most important determinant of misconception of fat intake. Furthermore, a large majority of respondents reported believing their fat intake to be equal to (32\%) or lower than (48\%) comparable others, indicating an optimistic bias in self-assessment of fat intake. Sex, age, knowledge about fat contents of food products, whether the respondents thought that only overweight people had high fat diets, whether respondents reported having reduced their fat intake in the past, and the belief that the general Dutch diet used to be higher in fat in the past, were ather significant correlates of misconception of fat intake in multiple regression analysis, but these variables contributed only modestly to total variance explained. In order to reduce misconception of fat intake, intervention materials should be developed and implemented that enable people to easily assess their personal fat intake in comparison to both recommended intake levels and their peer group average fat intake, in order to help people to make more realistic assessments of their own fat intake levels.
\end{abstract}

\footnotetext{
1This chapter will be subminted for publication as:

Brug, 1., Van Assema, P., Glani, K.. \& Kok, G. Misconception of fat intake: Determinanis and implications.
} 


\section{Introduction}

The growing body of epidemiological evidence of a relationship between fat $i$ and the etiology of various chronic diseases, especially cardiovascular diseases, has 1 preventive dietary recommendations for fat intake (Benito, 1992; Voedingsraad, 1 ! U.S. Department of Agriculture and Health and Human Services, 1990). Major discn cies have been found in the Netherlands between these guidelines on the one hand actual dietary behavior as measured through food consumption research on the (Hulshof, 1993). The Dutch Nutrition Council advised that healthy diet prom activities should focus on a reduction in total fat intake with special attention reduction in saturated fat, because the largest public health gain was expected from su reduction (Voedingsraad, 1986a).

From 1991 to 1994 the so-called Fat Watch campaign was carried out in the Net lands (Brug, Riedstra, Van der Feen de Lille et al., 1993). This national campaign designed to motivate and help Dutch subjects to reduce their fat consumption. Althc the campaign reached a high proportion of the Dutch population and received posi reactions, the campaign had no significant impact on motivation to reduce fat in among the Dutch population (Brug, Riedstra, Van der Feen de Lille et al., 1993; K 1994).

Subjects in the Fat Watch evaluation studies were also asked how they rated their c fat intake. Less than 10\% thought that their diet was too high in fat. From the first $\mathrm{Dr}$ National Food Consumption survey, which was carried out in the same period, it beca clear that approximately $80 \%$ of Dutch adults were eating too much fat at that ti compared to the Dutch dietary recommendations (Löwik et al., 1994). It seemed $t$ many Dutch adults misjudged their fat intake levels. Although they knew that high consumption is a risk behavior (Riedstra, Van der Feen de Lille, et al., 1993), th seemed to be unaware of performing this risk behavior themselves (Brug \& Kok, 19 ! Kok, 1994).

The concept of awareness of risk behavior has been recognized as important adopting preventive behavior in behavior change models. In the Transtheoretical Moc for example, awareness of risk bebavior is seen as essential in the transition from pr contemplation to contemplating changing the risk behavior (Prochaska \& DiClemenı 1992). In the Health Belief Model awareness of risk behavior is a determinant 'perceived threat' (Rosenstack, 1990). In relation to most risk behaviors, howeve awareness is defined as awareness of the relation between behavior and health (risks), $f_{1}$ 
example fat consumption and heart disease. But we hypothesized that for fat consumption, awareness of performing the risk behavior might also be important since evaluation of one's own dietary fat intake level is difficult. Fat can be found in various amounts in numerous food items. Even when people know that eating too much fat might be a health hazard, which most people do know in the Netherlands, they might do nothing with this knowledge when they perceive their personal diet to be low in fat (Brug \& Kok, 1995). The essential role of awareness of personal 'risk behavior' in the earlier stages of change has been further specified in the so-called "precaution adoption process' as described by Weinstein (1988). He distinguishes three levels of awareness of risk behavior. People who have reached the first level of awareness have heard about the risk (behavior), they are aware of the association between behavior and risk. In relation to fat consumption this would mean that people are aware of the fact that consumption of too much fat can be detrimental to health. At the second level of awareness, people are aware that (a lot of) other people participate in the risk behavior: They know that other people eat too much fat. At the third level of awareness, people realize that they participate in the risk behavior themselves: They realize that their personal fat intake is too high. According to the model, only after this third level of awareness of risk behavior has been reached, will people contemplate changing their risk behavior (Weinstein, 1988).

The possible prevalence of underestimation of personal fat intake and the effects of underestimation of fat intake on intention to reduce fat consumption have been assessed before (Brug, Van Assema, Kok, Lenderink \& Glanz, 1994). The results showed that more than half of the study population misjudged their fat consumption level. Most subjects underestimated their fat intake. A further study showed that subjects who rated their fat consumption as high were three times as likely to intend to reduce their fat consumption than subjects who rated their personal fat consumption as low, irrespective of their actual fat consumption level (Brug \& Kok, 1995). These results are in line with Weinstein's model and can be summarized as follows: Subjects who think that they are eating low fat diets are less likely to intend to reduce their fat intake, but this has little to do with their actual fat intake levels because of the high prevalence of misconception of fat intake. Subsequently, because of misconception, and especially underestimation, of fat intake, people who should reduce their fat intake are not motivated to do so. It can be concluded that lack of awareness of high fat intake is a barrier towards desirable dietary changes.

The logical next step is to study what might be the causes of misconception of personal fat intake. Misconception of fat intake has been attributed to lack of nutrition 
knowledge by different authors (Brug, Van Assema, Kok et al., 1994; Brug, Va Assema, Lenderink, Kok \& Glanz, 1994; Lloyd, Paisley \& Mela, 1993). For example knowledge about fat contents of food products might be necessary in order to correcth classify one"s own fat consumption. However, the association between nutrition knowl. edge and misconception has not been studied before.

A further possible determinant of underestimation of personal fat intake is optimism if comparing one's own intake to that of others. When underestimation of personal fal intake was only caused by lack of nutrition knowledge, it would be expected that subjecti would also underestimate other people's fat intake. Nevertheless, a large majority of the Dutch population think, correctly, that the Dutch diet in general is too high in fat, they just do not think that this applies to them (Brug \& Kok, 1995).

In an exploratory study, using focus group interviews with subjects who underestimat ed their fat intake level, possible additional causes for misconception of fat consumption were identified (Van Assema, Brug, Dolders, Kok \& Steenhuis, 1995). Respondents indicated that they thought that as long as they were not overweight, or when they did not have physical problems, their fat consumption was not too high. Furthermore, people indicated that they were unsure about what the most important dietary fat sources in their diet were. Other respondents thought that their diet was low in fat because they had already reduced their fat intake or tried to reduce their fat intake in the past, because they thought that fat intake was generally higher in the past, or that they could compensate a high fat diet by participating in sport activities. Finally, respondents indicated that they thought that their fat intake was not too high because they perceived their fat intake to be lower than the fat intake of others in their social environment. The possible predictors of misconception of fat intake are summarized in Table 3:1. The aim of the present study was to identify the most important correlates of misconception of fat intake in a quantitative study.

\section{Methods}

\section{Respondents}

A random sample of 2,000 address-telephone number combinations was obtained through the Dutch national telephone company. The selected telephone numbers were called in random order during the evening, approximately one week after introduction letters, explaining the procedure and general aim of the survey, were sent to the addresses. Respondents aged 16 years or older were asked to answer the questions at the first 
call. If that moment was inconvenient, an appointment was made to administer the questionnaire at a later time or day. The interview took between 15 and 20 minutes. The aim was to collect data from approximately 1,000 subjects. This was achieved after 1652 households were called. From this sample, 46 telephone numbers could not be reached because the phone had been disconnected, because no one answered the phone after six attempts were made, or because the respondent had moved, and 23 respondents were excluded from the survey because they did not have sufficient knowledge of the Dutch language to answer the questions. Of the remaining sample, 594 respondents refused to co-operate for different reasons. Therefore, the study population consisted of 989 respondents (response rate $=62 \%$ ).

\section{Questionnaire and measures}

A questionnaire suitable for telephone administration was used for data collection. Fat intake ('fat score") was objectively assessed by means of a 25 -item, validated food frequency instrument (Van Assema, Brug et al., 1992). Knowledge about fat contents of different food products ("knowledge about fat") was measured by means of 15 items in which respondents were asked to compare pairs of food items on their fat content. These items are part of a validated nutrition knowledge questionnaire (Steenhuis, Brug, Van Assema \& Imbos, 1996). A 'comparison to others' variable was measured with one item in which respondents were asked to compare their personal fat intake to that of others of the same age and sex on a 5-point (much less/much more) scale. Respondents were asked if they agreed with the statement that fat intake used to be higher in the past ('fat in the past"; no $=0$, yes $=1$ ) in order to assess the respondents' belief about general changes in the fat content of the Dutch diet. In order to assess the respondents' beliefs about whether physical exercise allows them to eat more fat; whether the absence of physical problems indicates that their fat consumption is not too high, and whether they thought that being or not being overweight is an important indicator of fat intake levels, the respondents were asked if they agreed or disagreed (disagree/no opinion $=0$, agree $=1$ ) with a number of statements. They were also asked to rate their personal weight (very low/very high), health (very poor/very good) and sport activities (very little/very much) on 5-point scales. New variables were created to distinguish,

- respondents. who rated their own weight as low or very low and who thought that not being overweight meant not eating to much fat from those who did not meet these criteria ("fat-weight relation"; no $=0$, yes $=1$ ), 
- respondents who reported participating in sport activities (much or very much) and who thought that participating in sport activities allows them to eat more fat from those who did not meet these criteria ( fat-sport relation'; no=0, yes $=1$ ),

- respondents who rated their own health as good or very good and who indicated that they thought that absence of physical problems meant an adequate fat intake from those who did not meet these criteria ('fat-health relation'; no $=0$, yes $=1$ ).

Respondents were asked to indicate whether they changed their fat intake in the past ("past changes") on a 5-point scale (much reduced/much increased). Knowledge of the recommendation of the Netherlands Food and Nutrition Bureau for fat intake was measured by asking the respondents what they thought their fat intake should be according to the recommendations of the Bureau (correct answers were coded ' 1 ', incorrect answers were coded ' $O$ '). Finally, "self-rated fat' intake was measured by asking respondents how high or low they thought their fat intake was on a 5-point (very low/very high-in-fat) scale. An 'underestimation' variable was created as follows: Respondents were divided in tertiles based on the objective assessment of fat intake (fat score) and based on self-rated fat intake. Subjects whose self-rated fat intake was in a lower tertile than their objectively assessed fat-score were classified as underestimating their fat intake.

\section{Statistics}

Stepwise multiple linear regression analysis with self-rated dietary fat intake as dependent variable was used in order to detect the strongest correlates of misconception. On the first step in the regression analysis, actual fat intake was forced into the equation. Self-rated fat intake adjusted for actulal fat intake can be considered as a measure of misconception of fat intake.

Knowledge about fat content of food products, comparison to others, fat-weight relation, fat-sport relation, fat-health relation, belief about fat intake being higher in the past ('fat in the past'), self-reported changes in fat intake in the past ("past changes'), knowledge of the recommendation for fat intake, sex, age, educational level, and body mass index were included as independent variables.

After objective assessment of fat intake was forced into the regression model on the first step, possible correlates of misconception of fat intake were identified. First, each of the independent variables was analyzed separately to assess bivariate associations with misconception of fat intake. Finally, all significant correlates of misconception of fat intake were included in a multiple regression analysis with the 'forward entry' method of the SPSSx regression procedure (SPSS Inc., 1988). 


\section{Table 3:1}

Standardized $\beta$-weights and explained variance $\left(R^{2}\right)$ in stepmise multiple regressiom anatyses whth self rated fat adjusted for objective assessmemt (step l) of fat intake as dependent wariable $(\mathrm{m}=989)$

\begin{tabular}{|c|c|c|c|}
\hline $\begin{array}{l}\text { Variable } \\
\text { (range) }\end{array}$ & $\begin{array}{c}\text { Bivariate } \\
\text { (r) }\end{array}$ & $\begin{array}{c}\text { Multiple } \\
\text { (B) }\end{array}$ & $\mathbf{R}^{2}$ \\
\hline Actual fat intake & $34^{* *}$ & $14^{*}$ & step $1: .12$ \\
\hline Comparison to others $(-2 / 2)$ & $.49^{m+2}$ & $.45^{4 i \pi}$ & step $2: .34$ \\
\hline Past changes $(-2 / 2)$ & $.24=$ & $.13^{m *}$ & step $3: .36$ \\
\hline $\operatorname{Sex}(0,1)$ & $-.10^{-\infty}$ & $-.14^{* n+4}$ & step $4: .37$ \\
\hline Age $(16 / 92)$ & $-.16^{\circ}$ & $-.07^{*}$ & step $5: .38$ \\
\hline Fat-weight relation $(0,1)$ & $.07 * *$ & $-.07^{\circ}$ & step $6: .39$ \\
\hline Knowledge about fat $(0 / 15)$ & $.07^{\circ}$ & $.06^{\circ}$ & $\operatorname{step} 7: .39$ \\
\hline Fat in the past $(0,1)$ & $.12^{m+n}$ & $.06^{\circ}$ & step $8: .40$ \\
\hline Body mass index $(17 / 53)$ & $.09^{-*}$ & ns: & \\
\hline Education (low, intermediate, high) & ns & ns & \\
\hline Knowledge of recommendation $(0,1)$ & ns & $\mathrm{ns}$ & \\
\hline Fiat-sport relation $(0,1)$ & ns & nsi & \\
\hline Fat-health, relation $(0,1)$ & ns & ns & \\
\hline
\end{tabular}

* significant association, $\mathrm{p}<.05$

*: significant association, $\mathrm{p}<.01$

: explained variance in the stepwise model

ns: not significant

\section{Results}

\section{Descriptives}

From the 989 respondents, $336(34 \%)$ were male and $653(66 \%)$ were female. The mean age was $47(S D=17)$ years. Twenty six percent of the study population had less than high school education, $49 \%$ had finished high school, while $25 \%$ had college or 
university training. The mean fat score (SD) was 28.3 (5.6). The proportion of 1 dents who rated their personal fat intake as high or very high was $17 \%, 30 \%$ thou their fat intake was neither high nor low, and $53 \%$ rated their personal fat intake or very low. Forty-one percent underestimated their fat intake. Pearson corr between fat score and self-rated fat was .35 $(\mathrm{p}<.01)$.

Forty-eight percent of respondents thought that their fat intake was lower than comparable others while only $8 \%$ thought that their fat intake was higher than the fat intake of people of the same age and sex. Forty-five percent of respondents $\mathrm{kn}$ right recommended intake levels for fat, $52 \%$ indicated that they did not know wl recommendations were, and the remainder of the subjects thought that the recomn tions were higher. Women significantly more often knew the recommendation than On average $8.0(\mathrm{SD}=2.2)$ of the 15 questions about fat contents of food products answered correctly.

Approximately $50 \%$ of the respondents indicated that they had reduced their fat in the past, and $86 \%$ indicated that they thought that fat intake in general used higher in the past in the Netherlands. Thirty-eight percent thought that people who not overweight did not eat too much fat, while similar proportions of respos indicated that they thought that sport activities could compensate for a high fat $(35 \%)$, or that the absence of physical problems indicated that their fat intake was problem (44\%).

\section{Correlates of self-rated fat}

The results of the regression analyses are shown in Table 3:1. B-weights for ea the independent variables after adjustment for objective assessment of actual fat is and for the stepwise multiple regression analysis with all predictors are presented. : variables were significantly associated with self-rated fat after adjustment for objecl assessed fat scores in bivariate as well as in multiple regression analysis. Compr with others was the strongest correlate of self-rated fat intake after adjustmen objectively assessed fat sores: The lower subjects thought their fat intake was in conr son with others, the more likely they were to underestimate their fat intake. changes' in fat intake was also positively associated with self-rated fat after adjustmer fat score, indicating that respondents who reported having reduced their fat intake $i$ past, rated their fat intake significantly lower, independent of their actual fat score. was inversely associated with self-rated fat adjusted for fat score, indicating that wi were more likely to underestimate their fat intake than men. Age was inversely assoc 
with self-rated fat adjusted for fat score, indicating that underestimation of fat intake increased with age. The fat-weight relation variable also correlated inversely with misconception, indicating that respondents who rated their personal weight as average or low and who believed that people who are not overweight do not eat too much fat, were more likely to underestimate their fat intake. Finally, knowledge about fat contents of food products and the belief that fat intake in the Netherlands was higher in the past, correlated positively with self-rated fat adjusted for fat score. Body mass index was significantly associated with misconception in the bivariate analysis but not in the multiple regression analysis.

\section{Discussion}

Misconception of fat intake was highly prevalent in the present study which confirms the findings of earlier studies on misconception of fat intake (Brug, Van Assema, Kok et al., 1994). Underestimation of fat intake has been identified as an important barrier for motivating people to reduce their fat intake (Brug \& Kok, 1995; Brug, Van Assema, Kok et al., 1994).

A majority of the respondents in the present study thought that they were eating less fat than the average other person of the same age and sex. A minority of only $8 \%$ thought that their fat intake was higher than the average comparable other. These results confirm the conclusions of earlier studies in which an optimism bias in relation to fat intake was found (Brug, Riedstra, Van der Feen de Lille et al., 1993; Riedstra et al., 1992). A first step in nutrition education aimed at fat reduction should be focussed on creating awareness of personal fat consumption. Since comparison with others proved to be the strongest correlate of misconception of fat intake, the optimistic bias in comparing one's own fat intake to that of others should be addressed to reduce misconception of fat intake. The fact that people use others to evaluate their own position on all kinds of socially relevant dimensions has been thoroughly documented in social psychology (e.g. Sulls \& Wills, 1991). In general, people seem to select comparison targets in a self-serving manner, that is, people are often biased towards a more positive evaluation of their own capabilities or characteristics compared to others. Just like most people think that they are, for example, better drivers than most others (Svenson, 1981), it was shown that a majority also think that they are eating diets lower in fat than the average other person (Brug, Van Assema, Lenderink et al., 1994). 
In recent campaigns in the Netherlands aimed at improving awareness of fat $c$ tion, the message that the general fat consumption level in the Netherlands is too been communicated successfully: A large majority of the Dutch population is cc that the average fat intake is too high. Nevertheless, to tell people that the genera too high in fat has not resulted in higher awareness of personal fat consumption. still think that others are the ones with the high fat diets. People should be encour be more realistic when comparing their fat intake to that of others. Further analysi present data showed that a relatively large proportion of respondents $(45 \%)$ thi certain food items that are very obviously high in fat, like fried snacks, are tt important fat source for the Dutch population in general, while only relative subjects $(15 \%)$ considered this to be an important fat source in their personal diet snacks are food items that are often eaten in public places. Therefore, when peo! other people eat, the food consists often of these well known high fat entrees which be a cause of the unrealistic estimations people make when they compare their fat to that of others. Further research should focus on what reference groups subjex when comparing their fat consumption to that of others which might lead to information to explain why subjects show unrealistic optimism in comparing th intake to that of others.

Six other variables were significant correlates of misconception of fat intake. Ho including these variables in the regression model resulted in very modest increa explained variance. Therefore, these variables are probably only minor determina: misconception of fat intake. Respondents who reported having reduced their fat int: the past were more likely to underestimate their fat intake. People who have (ma attempt to) reduce fat intake probably think that the changes they have made are suff to classify their fat intake as low. Nevertheless, among subjects who reported to reduced their fat intake, $42 \%$ underestimated their fat consumption level. There subjects who have reduced or have tried to reduce their fat intake in the past should be motivated to re-assess their fat intake levels and to further reduce their fat consi tion.

The belief that a high fat intake is primarily a problem of overweight people was prevalent in the present study and a significant correlate of misconception of fat intak order to improve awareness of fat intake, the message that people with normal wi may also eat too much fat should be communicated to the public.

Knowledge about the fat content of food products was significantly, but only we associated with misconception of fat intake. This indicates that lack of knowledge 0 
contents of food products, as measured in the present study, is not an important determinant of misconception of fat intake. This is in contrast with our expectations at the start of the present study. People with better knowledge about fat do not necessarily make more realistic assessments of their fat intake. This indicates that subjects might not make a rational calculation of their fat intake, based on their knowledge about the fat contents of food products, to assess their personal fat consumption. The lack of association between knowledge of recommended intake levels and misconception of fat intake points to a similar conclusion. Calculating how much fat one eats and comparing this to recommendations might be too difficult for most people to do. Easily accessible and easy to execute self-assessment tools for calculating one's fat intake as compared to recommended intake levels and average intake levels, could stimulate people to re-assess their fat intake in order to obtain a more realistic estimation of personal fat consumption.

A possible way to create better awareness of personal fat intake is individualized feedback about fat consumption. Instruments to provide subjects with easy to obtain feedback about personal fat intake have been developed and tested in the Netherlands as well as in the United States with promising results (Brug, Steenhuis, Van Assema \& De Vries, 1996; Campbell, DeVellis, Strecher, Ammerman, DeVellis \& Sandler, 1994). These feedback instruments should specifically provide subjects with feedback about personal fat intake as compared to the intake of comparable others. This might stimulate people to be more realistic in comparing their own fat intake to that of others, which might result in less underestimation of personal fat consumption. 
अ

ל




\title{
Chapter 4
}

\section{Differences in Psychosocial Factors and Fat Consumption Between Stages of Change For Fat Reduction ${ }^{2}$}

\begin{abstract}
Differences in fat consumption and psychosocial factors between subjects in different transtheoretical stages of change for fat reduction were studied. Data on fat consumption, self-rated fat intake, attitudes, social support and self-efficacy were collected among a sample of 507 adults. Analysis of variance with Scheffe's multiple-comparison test was used to study differences in these factors between stages of change. Attitudes and social support were most positive among subjects in prepararion and action. Self-efficacy expectations were lowest among subjects in contemplation and preparation. Fat consumption was highest among precontemplators but no substantial differences between other stages were found. It is concluded that subjects in different stages of change differ in psychssocial factors that are regarded as important determinants of behavioral change. Based on these differences it is recommended to develop stage-tailored nutrition educaiion. A majority of subjects in maintenance consumed more fat than is recommended. Therefore, it is suggested that the usually applied staging algorithms might need adjustment for a valid application in nutrition research.
\end{abstract}

This chapter will be published as:

Brig, I. Hospers, H.J., \& Kok, G. Differences in psychosocial factors and fat consumption between stages of change for fat reduction. Bsvchology \& Health 


\section{Introduction}

Consumption of high fat diets, especially diets high in saturated fats, is considered to be a risk factor for a number of chronic diseases like cardiovascular diseases, several kinds of cancer, diabetes mellitus, and obesity (Voedingsraad, 1986a; National Research Council, 1989). In order to develop healthy diet promotion interventions aimed at fat reduction it is important to have insight into the behavior change process by which people reduce their fat consumption. It is generally accepted that different stages can be distinguished in this behavioral change process. The Transtheoretical Model, proposed by Prochaska and DiClemente (1992) is at present one of the most widely applied models on stages of behavioral change. The model distinguishes five separate stages. People move from precontemplation (not (yet) considering the behavioral change of interest), through contemplation (considering change), and preparation (actually planning change), to action (actively changing) and maintenance (sustaining the desired changes in behavior). The model does not implicate that the process of behavior change is linear or continuous. Relapse to previous stages is possible and movement through the stages can involve a cycling and recycling process. Furthermore, subjects can remain in one stage for indefinite periods of time. One of the practical implications of the model is that subjects: in different stages of change might benefit most from stage-matched interventions or treatment (Prochaska, DiClemente \& Norcross, 1992). With a limited number of questions, subjects can be divided in stages of change that can be regarded as target group segments that require specific interventions. The most straightforward categorization of subjects in stages of change is based on a combination of intention on the one hand and behavior measures on the other.

The Transtheoretical Model has been utilized in research on various health behaviors with an emphasis on addictive behaviors, especially smoking cessation (Prochaska \& DiClemente, 1992; Prochaska et al., 1992), but also in research on, for example, physical exercise (Lechner \& De Vries, 1995) and various diet related behaviors (Curry, Kristal \& Bowen, 1992; Glanz et al., 1994; Greene, Rossi, Richards-Reed, Willey \& Prochaska, 1994; Sporny \& Contento, 1995). There is increasing evidence that stage-taillored interventions are more effective in stimulating people to proceed toward action and maintenance (Skinner, Strecher \& Hospers, 1994; Strecher, Kreuter, Den Boer, Kobrin, Hospers \& Skinner, 1994).

In smoking cessation research, various studies have been conducted on differences in psychosocial factors between stages. The major goal of these studies was to identify 
factor(s) for each stage that could enable subjects to proceed in the change process (DiClemente, Fairhurst, Velasquez, Prochaska, Velicer \& Rossi, 1991; De Vries \& Backbier, 1994; Velicer, DiClemente, Prochaska \& Brandenburg, 1985). Some implications for smoking cessation interventions were as follows: So-called attitude information, that is, information about pros and cons of the desired behavioral change, should especially be given to precontemplators in order to motivate them to contemplate behavioral change. Self-efficacy information, that is, information helpful to enhance skills to actually perform the behavioral change, should be made available for subjects in contemplation and preparation in order to motivate them to actively try and start changing their behavior (De Vries \& Backbier, 1994). However, it is unclear whether the same differences in psychosocial factors between stages of change occur in other health related behaviors, like for example fat consumption reduction.

Few studies have been reported that used the Transtheoretical Model in studying the process of dietary fat reduction. Curry and colleagues (1992) studied differences in sociodemographic factors, body mass, and fat consumption between subjects in different stages of change. They found that stages correlated with sex, age, and education. Furthermore, their results showed that the mean fat consumption decreased from precontemplation to maintenance. More recently, these results were supported in a study reported by Glanz and colleagues (1994) in which differences in certain consumption patterns and psychosocial factors between subjects in different stages of change were investigated. The authors concluded that subjects with high self-efficacy to change and high self-rated health were more likely to be in action or maintenance and subjects with low self-efficacy and selfrated health were more likely to be in contemplation or preparation. However, these studies provide no information about how psychosocial factors like attitudes and social influences, that are generally accepted as important determinants of behavior (Ajzen, 1991), might differ between stages of change in dietary fat reduction.

In a recent study it became clear that the way in which subjects evaluate the level of their own dietary fat intake might be an additional predictor of intention to change (Brug. Van Assema, Kok et al., 1994). Subjects who rated their personal fat intake as high were more likely to intend to reduce their fat consumption, independent of their actual level of fat consumption. Furthermore, a majority of the subjects tended to underestimate their level of fat consumption.

In the present study, differences in fat consumption, self-rated fat intake, outcome expectancies, self-efficacy, social support, and perceived fat intake of important others (modeling) between stages of change for dietary fat reduction were investigated. 
Furthermore, the proportion of subjects who underestimated their fat intake assessed and the implications for the validity of the stages of change classificati discussed.

\section{Methods}

A random sample of 689 employees of a major oil company in the Netherlands used for data collection. Data were collected with self-administered written questionn that measured fat consumption, intention to reduce fat intake; self-assessments 0 consumption (self-rated fat intake), and psychosocial factors that are regarded as in tant motivational factors for fat reduction. Fat consumption was measured with a 25 validated food frequency questionnaire from which fat scores can be obtained that ca used to rank subjects according to fat consumption level in a valid and reliable way ( Assema, Brug et al., 1992). This fat score can theoretically range from 12 to 60 ; scores of 22 for womien and 25 for men are the approximated upper levels of rec mended dietary fat intake. Self-rated fat intake was measured by asking the subject evaluate the level of their personal fat consumption on a bipolar 7-point scalle, ran! from "very low' to "very high".

Attitudes towards fat reduction were measured with eight items that asked subj about possible consequences (taste, health consequences, preparation time, financial co that they expected if they were to reduce their fat consumption $(\alpha=67)$. Self-effic towards fat reduction was measured by asking subjects how easy or difficult they expec reducing their fat intake would be in general and in two different "high-risk' situati (when eating out and at parties, $\alpha=.76$ ). Social support was measured using two 0 structs, namely social support (De Vries, Backbier, Kok \& Dijkstra, 1995) and model (Bandura, 1986). Social support was measured by means of three items in which subje were asked to what extent important others (spouse/partner, other household membe colleagues) stimulated them to eat low fat diets (very little/very much support, $\alpha=.6$ Modeling was measured by asking subjects to estimate the level of fat consumption of before mentioned important others (very low/very high $\alpha=.55$ ). All items on psycho: cial factors were measured on bipolar 7-point scales.

The selection of relevant outcome expectancies, of high-risk situations, and important others for social support was based on earlier research and on results of foc group interviews (Van Assema et al., 1993). Overall attitudes, social support, modelin and self-efficacy scores were created for each subject by computing the mean score of $t$ 
items for each of these concepts. Intention to reduce fat intake was measured by asking subjects whether they intended to reduce the amount of fat they consumed within the next six months and, if so, whether they planned to do this within the next 30 days. Furthermore, subjects were asked whether they were presently trying to reduce their fat consumption, whether they had tried to reduce their fat intake in the past and, if so, whether they had succeeded in maintaining a low fat diet.

The algorithm that was used to allocate subjects to the different stages of change was very similar to that used in earlier research (Curry et al., 1992; Glanz et al., 1994; Greene et al., 1994). Subjects who reported to be presently trying to eat less fat were classified as being in action and subjects who reported to eat a low fat diet and were not presently trying to lower their fat intake were classified in maintenance. The remaining subjects were classified in preparation when they reported the intention to reduce their fat intake within 30 days and in contemplation when they intended to cut down on fat within six months but not within 30 days. Subjects were classified in precontemplation when they did not consider themselves as eating a low fat diet, were not in the process of cutting down on fat and had no intention to reduce their fat consumption. The stages were mutually exclusive: A respondent could be allocated to one stage only.

Finally, the proportion of subjects in maintenance who consumed more fat than is officially recommended and who, therefore, underestimate their fat consumption, was assessed in order to evaluate the validity of the staging algorithm.

One-way analysis of variance with Scheffé's multiple comparison test was used to test for significant differences in psychosocial factors, self-rated fat intake and objectively assessed fat scores between specific stages of change. An $\alpha$ of .05 was used in the multiple comparison test.

\section{Results}

A total of 507 completed questionnaires were returned (response rate $=74 \%$ ). The mean age of the subjects was $39(\mathrm{SD}=7.7)$ and ranged between 21 and $59 ; 83 \%$ of the respondents were male. No significant association between stages of change on the one hand, and sex and age on the other, was found. 


\section{Table 4:1}

Distribution of respondents over stages of change

\begin{tabular}{lcc}
\hline & $\mathrm{n}$ & $\%$ \\
\hline Precontemplation & 73 & 14.4 \\
Contemplation & 41 & 8.1 \\
Preparation & 130 & 25.6 \\
Action & 61 & 12.0 \\
Maintenance & 202 & 39.8 \\
\hline TOTAL & 507 & 100 \\
\hline
\end{tabular}

The largest proportion of subjects was classified as being in maintenance. Also relatively many subjects, $26 \%$ of the study population, were classified as being in preparation (Table 4:1).

Differences in mean fat scores, self-rated fat, attitudes, social support, and selfefficacy scores between subjects in different stages of change are presented in Table 4:2.

Attitudes towards reducing fat consumption were most positive among subjects in preparation. Both social support and modeling scores towards dietary fat reduction were highest among subjects in action. All psychosocial variables except self-efficacy were lowest in preconternplation. Self-efficacy expectations were highest among subjects in maintenance and lowest among contemplators.

Subjects in maintenance had lower average attitude and social support scores as compared to people in preparation and action. Subjects in precontemplation had mean attitude and social support scores comparable to subjects in maintenance. Mean self-rated fat consumption and objectively assessed fat scores were highest in precontemplation. The mean fat score among precontemplators was significantly higher than among subjects in preparation and action. No significant differences in fat scores were found between the other stages.

The proportion of subjects who reported to have low fat diets but had fat scores above recommended levels were $56 \%, 55 \%, 77 \%$ and $74 \%$ in contemplation, preparation, action, and maintenance respectively. 


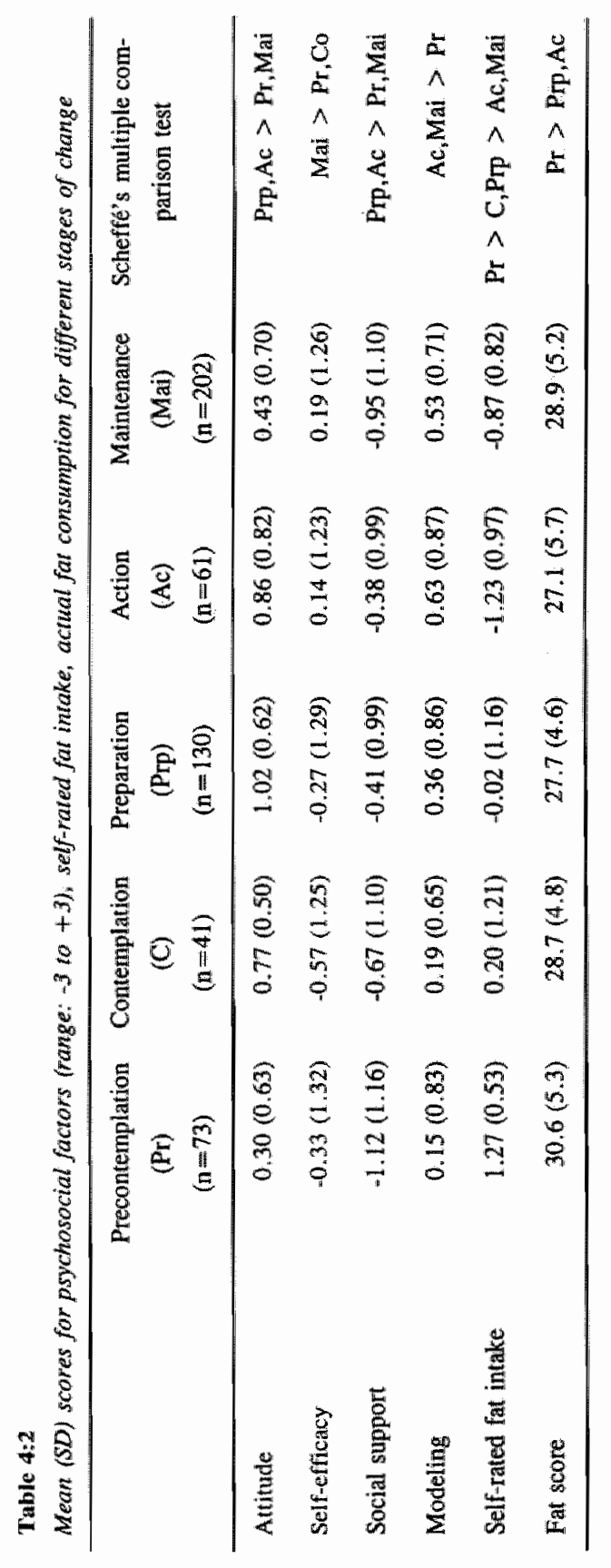




\section{Discussion}

This paper presented differences in psychosocial factors, fat consumption, and self rated fat between subjects in different stages of change according to Prochaska and DiClemente's Transtheoretical Model. Several significant differences were found. In general, subjects the preparation and action stages had more positive attitudes and experienced more positive social influences as compared to subjects in precontemplation. Subjects in maintenance also had generally lower attitude and social support scores than subjects in preparation or action. Subjects in maintenance are not actively involved in dietary changes and motivational factors might therefore be of less relevance for their situation. Furthermore, the psychosocial factors were measured in relation to dietary fat reduction (behavior change) and not in relation to low fat diets (present behavior). Subjects in maintenance will not be motivated to reduce their fat consumption since they consider their diets to be low in fat already, which might cause their psychosocial scores to be quite similar to those in precontemplation.

Prochaska and colleagues distinguish 10 so-called processes of change as predictors of changing addictive behaviors. These processes have been integrated in the stages of change model, since specific processes of change have been found to be particularly useful in specific stages of change. At present, no information is available about the validity and practicability of the processes of change concept for preventive dietary changes like fat reduction.

Similar to the studies on stages of change in fat consumption reduction that have been published so far (Campbell et al., 1994; Curry et al., 1992; Glanz et al., 1994), subjects were allocated to the different stages of change based on their intention and based on their subjective assessments of behavior. The classification into stages of change that was used in these studies resulted in relatively many subjects in action and maintenance and relatively few subjects in the earlier stages of change (Curry et al., 1992; Glanz et al., 1994). In recent studies it became clear that there can be large discrepancies between selfrated fat intake and actual fat intake levels, and that especially subjects with relatively high fat consumptions tend to underestimate their level of fat intake (Bowen, Fries \& Hopp, 1994; Brug, Van Assema, Kok et al., 1994).

This misconception of fat intake was also present in our data and led to a substantial number of subjects who were classified as being in action or maintenance while their fat consumption levels were way above recommendations. Greene et al. (1994) showed that 
$40 \%$ of subjects eating more fat than the U.S. recommendation were classified as maintainers based on their self-reports. Glanz et al. (1994) reported an average fat consumption among maintainers of $32 \%$ of total energy intake which also indicates that at least a substantial proportion of maintainers consumed more fat than is recommended. Curry et al. (1992) reported similar results: Among male maintainers the average fat intake was more than $35 \%$ of total energy intake. In the study presented here, the fat score for subjects in maintenance and action was not significantly lower than for subjects in contemplation and preparation. Among subjects in maintenance, $74 \%$ had fat scores above recommendation levels. Based on fat intake level of subjects classified as being in maintenance, it seems questionable to provide these subjects with nutrition education aimed at maintenance, that is, at sustaining the present behavior.

As was mentioned in the introduction, the majority of studies on stages of change have been conducted in the smoking cessation field. With respect to smoking behavior, the process of allocating people to the action or maintenance stages is relatively straightforward: assess whether people have quit smoking as well as the period they have managed to refrain from smoking.

Staging is more complicated with respect to dietary fat consumption for two reasons. First, fat consumption cannot and should not be completely avoided. Second, fat consumption is a relatively 'complex' continuous behavior. As a consequence, it is difficult for people to assess their own fat intake (Brug, Van Assema, Kok et al., 1994). If maintenance is defined as sustained behavior according to dietary recommendations, it would imply that it should be taken into consideration whether or not people adequately evaluate their fat intake (i.e. are aware of their fat intake level). A staging algorithm that also includes objectively assessed behavior might thus lead to a classification that more closely reflects the definitions of the Transtheoretical Model for the various stages.

Subjects who are classified as being in maintenance based on their self-classification but consume high fat diets might better be regarded as precontemplators who are unaware of their 'risk behavior'. Dietary feedback should be provided in order to make these subjects aware of their dietary risk behavior in order to motivate them to reduce their fat consumption (Brug, Van Assema, Kok et al., 1994). In Weinstein's precaution adoption model (Weinstein, 1988) it is argued that awareness of personal risk behavior is a necessary factor to proceed from precontemplation to contemplating behavior change.

It can be concluded that subjects in different stages of change for fat reduction differ in psychosocial factors that are considered to be important in motivating subjects to adopt preventive behavior. From these differences, specific implications for stage-tailored 
nutrition education can be drawn: Subjects in precontemplation are not yet convinced tia the pros of fat reduction outweigh the cons and might benefit from attitude information it which the negative consequences of high fat diets are stressed and positive aspects of low fat diets are demonstrated. Furthermore, the social environment of these subjects seems th be unsupportive towards fat reduction. Strategies that focus on coping with a negative social environment might be an additional nutrition education target for this group of subjects. Subjects in contemplation and preparation could benefit from self-efficacy information, in order to provide them with specific skills to realize a diet lower in fat and to cope with situations they experience as difficult for adopting a low fat diet.

The current study yielded cross-sectional data only. Therefore, the abovementioned implications should be regarded with caution and carefully tested in additional research. Such research should assess whether stage specific messages are indeed effective for interventions aimed at fat reduction. Personalized interventions aimed at smoking cessation, dietary fat reduction and participation in breast cancer screening in which the interventions tailored to, among other variables, stages of change have been found to be more effective that general health messages (Campbell et al., 1994; Prochaska, DiClemente, Velicer \& Rossi, 1993; Skinner, Strecher et al., 1994; Strecher et al., 1994).

Finally, a disregard for the level of awareness of personal dietary fat consumption might result in misclassifications of subjects in stages of change. Therefore, it is recommendable to include objective assessments of dietary behavior in the classification rulles for stages of change. 


\title{
Chapter 5
}

\section{Psychosocial Determinants of Fruit and Vegetable Consumption Among Adults:}

\author{
Results of Focus Group Interviews ${ }^{1}$
}

\begin{abstract}
Fruit and vegetable ( $F \& V$ ) consumption is supposed to be associated with prevention of chronic diseases. To tailor nutrition education aimed at increasing $F$ \& $V$ consumption to needs and beliefs of subjects in the target population, it is important to obtain information about what motivations people have for consuming or not consuming $F \& V$. But hardly any studies on psychosocial factors related to $F \& V$ consumption have been reported. Therefore, an explorative study was conducted, using focus group interviews as method for data collection, in order to identify relevant beliefs related to $F \& V$ consumption among Dutch adults.

Six different general issues were identified as important in relation to $F \& V$ consumption. Satisfaction, and especially taste, perceived health consequences, social influences, skills and barriers, habit, and lack of awareness of adequate intake levels, were brought forward during the interviews as determinants of $F \& V$ consumption.
\end{abstract}

This chapter was published as:

Brug, I., Debie. S., Van Assema, P., \& Weijts, W. (1995). Psychosochal determinants of fruit and vegetable consumption among adults: Results of tocus group interviews. Food Quality and Preference, 6, 99-107. 


\section{Introduction}

A large body of epidemiological evidence has been reported regarding the possible preventive effects of fruit and vegetable ( $F \& \mathrm{~V}$ ) consumption for several kinds of cancer and cardiovascular disease (Block, Patterson \& Subar, 1992; Gerster, 1991; Hertog et al., 1993). This epidemiological evidence resulted in dietary recommendations for F \& V consumption in many countries. The U.S. Dietary Guidelines and the Food Guide Pyramid both recommend to eat five or more servings of F \& V per day (U.S. Depart. ment of Agriculture and Health and Human Services, 1990; U.S. Department of Agriculture, 1992). In many European countries the recommendation to increase consumption of F \& V is part of dietary guidelines but is often not quantified. (Benito, 1992). In the Netherlands, the advice to eat ample amounts of F \& V is part of the official dietary guidelines (Voedingsraad, 1986a). A more specific, somewhat quantitative recommendation has been formulated by the Netherlands Bureau for Food and Nutrition. This organization recommends for adults to eat four so-called serving spoons (approximately 200 grams) of vegetables and one piece (approximately 150 grams) of fruit per day (Netherlands Bureau for Food and Nutrition, 1992). ${ }^{2}$

In a study comparing the first and second National Food Consumption Survey in the Netherlands it was concluded that F \& V consumption declined in this country by approximately 10\% between 1988 and 1993 (Hulshof et al., 1994). In 1993 mean consumption was 128 grams of vegetables and 114 grams of fruit per day (Netherlands Bureau for Food and Nutrition, 1993). Nationwide food consumption surveys in the U.S. revealed that the level of consumption of $\mathrm{F} \& \mathrm{~V}$ in this country was also lower than recommended (Patterson \& Block, 1988). These discrepancies between dietary recommendations and actual $F \& V$ consumption has lead to public health initiatives aimed at increasing $\mathrm{F} \& \mathrm{~V}$ consumption among the general public. For example, in the United States a number of projects aimed at reaching the 'five a day' goal are underway at this moment (Havas et al., 1994). In Europe, the major goal for the 1994 European Week Against Cancer, a European Community initiative to implement the European Code against Cancer (European Community Commission, 1994), is an increase in F \& V consumption among the general public. In the Netherlands, the Dutch Cancer Society supports this initiative and started a mutrition education campaign aimed at promoting $\mathrm{F} \& \mathrm{~V}$ consumption. In order to develop interventions aimed at promoting $\mathrm{F}$ \& V

\footnotetext{
${ }^{2}$ Since this study was condueted the recommendation for fruit intake has been changed wo two pieces of fruit.
} 
consumption, understanding of determinants of fruit and vegetable consumption is necessary (Green \& Kreuter, 1991; Kok, 1985). However, research on determinants of F \& V consumption is rather restricted to studies on socio-demographic correlates of $F \& V$ consumption. In summary, these studies report positive associations between socioeconomic status and $\mathrm{F} \& \mathrm{~V}$ consumption and between age and $\mathrm{F} \& \mathrm{~V}$ consumption (Patterson \& Block, 1988; Hulshof et al, 1991). The assoctation with sex is less clear. In the Netherlands fruit consumption was found to be lower and vegetable consumption was higher among men as compared to women (Hulshof et al., 1991). Other studies have focused on differences among consumers in preferences for, and attitudes towards different kinds of F \& V (e.g. Harper, 1963; Produktschap voor Groente en Fruit, 1994) but hardly any studies have been conducted on psychosocial correlates of $F$ \& $\mathrm{V}$ consumption in general. Research on psychosocial determinants of other health-related dietary behaviors, like for example fat consumption has been done before (Stafleu, De Graaf \& Van Staveren, 1991), often based on well known models from social psychology like Fishbein and Ajzen"s Theory of Reasoned Action (Ajzen \& Fishbein, 1980) and Bandura's (1986) Social Cognitive Theory in which behavior is determined by attitudes, social influences and/or self-efficacy beliefs. One study on psychosocial correlates of $F \& V$ was done by Baranowski et al. (1993) where focus groups were used in order to study important psychosocial factors in determining an increase in F \& V consumption among school children in the U.S.A. The interview protocol was based on a Social Learning Theory perspective. Based on this study the authors concluded that availability of $F \& V$, affect for $F \& V$, and skills to prepare $F \& V$ are important factors that should be addressed in interventions aimed at increasing $F \& V$ consumption among 4 th and 5 th grade students.

Studies among adult populations as well as European studies on important psychosocial factors in determining $\mathrm{F} \& \mathrm{~V}$ consumption seem to be lacking in the international literature. Therefore, a study was conducted on psychosocial determinants of $\mathbb{F} \& \mathrm{~V}$ intake among adults in the Netherlands. The purpose of this study was to identify outcome belief's, social normative beliefs, self-efficacy beliefs, and beliefs about barriers, related to $F \& V$ consumption among Dutch adults by means of focus group interviews.

The results of this study can and will be used in two ways: to tailor health education messages aimed at increasing fruit and vegetable consumption to beliefs about $\mathrm{F} \& \mathrm{~V}$ in the target population, and to operationalize theoretical concepts in order to develop a selfadministered questionnaire suitable for measuring psychosocial determinants of $F \& V$ consumption in a quantitative way in larger populations. 


\section{Methods}

Focus group interviews were used for data collection. This method is considered : useful means of data collection in studies where rather little is known about the pheno non of interest (Stewart \& Shamdasani, 1990). Focus group interviews have been wir used in explorative research related to health promotion (Krueger, 1988) and have : been used before in nutrition related research (Baranowski et al., 1993; Van Assem: al., 1993). The focus group procedure has been described thoroughly by others ( Krueger, 1988; Stewart \& Shamdasani, 1990).

\section{$\underline{\text { Subjects }}$}

Subjects were recruited through an announcement in two local newspapers. general topic for the discussion, dietary habits, was mentioned in this announcement the specific goals of the study were not described.

Four focus group interviews were conducted with a total of 29 participants, 7 men : 22 women. The mean age of the participants was 45 years and ranged from 24 to 66 . $]$ majority of the participants were middle aged women. All participants were caucasi: and lived in the Maastricht region (south of the Netherlands). A large proportion of participants were housewives. Most participants were not familiar with each other.

All subjects received a gift coupon of 25 Dutch Guilders (about US\$13) for th participation.

\section{Interview guide}

The focus group discussions followed a protocol based on a semi-structured intervit guide developed in accordance with established guidelines (Krueger, 1988). The intervit guide consisted of instructions for the interview procedure and a check list of qut tions/topics that had to be discussed. In the construction of the interview guide for $t]$

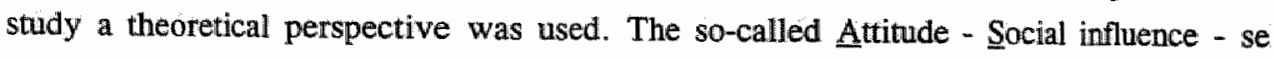
Efficacy (ASE) model was used for this purpose (De Vries et al., 1988), which is integration of Fishbein and Ajzen's Theory of Reasoned Action (Ajzen \& Fishbein, 198 and Bandura's Social Learning Theory (Bandura, 1986). The ASE model is very simil to the Theory of Planned Behavior (Ajzen \& Madden, 1986). The ASE-model and relat expectancy value models have often been used in describing and explaining dieta behaviors (Stafleu et al., 1993; Van Assema et all, 1993). 
According to the ASE model, (health) behavior is primarily a result of behavioral intention. Behavioral intention is influenced by three determinants: attitude towards the behavior, perceived social influence, and self-efficacy expectations. These determinants are supposed to have a direct influence on behavioral intention. External variables, for instance socio-demographic factors, are assumed to influence behavior through the behavioral determinants and intention. A person's attitude towards a specific dietary behavior is determined by comparing relevant pros and cons of the expected consequences of the specific behavior. Social influence consists of two components: direct and indirect social influence. Direct influence is the perceived expectations of important others. Indirect social influence appears when the behavior of important others is taken as an example (modeling; Bandura, 1986). Self-efficacy refers to a person's expectations regarding his or her capability to realize a (desired) behavior. Self-efficacy is dependent on a person's abilities to perform a behavior and on barriers that stand in the way of performing the behavior (Bandura, 1986; De Vries et al., 1988). Finally, the behavior, or trying to perform the behavior, will lead to feedback that may, in turn, influence the determinants (Kok et al., 1991).

A checklist with topics related to these theoretical issues was made. Most topics were 'automatically' brought forward because the discussion simply addressed these issues. If not, the moderator asked a question aimed at steering the discussion towards one of the topics at a moment when the discussion failed to reveal new relevant data.

For the interviews, F \& V consumption was split into three sub-behaviors: consumption of boiled, cooked, or otherwise heated vegetables (boiled vegetables), consumption of raw vegetables as salads (salads), and consumption of fresh fruit (fruit). Based on information about the general eating pattern in the Netherlands it was assumed that respondents would have different motivations for eating these three groups of food items.

The questions asked during the interviews were designed to raise a discussion about pros and cons, influences and behavior of important others, who important others are, and beliefs about skills and barriers regarding consumption of boiled vegetables, salads, and fruit. The first concept of the interview guide/checklist was discussed with experts on nutrition and qualitative research, and was revised according to their comments. The three sub-topics were addressed separately during the interviews. The line of questioning is illustrated in Table 5:1. Table 5:1 does not give the exact questions as asked during the interviews. In which way the questions were formulated during the interview depended on the progress of the discussion. Many questions were not actually asked because the group discussions addressed the subjects anyway. 
For each topic the respondents were first asked about their consumption of, for example, fruit, as an introduction for further discussions. After each of the respondents had the opportunity to tell about their fruit consumption, subjects who reported never, or hardly ever, eating fruit were asked about their reasons for not doing so. The same question was asked to subjects who reported eating fruit every day. Other group members were asked to respond to these motivations and beliefs.

\section{Procedure}

Subjects participated in one of four focus group interviews. The smallest group consisted of five subjects, the largest of eight. The interviews took between one and a half and two hours each. The interviews were audiotaped. Participants were informed about this beforehand.

\section{Table 5:1}

General line of questioning in interview guide, fruit as an example

1 Who eats fruit every day?

2 Who eats fruit never or hardly ever?

3 Why do you never eat fruit?

$4 \quad$ Why do you eat fruit wery often?

5 Do the others have the same reasons?

6 Are other people important for how much or little fruit you eat?

7 Is it easy or difficult to eat ample amounts of fruit? Why?

8 Can you think of specific situations in which it is difficult to eat fruit?

9 Could you think of reasons to start eating more fruit? 
The interviews were led by two persons of the research team, one acted as moderator, the other as assistant to the moderator, following suggestions given by Krueger (1988). The moderator was responsible for facilitating the group discussions. The assistant took care of the audio equipment and took notes during the interviews.

Coffee and tea were served to the participants on arrival. After about one quarter of an hour the moderator started the discussion by introducing herself and the general subjects for the discussion. Subsequently, the participants were asked to briefly introduce themselves. After introductions were made, the discussions commenced. After the discussion the more specific goals of the group discussions were explained to the participants and the gift coupons were handed out.

\section{Analysis}

After each interview the first impressions from the interview were discussed and written down by the two researchers. During the days following the interview a complete transcript was made of the discussion. The transcripts and tapes were analyzed using content analysis by the two researchers separately by means of a four step approach according to guidelines given by Krueger (1988) and by Stewart and Shamdasani (1990). After each step the analysis results from both researchers were compared. When essential differences occurred, a third reviewer was asked for her judgement. At the first analysis step the transcripts were re-ordered to the three behaviors addressed by the discussion: boiled or otherwise heated vegetable consumption, consumption of raw vegetables, and fruit consumption. At the second step of analysis, important issues and sub-issues, issues that were brought forward repeatedly or were discussed at length by the participants, were identified for each behavior and relevant parts from each interview transcript were ordered by these issues, using a 'cut and paste' method in which paragraphs from the transcripts were selected and were put together according to issues. The third step was to make a summary of the results of each interview, based on the issues and sub-issues that were addressed in the interviews. These summaries were reviewed by two other persons experienced in the focus group procedure, to test whether the summaries were good representations of the interviews, and were revised, based on their comments. Finally, an overall summary of the four interviews was made. Issues were regarded as important enough for inclusion in the generall summary when they were mentioned in at least three of the four interviews. 


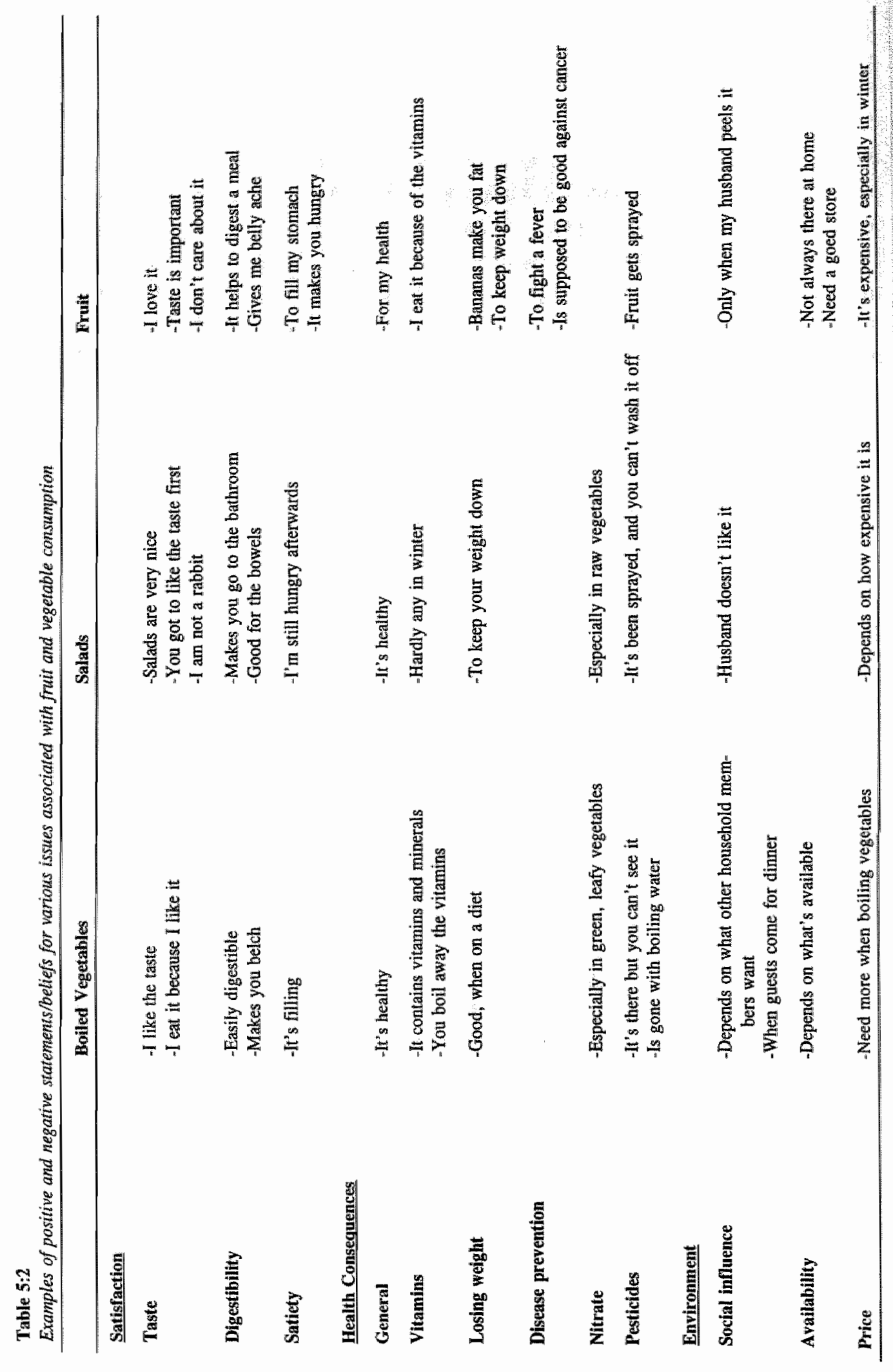




\section{Results}

The discussions revealed that often similar beliefs were of influence on consumption of boiled vegetables, salads, and fruit among the respondents. But the importance of the different beliefs, and the way these beliefs were valued, were not the same for the three sub-behaviors. Therefore, the description of the results concerning the three separate behaviors will be integrated. The results will be described according to important issues that were derived from the analysis. For each issue the three sub-behaviors are discussed separately when necessary. The description of the results will be illustrated by quotes from the respondents in order to exemplify the results.

Six issues arised from the interviews: satisfaction, health consequences, social influences, habit, abilities and barriers, and awareness. The issues and sub-issues that were mentioned during the interviews are summarized in Table 5:2 for the three different behaviors. The sub-issues of taste (satisfaction), vitamins and general health issues (perceived health consequences) were mentioned in all four focus groups.

\section{Outcome Beliefs}

\section{Satisfaction}

'Satisfaction' seemed to be the primary motivation to eat $\mathrm{F} \& \mathrm{~V}$. Different aspects of satisfaction were mentioned by the respondents. Taste was mentioned most often for all three behaviors and stressed as being an essential prerequisite to decide whether or not to eat $F \& V$. Subjects who did not like the taste of vegetables, salads or fruit were not eating it. The following quotes are illustrative: "In the first place, I eat it because I like it" , "But you got to like the taste of it first".

Other 'satisfactive' beliefs that were mentioned were 'digestibility" and "satiety". For salads 'good digestibility' was seen as a positive characteristic. For boiled vegetables good digestibility as well as bad digestibility was mentioned. Exemplative quotes are: "I think it makes you belch". "What I consider as a pro is that it is very easily digestible".

'Satiety' was mentioned for all three behaviors, both in a positive as well as in a negative sense. Boiled vegetables were considered as filling/satisfying, while for salads the opposite was true. Salads were not considered good for relieving hunger. 


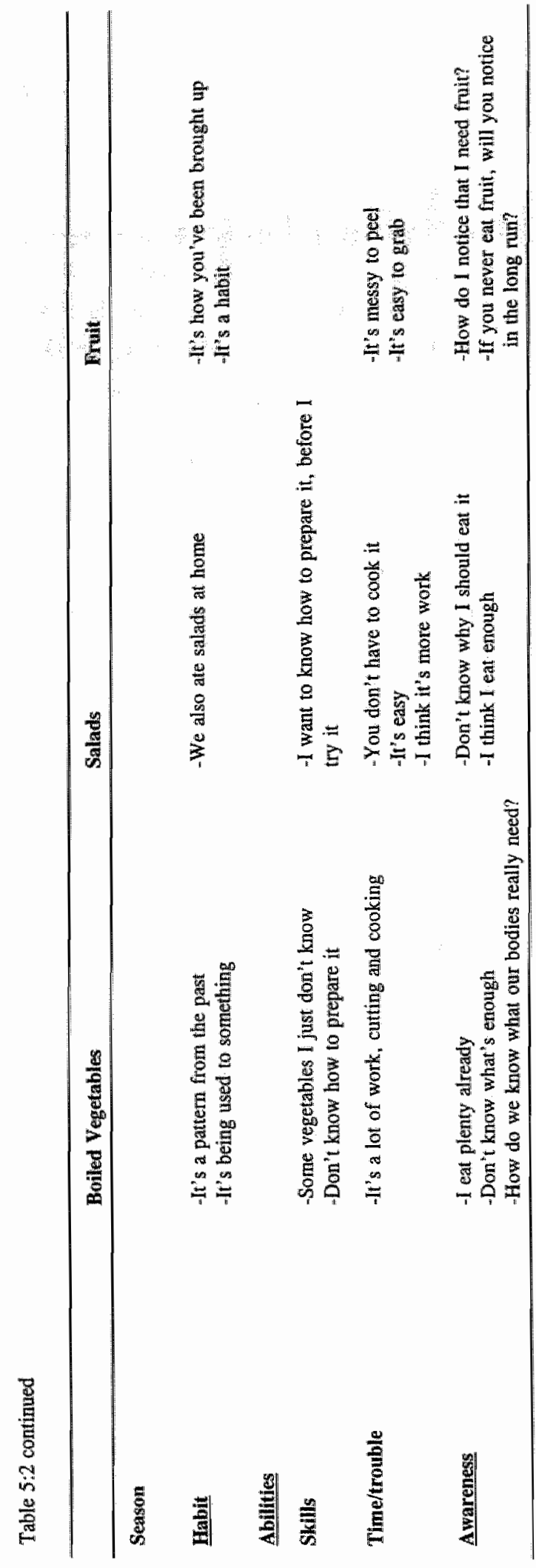


A notable, often mentioned consequence of eating fruit was that it did not relieve the feeling of hunger but in fact initiated hunger: "I would like to eat fruit but it doesn't suit me, it makes me extremely hungry" "An apple, it fills you up for just a minute but soon afterwards I get extremely hungry".

\section{Perceived health consequences}

The health consequences of eating $F \& V$ were mentioned as being of great importance in determining the consumption of all three groups of food items. General positive remarks about $F \& V$ consumption being healthy were made in all four interviews for all three behaviors. Sometimes comparative remarks were made like: "I have the feeling that row eaten vegetables in salads are better for your health than boiled vegetables" " "I think that I value fruit more than vegetables where health is concerned"

More specific health related remarks could be divided in a number of sub-issues. On the positive side "vitamins", and "losing weight' were mentioned for all three behaviors. Vitamins was mentioned only in a positive way for consumption of fruit. For boiled vegetables positive remarks ("Vitamins, minerals, one really should eat it") as well as negative remarks ("You throw the vitamins away with the boiling water") were made. This was also true for salads, where seasonal differences in vitamin contents were believed to occur ("You really think there are any vitamins in green salads in winter?").

All three behaviors were mentioned as being helpful when trying to lose weight. Trying to lose weight was also mentioned as a possible motivation to increase $\mathrm{F} \& \mathrm{~V}$ consumption.

'Disease prevention or curation' was mentioned by a number of respondents in different interviews in relation to consumption of fruit ("And pineapple, it keeps you from getting cancer" "When I have the flu, I take a couple of oranges in the morning"). Consumption of fruit was also mentioned as a way to keep oneself from eating "unhealth$y^{\prime \prime}$, especially sweet foods ("I drop the sweet things and eat fruit").

With regard to health consequences, on the negative side, "nitrate" and "residues of pesticides' were mentioned. 'Nitrate" was often mentioned in relation to boiled vegetables as well as salads. 'Residues of pesticides' was especially mentioned in relation to salads and fruit. For boiled vegetables 'pesticides" was not seen as a negative aspect because it was believed that the residues would end up in the boiling water ("It gets boiled of, then it"s gone" ). 


\section{Social Influences}

Influences of others were often mentioned as determining one's own behavior. A distinction can be made between influence of members of the same household (partmer and other family members) and influence of others (friends etcetera).

For boiled vegetables and salads the influence of other household members seemed. important. Especially the partner of male respondents and children seemed to have a large: influence in deciding whether or not to eat (certain kinds of) F \& V.

Influence of 'others' was also mentioned for boiled vegetables and for salads. The point that was often made was that preparing a meal for others not from the same household was a stimulation to include ample amounts of boiled and/or raw vegetables in the meal: "When somebody comes for dinner, I do my extra best". When eating alone, the respondents stated that they did not take the 'trouble' to prepare boiled vegetables or salads.

\section{Self-Efficacy and Barriers}

Different aspects were mentioned as stimulating or as barriers in relation to $F \& V$ consumption: abilities, availability of $F \& V$, the financial costs of $F \& V$, and the time of year or seasonal influences.

\section{Abilities}

The abillity to buy, prepare, and consume $\mathrm{F} \& \mathrm{~V}$ seemed to be dependent on perceived skills and the perceived amount of time and/or trouble consumption of F \& V will cost.

Certain skills and practical knowledge were perceived as important for deciding whether to eat vegetables (raw and boiled). Especially, (lack of) practice in preparing certain vegetables seemed to make a difference ("When I eat at -., he always makes good salads. I ask him how he prepares that stuff, and try it myself" "There are all sorts of vegetables but I don"t know how to prepare them and that keeps me from buying them ").

Preparing boiled vegetables was considered as time consuming but preparing salads was considered to be a relatively quick and easy way to get a meal: "I eat it raw, it "s easy, you don't have to cook it".

For fruit both positive and negative time and work consequences were mentioned. A number of respondents stated that eating fruit was awkward or messy ("I never eat fruit, it's got to do with laziness", "I would never clean an orange myself, your hands getting 
sticky and all"). Other respondents remarked that eating fruit was an easy snack between meals: "It's easy to grab".

\section{Availability}

Availability of $\mathrm{F} \& \mathrm{~V}$ was mentioned for all three behaviors as a possible barrier for F \& V consumption. Two aspects were mentioned: availability of good and easy-to-get-to points of purchase ("You've got to live in the neighborhood of a $F \& V$ market") and (lack of) availability of $F \& V$ because of seasonal influences.

\section{Price}

Financial costs was mentioned as a barrier, but this seemed to be dependent on seasonal variations in availability. Some $\mathrm{F} \& \mathrm{~V}$ were considered to be very expensive out of season. Respondents stated that food items were not bought when they were too expensive according to their judgement ("And the price maybe. When it would be much cheaper, I would buy it more often").

\section{Season}

Seasonal influences seemed to be strongly associated with the issues of taste, availability, and price. For seasonal influences, quantity ("In the summer, then there's more"), quality ("In summer the taste is much better"), as well] as financial aspects ("I'm not going to buy strawberries out of season") were mentioned.

Two other important issues came forward during the interviews that are not readily compatible to the ASE model. These issues were labelled 'habit' and 'awareness'.

\section{Habit}

Habit or tradition was mentioned as a determinant of consumption for all three behaviors in all the interviews. Subjects stated that the amount of $\mathrm{F} \& \mathrm{~V}$ was largely dependent on what they were used to eat. It was said repeatedly during the interviews that they were eating the way they were taught at home in the past and continued eating according to those habits when they left their parents to go and live on their own or started their own family ("Well it's easily explainable, it comes from my own parents"). 
Respondents explicitly stated that it would be difficult and not desirable to leave those habits behind ("What they taught you at home is hard to change").

\section{Awareness}

The final issue that seemed to be important for F \& V consumption was "awareness". Two aspects of awareness were mentioned repeatedly in the interviews: (un)awareness of, especially, health consequences of F \& V consumption and (un)awareness of what a sufficient or recommendable amount of F \& V would be. Some respondents seemed to be rather unaware of the health related beneficial effects of $\mathrm{F} \& \mathrm{~V}$ consumption. They $\mathrm{knew}$, or were told, that F \& V are supposed to be healthy, but they were not sure what the negative consequences would be if they were not eating (enough) F \& V. ("That it is healthy, how do I notice that?"). The right amount of $\mathrm{F} \& \mathrm{~V}$ to eat was also something that most respondents were uncertain about ("How do you know whether you're eating enough?"). In fact, rather independently of how much $F \& V$ subjects were eating, it seemed that almost all were thinking that they were eating sufficient amounts of $F \& V$ : "I eat plenty (of $F \& V$ " , "I can't eat more than I do").

\section{Discussion}

Consumption of ample amounts of $\mathrm{F} \& \mathrm{~V}$ is recommended by various health authorities because it is assumed that higher consumption of $\mathrm{F} \& \mathrm{~V}$ is effective in preventing chronic diseases like cardiovascular dísease and cancer (Block et al., 1992; Hertog et al., 1993). The present study was conducted in order to investigate what motivates adults to eat $F$ \& $\mathrm{V}$ or not.

The study revealed that a number of different issues seemed to be important for consumption of $\mathrm{F} \& \mathrm{~V}$. In general the data were straightforward and agreement between the researchers in interpretation of the data was reached on the reported issues. Satisfaction, and especially taste, seemed to be the most important attitude belief in relation to F \& V consumption: A (not unexpected) outcome was that subjects who did not appreciate the taste of a fruit or vegetable stated that they would not eat it. Satisfaction or 'liking' has been identified as the most important determinant of dietary behavior before (Stafleu et al., 1991). Shepherd and Farleigh (1986), for example, found that taste preference was a strong correlate of salt use. Tuorila-Ollikainen, Lahteenmäki and 
Salovaara (1986), and Tuorila (1987) found that hedonic response was a significant predictor of both consumption of low salt bread and of milk with different fat contents.

Other important outcome beliefs were related to perceived health consequences. As far as "perceived health consequences" is concerned, the general opinion seemed to be that eating $\mathbb{F} \& V$ is good for your health. A number of more specific health related issues were mentioned repeatedly during the interviews. However, a possible association between F \& V and prevention of chronic diseases was mentioned only once. Possible health consequences have been considered as an important determinant of dietary behavior (Stafleu et $\mathrm{al}_{\text {, }}$ 1991). Most nutrition education programs focus on the health benefits of dietary changes. It seems that the general healthfulness of $F \& V$ is already generally known but that relatively new scientific insight into the relation between $F \& V$ consumption and reduced risk for, for example, cancer is not yet common knowledge. Furthermore, although respondents expressed beliefs about $F \& V$ and health, they were unsure about recommendable amounts of $\mathrm{F} \& \mathrm{~V}$ in relation to health.

'Season' also seemed to be important in relation to F \& V consumption. 'Season' was not a direct determinant of $\mathrm{F} \& \mathrm{~V}$ consumption but seemed closely associated with beliefs about taste, price, availability, and perceived health consequences of $\mathrm{F} \& \mathrm{~V}$. The general opinion was that F \& V are better tasting, cheaper, easier available, and better for health in summer than in winter.

Two important issues were identified that could not be fitted into the theoretical framework that was used for the construction of the interview guide: habit and awareness.

Various authors have proposed the inclusion of habit as an independent determinant in the Theory of Planned Behavior (Triandis, 1977; Godin \& Shepherd, 1990). Habit is usually operationalized as "prior behavior". It is assumed that repeated behavior over a long period of time will result in performing that behavior habitually, that is (partly) without mediation of attitudes, subjective norms, perceived control or intentions. Ajzen argued that prior behavior itself is a reflection of internal and external factors like attitude, social norms and perceived behavioral control but he also admitted that extended past experience might result in habitual instead of reasoned behavior (Ajzen, 1991). Respondents reported that habitual consumption of $F$ \& $V$ was strongly influenced by what their parents used to do. Habitual consumption of F \& V might therefore be a result of modeling (Bandura, 1986). Modeling was proposed as an indispensable aspect of learning or adopting behavioral patterns. Habit has been identified as a determinant of dietary behavior before (Stafleu et al., 1991). Dietary behavior in general seems to be influenced strongly by habit and should therefore be taken into consideration in nutrition 
education. As it might be very difficult to change specific habits, nutrition education aimed at increasing $\mathrm{F} \& \mathrm{~V}$ consumption should be tailored to existing habitual dietary patterns.

The concept of lack of "awareness" seemed to be especially important as a barrier for promoting a higher consumption of $F \& V$ among Dutch adults. In general, the respondents were not aware of a discrepancy between their consumption of $F \& V$ and $a$ desirable or recommended level of F \& V consumption. Most respondents were unaware of the possibility that their F \& V consumption could be (too) low according to mutritional standards. It is unlikely that subjects who are unaware of the fact that they are eating a diet that is (rather) low in $F$ \& $V$ will be interested in health education messages aimed at increasing F \& V consumption. Lack of a clear quantitative recommendation for $F$ \& V consumption in the Netherlands might be partly responsible for this lack of awareness. A similar kind of unawareness of one's own dietary intake has been found for fat consumption both in the Netherlands and in the UK (Brug, Van Assema \& Kok, 1993; Lloyd et al., 1993).

Baranowski et al. (1993) also used focus group interviews to collect data on psychosocial factors related to $F \& V$ consumption. They found that among school children, three general issues could be identified as important for promoting a higher consumption of F \& V: environment, affect, and skills. Compared to that study several similarities were found in the present study. 'Environment' was also identified as a major influence on F \& V consumption. Availability, social influence, and financial costs were important environmental aspects. Satisfaction and perceived health consequences have similarities with "affect" as identified by Baranowski et al. (1993). "Abilities" is very similar to Baranowski"s skills. Important differences were also found. Habit, specific health consequences and awareness did not come forward from the research by Baranowski et al. (1993). The differences in results show that psychosocial beliefs about $F$ \& $V$ can differ substantially between countries and age groups.

Focus group interviews have been found to be a suitable means of data collection in explorative research. In the present study, exploring beliefs associated with $\mathbf{F} \& \mathrm{~V}$ consumption was the research goal. Personal in depth interviews are also often used for collecting qualitative data for exploring new research topics. Compared to personal interviews focus groups enable researchers to collect more data in a shorter time period. Furthermore, focus groups allow respondents to react and build upon responses of other group members. This process may result in data that would otherwise remain uncovered. Of course, the choice of data collection method is dependent on the study topic. Focus 
group interviews can only be used when respondents are prepared to talk about the subject with unfamilliar others. Compared to quantitative survey research, focus groups produce a richer amount of data: Focus groups enables the researcher to identify subtle differences in responses, the researcher can ask follow-up questions for clarification immediately based on the responses given, and non-verbal communications can be observed for interpretation of the responses (Stewart \& Shamandasani, 1990).

Nevertheless, it should be kept in mind that the results of this study can only be used to identify beliefs that are probably important in $F \& V$ consumption. It is far from possible to draw definite conclusions about the relative importance of the various beliefs or about the variance explained by different determinants. Additional research needs to be conducted to study psychosocial factors associated with $F$ \& V consumption in a quantitative way.

The results of this study will be used in order to develop a questionnaire on psychosociall determinants of $\mathrm{F} \& \mathrm{~V}$ consumption that will be used in further quantitative research. Furthermore, the results can help nutrition educators in tailoring their educational material to the needs and beliefs of the target population.

The results suggest that for nutrition education in the Netherlands aimed at increasing F \& V consumption to be effective, it should focus first on the subjects" awareness of the adequacy of their level of consumption of $\mathrm{F} \& \mathrm{~V}$. Therefore, an agreement on a quantitative recommendation for $F \& V$ consumption similar to the 'five a day' recommendation that is used in the U.S. would be very helpful in the Netherlands. Without some kind of quantitative standard it will be impossible for subjects to evaluate their own $\mathrm{F} \& \mathrm{~V}$ intake.

Additionally, nutrition education aimed at promoting $F \& V$ consumption in the Netherlands might focus more on the possible preventive effects of $\mathrm{F} \& \mathrm{~V}$ consumption for cancer and cardiovascular disease because this seems to be rather unknown among Dutch adults. 


\title{
Chapter 6
}

Psychosocial Determinants of Fruit and Vegetable Consumption:

\author{
Telephone Survey?
}

\begin{abstract}
Psychosacial correlates of fruit and vegetable consumption were studied in an adult Dutch population $(n=367)$ based on the ASE-model of Attitudes, Social influence and selfEfficacy. Attitudes were a summation of beliefs about taste, different health consequences and costs in time and money. Social influences were measured through the social stimulation respondents expected to get from important others to consume adequate amounts of fruit and vegetables and by asking the subjects about the behavior of important others. Self-efficacy reflected the respondents' ability to consume adequate amounts of fruit and vegetables in various situations. Self-efficacy and attitudes were consistently and significantly associated with consumption of boiled or otherwise heated vegetables, of salads, and of fruit. Furthermore, respondents reporting low consumption of these food groups had lower self-efficacy expectations and less positive attitudes than subjects with relatively high consumption of fruit and vegetables. It is concluded that nutrition education aimed at stimulating fruit and vegetable consumption should focus especially on changing attitudes and self-efficacy expectations.
\end{abstract}

Ihis chapter was published as:

Brug, r., Lechner, L., \& De Vries, H. (1995). Psychosocial determinants of fruit and wegetable consumprion. Appetite, 25. $285-296$ 


\section{Introduction}

Fruit and vegetable ( $F \& V$ ) consumption is considered to have preventive effects on several kinds of cancer and coronary heart disease (Gerster, 1991; Block et al., 1992; Hertog et al., 1993). Therefore, recommendations for $\mathrm{F} \& \mathrm{~V}$ consumption have been published in many countries. The U.S. Dietary Guidelines and the Food Guide Pyramid both recommend eating five or more servings of F \& V per day (U.S. Department of Agriculture and Health and Human Services, 1990; U.S. Department of Agriculture, 1992). In many European countries, including the Netherlands, the recommendation to increase consumption of F \& V is part of dietary guidelines (Voedingsraad, 1986; Benito, 1992). The Netherlands Bureau for Food and Nutrition recommends that adults eat three to four "serving spoons" (approximately 150-200 g) of vegetables and two pieces of fruit per day.

Nationwide food consumption surveys in the Netherlands as well as in the U.S. revealed that the level of consumption of $\mathrm{F} \& \mathrm{~V}$ in both countries was lower than recommended (Patterson, Block, Rosenberg, Pee \& Kahle, 1990; Hulshof et al., 1994). These discrepancies between dietary recommendations and actual F \& V consumption have led to public health initiatives aimed at increasing $\mathbb{F} \& \mathrm{~V}$ consumption among the general public, such as, for example, the 'five a day' projects in the United States (Havas et al., 1994) and the 1994 European Week Against Cancer (European Community Commission, 1994). In order for these interventions to be effective, understanding of determinants of F \& V consumption is needed (Green \& Kreuter, 1991; Thomas, 1993). However, research on determinants of $F$ \& V consumption is limited to studies of its socio-demographic correlates. Hardly any studies have been conducted on psychosocial determinants of $\mathrm{F} \& \mathrm{~V}$ consumption. The exceptions are two qualitative studies conducted in the U.S. (Baranowski et al., 1993) and in the Netherlands (Brug, Debie, Van Assema \& Weijts, 1995) where focus groups were used in order to study important psychosocial factors in determining (an increase in) $\mathrm{F} \& \mathrm{~V}$ consumption.

The Attitude - Social influence - self-Efficacy (ASE-) model (Figure 6:1; De Vries et al., 1988; De Vries \& Backbier, 1994) and the Planned Behavior model (Ajzen, 1991) predict various health behaviors, including dietary behavior (Stafleu et al., 1991; Van Assema et al., 1993). In the ASE-model, behavior is considered to be a result of behavioral intention. Furthermore, three main psychosocial factors have been identified that predict (health-related) behavioral intention: attitudes, social influences, and selfefficacy. A person"s attitude towards a specific behavior is a result of the consequences 
that person expects from performing the behavior. Social influence is a result of social norms relevant to the behavior, support from others to perform or refrain from the behavior, and whether important others perform or refrain from the behavior themselves. Self-efficacy expectations can be seen as a person's belief whether he can perform the desired behavior and can cope with barriers that may hinder actual performance. The implication of the model is that a person's health behavior can be changed, by changing his attitude, his perception of social orms and social support, and his self-efficacy expectations. External variables, such as socio-demographic factors, are expected to influence behavior through the behavioral determinants and intention. Moreover, selfefficacy not only influences behavioral intention but also has a direct influence on behavior. Finally, the behavior, or trying to perform the behavior, will lead to feedback that may, in turn, influence the determinants (De Vries et al., 1988).

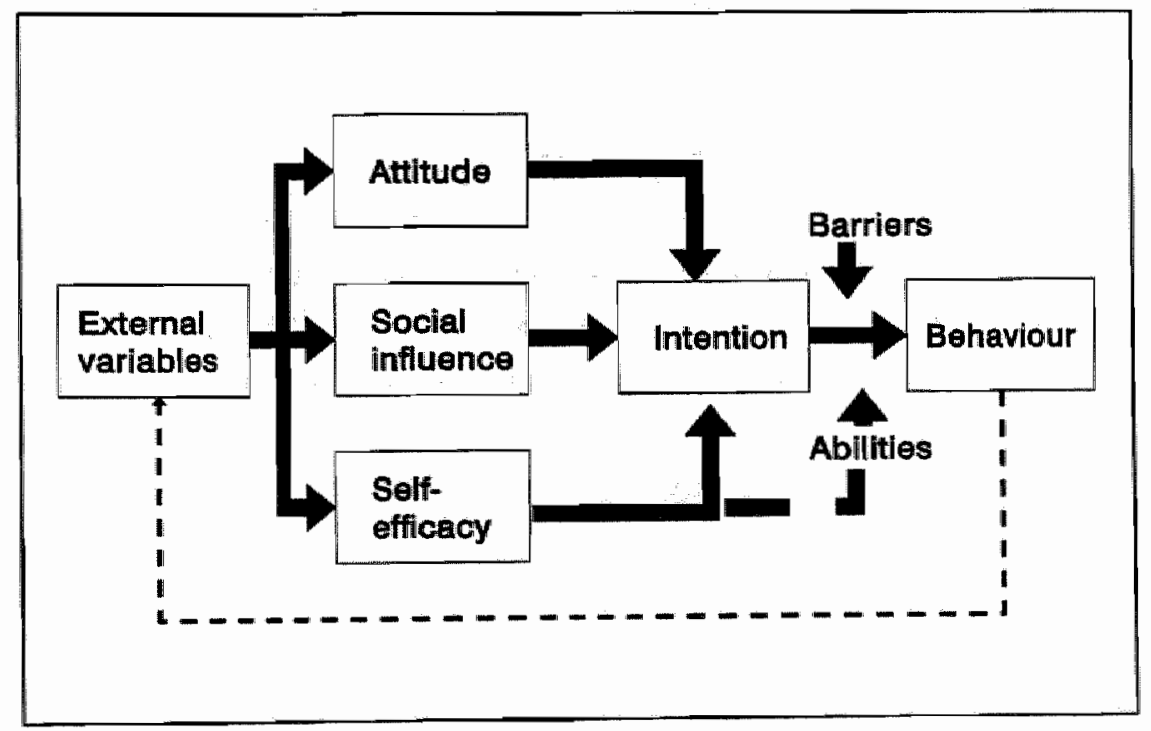

Figure 6:1. Attitudes, Social influence and self-Efficacy model of determinants of behavior

The purpose of this study was to analyze the relative importance of determinants of consumption of boiled or otherwise heated vegetables (boilled vegetables), raw vegetables eaten as salads (salads), and fruit, respectively. The results of this study give us more 
theoretical insight in subjects' motivations to consume $F$ \& V. The implications of the results for mutrition education interventions aimed at increasing $\mathrm{F} \& \mathrm{~V}$ consumption, will be discussed.

\section{Methods}

\section{Respondents}

A random sample of 598 address-telephone number combinations was obtained through the Dutch national telephone company. The selected telephone numbers were called during the evening a week after introduction letters, explaining the procedure and general aim of the survey were sent to the addresses. Respondents had to be older than 17 years. When a younger person answered the phone he or she was asked if an adult was present. Respondents were asked to answer the questions at the first call. If that moment was in any way inconvemient, an appointment was made to administer the questionnaire at another time or day. The interview took about 15 minutes. From the original sample, 40 telephone numbers could not be reached because the phone had been disconnected or because no one answered the phone after several attempts were made. Ten respondents were excluded from the survey because they did not have enough knowledge of the Dutch language to answer the questions and six subjects were excluded because no one on their address had reached the age of 18 . Of the remaining sample, 175 respondents refused to co-operate for different reasons. Therefore, the study population consisted of 367 respondents (response rate $=68 \%$ ), of which $162(44 \%)$ were male and $203(56 \%)$ were female. The mean age (SD) was 46 (17).

\section{Questionnaire}

A questionnaire was developed based on the ASE-model. It addressed three separate dietary behaviors related to $\mathrm{F} \& \mathrm{~V}$ consumption: consumption of boiled vegetables, salads, and fruit. The general dietary behavior described as F \& V intake was divided into these three sub-behaviors because it was assumed, on the basis of Dutch dietary patterns and the results of qualitative research, that Dutch citizens motivations for consumption would vary among these three groups of food products (Brug, Debie et al., 1995). Salient beliefs were identified through focus group interviews (Brug, Debie et al., 1995). From this research it became clear that similar beliefs were relevant for the three separate behaviors, but that these beliefs were of different importance or direction for the separate behaviors. For example, vitamin content of raw vegetables was often mentioned 
as a reason to eat salads but (lack of) vitamins was also mentioned as a disadvantage of boiled vegetables. Hence, salient attitude, social influence and self-efficacy beliefs, as well as behavioral intention and dietary intake, were assessed for the three behaviors separately.

For example, for boiled or otherwise heated vegetables, attitudes were measured through 11 items in which respondents were asked to score the most salient beliefs on bipolar, 5-point scales. General health consequences, taste, vitamin content, digestibility, stimulating weight loss, pesticide and nitrate content, relieving hunger, price, and time to prepare, were included as outcome beliefs. For example, the respondents' beliefs about the general health consequences were asked as follows: "Do you consider eating boiled vegetables to be healthy or unhealthy?". The respondents could answer this question with "healthy", "unhealthy", or 'don't know/in between". When the respondent gave the first. answer, the interviewer asked whether the respondent considered boiled vegetables to be "healthy" or "very healthy". The same two categories were possible for the answer 'unhealthy'; thus a 5-point (very healthy - very unhealthy) scale was created.

Self-efficacy was assessed by means of five items in which respondents were asked to ewaluate how certain they were, on bipolar 5-point (very certain - very uncertain) scales, that they were able to consume adequate amounts of vegetables in different situations (when eating alone, during weekends, when in a hurry, when preparation is difficult, and during winter when there is less choice).

Social influence was assessed by two items: In one item respondents were asked how much social support they perceived from important others (partner, (other) members of same household, family and/or friends) to eat vegetables (social stimulation), on a unipolar 5-point (very much - very little support) scale. In the second item respondents were asked to assess the level of vegetable consumption of important others also on a unipolar 5-point (very high - very low consumption) scale.

The items for measuring determinants of salad and fruit consumption were similar except that for fruit one additional outcome belief ("Do you consider eating fruit to be messy?") was included in the attitude construct and one self-efficacy item was left out ("when preparation is difficult"). Attitude beliefs, beliefs about social influences, and selfefficacy beliefs were added up and divided by the total number of items in order to form attitude, self-efficacy and social influence scales for the three separate behaviors.

Consumption of $F$ \& V was estimated by means of an eight-item food frequency method in which respondents were asked to indicate the frequency and portion size in which they consumed boiled vegetables, salads, and fruit during the last month. Portion 
size for boiled vegetables and salads could be answered either in serving spoons or in grams, but were codled as grams (1 serving spoon $=50 \mathrm{~g}$, according to Netherlands Bureau of Food and Nutrition Education instructions). The food frequency was tested in small scale study in which the reproducibility $(\mathbb{R}=.77$ between first and second administration in a test-retest procedure) and the relative validity in classifying subjects according to intake lewels were assessed in relation to a validated comprehensive food frequency questionnaire (Cohen's kappa $=.59$; Goldbohm, Van den Brandt, Brants, Van 't Veer, Sturmans \& Hermus, 1994).

Finally, intention was measured with one item in which respondents were asked to indicate on a 5-point scale whether they intended to eat the groups of food products in adequate amounts. The fourth part of the questionnaire consisted of questions on certain socio-demographic characteristics.

\section{Statistical analysis}

Cronbach's $\alpha$ 's were computed in order to evaluate the internal consistency of the attitude, self-efficacy, and social influence scores. Values greater than .5 were considered as sufficient for summation of items to form overall determinant scores (Nunnally, 1967). The number of items for each determinant construct, Cronbach $\alpha$ 's, and mean scores are given in Table $6: 1$.

Simple and multiple regression analyses, using forced entry, were carried out with intention to consume boiled vegetables, salads, and fruit as dependent variables and attitude, self-efficacy, and social influence as independent variables, in order to detect the strongest correlates of intention to consume the given groups of food-items. Simple and hierarchical stepwise regression analyses were used in order to study the association between intention and behavior and to study whether self-efficacy or the other determinants had unique direct effects on the dietary behaviors above behavioral intention.

Analysis of variance was performed in order to sudy differences in determinantsscores between subjects in different consumption tertiles for consumption of salads, boiled vegetables and fruit. All analyses were performed using the SPSS- $x$ statistical analysis program (SPSS Inc., 1988). 


\section{Table 6:1}

Number of items and Cronbach $\alpha$ 's and mean scores for the determinant scales ( $n=367$ )

\begin{tabular}{|c|c|c|c|c|c|}
\hline Behavior & $\begin{array}{l}\text { Construct } \\
\text { (range) }\end{array}$ & $\begin{array}{l}\text { Number } \\
\text { of items }\end{array}$ & $\alpha$ & $\begin{array}{l}\text { Mean } \\
\text { score }\end{array}$ & $\mathrm{SD}$ \\
\hline \multirow{3}{*}{ Consumption of salads } & Attitude $(-2,2)$ & 11 & .62 & 0.58 & 0.34 \\
\hline & Social influence $(0,4)$ & 2 & .70 & 2.08 & 0.92 \\
\hline & Self-efficacy $(-2,2)$ & 5 & .70 & 0.50 & 1.01 \\
\hline \multirow{3}{*}{$\begin{array}{l}\text { Consumption of boiled } \\
\text { vegetables }\end{array}$} & Attitude $(-2,2)$ & 11 & .54 & 0.63 & 0.29 \\
\hline & Social influence $(0,4)$ & 2 & .58 & 2.35 & 0.77 \\
\hline & Self-efficacy $(-2,2)$ & 5 & .64 & 1.21 & 0.82 \\
\hline \multirow{3}{*}{ Consumption of fruit } & Attitude $(-2,2)$ & 12 & .62 & 0.78 & 0.31 \\
\hline & Social influence $(0,4)$ & 2 & .61 & 2.18 & 0.88 \\
\hline & Self-efficacy $(-2,2)$ & 4 & .79 & 1.38 & 1.35 \\
\hline
\end{tabular}

\section{Results}

The mean consumption of raw and boiled vegetables was $68 \mathrm{~g}(\mathrm{SD}=60)$ and $140 \mathrm{~g}$ $(S D=76)$ per day respectively. More than $50 \%$ had a total vegetable consumption of less than $200 \mathrm{~g}$ per day, $32 \%$ ate less than $150 \mathrm{~g}$. Of the study population $8 \%$ reported that they ate salads seven days a week and $25 \%$ reported that they ate boiled vegetables every day. The average consumption of fruit was $2.0(\mathrm{SD}=1.9)$ pieces per day; $56 \%$ ate less than two pieces of fruit per day.

\section{Predictors of intention}

Attitudes, social influence and self-efficacy were significantly associated with intention to consume salads (Table 6:2). 
Table 6:2

Results of simple and multiple regression analyses with intention to consume salads, boiled vegetables and fruit as dependent wariables and antitudes, social influences and self-efficacy as independent variables $(n=367)$

\begin{tabular}{llccc} 
Predicted intention to & Predictors & $\begin{array}{c}\text { Pearson } \\
\text { correlation }\end{array}$ & B-Weights & $\mathrm{R}^{2 *}$ \\
\hline \multirow{2}{*}{ Consume salads } & Attitude & $.30^{* *}$ & $.19^{* *}$ \\
& Social influence & $.19^{* *}$ & $.12^{*}$ & $.17^{* *}$ \\
& Self-efficacy & $.35^{-*}$ & $.27^{* *}$ & $.13^{* *}$ \\
\hline Consume boiled & Attitude & $.17^{* *}$ & $.11^{*}$ & .03 \\
vegetables & Social influence & .09 & $.31^{* *}$ & $.47^{* *}$ \\
& Self-efficacy & $.34^{* *}$ & .00 & .02 \\
Consume fruit & Attitude & $.17^{* *}$ & .06 & $.69^{* *}$ \\
\hline
\end{tabular}

$" \mathrm{p}<.05$

$" \mathrm{p}<.01$

"Variamce accounted for by multiple regression from all predictors

Attitude and self-efficacy were significant correlates of intention to consume boiled vegetables in the simple as well as in the multiple model. Social influence was not significantly associated with intention to consume boiled vegetables.

Attitude and self-efficacy were also significant correlates of intention to consume fruit. In the multiple model, self-efficacy was the only significant correlate of intention to consume fruit. Explained variance in the multiple models was highest for intention to eat fruit where approximately half of the total variance was accounted for by the three determinants. For intention to eat salads and boiled vegetables the explained variance was substantially lower (Table $6: 2$ ). 


\section{Table 6:3}

Results of simple and hierarchical regression analyses with consumption of salads, boiled vegetables, and" fruit as dependent variables and intention and determinonts as independent variables $(n=367)$

\begin{tabular}{llccc} 
Predicted behavior & Predictors & $\begin{array}{c}\text { Pearson } \\
\text { correlation }\end{array}$ & $\begin{array}{c}\text { B-weights } \\
\text { Consumption of salads }\end{array}$ & $\begin{array}{c}\text { Stepwise } \\
\mathrm{R}^{2 *}\end{array}$ \\
\hline & Self-efficacy & $.52^{* *}$ & $.37^{* *}$ & $.27^{* *}$ \\
& Attitudes & $.39^{* *}$ & $.18^{* *}$ & $.37^{* *}$ \\
& Social influences & $.38^{* *}$ & $.16^{* *}$ & $.07^{* *}$ \\
Consumption of boiled & Intention & $.28^{* *}$ & $.14^{* *}$ & $.18^{* *}$ \\
vegetables & Self-efficacy & $.27^{* *}$ & $.18^{* *}$ & $.12^{* *}$ \\
& Attiudes & $.27^{* *}$ & .10 & $.19^{* *}$ \\
& Social influences & .09 & .03 & $.17^{* *}$ \\
\hline \multirow{2}{*}{ Consumption of fruit } & Intention & $.44^{* *}$ & $.30^{* *}$ & $.21^{* *}$ \\
& Self-efficacy & $.40^{* *}$ & $.20^{* *}$ & .01 \\
\hline
\end{tabular}

$" p<.01$

Explained variance for step $1=$ intention and step 2 = self-efficacy, attitudes and social influences.

\section{Predictors of behavior}

The association between intention and behavior was strongest for consumption of salads (Table 6:3). For all three behaviors, self-efficacy was significantly associated with behavior after adjustment for intention. For salad consumption, attitudes and social influences also had a unique association with behavior after adjustment for intention was made. 


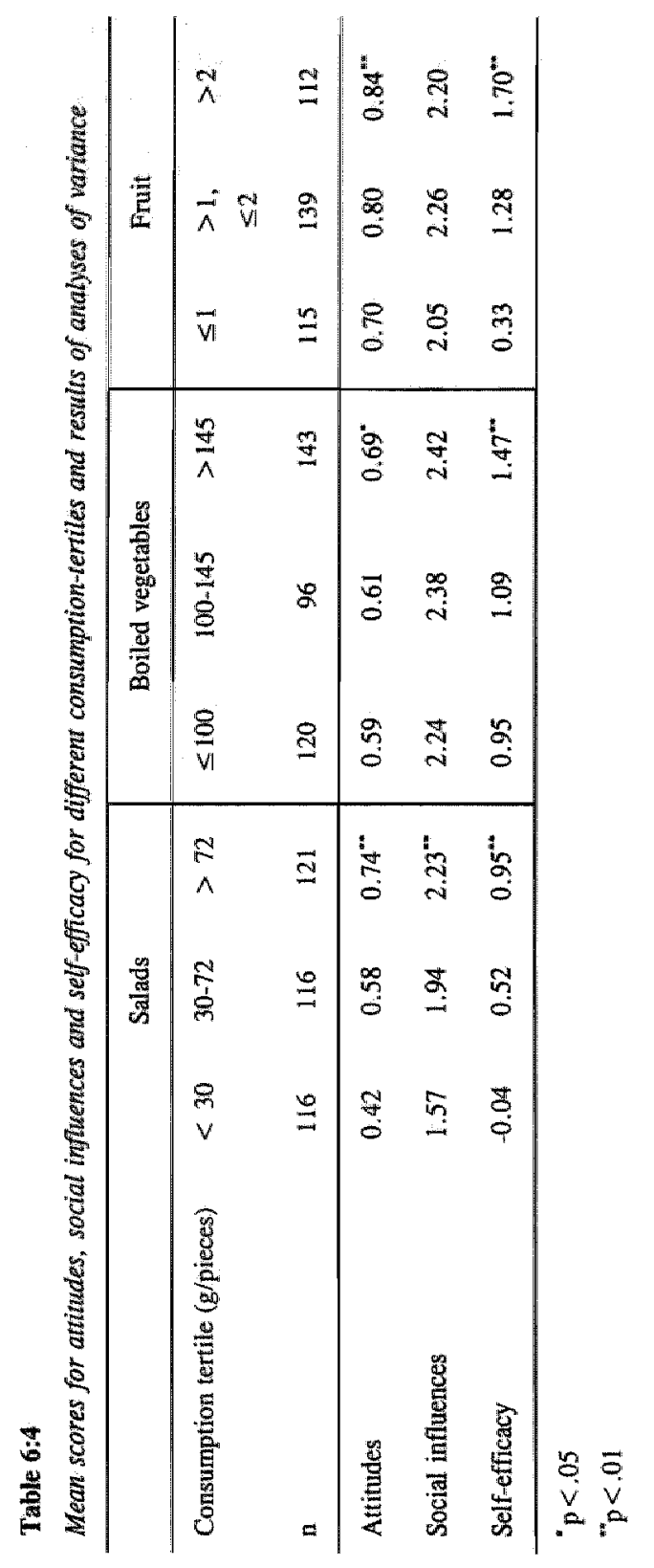


For all three behaviors, significantly higher determinant scores were found for subjects in the highest consumption tertile compared to the lowest, with the exception of social influence scores for boiled vegetables and fruit (Table 6:4).

Further analyses of variance to assess differences in specific beliefs between 'high' and 'low' consumers showed that for consumption of boiled vegetables, high consumers had especially more positive beliefs about general healthfulness, about taste, and about the pesticide content of boiled vegetables. They were also more certain about being able to consume enough vegetables when alone or with lack of time, at weekends, in winter, and when preparation is difficult. Respondents in the highest consumption tertile for salads had more positive beliefs about taste, health consequences, vitamin content, digestibility, and pesticide residues, and were more certain about managing eating adequate amounts of salads for all situations mentioned above, as compared to the lowest consumption tertile. For fruit consumption, there were differences in beliefs about health consequences and taste between the highest and the lowest consumption tertile. Furthermore, consumers in the highest tertile were more certain that they would be able to eat enough fruit in all circumstances that were included in the questionnaire.

\section{Discussion}

The high prevalence of rather low $\mathrm{F} \& \mathrm{~V}$ consumption that has been reported before (Hulshof et al., 1994) was confirmed in this study. The average consumption of $F$ \& in the present study was somewhat higher than in the most recent Dutch nationwide food consumption survey (Netherlands Bureau for Food and Nutrition, 1993). This is possibly a result of the difference in methodology in measuring food consumption. In the nationwide survey a 2-day diet record was used. Furthermore, our study was conducted in late summer/early fall when there is a large supply of fresh $F \& V$.

Self-efficacy was the strongest correlate of intention for consumption of boiled vegetables, salads, and fruit. In a study by Sparks, Hedderly and Shepherd (1992), perceived control was of less significance as a determinant of consumption of intention to eat wholemeal bread and biscuits than attitudes were. However, Shamnon, Bagby "Wang and Trenker (1990), concluded that self-efficacy was a consistent determinant of eating behavior and of changes in eating behavior over time. Raats, Shepherd and Sparks (1993) found inconsistent results for the association between perceived control and intention to use different kinds of milk. 
The inconsistencies in the relation between self-efficacy or perceived control and intention to perform a specific dietary behawior might be attributed to different causes. First, different dietary behaviors were studied and it is not possible to generalize associations found between self-efficacy and a particular dietary behavior to dietary behavior in general. A second reason for the inconsistencies might be the different ways in which self-efficacy was measured in the various studies. For example, Raats et all. (1993) used only one item to measure perceived control in a general matter while Sheeshka, Woolcott and MacKinnon (1993) used 11 items to measure self-efficacy in specific 'high risk' situations. According to Bandura (1986) self-efficacy should be assessed in relation to specific behaviors in specified situations. Furthermore, if selfefficacy is measured towards changing dietary behavior towards a specific dietary recommendation with which the subjects have no experience, relations with behavioral intention might be different than for 'habitual' dietary behaviors.

This study also confirms earlier findings showing a unique contribution of selfefficacy in explaining behavior, after adjustment for behavioral intention. Ajzen (1991) stated that perceived behavioral control, which is similar to self-efficacy, is supposed to predict behavior independently when the behavior is not under complete volitional control. It could be argued that this is the case for the dietary behaviors studied here. Lack of availability of fruit and vegetable items, not being the one who prepares meals or does the shopping, and lack of time, might be factors that prevent the perception of complete control over one's dietary behavior. Further analyses showed that in our study subjects responsible for preparing meals and shopping had in fact significantly higher selfefficacy expectations in relation to consumption of boiled vegetables and salads as compared to subjects not responsible for cooking and shopping.

Like self-efficacy, attitudes were significantly correlated to all three behaviorall intentions, although attitudes were not significantly associated with intention to consume fruit in the multiple regression model. The association between attitudes and intention was smaller than between self-efficacy and intention. This might have been a result of the smaller variances in attitude scores as compared to self-efficacy scores that were found in this study. For other dietary behaviors studied with similar models, attitudes proved to be a strong predictor of behavioral intention (Stafleu et al., 1991; Shepherd \& Farleigh, 1986). The relatively small predictive value of attitudes in the present study might also be caused by the different way attitudes were assessed. In most studies using expectancy value models to predict dietary behavior, attitudes are either assessed directly or by a summation of the products of salient beliefs and evaluation of those beliefs $\left(\sum \mathrm{b} * \mathrm{e} ; \mathrm{Ajzen}\right.$, 
1991). Nevertheless, there is some confusion about the way associations between multiplicative composites (e.g. attitude) and a simple variable (intention, behavior) should be analyzed (Evans; 1991). Furthermore, including evaluations of beliefs to create the muliplicative attitude composition often leads to lower instead of higher total explained variance and it has been proposed to leave the "values" out of the attitude composite (Swanborn, 1996). Therefore, in the present study, attitudes were assessed by computing a mean score of different attitude beliefs that were carefully selected based on focus group interviews (Brug, Debie et al. 1995) similar to the way attitude-like constructs are measured in Social Cognitive Theory (outcome expectancies; Bandura, 1986) or the Health Belief Model (efficacy minus barriers; Rosenstock, 1990).

Most respondents had relatively positive beliefs towards all three behaviors, even those with low consumption patterns but respondents in the lowest consumption tertile were less positive about certain health consequences for all three food groups.

Social influence was significantly associated with salad comsumption but not with consumption of boiled vegetables or fruit. Lack of association between social influences and intention has been reported for dietary behavior before (Staflew et al., 1991). Often, social norms are measured as a possible predictor of behavior, according to the Theory of Reasoned Action. This model has been criticized for its incompleteness in the measurement of social influences (Grubbe, Morgan \& McGee, 1986; De Vries et al., 1995). Social Learning Theory indicates that observational learning (modelling) is important (Bandura, 1986). Also direct pressure to refrain from preventive health behavior or stimulation to perform the desirable behavior have been proposed as important social influences (Evans, Rozelle, Mittelmark, Hansen, Bane \& Havis, 1978). Both modeling and social stimulation were included in this study. It could be that higher associations between intention and social influence would have been found when social norms had been used, although social norms have been found to be related to social stimulation and modeling (De Vries et al., 1995).

According to the ASE-model, attitudes and social influences are supposed to influence behavior mainly through behavioral intention. This was confirmed by the data presented here except for consumption of salads where attitudes and social influences contributed significantly to the explained variance in consumption after adjustment for intention and self-efficacy was made, although the extra contribution to explained variance was relatively small. These unexpected unique contributions have been found before for other health related behaviors (Basen-Enquist \& Parcel, 1992; De Vries et al., 1995). The unique contributions found in the present study might have been caused by a measurement 
artefact, since intention was measured with just one item which might not have covered the overall concept of intention.

Total explained variance for the three behaviors was similar to that found in studies on dietary fat consumption (Stafleu et al., 1991; Van Assema et al., 1993). However, a large percentage of total variance remains unaccounted for. A possible reason for this might be the lack of specificity in the assessment of the determinants, intention and behavior. Determinant - behavior correlations tend to be stronger for more specificly defined behavior (e.g. consumption of carrots tonight, in stead of consumption of wegetables in general). We nevertheless choose to study the more generally defined behavior because the present study was meant to help nutrition educators in developing strategies and interventions to stimulate fruit and vegetable consumption in general, not to promote consumption of specific kinds of fruits or vegetables. The design of the present study may be a further reason for the relatively large proportion of unaccounted variance. The ASE-model suggests that attitudes, self-efficacy expectations and social influences predict behavior in the (near) future. Because of the cross-sectional design of the study, determinants and behavior were assessed at the same time and behavior (consumption of fruit and vegetables) was assessed with a food frequency questionnaire, that is, consumption in the recent past was assessed, instead of future behavior. A final reason for (some of) the unexplained variance may be aditional determinants that were not included in the present study. Several authors have argued that behavior performed repeatedly over a long period of time becomes babitual. In such situations one may become less aware of the 'reasons' for engaging in a particular behavior. As a result, the behavior may be less well predicted by attitudes, social influences and self-efficacy expectations (Triandis, 1977). Therefore, it has been proposed to include habit as an independent variable in the determinant model. Habit is usually operationalized as 'prior behavior'. In research where dietary behavior is studied, dietary intake itself is often measured in a retrospective way and, therefore, behavior and prior behavior would be the same thing. Furthermore, Ajzen has argued that prior behavior itself is a reflection of internal and external factors like attitudes, social norms and perceived behavioral control, although he also admitted that extended past experience might result in habitual rather than reasoned behavior (Ajzen, 1991).

The implications of the results presented here are that interventions to increase $\mathrm{F} \& \mathrm{~V}$ consumption should include strategies aimed at increasing self-efficacy towards eating $F$ \& $\mathrm{V}$ and at increasing positive attitudes towards $\mathrm{F} \& \mathrm{~V}$ consumption. For boiled vegetables and salads as well as fruit, practical information on how to obtain $F \& V$ that 
are easy and quick to prepare, and with ingredients that are also available in winter should be included. Furthermore, the results indicate that certain specific beliefs could be addressed in nutrition education aimed at increasing $F$ \& $V$. Information should be focused on the positive health consequences of consuming ample amounts of $F \& V$. Concerns such as digestibility, vitamin content, and pesticide residues could also be addressed. 


\title{
Chapter 7
}

\section{Do Eating Practices and Psychosocial Factors Differ Across Stages of Change for Fruit and Vegetable Intake? ${ }^{1}$}

\begin{abstract}
This study examined whether eating practices and psychosocial factors differed across stages of change for fruit and vegetable consumption. Data were collected using a one time self-administered, written survey, as part of the baseline assessment for a nutrition intervention study in the Netherlands. Subjects were 739 Dutch adults aged 18 years and older. Fruit and vegetable intake were measured as self-reported consumption with an eight item validated food frequency questionnaire. Psychosocial variables were measured on bipolar 7-point scales and stage of change classifications were based on separate 4item algorithms for fruit and vegetables. Significant differences were found between stages of change in dietary intake, attitudes, self-efficacy, and social comparison. Differences in attitudes were largest between precontemplation and contemplation and differences in intake and self-efficacy were most marked between pre-action stages and action/maintenance.

The findings suggest that nutrition education aimed at encouraging higher intake of fruits and vegetables might be most effective if it is stage-tailored. Messages to influence attitudes about the benefits of fruits and vegetables is likely to affect people in precontemplation, and self-efficacy information to increase confidence in overcoming barriers to consumption is likely to be effective with persons in contemplation and preparation stages.
\end{abstract}

'This chaprer has been submitted for publication as."

Bng. 1., Glanz, K. Kok, G.J. Do eating practices and psychosocial factors differ across stages of change for fruat and vegetable incake? 


\section{Introduction}

Fruit and vegetables are considered to have preventive effects on coronary heart disease and some kinds of cancer (Block et al, 1992; Gerster, 1991; Hertog et al., 1993). Dietary guidelines in the U.S.A. recommend that each person eats five or more servings of fruit and vegetables per day (Benito, 1992; U.S. Departments of Agriculture and Health and Human Services, 1990; Voedingsraad, 1986a). Recommendations to consume more fruits and vegetables are also included in dietary guidelines in several European countries, including the Netherlands (Voedingsraad, 1986). In the Netherlands, the recommendation for adults is to eat four "serving spoons" (approximately 200 grams) of vegetables and two pieces of fruit per day (Netherlands Bureau for Food and Nutrition, 1993).

Food consumption surveys in the U.S.A. and in the Netherlands have revealed that the level of consumption of fruit and vegetables was lower than recommended (Block, 1993; Hulshof et al., 1994). Widespread health promotion efforts have been launched to address this concern, including the "5 A Day for Better Health" campaign in the U.S. and the 1994 European Week Against Cancer (European Community Commission, 1994; Havas et al., 1994). An understanding of the process of behavior change and factors associated with healthful eating patterns can improve the effectiveness of nutrition promotion interventions.

The Transtheoretical Model of behavior change suggest a framework for understanding readiness to adopt healthy eating habits (Prochaska \& DiClemente, 1992). A central construct in this model is stages of change: five separate stages through which people may progress toward long term positive health behaviors. People may be in precontemplation (not (yet) considering the desired behavioral change), contemplation (considering change), and preparation (actually planning change), action (actively changing), or maintenance (maintaining desired behaviors). The Transtheoretical Model originated in research related to change achieved through psychotherapy, and has been applied to various health behaviors, like for example smoking cessation. An assumption of the model is that people in different stages of change can benefit most from stagetailored interventions to move them from early stages to action and maintenance.

Various authors have studied factors that might promote movement through various stages in the change process. In this line of research links have been proposed between behavior determinant models like the Theory of Planned Behavior (Ajzen, 1991), Social Cognitive Theory (Bandura, 1986) and the Health Belief Model (Rosenstock, 1990) on the 
one hand and the Transtheoretical Model on the other. The relative importance of psychosocial determinants like attitudes, social influences, and self-efficacy expectations have been found to differ across different stages of change (Brug, Hospers \& KoK, in press; De Vries \& Backbier, 1995; Glanz et all., 1994; Sporny \& Contento, 1995). For example, it has been reported that smokers in different stages of change differ in some psychosocial determinants of quitting smoking (De Vries \& Backbier, 1995; DiClemente et al., 1991). Attitudes were most negative among those in precontemplation and were more positive among those in contemplation and preparation. Self-efficacy has been found to be low among precontemplators as well as contemplators, but higher in action. Social influences have been found to become more positive in a linear fashion from precontemplation to action (De Vries \& Backbier, 1995). More recently, similar results were found for stages of change for reducing fat consumption (Brug, Hospers et al., in press; Sporny \& Contento, 1995).

To date, there has been little research on stages of change for fruit and vegetable consumption. However, in a study by Glanz et al. (1994), stages of change for fiber intake were assessed along with differences in eating habits, self-efficacy, and self-rated health. Most subjects were in the action stage, and both fiber intake and fruit and vegetable consumption were significantly higher among subjects in action and maintenance stages. Subjects in preparation, action, and maintenance stages had higher selfefficacy expectations.

Brug, Hospers et al. (in press) found that attitudes became more positive from precontemplation to preparation and self-efficacy expectations were negative in the first three stages of change and positive in action and maintenance in relation to fat reduction. Social support was more positive among subjects in preparation and action as compared to subjects in earlier stages. Sporny and Contento (1995) studied the association between concepts derived from the Health Belief Model (Rosenstock, 1990) and from Social Learning Theory (Bandura, 1986) on the one hand and transtheoretical stages of change for fat reduction on the other. Cues to action were most positive in the contemplation stage while reduction of perceived barriers, overall health concern, social modeling and self-efficacy were most positive in the action and maintenance stages.

In the present study, stages of change for fruit consumption and for vegetable consumption were studied. Differences in consumption patterns, attitudes and self-efficacy expectations between stages of change for fruit and for vegetable consumption were examined. The aim was to investigate the criterion validity of the stages of change 
measures for fruil and vegetable consumption and to assess their potential usefulness for target group segmentation across stages of change.

\section{Methods}

\section{Subjects}

Advertisements in local door-to-door newspapers in different regions of the Netherlands were used to recruit study participants. A total of 799 subjects responded by calling a telephone number to register, and they received a self-administered questionnaire mailed to their homes. Completed questionnaires were returned by 761 respondents $(95 \%)$. Twenty-two incomplete surveys were excluded from data analyses $(n=739$, response rate $=92 \%$.

\section{Measures}

The questionnaires collected data on consumption of fruits and vegetables, stages of change, attitudes, self-efficacy expectations, and estimated self-evaluation of fruit and vegetable consumption.

Fruit and vegetable intake was assessed with a validated 8 -item food frequency questionnaire from which the number of servings of fruit and vegetables per day could be computed (Brug, Lechner \& De Vries, 1995).

Stage of change was assessed by a 4-item algorithm based on measures in previous similar studies (Glanz et al., 1994; Sporny \& Contento, 1995). Subjects were classified as being in action for fruit consumption when they were presently trying to eat more fruit and in maintenance when they reported currently eating adequate amounts of fruit and had not increased their fruit consumption in the past 6 months. Subjects were considered in preparation when they intended to increase their consumption within 1 month and in contemplation when they intended to increase their consumption within 6 months but not in the next month. Subjects were classified as being in precontemplation when they did not report eating adequate amounts of fruit and did not intend to increase their fruit intake. A similar algorithm was used to divide subjects in stages of change for vegetable consumption.

Attitudes towards increasing fruit consumption were assessed with one item in which the respondents were asked to give their opinion about increasing their fruit consumption on a seven-point bad-good scale. Self-efficacy expectations were assessed by asking the 
respondents how easy or difficult they thought increasing their fruit consumption was on a seven-point easy-difficult scale.

In order to investigate how realistic subjects were about their consumption levels, they were asked to compare their own consumption of fruit and vegetables to that of other people of the same sex and age group on a seven-point much less-much more scale.

Oneway analyses of variance with Scheffé's multiple comparison test $(\alpha=.05)$ were used to test for significant differences in number of servings and psychosocial factors between specific stages of change for fruit and vegetable consumption respectively.

\section{Results}

\section{Vegetables}

The largest proportions of subjects were in maintenance $(48 \%)$ and in preparation $(33 \%)$. Relatively small numbers of subjects were in precontemplation (6\%), contemplation ( $8 \%$ ) and action (5\%). Significant associations between stages of change on the one hand and vegetable intake, attitudes and self-efficacy towards increasing vegetable intake, and comparison with others' vegetable intake were found (Table 7:1).

Subjects in precontemplation had the lowest vegetable intake, subjects in action the highest. In the multiple comparison analyses, significant differences in intake were found between subjects in action and maintenance on the one hand and the first three stages of change on the other. Among subjects in action and maintenance $31 \%$ ate less than one serving of vegetables per day.

Subjects in preparation and action had the most positive mean attitude scores. The mean attitude towards increasing vegetable intake of subjects in preparation was significantly more positive than the mean precontemplators' score.

Self-efficacy expectations towards increasing vegetable intake were highest among subjects in action. Lowest self-efficacy was found among subjects in precontemplation which was significantly lower than in the other stages of change. Other significant differences in self-efficacy berween stages are indicated in Table $7: 1$. 


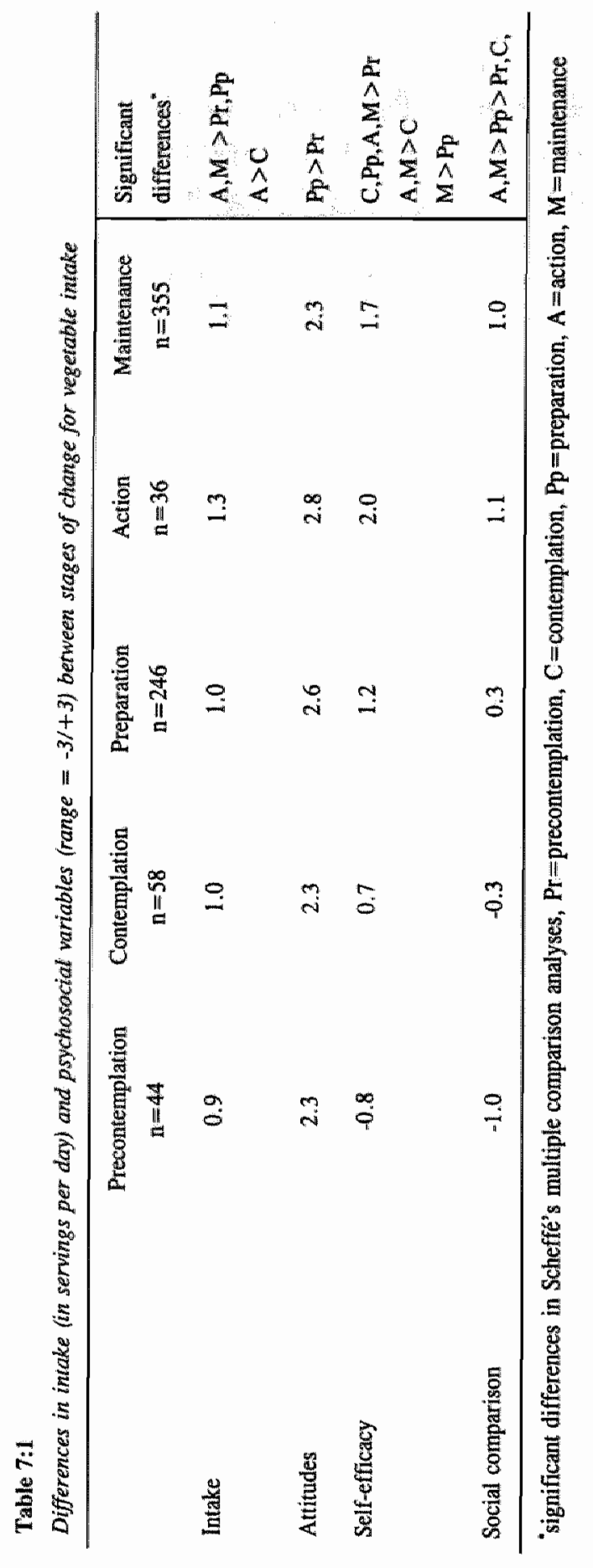


On average, subjects in the first two stages rated their vegetable intake as lower than others of the same age and sex, while subjects in the other three stages thought that their vegetable intake was higher than that of comparable others. The mean comparison score among subjects in action and maintenance was significantly higher than the mean scores of subjects in the first three stages. The preparators" comparison score was significantly higher than the mean score in precontemplation and contemplation.

\section{Fruit}

Differences in intake, attitudes, self-efficacy expectations and comparison with others between stages of change for fruit consumption are presented in Table 7:2. About $40 \%$ of the respondents was in maintenance, $36 \%$ was in preparation and $9 \%, 8 \%$, and $5 \%$ were in precontemplation, contemplation and action respectively.

Mean fruit consumption was highest among subjects in action. Their mean number of servings of fruit was significantly higher than in all other stages of change. Mean fruit intake among subjects in maintenance was significantly higher than in precontemplation, contemplation and preparation. Only subjects in action and maintenance had mean fruit intakes above the recommended levels of two pieces per day although the proportion of these subjects with lower intakes was still $26 \%$.

Differences in attitudes towards increasing fruit consumption between subjects in different stages of change were small. Subjects in precontemplation and maintenance had significantly less positive attitudes towards increasing fruit consumption than subjects in preparation. Attitudes among subjects in action were significantly more positive than arnong subjects in maintenance.

Self-efficacy expectations towards increasing fruit consumption were significantly higher in action and maintenance than in the other stages of change. Self-efficacy among subjects in precontemplation was significantly lower than in all other stages.

Subjects in the first three stages had negative mean comparison scores, which indicates that they thought that their fruit consumption was generally lower than that of comparable others. Mean comparison score was lowest among subjects in precontemplation and significantly lower than in all other stages. Mean comparison scores in action and maintenance were positive and significantly higher than the mean scores in other stages. 


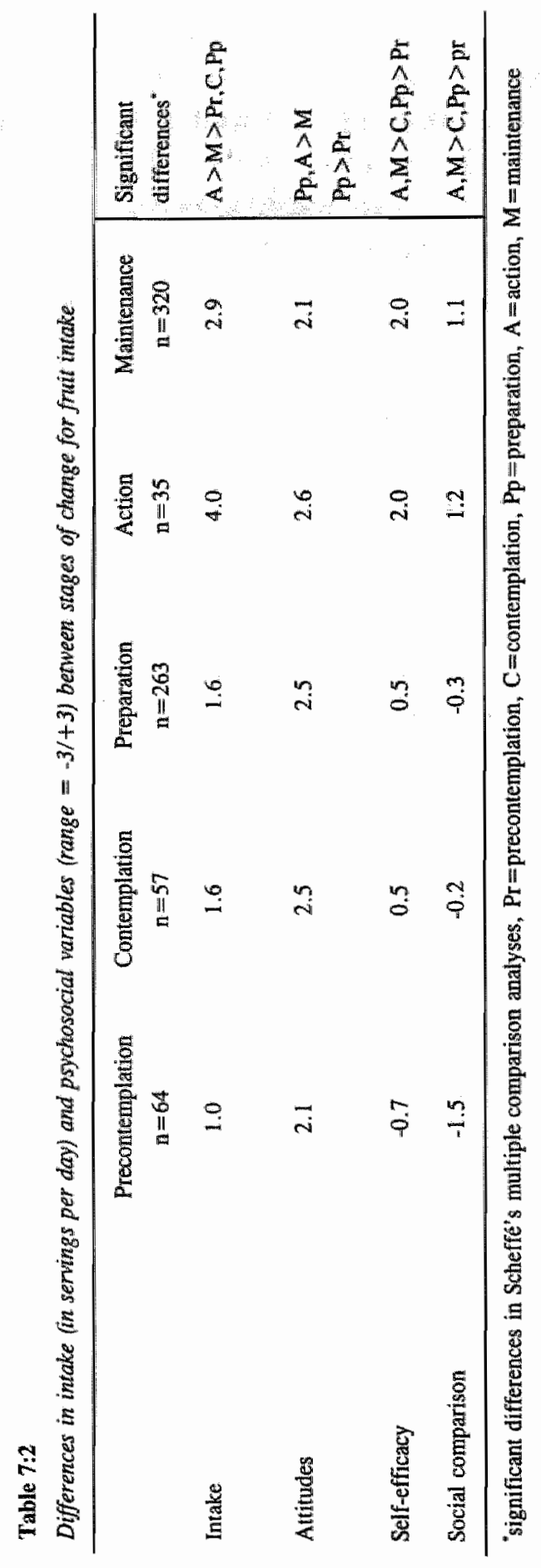




\section{DISCUSSION}

Significant differences in intake and psychosocial factors were found between subjects in different stages of change for fruit and vegetable consumption. The differences that were found in the present study are consistent with results of studies on stages of change for smoking cessation (De Vries \& Backbier, 1995), fat consumption (Brug, Hospers et al., in press) and fiber consumption (Glanz et al., 1994).

Fruit and vegetable intake was significantly higher in action and maintenance as compared to the other stages. This result is in line with the concept of the stage model in which behavior changes are expected in action and maintenance and not in the earlier stages (Prochaska \& DiClemente, 1992).

Both for fruit and for vegetable consumption, a large proportion of subjects were in the preparation stage. This was probably caused by the recruitment procedure but might also be a further indication that recent Dutch campaigns to stimulate fruit and vegetable consumption were successful in stimulating the Dutch public to consider increasing their fruit and vegetable consumption. Krebs-Smith, Heimendinger, Patterson, Subar, Kessler and Pivonka (1995) found that knowledge about recommendations, which was the primary aim of the campaigns, was an important determinant of increased consumption of fruit and vegetables in the U.S.A. In a study on the impact of feedback on dietary intake patterns in the Netherlands, it was found that information about recommended intake levels for fruit and vegetables can lead to substantial changes in consumption (Brug, Steenhuis, Van Assema \& De Vries, 1996).

Attitudes towards increasing vegetable and fruit intake were least positive among people in precontemplation and maintenance. People in both of these stages were not convinced about the positive consequences of increasing their consumption although the reasons for less positive attitudes might have been different. Subjects in maintenance already have a relatively high intake and are probably well aware of the benefits of fruit consumption but might not see the positive consequences of increasing their intake any further. Subjects in precontemplation might be unaware of the positive consequences of fruit consumption in the first place. Therefore, in order to stimulate people in precontemplation to contemplate increasing their intake, attitude information might be necessary. An earlier study on determinants of fruit and vegetable consumption in the Netherlands indicated that people with less positive attitudes are less convinced about the positive health consequences and vitamin content of fruit and vegetable and more often 
thought that frust and vegetables contained residues of pesticides (Brug, Lechner \& De Vries, 1995). Nutrition education for people in precontemplation might therefore be aimed at changing these specific beliefs. This conclusion might seem to be contrary to findings reported by Krebs-Smith and colleagues (1995) who did not find an association between beliefs about healthfulness of fruit and vegetables and intake levels. Nevertheless, similar to the study conducted by Krebs-Smith et al., in the present study no significant increases in attitudes were found between the later stages of change. People in maintenance had relatively low attitude scores while consumption among maintainers was relatively high. The conclusion might be that beliefs about positive consequences of fruit and vegetable consumption do not determine higher consumption, but are important for people to start contemplating a higher intake.

In order for people to actually increase their consumption, or, in other words, to move from contemplation and preparation to action, self-efficacy seems to be more important. The greatest increase in self-efficacy expectation towards increasing fruit and vegetable consumption was found between preparation and action. This might implicate that people will only start making actual changes in consumption when they are confident enough about their abilities to change. People in contemplation and preparation might therefore benefit most from nutrition education that is aimed at increasing their selfefficacy. From earlier research it became clear that Dutch subjects are least confident about being able to eat enough fruit and vegetables in situations when they have to eat alone, in lack of time, and in weekends (Brug, Lechner et al., 1995). Therefore, nutrition education to stimulate fruit and vegetable consumption for contemplators and preparators should include suggestions about how to eat enough fruit and vegetables in a way that is easy and requires little time and effort. Health promotion activities that help to make fruit and vegetables easily available in a way that requires little preparation time, might also enhance self-efficacy expectations to increase fruit and vegetable consumption.

Substantial numbers of subjects who were classified in action and maintenance (because they rated their intakes as high), actually had fruit or vegetables intakes below recommended levels. These subjects might be better classified as precontemplators who are unaware of their need to change. This division between different precontemplators has been proposed by Weinstein in his Precaution Adoption model (Weinstein, 1988). In this model a further distinction between phases within the precontemplation stage is proposed based on three levels of awareness of risk behavior. At the first level, people should be aware of the association between behavior and risk ("Low fruit consumption is associated with higher cancer risk"). At the second level they should be aware that the risk behavior 
is present among others ("many people have low fruit intake"), and at the third level they should be aware of participating in the risk behavior themselves ("I have a low frait intake myself"). Only when that third level of risk awareness has been accomplished, people will start to consider changing their behavior and move from precontemplation to the contemplation stage. Nutrition education aimed at subjects who overestimate the adequacy of their intake levels, should be focussed on helping people to compare their consumption to recommendations.

It can be concluded that stages of change is a relatively valid and useful modiel for target group segmentation for fruit and vegetables consumption. People in precontemplation should be addressed with nutrition information about the benefits of fruit and vegetable consumption, while people who are ready for change should be helped to start making the required changes by self-efficacy enhancing information. 


\section{Part III}

Development and Evaluation of ComputerTailored Nutrition Education 


\section{Outline}

The implications of the determinant studies described in part II were used to develop and implement a nutrition education intervention. The intervention and its impact will be described in part III of this thesis. Because of the high prevalence of underestimation of risk behavior for fat consumption as well as fruit and vegetable consumption, we developed a computer-tailored intervention with which individualized feedback about personal dietary intake could be provided. Computer-tailoring is a new technique in health education that makes individualized feedback attainable for larger population groups. In the first chapter of this part of the thesis, the literature on foundations, applicability and effectiveness of computer-tailored nutrition education will be briefly reviewed. In the remaining chapters, three experiments are described in which the impact of computertailored nutrition education aimed at fat reduction and stimulating fruit and vegetable intake was studied. In the first experiment, the impact on dietary changes of a computertailored intervention as compared to general dietary advice was tested. This experiment is described in Chapter 9. In the second experiment two computer-tailored nutrition education interventions were compared in order to test whether the original intervention could be improved. In this experiment, which is described in Chapter 10, the impact of a comprehensive feedback letter tailored to dietary habits and psychosocial factors was compared to tailored letters that provided respondents with dietary feedback only. Finally, in Chapter 11 the methods and results of a third experiment are described and discussed in which the longer term impact of computer-tailored nutrition education was studied. Furthermore, in this final experiment, the impact of a second, ipsative tailored feedback letter was assessed. 


\title{
Chapter 8
}

The Application and Impact of Computer-Tailored Nutrition Education:

A Brief Review of the Literature

\begin{abstract}
Computer-tailored health messages might be more effective than general health messages because messages that are tailored to individual behavior, needs and beliefs of subjects, the messages will be more personally relevant and might therefore have a stronger motivational impact. Computer-generated nutrition education has been implemented and studied for different dietary behaviors, in different target populations, and in different settings. Most of these computer-generated interventions provide respondents with "risk' information only and' do not give practical information about how to change risk behavior or psychosocial information that might enhance behavior change. Furthermore, only few computer-generated nutrition interventions have been evaluated in randomized trials. The results of the reviewed studies point to the conclusion that computer-tailored nutrition education has potential when nutritional risk information is supplemented with psychological and practical information that might facilitate changing one's diet towards recommendations.
\end{abstract}




\section{Introduction}

In health education, different methods and materials, like brochures, posters, self-help materials and person-to-person counseling can be applied to communicate with members of the target population. A recent development in health education that has also been used in nutrition education interventions, is computer-tailored feedback. Tailoring health education messages to characteristics of the target population is fairly similar to patient counseling in which a health professional and a patient decide about a treatment plan or therapy based on the patient's health status, health habits, motivation and/or other psychosocial characteristics. But tailoring is also possible in health education interventions in which larger population groups have to be reached. Target group segmentation, and development of different interventions for different target group segments, can be considered as a basic way of tailoring health education. Target group segmentation is often based on socio-demographic variables like sex, age, or socio-economic status, but there are also examples in which psychosocial characteristics, like stages of change, were used to divide the target population in different groups for which specific intervention activities were provided (e.g. Mudde, De Vries, Willemsen \& Van Assema, 1994; Sorensen, Grasgow \& Corbett, 1990; Strecher, Rimer \& Monaco, 1989; Van Assema et al., 1994). Interventions that are tailored to certain target group segments still do not account for personal differences in intervention needs between individuals of a target population. In recent years, computer programs have been developed, especially in the U.S.A., that enable personalized feedback for larger target populations. Using computers to tailor health education messages to characteristics of individuals has been applied to various health related behaviors, most often in smoking cessation interventions (e.g. Burling et al., 1989; Prochaska et al. 1993; Strecher et al., 1994), but also to stimulate participation in breast cancer screening (Skinner, Strecher et al., 1994), and to help people to adopt healthier diets (Campbell et al., 1994). With computer-tailoring it is possible to combine the positive characteristics of patient counseling on the one hand and mass media interventions on the other: With computer-tailoring, individualized health education for relatively large target populations with relatively low costs per person reached, can be realized (Strecher et al., 1994; Velicer, Prochaska, Bellis, DiClemente, Rossi, Fava, \& Steiger, 1993).

There are a number of reasons why computer-tailored health education might be more effective than general health education. Since computer-tailoring provides personalized information, the health education messages contain less redundant information. People are 
therefore more likely to pay attention to the essential, relevant information. Attention to the message is of essential importance in order for the health message to have an impact (McGuire, 1985). Since subjects have a limited information processing capacity, it is important to provide them only with information that is worth the processing effort (Rudd \& Glanz, 1990). According to Petty and Cacioppo (1986) involvement with the topic and contents of the message is an important determinant of the amount of cognitive effort people want to invest in reading, comprehending and processing the message. In computer-tailoring, involvement with the health education messages can be increased by using the subject's name and other personal characteristics in the feedback. Furthermore, the information can be tailored to the personal level of motivation of subjects. According to stages of behavior change models, health interventions tailored to motivational stages have higher changes to be successful (Prochaska \& DiClemente, 1992; Weinstein, 1988).

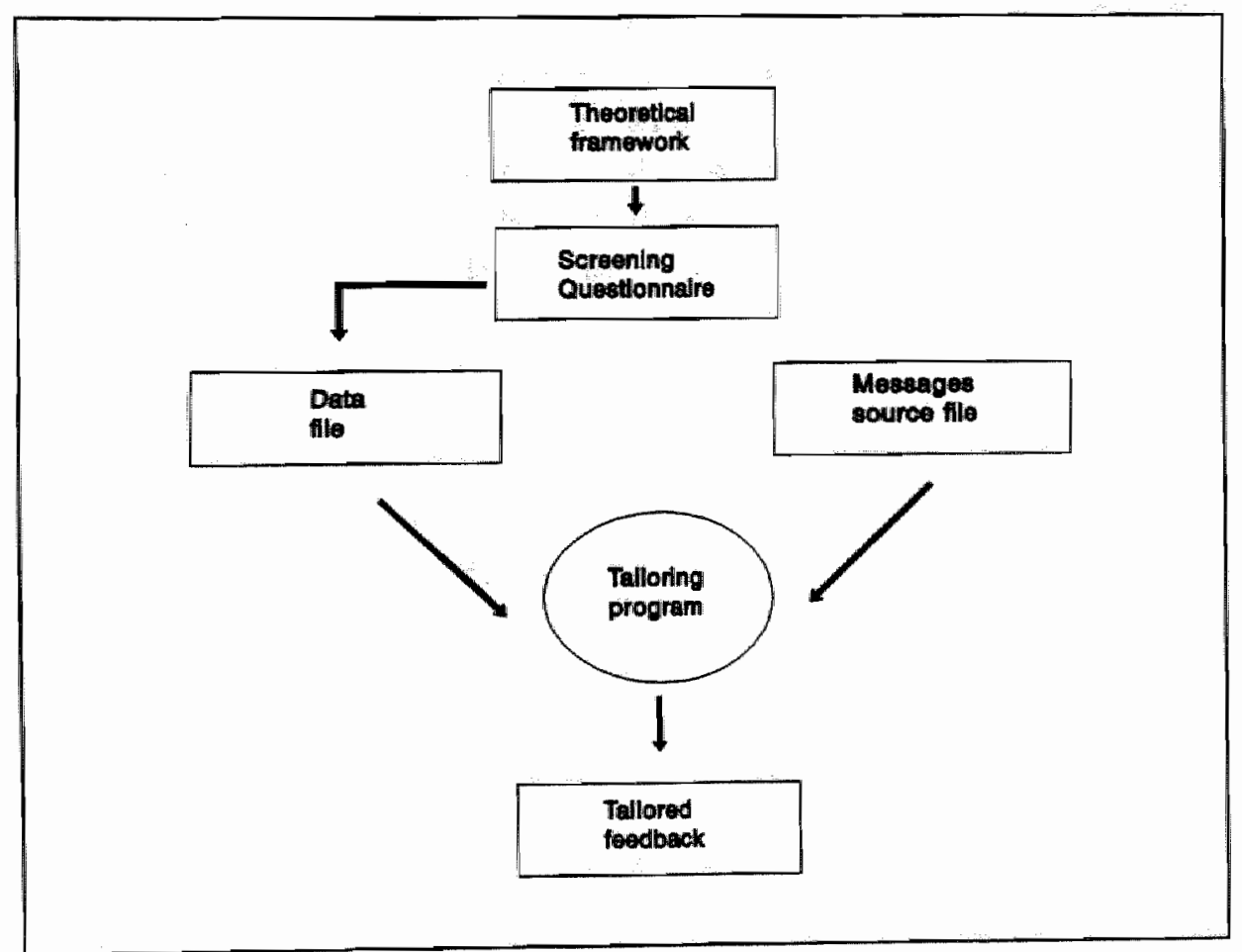

Figure 8:1. The process of computer-tailoring 
The process of generating computer-tailored messages is as follows: People are surveyed with a screening questionnaire, and the survey results are fed into a computer in which they are linked with a feedback source in which the health education expertise has been documented. The computer generates output for each individual based on his or ber personal survey results. The process of computer-tailoring is summarized in Figure 8:1.

There are different options for input, computer operation, and output of computertailoring. The questionnaire, for example, can be a self-administered written questionnaire, a telephone survey, or a questionnaire that is administered interactively with a computer (Winett et al., 1991). Data can be entered manually, but survey questionnaires can also be scanned automatically, or respondents can enter their answers on the survey questions directly into a computer. Similar alternatives can be applied for the output: For example, feedback can be printed directly on the computer screen or it can be provided in personal letters.

In computer-tailored interventions that have been reported to date, individual characteristics like behavior (number of cigarettes per day, dietary fat consumption, etc.), sociodemographic variables (sex, age, etc.), health status (cholesterol levels, blood pressure, etc.), and psychosocial factors like attitudes, self-efficacy expectations, perceived threat and readiness for change have been used to individualize the feedback (Bowen et al., 1994; Brug et al., 1996; Burling et al., 1989; Campbell et al., 1994; Van Beurden, James, Dunn \& Tyler, 1990).

The availability of powerful computers makes it possible to use almost infinite survey results and feedback sources with numerous variations in specific feedback messages for computer-tailoring. The number of different output possibilities increases exponentially with the number of individual characteristics that the feedback messages are tailored to. If , for example, a tailored intervention has been developed in which fat consumption (two categories: high versus low) and stages of change according to the transtheoretical model (five stages) are used as variables to tailor on, seven $(2+5)$ different messages have to be written. However, with these messages 10 ( $2 \times 5$ ) different feedback combinations can be provided. If a third tailoring variable with two categories is included, for example blood pressure (hypertension vs. normal blood pressure), two additional messages have to written and included in the source file while the total number of different feedback combinations increases to 20 . With each additional tailoring variable the number of feedback possibilities is multiplied with the number of categories that can be distinguished within the additional variable. 
Nevertheless; the specificity and extensiveness of the number of characteristics to survey and therefore the feedback possibilities is of course restricted by the time participants want to spend on completing the survey and reading the feedback. Even more important, the characteristics on which the information is tailored should be relevant and important for the behavior that is targeted with the tailored intervention. Therefore, choices will have to be made to which individual characteristics the messages will be tailored. Criteria for selecting these characteristics are: The characteristic should be important for behavior change, it must be possible to survey the characteristics in a valid, reliable and relatively easy way, and meaningful differences in feedback must be possible for different levels of these characteristics. It is therefore important to apply theoretical insights about determinants of (health) behaviors and processes of behavior change as guidelines in this selection (Strecher et al., 1994; Velicer et al., 1993), while validated instruments should be used for screening.

In this chapter, studies on computer-tailored nutrition education will be reviewed. Differences in dietary behaviors, target populations, theoretical frameworks for tailoring, possibilities for providing dietary feedback and impact of the various computer-tailored interventions will be described and discussed.

\section{Computer-Tailored Nutrition Education}

A number of studies have been reported on the practical applicability and impact of computer-generated nutrition. education. Although the interventions that have been studied do all provide the participants with some sort of individual feedback gesserated with computer assistance, there are large differences between these interventions based on, for example, the goals of the intervention, the target populations, the variables that were tailored, and the settings in which the intervention was studied.

\section{Target behaviors and target populations}

Computer-generated nutrition education has been aimed at different dietary behaviors or diet related problems. Interventions have been aimed at reductions in consumption of fat (Campbell et al., 1994), lowering cholesterol levels (e.g. Lackley, Kolasa \& Horner, 1992; Van Beurden et al., 1990), and weight loss (Burnet, Magel, Harrington \&aylor, 1989). Computer-tailoring has also been applied to stimulating fruit and vegetable or dietary fiber consumption (Campbell et al., 1994; Winett et al., 1991). 
A number of studies on computer-tailoring in nutrition education were conducted among healthy adults who were encouraged to change their diets towards dietary recommendations (e.g. Camplbell et al., 1994; Wagner, Winett \& Walbert-Rankin, 1992). Computer-generated feedback has also been used for risk groups, for example for people with high cholesterol levels (Van Beurden et al., 1990), or for overweight subjects (Burnett et al., 1989).

\section{Tailoring variables and theoretical insights}

In most studies on computer-generated nutrition education, personalized feedback has been provided on dietary intake levels \ike fat intake, or risk indicators like serum cholesterol levels. The personalization of the feedback has often been restricted to feedback about individual risk (or health) behavior or risk (or health) status. So-called health risk appraisals (HRA's), for example, provide health status and often health behavior feedback (Gemson \& Sloan, 1995; Hyner, Petri, Melby, Duda \& Huddy, 1987). In HRA's different health status indicators are often combined into an overall health risk score, and expressed as personalized mortality risk or 'risk age' (Gemson \& Sloan, 1995). Assessments of dietary behavior are often part of HRA's. Although in most studies on computerized feedback, additional nutrition information has been provided next to risk feedback, this additional information has often been provided as leaflets, brochures or video that were not tailored to individual characteristics, or the additional feedback was tailored to individual characteristics of the participants, but not through a computerized process. HRA feedback has, for example, been supplemented with individual person to person counseling by a physician, health educator or registered nurse (Kellerman, Felts \& Chenier, 1992). In these cases, only the screening and the initial risk feedback can be considered as a computer-generated intervention, while the major part of feedback is interpersonal health education.

In few tailored interventions, comprehensive feedback has been provided through a computer-generated process. Burnett et al. (1989), for example, not only provided their respondents with computer-generated feedback about their dietary fat intake, but also presented their respondents with low fat alternatives tailored to their high fat choices.

Computer-tailoring can be taken one step further when psychological variables are screened and psychological information is included in the computer-generated feedback. The term computer-tailoring was introduced for this form of comprehensive, theory-based computer-generated health education (Campbell et al., 1994; Kreuter \& Strecher, 1995; Strecher et al., 1994). Only a few studies explicitly used theoretical insights from social 
psychology models of behavior change to develop a computer-tailored intervention (Kreuter \& Strecher, 1996; Skinner, Strecher et a1., 1994; Strecher et al., 1994; Velicer et al., 1993). Two studies on comprehensive computer-tailored mutrition education were published apart from the studies described in the following chapters of this thesis. In a study conducted and reported by Campbell and colleagues (1994) on the impact of computer-tailored advice aimed at reducing fat intake and increasing fruit and vegetable consumption, a theoretical framework based on the Health Belief Model (Janz \& Becker, 1984) and the Transtheoretical Model (Prochaska et a1., 1991) was used to develop tailored feedback. Based on these theoretical insights, respondents received behavioral feedback tailored to their personal dietary habits as well as psychological feedback taillored to their personal beliefs about perceived dietary risks, self-efficacy expectations related to dietary change and motivational stages to change their diet. A similar computertailored intervention developed by the same research group, was tested in a study aimed at changing multiple risk factors in combination with a HRA (Kreuter \& Strecher, 1996).

\section{Intervention settings and feedback tools}

Different settings have shown to be suitable for implementing computer-tailored interventions. In point of choice settings like supermarkets or (worksite) restaurants, participants can be provided with feedback about their purchase choices (Winett et al., 1991). Participants can enter their intended food purchase data into a computer and are provided with immediate feedback about their intended choices. Worksites are also suitable for providing computer-tailored feedback. HRA's have often been used within the worksite setting with high participation rates. HRA results are usually given to the participants in print, sometimes with a personal explanation from a health professional (Gemson \& Sloan, 1995).

Campbell et all. (1994) used family practices to recruit participants for their computertailored program with positive attendance: More than $80 \%$ of the original sample completed the study. The participants received personal feedback letters mailed to their home addresses. In a study among high school students, Burnett et al. (1989) studied the impact of a computer-tailored weight loss intervention, in which the feedback was also provided in personal letters.

\section{Impact of computer-tailored nutrition education}

Because of the differences in variables that have been tailored, the level of comprehensiveness of computer-tailored interventions, the theoretical frameworks that were used 
to develop tailored feedback, and the populations that were addressed, no straightforward conclusions about the effectiveness of computer-tailoring can be drawn. Furthermore, the impact of computer-tailored nutrition intervention has not often been studied in randomized trials.

Campbell et al. (1994) used a pretest-posttest control group design to study appreciation and impact of a computer-tailored nutrition intervention aimed at fat reduction and increases in fruit and vegetable consumption. The tailored intervention was compared to general nutrition information and no intervention. Family practice patients were randomly assigned to one of the three study groups. Participants in the tailored intervention group received a one-time nutrition information packet with information about their personal fat consumption levels and intake of fruit and vegetables. Further information was given based on their readiness for change, perceived risks, and self-efficacy expectations related to the recommended dietary changes. Respondents in the tailored group significantly moreoften remembered that they received dietary feedback and more often read the feedback than respondents in the non-tailored group. Although fat reduction was larger in the tailored group as compared to the non-tailored group, this difference was not statistically significant. Nevertheless, the tailored intervention's impact on fat reduction was significantly larger than no intervention, while the non-tailored intervention was not. No significant impact on fruit and vegetable consumption was found in both intervention groups. A very similar tailored nutrition intervention was also tested by Kreuter and Strecher (1996) in a study on the impact of tailored information about multiple health risk behaviors on the effectiveness of a HRA. The tailored feedback significantly enhanced the impact of the HRA on fat reduction.

Burnett et al. (1989) studied the impact of a computer-tailored weight reduction intervention as compared to two active control conditions. The tailored group received three computer-generated feedback letters tailored to survey results during the study period. The feedback letters were supplemented with so-called 'health tip sheets' with information about behavior change tactics related to 14 different nutritional topics important in weight reduction. The first control condition was surveyed similar to the tailored condition but did not receive feedback. The second control condition was surveyed and received the health tip sheets but no personalized feedback. The tailored condition proved to be significantly more effective in promoting weight loss than the health tips condition. No significant difference was found with the survey-only condition but the number of subjects in each condition was very small $(15-45)$. The results were based on self-reported changes. No actual weight loss was found in any condition. 
In a study among supermarket customers, subjects were randomly assigned to one of two conditions. Subjects in the experimental condition were offered feedback concerning their intended purchases as well as prompts to encourage low fat and high fiber purchases. They were further encouraged to use the videodisc programs with information about how to change food purchases and meals towards healthy choices. During the intervention, subjects in the experimental condition choose significantly less often high fat meats and dairy products than control subjects. The difference in dairy choices was still present at follow-up five weeks after the intervention was stopped (Winett et al., 1991).

The impact of HRA's has been studied quite extensively. From reviews of impact studies, it can be concluded that the effects of HRA's are not consistently positive although HRA's are often appreciated by participants (Hymer et al., 1987; Meeker, 1988). In his 1988 review, Meeker reported a positive impact of HRA's in one of the five controlled studies that were available at that time. In a study in which the impact of three different HRA's were compared, only few subjects in each HRA condition reported to have made behavior changes after receiving HRA feedback (Hyner et al., 1987). In later studies, in which HRA feedback was supplemented with counseling or other health promotion activities, more positive results were reported (Gemson \& Sloan, 1995; Kellerman et al., 1992; Kreuter \& Strecher, 1996). In a study among factory workers, for example, employees reported to have changed a number of dietary behaviors, especially fat intake, after receiving HRA feedback and counseling. These self-reported changes were significantly higher among subjects who received feedback and counseling (Kellerman et al., 1992).

\section{Discussion}

Computer-tailored nutrition education has been implemented and studied for different dietary behaviors, in various target groups, with more or less comprehensive feedback and in different settings. The rationale for tailored feedback is based on the assumption that when nutrition information is tailored to individual dietary behavior, needs and beliefs of subjects in the target population, it will be of more relevance to these subjects and might therefore have a stronger motivational impact than general nutrition information. From research that has been published to date there are indications that personalized feedback is relatively well appreciated and has the potential to motivate people to change their diet in the recommended way. No definite conclusions about the effectiveness of computer-tailored nutrition education can be drawn because the studies that have been 
reported to date are difficult to compare due to design differences which may have caused the inconclinsive results.

There is a great variety of variables that can be used as a basis for generating tailored feedback. In the studies on personalized dietary feedback that have been published to date, feedback has been provided on dietary intake levels, dietary patterns, psychosocial factors like outcome expectancies and self-efficacy expectations, and/or stages of change (Bowen et al., 1994; Brug et al., 1996; Campbell et al., 1994). It is yet unclear what specific feedback elements are necessary in order to realize dietary changes although it seems justified to conclude that feedback about the level of risk behavior alone is not sufficient to motivate people to start changing their diet. People at risk tend to respond negatively to this information and might therefore not succeed in altering their risks when no practical information for risk reduction is provided (Bowen, Fries \& Hopp, 1994).

Therefore, it is important to supplement risk information with personalized suggestions on how to reduce risks and psychosocial information to motivate subjects to start contemplating and carry out behavior changes. This supplementary feedback has often been provided through person to person counseling which, of course, eliminates one of the important advantages of computer-tailoring: providing large groups of subjects with individualized feedback with little additional costs.

Settings like worksites and schools are suitable for interventions because participants are easily reached repeatedly for surveys and feedback Periodical health examinations. that are routinely conducted in many worksites offer good opportunities to include some form of computer-tailoring. In such a setting ipsative feedback can be provided that is not only tailored to the results of the most recent screening but also to changes in behavior, psychosocial variables or risk indicators between different sereening periods.

It can be concluded that computer-tailored nutrition education might have potential but that additional research is needed to study the impact of tailored intervention as compared to general interventions, and which behavioral or motivational factors should be addressed in computer-tailored nutrition education. 


\title{
Chapter 9
}

The Impact of a Computer-Tailored Nutrition Intervention ${ }^{1}$

\begin{abstract}
Nutrition education tailored to individual characteristics of people might be more effective than general nutrition education. Nowadays, the use of computers makes individualized feedback available for larger groups. The impact of tailored nutrition information on changes in fat, vegetable, and fruit consumption was tested in a randomized trial amang 347 employees of a major oil company. Respondents in the experimental group received computer-generated feedback letters tailored to their personal dietary behavior, attitudes, perceived social influences, self-efficacy expectations, and awareness levels. Respondents in the control group received general nutrition information.

Respondents in the experimental group decreased their fat consumption significantly more than the control group between baseline and posttest. A significant effect of tailoring was also found for changes in attitudes and intentions towards reducing fat intake and increasing fruit and vegetable consumption. Furthermore, respondents in the experimental group were more satisfied with the nutrition information they received and more often reported changing their diet or intention as a result of the information. It is concluded that computer-tailored nutrition information is a promising means of stimulating people to change their diet toward dietary recommendations.
\end{abstract}

"This chapter was published as:

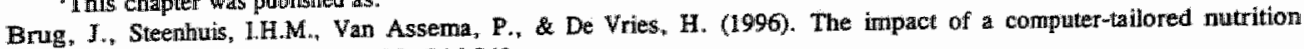
intervention. Preventive Medicine, 25, 246-242. 


\section{Introduction}

Diets low in fat and with ample amounts of fruit and vegetables are regarded as preventive for cardiovascular disease and cancer (Willett, 1994). Therefore, nutrition education activities aimed at reducing fat intake and increasing fruit and vegetable consumption have been included in primary prevention projects aimed at reducing cancer and cardiovascular disease risk. In the Netherlands the mean fat consumption is substantially higher than the recommended upper level of $35 \%$ calories from fat. Approximately $70 \%$ of the Dutch adult population eats more fat than is recommended. Furthermore, the mean fruit and vegetable consumption in the Netherlands does not meet the recommended consumption levels of two pieces of fruit and $200 \mathrm{~g}$ of vegetables per day and has been declining in recent years (Hulshof et al., 1993).

Nutrition education materials designed and developed to provide information for large population groups are not meant to provide nor are they suitable for providing individualized information to specific subjects. As a result, parts of the information may be irrelevant for individual subjects. Furthermore, it seems that most nutrition education is designed for subjects who are aware of their dietary risk behavior and are already prepared to consider changing their dietary behavior (Prochaska, 1992). Subjects who are not contemplating change are difficult to reach since they are less prone to behavioral change messages or believe that these messages are not relevant for them.

Recently, it has become clear that people, and especially those with unfavorable diets, tend to be unrealistically optimistic about the healthiness of their dietary habits. Many people who are eating more fat than is recommended think of themselves as eating low fat diets, which makes them unaware of their dietary risk behavior (Bowen et al., 1994; Brug, Van Assema, Kok et al., 1994; Lloyd et al., 1993). This has been identified as an important reason why these subjects are not contemplating dietary changes (Brug, Van Assema, Kok et al., 1994: Lloyd et al., 1993). With respect to tat, different mass media interventions in the Netherlands have been aimed at creating awareness of dietary fat consumption among the Dutch population (Brug, Riedstra, Pruyn et al., 1993; Riedstra et al., 1993). The effects of these interventions were disappointing since most subjects remained optimistic about their personal dietary habits and attributed high fat consumption patterns to others (Kok, 1994).

There are indications that when nutrition education is tailored to the behavior, needs, and beliefs of individuals in the target population, it may be more effective (Campbell et al., 1994). By means of personalized tailoring, individual subjects can be provided with 
only that information relevant for their personal situation. Furthermore, in this way personal dietary feedback can be given in order to make subjects aware of their consumption patterns.

In patient education, tailoring has been used extensively: Individual patients are interviewed by a health counselor, and based on the results of this interview the counselor and patient develop an individual treatment or educational plan. Providing nutrition education to large population groups in this way is not realistic, since the costs of professional interpersonal counseling are very high. Recently, it has become feasible to make personalized feedback and advice availlable for larger population groups in a cost-effective way by using computers (Skinner, Seigfreid, Kegler \& Strecher, 1994; Velicer al. 1993). In this way, individualized advice can be given to subjects without actual interaction with a human expert. The expertise can be programmed into a computer which generates the feedback messages.

In the study described in this paper the effectiveness of computer-tailored nutrition education aimed at reducing fat intake and increasing fruit and vegetable consumption was investigated, and compared with general nutrition education.

The following hypotheses were tested:

1 Respondents in the tailored group were expected to judge the nutrition information they received more positively than respondents in the control group.

2 Subjects in the tailored group were expected to decrease their consumption of fat and increase their consumption of vegetables and fruit significantly more between baseline and posttest than subjects in the non-tailored group. It was expected that this effect would occur especially among subjects with high baseline fat consumptions and low baseline vegetable and fruit consumptions, since in the tailored group only subjects with unfavorable diets at baseline were stimulated to change.

3 Subjects who received taillored feedback were expected to obtain more positive attitudes, perceived social influences, self-efficacy expectations, and intentions toward the dietary changes in fat, vegetables, and fruit compared with the non-tailored group.

\section{Intervention}

For the computer-tailored nutrition education, three interrelated elements were necessary (see chapter 8 , figure $8: 1$ ): (1) a screening instrument with which it is possible to assess dietary intake as well as the most important determinants of and barriers 
against; behavioral change, (2) a message source file with nutrition education messages tailored to all possible screening results, and (3) a computer program that selects relevant feedback messages from the message source fille based on the individual screening results.

\section{Screening instrument}

A screening instrument is necessary to make a diagnosis on which the decisions about the contents of the dietary feedback can be based. A self-administered questionnaire, which took about 20 minutes to complete, and consisted of a total of 121 items, was developed to make the diagnosis. This questionnaire consisted of two parts.

The first part was a validated 30 -item food frequency questionnaire developed to assess a fat consumption score and to assess intake of fresh fruit in pieces per day and consumption of vegetables in servings per day (Brug, Lechner et al., 1995; Van Assema, Brug et al., 1992). The fat consumption score could range from 12 to 60 . Scores of 22 for women and 25 for men correspond with the approximated upper levels of recommended dietary fat intake in the Netherlands. The relative validity of the food frequency questionnaire for fat was assessed as compared with a seven-day dietary record (Pearson correlation $=59$ ) and for fruit and vegetable consumption compared with a comprehensive food frequency questionnaire (Pearson correlation $=58$ ). The test-retest reliability for the fat score and the fruit and vegetable score as assessed with Pearson correlation between the scores for the first and the second administration was .71 and .77 respectively.

The second part of the screening questionnaire was developed to assess the most important psychosocial determinants of dietary fat, fruit, and vegetable intake. There are strong indications that health behavior is primarily a result of behavioral intention, which in turn is predicted by three main psychosocial factors: attitudes, social influences, and self-efficacy (Ajzen, 1991; De Vries et al., 1988). A person's attitude toward a specific behavior is a result of the consequences that person expects from performing the behavior (Ajzen, 1991; Brug, Lechner et al., 1995; De Vries \& Backbier, 1995; De Vries et al., 1988). Social influence is a result of social norms relevant to the behavior (Ajzen, 1991), support from others to perform or refrain from the behavior (De Vries et al., 1995), and whether important others perform or refrain from the behavior themselves (modeling; Bandura 1986). Self-efficacy expectations can be seen as a person's belief as to whether he can perform the desired behavior and can cope with barriers that may hinder actual performance (Bandura, 1986; De Vries et al., 1988). Based on research on determinants of motivation to reduce fat consumption (Brug, Van Assema, Kok et al., 1994), awareness of personal fat intake was included as a fourth determinant. The implication of these 
determinants is that health behavior can be changed by creating awareness of personal risk behavior, and by changing attitudes, perceptions of social norms and social support, and self-efficacy expectations (Brug, Van Assema, Kok et al., 1994; De Vries et al., 1988).

Attitudes were assessed by asking respondents about possible outcome expectancies (taste, amount of effort, price, and several health consequences). Perceived social influence was measured by asking respondents about dietary habits of important others (spouse, (other) members of the same household, and colleagues) and whether they expected social support from these important others if they tried to change their diet. Selfefficacy was measured by asking respondents how confident they were about making the necessary changes in various difficult situations. Self-assessed dietary intake was measured by asking the respondents to assess their intake of fat, fruit, and vegetables on 7 point (very low/very high) scales. An awareness variable was created by comparing objectively assessed dietary intake with self-assessments as proposed by Brug, Van Assema, Kok et al. (1994). Questions about the subjects' intention to change the three dietary behaviors in the desired direction were also included. Finally, respondents were asked about their sex, age, weight, and height, and whether they were responsible for purchasing and cooking food for their household on a regular basis.

Based on the diagnosis results, subjects were classified according to dietary behaviors, individual awareness levels, and personal beliefs.

\section{The feedback messages file}

Feedback messages aimed at reducing fat intake and increasing fruit and vegetable consumption were tailored to dietary intake levels and to the individual beliefs and awareness levels. The feedback messages were written by professional health educators in cooperation with a nutritionist. The feedback messages were pretested extensively, first among experts, later among 30 subjects from a similar target population. The messages were rewritten according to pretest results.

For example, for fat consumption different messages were written for subjects eating recommended amounts of fat, subjects eating more fat than is recommended, and for subjects eating both more fat than recommended and also more than the average person of the same sex. Different messages were written for subjects who made unrealistic assessments of their own fat consumption and for subjects with realistic self-assessments. Subjects indicating that they expected certain negative consequences or did not expect certain positive consequences of fat consumption reduction received information about 
these consequences in order to try to change their attitudes toward fat reduction. Subjects with favorable beliefs were provided with feedback designed to sustain their attitudes. Subjects with low self-efficacy expectations were provided with information about practical skills to recognize low-fat alternatives for their most important dietary fat sources and to utilize techniques to prepare low-fat meals. Furthermore, suggestions were given how to cope with situations reported by the subjects as being difficult for sustaining a low-fat diet. Similar feedback alternatives were provided for stimulating subjects to increase their consumption of fresh vegetables and of fresh fruit. A total of 223 feedback messages were written that could be combined to more than one million different tailored letters. It was highly improbable that two subjects would have the same screening results. Although tailored letters for different subjects might be similar in the general message communicated, almost all letters differed to some extent, because they were based on the subjects" individual screening results, in order to make the letters as personal as possible.

\section{Tailoring device}

The central part of the tailoring program is the algorithm in which specific theorybased decisions are established about which answers to the questions in the screening instrument should lead to which feedback messages. The tailoring device was a collection of 'if-then' statements that controlled the selection of feedback messages based on the screening results.

The screening results of each individual respondent were read into a computer, and based on the screening results, the relevant feedback messages were selected from the message file and were put in a logical order in an easily readable personal letter layout with the name of the specific subject printed in the letter heading and in the last summarizing paragraph of the letter. A 'normal' tailored letter would introduce the subject of healthy nutrition first. Subsequently, the participant's individual fat score would be presented and compared with the recommendations and the participant's peer group average fat score both in words and in a graph. Thereafter, low fat alternatives would be suggested for the participant's main dietary fat sources. Finally, the letter's 'Fat paragraph' would end with addressing the participant's specific positive and negative beliefs about fat reduction, which were derived from the screening questionnaire. Similar paragraphs on vegetables and fruit would follow the "Fat paragraph".

The algorithm and the linkage between the screening results, the algorithm, the feedback messages file, the word processor, and the letter printer were programmed in Turbo Pascal (Borland International Inc., 1990). 


\section{Methods}

A pilot study was conducted among 30 employees of a photography equipment producing company in the south of the Netherlands to test the tailored feedback procedure and the respondents" reactions to the tailored feedback letters. The procedure and the feedback messages were further improved, based on the results of the pilot.

Subsequently, the computer-tailored instrument was tested in a randomized trial among a population of employees of the Royal Shell Laboratory in Amsterdam, the Netherlands. A sample of 686 employees was approached to participate in the study and provided with the screening questionnaire. A total of 507 employees (74\%) completed and returned the screening questionnaire (baseline measurement). After two weeks, approximately half of the participants were randomly selected to receive the tailored feedback, while the other half of the respondents received general nutrition information, based on leaflets and recommendations from the Netherlands Bureau for Food and Nutrition Education. The general information was printed in the same letter format and font size as the tailored feedback. The letters were printed on paper that was specially designed for the tailored program. The program was presented as a collaboration between the company's health department and the University of Limburg. The length of the tailored nutrition information letters varied between four and nine pages, while the general information letters consisted of five pages. An example of both letters can be found in the Appendix. The participants received their nutrition information letters at their home address between two and three weeks after completing and returning the screening questionnaire.

Three weeks after receiving the nutrition information letters, the participants received a second screening questionnaire by mail, in order to assess changes in dietary fat, vegetables, and fruit intake, as well as changes in attitudes, social infiuences, and selfefficacy expectations toward these dietary behaviors (posttest). In this posttest questionnaire, the participants were also asked about their reactions to the nutrition information letter that they received and whether the nutrition information letter had resulted in changes in their opinions about their diets, in their intentions, and in their dietary behavior.

\section{Statistics}

Analyses of variance and chi-square tests were conducted to study differences at baseline in possible confounding factors between the tailored and the non-tailored group. Chi-square tests were also conducted to study differences in the employees" reactions to 
the feedback letters for the tailored and the non-tailored group. Analyses of variance were used in order to test for significant differences in mean consumption of fat, fruit, and vegetables, and psychosocial factors at posttest between the tailored and non-tailored group.

\section{Results}

A total of 347 employees ( $68 \%$ of the employees who returned the screening questionnaire; $51 \%$ of the original sample), 178 from the tailored group and 169 from the nontailored group, completed and returned the posttest questionnaire and therefore participated in the whole study. There was no difference in response rate between the tailored and the non-tailored group. The majority $(83 \%)$ of the participants were male; mean age 39 $(\mathrm{SD}=8)$. The study population was highly educated in comparison with the general Dutch population: $34 \%$ of the subjects had a university training, $59 \%$ had a technical degree. Only $7 \%$ had less than high school education.

At baseline, no differences in sociodemographic variables, body mass index, levels of fat, vegetable and fruit intake, and determinant scores were found between the tailored and the non-tailored group. Furthermore, no significant differences in these variables were found at baseline between subjects who did and those who did not return the posttest questionnaire.

Respondents who received tailored nutrition information letters were more positive about almost all aspects of the feedback letter. The results are summarized in Table 9:1.

No difference in comprehensibility and credibility of the feedback letters was found between tailored and non-tailored feedback, but the respondents in the tailored group were more positive about the appearance of the feedback letter.

Compared with the non-tailored respondents, respondents in the tailored group had significantly more positive attitudes toward increasing vegetable and fruit consumption at posttest (both $\mathrm{p}$ 's $<.01$ ). The difference in attitudes toward fat reduction at posttest were of borderline significance $\left(\mathrm{p}={ }_{\mathrm{A}} 06\right)$. Finally, a significant difference in intentions to change consumption of fat $(p<.01)$ and fruit $(p<.01)$ towards the recommendations at posttest was found in the analyses of variance. No tailoring effects on self-efficacy expectations and social influences were found. 
Table 9:1

Respomdents reactions to the feedback letters; percentage of respondents who agreed with the given statements

Tailored feedback General feedback

I have read the nutrition information letter completely

$90 \%$

$60 \%$

I have saved the nutrition information letter

$71 \%$

$46{ }^{*}=$

I have discussed the nutrition information letter with others

$81 \%$

$59 \% *$

The nutrition information letter is of personal relevance for me

$50 \%$

$1.5 \%$

The nutrition information letter was especially written for me

$53 \%$

$2 \%$

The nutrition information letter contained a lot of new information

$24 \%$

$4 \%{ }^{* *}$

The nutrition information letter was interesting

$57 \%$

$17 \%$

The information about fat was interesting

$61 \%$

$16 \%$

The information about vegetables was interesting

$50 \%$

$19 \%$

The information about fruit was interesting

$52 \%$

$19 \%$

The nutrition information letter was comprehensible

$89 \%$

$84 \%$

The nutrition information letter was credible

$56 \%$

$47 \%$

The appearance of the feedback letter is good

$50 \%$

$32 \%$

As a result of the nutrition information letter,

...., I changed my opinion about my diet

$39 \%$

$11 \%$

...., I changed my diet

...., changed my fat consumption

...., I changed my vegetable consumption

..... I changed my fruit consumption

...... I intend to change my diet

$40 \%$

$* \mathrm{p}<.01$ 


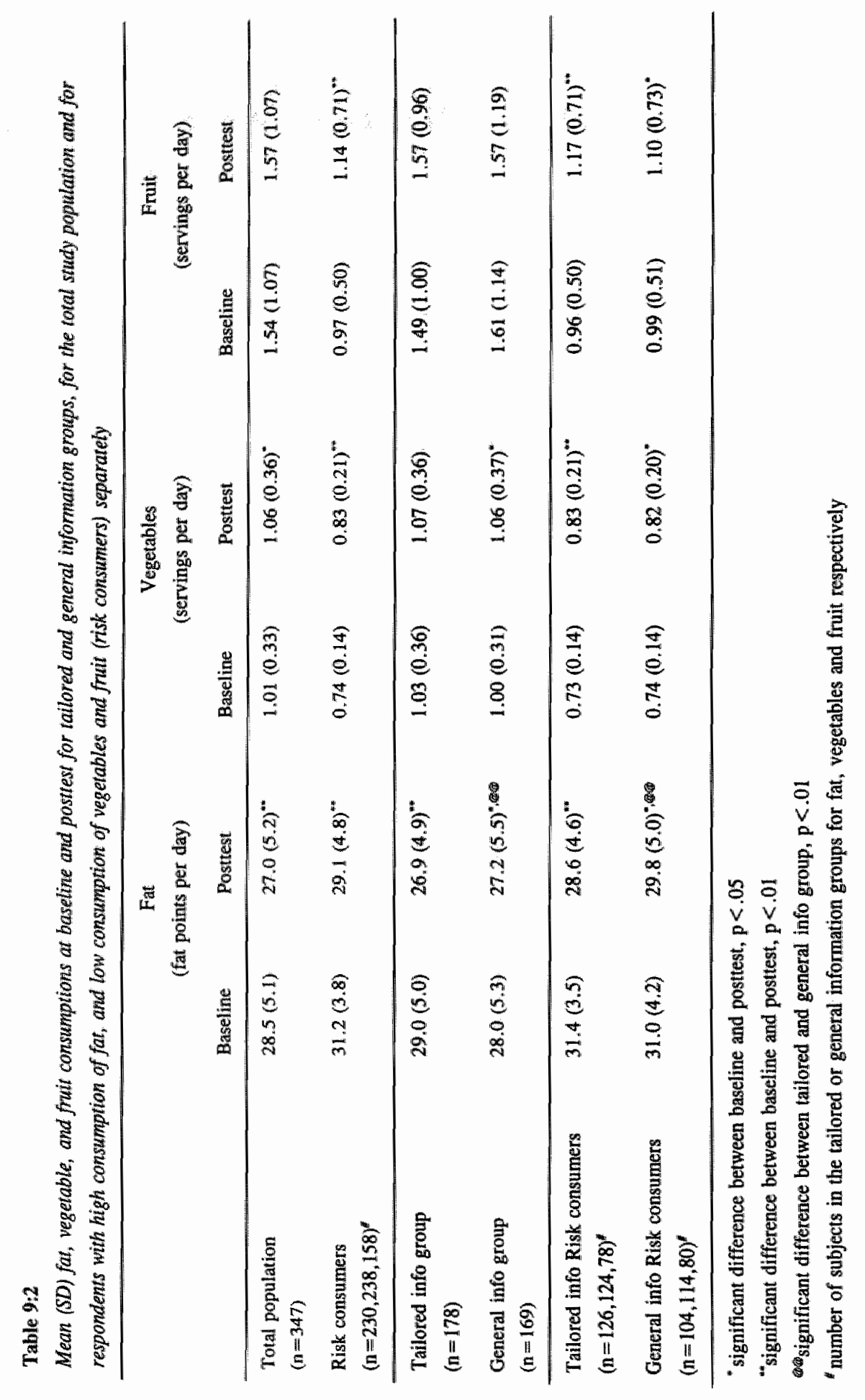


The mean fat, vegetable and fruit intake scores at baseline as well as at posttest are given in Table 9:2. A significant reduction in mean fat score was found for the whole study sample, between baseline measurement and posttest. The tailored group had a significantly lower mean fat score at posttest than subjects in the non-tailored group. Among subjects with fat consumption levels at baseline above the recommendations ( $r i s k$ consumers'), the impact of tailoring was even more substantial: The mean posttest fat score among 'risk consumers' in the tailored group was $9 \%$ lower than their mean baseline fat-score. Among 'risk consumers' in the non-tailored group a reduction of $3 \%$ was found.

Vegetable consumption increased significantly between baseline measurement and posttest, but fruit consumption did not. Among subjects who at baseline indicated to eat vegetables less than once a day ('risk consumers'), the subjects' mean vegetable consumption in the tailored group increased significantly by $14 \%$, compared with $11 \%$, also significant, in the non-tailored group. The difference in change between the tailored and the non-tailored group was not significant. Subjects in the tailored group with a mean fruit consumption of less than the recommended two pieces per day at baseline ('risk consumers") increased their fruit consumption by $22 \%$ as compared to $11 \%$ in the nontailored group. Both increases were significant. The difference in fruit consumption level between the tailored group and the non-tailored group at posttest was of borderline significance $(\mathrm{p}=.07)$.

\section{Discussion}

A significant short-term effect of tailored nutrition education messages on consumption of fat and psychosocial determinants of consumption of fat, vegetables, and fruit was found. Differences in dietary changes were also found for vegetable and fruit consumption between respondents who received tailored feedback as compared with the non-tailored group, but these differences were not statistically significant. In 1991 the Dutch Nutrition Councill initiated a long-term national campaign to motivate the Dutch population to reduce their fat consumption by $10 \%$. The $9 \%$ reduction in fat among high fat consumers who received tailored feedback that was found in the study, therefore, appears to be relevant.

Few studies have been conducted on effects of tailored feedback in relation to nutrition. Bowen et al. (1994) reported the effects of dietary fat feedback on intentions to reduce fat intake and on other motivational factors in relation to fat reduction. The 
authors concluded that dietary feedback alone was not sufficient to motivate subjects to lower their fat consumption. However, no control group was included in the study and no psychosocial information was provided. In our study; the information in the feedback letters was also tailored to psychosocial beliefs such as attitudes, self-efficacy expectations, and social influences. Since a signifficant positive tailoring impact on attitudes or intentions was found for all three dietary behaviors, adding psychosocial feedback might motivate subjects more to reduce their fat consumption than dietary feedback alone. Campbell and colleagues (1994) provided subjects with tailored feedback based on the Health Belief Model. Subjects received letters with information about their consumption of fat, fruit, and vegetables and psychosocial information, tailored to their perceived susceptibility to chronic diseases, to their self-efficacy expectations of changing their diet, and to perceived benefits related to the targeted dietary changes. A significant effect of the tailored nutrition information intervention on fat consumption reduction was found as compared with no intervention, but no significant difference was found between tailored advice and general advice. Similar to the study reported here, no substantial tailoring effects on increase in fruit and vegetable consumption were found. The impact on fat reduction in our study was more substantial compared with the other studies that reported the effects of personalized feedback on fat consumption.

The difference in tailoring effects on dietary behavior between fat reduction and fruit and vegetable stimulation might be caused by the relative complexity of dietary fat consumption compared with consumption of fruit and vegetables. The adequacy of one's. individual fruit and vegetable consumption is quite easy to assess as soon as the dietary recommendations for these food groups are known. The Dutch recommendations were provided to the respondents in the tailored feedback as well as in the general feedback letters, and a relatively large increase in fruit and vegetable consumption was found for both the tailored and the non-tailored group among subjects with low consumption at baseline. For fat consumption, self-assessment of individual intake is more difficult since fat is present in a great number of different food products from different food groups. Therefore, tailored advice, which provides the necessary information to make valid selfassessments, might be more relevant in relation to fat reduction.

The tailored and non-tailored feedback letters were as similar in layout as possible in order to prevent confounding effects of differences in the appearance of the feedback letters. No differences in perceived credibility and comprehensiveness of the feedback letters was found but respondents in the tailored group did like the appearance of the feedback letter better than the non-tailored respondents did, which might have caused part 
of the tailoring impact. However, it might also be that tailored respondents rated the appearance of the feedback letter more positively because they were more satisfied with the information they received.

The response rate, especially at baseline, was relatively high. Therefore, more than $70 \%$ of the initial group received feedback. This can be interpreted as an additional pasitive result of the study. Since a large majority of the original sample was male, the high response rate indicates that men are interested in nutrition information, at least when it is provided to them personally and especially when it is tailored to their personal characteristics, since $90 \%$ of the respondents in the tailored group stated they had read the complete feedback letter. Additional reasons for the relatively high response rate could be the way the program and the study were presented, the support the company"s health department gave to the study by stimulating the employees to participate, and the relatively highly educated study population that was addressed in this study.

Tailoring nutrition information with computers does require some additional investments compared with general written nutrition education materials. The decision rules for the computer-tailoring have to be programmed, individual screening data have to be processed, and letters have to be printed for each individual participant. In the study presented here, the programming for the tailoring device was done in approximately three weeks by a nutrition educator in cooperation with an experienced computer programmer. For the present study, the screening data were processed manually, which took about 10 minutes per questionnaire. In future studies, questionnaires that can be processed automatically will be used, which might improve the practical feasibility of tailoring. Worksites seem to offer good opportunities for tailored programs since the tailoring might be included in the periodic health checks, but Campbell et al. (1994) has shown that general practices are another setting where computer-tailoring might be feasible.

Since the respondents who received tailored feedback evaluated their feedback letters more positively on personal relevance, interest, and motivation and since significant positive effects of tailoring were found on consumption, attitudes, and/or intentions related to fat, fruit, and vegetables, we conclude that computer-tailored nutrition education appears to be a promising way to stimulate people to change their diet toward dietary recommendations. Further research should be conducted to study the longer-term effects of tailored nutrition information. 


\title{
Chapter 10
}

\section{Differences in Impact Between Two Computer-Tailored Nutrition Education Interventions ${ }^{1}$}

\begin{abstract}
The impact of two computer-tailored nutrition education interventions was assessed and compared in a randomized trial among 315 subjects with a pretest-posttest control group design. Respondents in both the experimental and the control group received feedback tailored to their consumption of fat, fruit, and vegetables. Respondents in the experimental group received additional psychosocial feedback tailored to their attitudes, perceived social support and self-efficacy expectations towards reducing their fat consumption and increasing their consumption of fruit and vegetables. A significant reduction in fat consumption and increase in the consumption of fruit and vegetables were found in both the experimental and the control group between pretest and posttest. Respondents in the experimental group more often indicated that the feedback they received was interesting and easy to understand. Respondents in the control group more often reported having reduced their fat consumption because of the feedback they received. No significant differences in consumption of fat, fruit and vegetables were found at posttest between the experimental group and the control group. These results do not support the hypothesis that additional psychosocial information is an essential component of effective tailored feedback. The results illustrate that tailored feedback is effective in inducing dietary changes.
\end{abstract}




\section{Introduction}

Diets high in fruit and vegetables and low in fat are associated with lower risk for chronic diseases, particularly cardiovascular disease and some cancers (Willett, 1994). However, in the Netherlands as well as in other European countries and the U.S.A, high proportions of the population eat more fat than is recommended (Hulshof et al., 1993; Subar, Ziegler, Patterson, Ursin \& Graubard, 1994). Furthermore, for most people fruit and vegetable intake does not meet the recommended daily intake levels (Hulshof et al., 1994; Block, 1991).

In the Netherlands, a number of different nutrition education approaches have been used in order to encourage people to adopt healthier diets. Important dietary problems in relation to primary prevention of the most common chronic diseases are present among a majority of the population. As a result, most nutrition education interventions have been designed to reach large population groups and often used mass media educational materials. Four consecutive nationwide mass media nutrition education campaigns were found to be unsuccessful in motivating the majority of the Dutch people with high fat diets to reduce their fat consumption. Probably one of the main reasons for this lack of success was derived from the evaluation studies and from additional research: It has become clear that many Dutch persons are not aware of their high fat intakes and that awareness of personal dietary risk behavior is an important determinant of motivation to change (Brug, Van Assema, Kok et al., 1994; Riedstra et al., 1994). Therefore, mutrition education tools have been designed to make it easy for people to compare their dietary intake with dietary recommendations.

A recent development in personalized nutrition education is the use of 'computertailored feedback' (Brug et al., 1996; Campbell et al., 1994). By means of computertailored feedback, subjects are provided with nutrition education information that is relevant for their personal (dietary) habits and/or personal beliefs toward healthy eating. There are clear indications that when health education is individualized by tailoring information to the personal behavior, needs, and/or beliefs of subjects, it is evaluated more positivelly and may be more effective than providing subjects with general health education (Brug et al., 1996; Campbell et al., 1994; Strecher et al., 1994).

The process of computer-tailoring is similar to person-to-person patient counseling: Individual subjects are interviewed or surveyed ("screened") and the results are used to develop an individual treatment plan, behavior change plan, or dietary advice. In 
computer-tailoring the expertise of the nutrition educator is programmed into a computer which reads the (coded) survey responses and generates individualized feedback messages.

There is a great variety of variables that can be included in the screening tool as a basis for generating tailored feedback. In the studies on personalized dietary feedback that have been published to date, feedback has been provided on dietary intake levels, dietary patterns, psychosocial factors like outcome expectancies and self-efficacy expectations, and/or stages of change (Bowen et al., 1994; Brug et al., 1996; Campbell et al., 1994). It is yet unclear what specific feedback elements are necessary in order to realize dietary changes.

In a study on the effects of personalized dietary feedback without additional psychosocial information, Bowen and colleagues (1994) reported that subjects with the highest fat consumptions who received feedback about their fat consumption were least likely to intend to reduce their fat intake. In two other studies that have been reported on the effectiveness of (computer-)tailored nutrition education, a combination of dietary feedback and psychosocial information was given. Both studies showed that these tailored interventions were effective in inducing dietary changes (Brug et al., 1996; Campbell et al., 1994). Based on the literature to date, one could hypothesize that supplementing personaiized dietary feedback with psychosocial information is necessary in order for the feedback to be effective in motivating subjects to change their diets.

In the present study, the effects of two computer-tailored nutrition education interventions were compared in a randomized trial. The first intervention (control group) provided subjects with personal letters with tailored dietary feedback about fat, fruit and vegetables only. In the second intervention (experimental group), tailored letters with dietary feedback was supplemented by feedback about personal outcome expectancies, perceived social influences and self-efficacy expectations. This second intervention has been tested before in a randomized trial in which its impact was compared to general nutrition information (Brug et al., 1996). The results of this study showed that the comprehensive tailored nutrition information letters were more effective in inducing a reduction in fat consumption than personal letters with general nutrition information.

It was hypothesized that both tailored letters would have a significant impact on reduction of fat intake and increases in fruit and vegetable consumption. Furthermore, it was hypothesized that subjects in the experimental group, compared to subjects in the control group, would:

1- judge the tailored feedback letters more positively, 
2- increase their intentions to reduce their fat intake and their intentions to increase fruit and vegetable intake more, and

3- decrease their consumption of fat and increase their consumption of fruit and vegetables more.

\section{Methods}

For providing subjects with computer-tailored mutrition education three interrelated elements are necessary: (1) a screening instrument with which it is possible to assess the variables on which the tailored feedback will be based. (2) a message source file with feedback messages tailored to all possible screening results, and (3) a computer program that selects specific feedback messages for each individual subject from the source file based on the subject's screening results (see chapter 8 , figure $8: 1$ ).

\section{The screening questionnaire}

A self-administered written questionnaire, which consisted of a total of 102 items, was used as a screening tool. The questionnaire took about 20 minutes to complete. The first part of the questionnaire consisted of a food-frequency questionnaire with which it is possible to assess consumption of fat, fruit and vegetables in a relative valid and reliable way. Specific information about the validity of the food-frequency questionnaire has been published elsewhere (Brug, Lechner et al., 1995; Van Assema, Brug et al., 1992). From the food-frequency questionnaire a fat score can be computed that ranges between 12 and 60. This score can be used in order to rank subjects according to absolute fat intake and to detect changes in fat consumption over time (Van Assema, Brug et al., 1992). For fruit and vegetable consumption the number of servings per day could be computed (Brug, Lechner et al., 1995).

In the second part of the questionnaire the subjects were asked about possible outcome expectancies (taste, amount of effort, price, and several health consequences) of reducing fat intake and increasing fruit and vegetable consumption that together were supposed to reflect the respondents' attitudes. Furthermore, items were included about the perceived social influence of important others (spouse, (other) household members, colleagues), and self-efficacy expectations. The latter were assessed by asking subjects how confident they were about being able to reduce their fat intake and increase their fruit and vegetable consumption in general and in different difficult sinuations (eating out, eating snacks, at parties). Finally, questions were included about how subjects rated their level of con- 
sumption of fat, fruit and vegetables and questions about subjects' intentions to reduce their fat intake and increase their fruit and vegetable consumption. All questions on these psychosocial factors could be answered on 7-point scales. Attitudes, social influences, self-efficacy expectations and self-rated intake have been repeatedly identified as important psychosocial determinants of dietary behavior (Brug, Van Assema, Kok et al., 1994; Brug, Lechner et al., 1995; Raats et al., 1993; Sheeka et al., 1993; Stafleu et al., 1991). The psychosocial questionnaire was based on focus group interviews (Brug, Debie et al., 1995; Van Assema et al., 1993). The psychosocial questions have been used before in determinant studies and proved to be significant correlates of intention and dietary intake (Brug, Van Assema, Kok et al., 1994; Brug, Lechner et al. , 1995).

\section{The message source file}

The message source file consisted of 223 different feedback messages. The messages could be divided into two categories: dietary feedback and psychosocial feedback.

Different dietary feedback messages were written for various categories of dietary behavior for fat, fruit, and vegetables. For example for fat, the source file included messages for subjects eating more fat than is recommended, for subjects eating more fat than is recommended as well as more than their peer group average fat consumption, and for subjects who were eating according to the recommendations for fat. Further messages were included that addressed six different possibly important dietary fat sources (milk and milk products, meat and meat products, spreads, cheese, hot snacks, and sweet snacks) in which low fat alternatives for high fat choices were suggested. Fat scores of 22 for women and 25 for men were used as operationalizations of the upper levels of the Dutch recommended intake of $35 \%$ energy from fat. Fruit and vegetables messages were included for subjects eating less than the recommended amount of fruit and vegetables and subjects eating according to recommendations. One serving of vegetables per day and two pieces of fruit per day were used to operationalize the Dutch recommendations $(200 \mathrm{~g}$ vegetables and two pieces of fruit per day). Messages also included suggestions on how to eat more fruit and vegetables during meals and for snacks Subjects were advised to change their dietary behaviors that were not in accordance with recommendations and to sustain their dietary behaviors that were according to recommendations.

In order to provide subjects with psychosocial feedback, messages were included in the source file that addressed possible negative outcome beliefs and messages meant to sustain positive outcome expectancies of fat reduction. For subjects who did not expect social support for fat reduction a message was included with suggestions on how to cope 
with a negative social environment. For subjects with low self-efficacy expectations in certain situations (when eating out, at parties, etc.), messages were included with suggestions on how to cope with these situations. Similar feedback alternatives were included in the messages source file for psychosocial feedback related to fruit and vegetable consumption.

\section{The tailoring computer program}

A computer program was written in Turbo Pascal (Borland International Inc., 1990) which linked individual screening results to specific feedback messages from the source file. For this purpose each different message was given a unique code. The program consisted mainly of a number of so-called 'IF-THEN statements'. These statements were the decision rules for the selection of specific feedback messages from the source file for individual subjects based on their answers on the screening questions. Further, the program controlled the creation and printing of personal feedback letters from the selected messages.

In both interventions subjects received personal tailored feedback letters, mailed to their home addresses. The letters for both interventions were printed on identical paper that was specially designed for the tailored nutrition education letters. In both interventions the name of the subject was printed in the letter's introduction and in the final paragraph of the tailored letter. In both types of tailored letters similar illustrative cartoons were used and similar recipes for low fat meals were included.

The control intervention provided subjects only with dietary feedback about their fat, fruit and vegetable consumption as compared to recommended dietary intake levels and suggestions on how to make healthier choices based on the person's dietary habits. In the experimental intervention the dietary feedback was supplemented with psychosocial information tailored to the subjects' individual attitudes, perceived social support, and self-efficacy expectations.

\section{Study design and procedure}

The study was conducted among a predominantly female population of employees of a regional organization for home care. The screening questionnaires were distributed to 696 employees by 36 middle managers. Subjects were randomly assigned to the experimental or control intervention. The screening questionnaire was returned by 347 respondents ( $50 \%$ response), of which 170 were assigned to the experimental group, and 177 to the experimental group. Respondents who completed the screening questionnaire received 
their tailored nutrition information letter at their home address approximately two weeks after returning the screening questionnaire. Three to four weeks later a second questionnaire was mailed to the home addresses of the respondents. This questionnaire was similar to the screening questionnaire but a number of questions that were used solely for tailoring purposes and not as impact measures were left out. Additional questions were included about the respondents' reactions to the tailored letters they received.

The posttest questionnaire was completed and returned by 315 subjects (152 in the experimental group and 163 in the control group). All andyses were conducted among these 315 subjects who completed both questionnaires $(91 \%$ of the subjects who conpleted the baseline screening, $45 \%$ of the original sample).

\section{Statistical analysis}

Differences between the experimental group and the control group at baseline in sex distribution, education, age, intentions, consumption of fat, fruit, and vegetables and selfrated intake were tested with chi-square tests or analyses of variance.

Analyses of variance were used to test for differences in consumption of fat, frut, and vegetables and differences in intentions between baseline and posttest. Since respondents who had high fat intake or low intake of fruit or vegetables at baseline were nost strongly advised to change, the changes among these respondents were of special interest. Therefore, the differences between baseline and posttest were analyzed separately for these subjects.

Differences in the subjects' reactions to the tailored letters between the experimental group and the control group were also tested with chi-square tests or with analyses of variance.

Finally, in order to test for differences in intervention effects between the experimental group and the control group, analyses of co-variance were conducted, testing for significant differences at posttest in fat consumption-per-day scores, servings of vegetables and fruit per day, intentions to reduce fat consumption and intentions to increase fruit and vegetable consumption, while adjusting for baseline levels and other possible confounding variables. Differences with a $p$-value $<.05$ were considered to be significant. All analyses were two-tailed. 


\section{Results}

The participants were predominantly female ( $89 \%)$ and the majority of the respondents had lower professional education or less. The subjects were between 19 and 59 years old with a mean age of 40 years. No significant differences were found between subjects who completed the whole study and those who dropped out between pretest and posttest in socio-demographic features, body mass index, dietary behavior, intentions, or psychosocial factors. No significant difference in response rate was found between the experimental and control group.

Table 10:1

Mean values (SD) for key variables at baseline

\begin{tabular}{lcc}
\hline Age & $\begin{array}{c}\text { Experimental group } \\
(\mathrm{n}=152)\end{array}$ & $\begin{array}{c}\text { Control group } \\
(\mathrm{n}=163)\end{array}$ \\
\hline BMt & $38.6(10.0)$ & $41.3(10.0)^{*}$ \\
Fat score & $24.2(3.7)$ & $23.9(4.1)$ \\
Servings of vegetables & $26.5(4.8)$ & $27.4(4.8)$ \\
Servings of fruit & $1.14(0.34)$ & $1.04(0.33)^{-*}$ \\
Intention to reduce fat & $1.62(1.40)$ & $1.61(1.42)$ \\
Intention to increase vegetables & $0.26(1.91)$ & $0.11(1.97)$ \\
Intention to increase fruit & $-1.21(1.65)$ & $-0.91(1.62)$ \\
Self-rated fat intake & $-0.31(1.93)$ & $-0.40(1.94)$ \\
Self-rated vegetable consumption & $-0.59(1.42)$ & $-0.32(1.25)^{*}$ \\
Self-rated fruit consumption & $1.37(1.27)$ & $0.91(1.19)^{* *}$ \\
\hline
\end{tabular}

* significant difference, $p<.05$

"m significant difference, $p<.01$

(")orderline significant, $\mathrm{p}=.072$

"range: -3 (very surely not) to +3 (very sure)

range: -3 (very low intake) to +3 (very high intake) 


\section{Differences at baseline}

At baseline, subjects in the experimental group had a significantly lower mean age, ate significantly more servings of vegetables per day and estimated their personal intake of vegetables and fruit significantly more positive than subjects in the control group (Table 10:1). The difference in self-rated fat intake was of borderline significance: Subjects in the control group rated their personal fat intake somewhat higher.

\section{Differences between pretest and posttest}

A significant reduction in mean fat score from 27.0 to 26.1 ( $F=17.1, p<.01)$ between pretest and posttest was found for the whole study population. Among respondents with high fat intake at baseline (fatscore $>25$ for men and $>22$ for women, $\mathrm{n}=233$ ) the reduction in fat points was $6 \%$ from 29.0 to $27.2(\mathrm{~F}=52.1, \mathrm{p}<.01)$. The mean vegetable consumption did not change significantly between pretest and posttest, but among respondents with low vegetable intake at baseline (vegetable intake $<1$ serving per day, $\mathrm{n}=106)$ a significant $13 \%$ increase from 0.8 to $0.9(\mathrm{~F}=23.8, \mathrm{p}<.01)$ servings per day was found. The mean fruit consumption increased from 1.6 to $2.0(\mathrm{~F}=28.6$, $p<.01$ ) servings per day, and among respondents with low fruit intake at baseline (fruit intake $<2$ servings per day, $\mathrm{n}=207)$ a $70 \%$ increase from 0.8 to $1.4(\mathrm{~F}=78.3, \mathrm{p}<.01)$ in the mean number of servings per day was found.

\section{Table 10:2}

Adjusted means (SD) at postrest for fat scores, and servings of vegetables and fruit per day and intentions for the experimental and the control group

\begin{tabular}{lcc}
\hline & $\begin{array}{c}\text { Experimental group } \\
(\mathrm{n}=152)\end{array}$ & $\begin{array}{c}\text { Control group } \\
(\mathrm{n}=163)\end{array}$ \\
\hline Fat score & 26.2 & 25.9 \\
Servings of vegetables & 1.07 & $1.13^{\circ}$ \\
Servings of fruit & 2.02 & 1.91 \\
Intention to reduce fat & 0.37 & 0.50 \\
Intention to increase vegetable consumption & 0.51 & 0.47 \\
Intention to increase fruit & -0.17 & -0.13 \\
\hline
\end{tabular}

borderline significant, $p=.06$

range: -3 (very surely not) to +3 (very sure) 


\section{Differences in impact between the tailored letters}

No difference in posttest fat scores was found between the experimental group and the conitrol group after adjustments were made for baseline differences in fat scores, self-rated fat intake and age (Table 10:2). The difference in posttest adjusted mean vegetable intake between the experimental group and the control group was of borderline significance, the control group had the higher mean intake. The adjusted mean fruit intake at posttest was not significantly different between the experimental group and the control group. Furthermore, no differences in adjusted posttest intentions were found between the two groups.

\section{Table 10:3}

Participants" reactions to, and the subjective impact of, the tailored letters (\% yes)

\begin{tabular}{|c|c|c|}
\hline & $\begin{array}{l}\text { Experimental group } \\
\qquad(\mathrm{n}=152)\end{array}$ & $\begin{array}{l}\text { Control group } \\
\qquad(n=163)\end{array}$ \\
\hline Have you receiwed your nutricion information letter? & 100 & 100 \\
\hline Have you read the entire letter? & 95 & 94 \\
\hline Have you saved the letter? & 83 & 82 \\
\hline Have you shown the letter to others? & 49 & 51 \\
\hline Have you talked about the letter with others & 74 & 77 \\
\hline Have you used one or both of the recipes in the letter? & 16 & 20 \\
\hline \multicolumn{3}{|l|}{ As a result of the nutrition information ... } \\
\hline ... have you changed your opinion about your diet? & 69 & 73 \\
\hline$\ldots$ have you changed your diet? & 49 & $59 \%$ \\
\hline ... have you reduced your fat consumption? & 49 & $62^{\circ}$ \\
\hline ... have you increased your vegetable consumption? & 17 & 22 \\
\hline ... have you increased your fruit consumption? & 43 & 42 \\
\hline ... do you intend to change your diet? & 67 & 68 \\
\hline
\end{tabular}




\section{Participants' reactions to the tailored letters}

The majority of the participants in both the experimental and the control group reported that they read and saved the letter and talked about the letter with others (Table 10:3). Respondents in both groups rated the information in their tailored letters as interesting, personally relevant and credible (Table 10:4).

Respondents in the experimental group thought that the letter, and especially the information about vegetables and fruit, was significantly more interesting and somewhat less difficult to understand, than did respondents in the control group. Substantial proportions of subjects in both groups stated that they changed their opinion about their diets and/or changed their dietary intake as a result of the letters they received (Table 10:3). Respondents in the control group significantly more often stated that they changed their fat consumption as a result of the tailored letters.

\section{Table 10:4}

Participants' opinions of the tailored lesters. (Mean scores (SD))

\begin{tabular}{lll}
\hline Range $=-3$ (very negative) to 3 (very positive) & $\begin{array}{c}\text { Experimental group } \\
(\mathrm{n}=152)\end{array}$ & $\begin{array}{c}\text { Control group } \\
(\mathrm{n}=163)\end{array}$ \\
\hline How interesting was the tailored letter? & $2.17(1.27)$ & $1.85(1.35)^{*}$ \\
How interesting was the information about fat? & $2.19(1.26)$ & $2.02(1.22)$ \\
How interesting was the information about vegetables? & $2.12(1.21)$ & $1.75(1.34)^{*}$ \\
How interesting was the information about frut? & $2.12(1.23)$ & $1.83(1.24)^{*}$ \\
How personally relewant was the nutrition information & $1.73(1.62)$ & $1.71(1.46)$ \\
letter? & & $0.35(1.71)$ \\
How much of the information was new for you? & $2.34(1.05)$ & $2.07(1.40)^{\circ}$ \\
How difficult or easy to understand was the information? & $1.31(1.75)$ & $1.34(1.71)$ \\
How credible was the information? & $1.28(1.13)$ & $1.15(1.08)$ \\
What did you think about the appearance of the informa- & & \\
tion letter? &
\end{tabular}

\footnotetext{
- significant difference, $p<.05$

(oorderline significani, $p=.05$
} 


\section{Discussion}

Significant changes in dietary intake of fat, vegetables and fruit were reported by the participants in this study after receiving a tailored nutrition information letter. These changes were found especially among subjects who were more strongly advised to change based on their unfavorable consumption patterns at baseline. Among these subjects, the mean fat score dropped approximately $6 \%$, vegetable consumption increased $13 \%$ and the mean fruit consumption increased $70 \%$. The Dutch Nutrition Council has initiated nationwide campaigns in order to reach a $10 \%$ reduction in mean fat intake in the Netherlands. Therefore, a $6 \%$ reduction, as was found in the present study with a single intervention activity, seems to be a clinically relevant change. Fruit and vegetable consumption is substantially lower than recommended in the Netherlands and has been declining in recent years. The increase in vegetable intake and, especially, fruit intake that was found in the present study was substantial. For fruit intake, the mean intake at posttest met the Dutch recommendation to include two pieces of fruit in the daily diet.

In an earlier study in which the impact of the comprehensive tailored letters were compared to general dietary advice, similar changes in fat, fruit and vegetable consumption were found in the tailored feedback condition (Brug et al., 1996) while in a study conducted in the U.S., Campbell and colleagues (1994) found a $23 \%$ decrease in total fat but little change in fruit and vegetable consumption among subjects who received tailored nutrition information (Campbell et al., 1994).

Respondents in the present study were quite positive about the feedback they received. A majority of the study population said that they changed their opinion about their diets and changed their diets as a result of the feedback they received. These proportions were greater than in a study where a comparable feedback tool was used among predominantly male and relatively highly educated employees at an oil company in the Netherlands where proportions between $8 \%$ and $39 \%$ of self-reported changes were found (Brug et al., 1996). Differences in sex distribution and educational level might account for the differences between these two studies. Additional analyses of our data showed that respondents in the lowest educational category had read their letters more often and found their tailored letters significantly more interesting and relevant than respondents with higher education. Our study did not include enough men to study sex differences.

There were only small differences in impact between the experimental and control conditions in this study. The respondents in the experimental group were more satisfied with their feedback letters but the control intervention had a somewhat greater impact on 
vegetable consumption. Also, respondents in the control group more often reported having changed their diets because of the letters. It could be that, even though they were judged as more interesting, the more abundant information in the experimental group diluted the most important messages in the letters that encouraged them to make changes. Perhaps the specific messages were more prominent in the shorter letters that the subjects in the control group received because there was less additional information to 'obscure' the essential information. Furthermore, the information that was given to the control group, solely based on dietary intake data, could have improved self-efficacy expectations and outcome expectations, and might therefore have improved psychosocial factors indirectly, by providing subjects with practical skills to make changes and information on what consequences these recommended changes would have for their diet.

It can be concluded that the results of this study do not support the hypothesis that additional tailored psychosocial information is an essential element of effective computertailored nutrition education. Nevertheless, respondents who received the tailored letters with additional psychosocial feedback were more satisfied with the information they received. The results confirm the conclusions from earlier research that computer-tailored nutrition education is a promising means to motivate subjects to change their diets towards recommended intake levels (Brug et al., 1996; Campbell et al., 1994) and the results indicate that extensive dietary feedback without psychosocial information is sufficient to accomplish these results. 


\title{
Chapter 11
}

\section{Computer-Tailored Nutrition Education:}

\section{Longer Term Impact and Impact of Ipsative Feedback ${ }^{1}$}

\begin{abstract}
Computer-tailored nutrition education has been found to have greater impact on shortterm dietary changes than general nutrition information. In the present study the longer term impact of individualized computer-generated nutrition information and the additional effects of ipsative feedback on changes in intake of fat, fruit and vegetables was studied in a randomized trial among 646 Dutch adults. Respondents in the experimental group received computer-generated feedback letters tailored to their dietary intake, intentions, attitudes, self-efficacy expectations and self-rated behavior. Half of the respondents in the experimental group received additional ipsative feedback tailored to changes in behavior and intentions after the first feedback letter. Respondents in the control group received a single general nutrition information letter in a similar format as the tailored letters. Computer-tailored nutrition education had a significant greater impact on fat reduction and increases in fruit and vegetable intake than general information. Ipsative computertailored feedback had an additional significant impact on fat and fruit intake. A reduction of $10 \%$ in fat scores and a $15 \%$ increase in fruit intake was found in the ipsative feedback group as compared to a $2 \%$ reduction in fat and a $3 \%$ reduction in fruit intake among respondents receiving general nutrition information. The results confirm that computergenerated individualized feedback can be effective in inducing dietary changes towards recommended intake levels. The results indicate that ipsative feedback might increase the longer-term impact of computer-tailored nutrition education.
\end{abstract}

This chapter has been submitted for publication as: Brug, J., Glanz, K., Van Assema, P, \& Kok, G. Compater-ailoted nutrition education: The impact of ipsative feediback. 


\section{Introduction}

There are clear indications from epidemiological research that diets high in (saturated) fat and low in fruit and vegetables can increase risk for cardiovascular diseases and certain cancers (Willet, 1994). In most countries in Europe as well as in the United States, large proportions of the population eat more fat and fewer fruit and vegetables than is recommended by health authorities (Block, 1991; Hulshof, 1993; Subar, 1994). In order to contribute to primary prevention of chronic diseases like cardiovascular disease and cancer, nutrition educators have tried to encourage people to eat less fat and more fruit and vegetables. A recent development in health education is the use of computergenerated personalized feedback in health education. There are clear indications that when health education is individualized by tailoring information to the personal behavior, needs, and/or beliefs of subjects, it is evaluated more positively and may be more effective than providing subjects with general health education (Brug et al., 1996; Campbell et al., 1994; Strecher et al., 1994). Using computer technology makes personalized feedback feasible for large target groups. This way of providing subjects with personalized feedback is referred to as computer-tailoring.

In computer-tailored nutrition education, subjects are provided with nutrition education information that is relevant for their personal (dietary) habits and/or personal beliefs about healthy eating. The process of computer-tailoring is similar to person-to-person patient counseling: Individual subjects are interviewed or surveyed and the results are used to develop an individual treatment plan, behavior change plan, or dietary advice. In computer-tailoring the survey is often self-administered and the expertise of the nutrition educator is programmed into a computer which reads the survey responses and generates individualized feedback messages.

To date three studies have been published in which the impact of computer-tailored nutrition education was studied (Brug et al., 1996; Campbell et al., 1994; Kreuter \& Strecher, 1996). The first study was conducted by Campbell and colleagues (1994) among patients who visited their general practitioner. This study compared the impact of computer-tailored nutrition education letters to letters with general nutrition information and to a no-intervention control group. The study showed that participants in the tailored condition reacted more positively to the letter they received and reduced their fat consumption more, although the difference in mean fat consumption compared to the group who received general information was not statistically significant. A very similar tailored nutrition intervention was also tested by Kreuter and Strecher (1996) to study 
whether tailored information about multiple health risk behaviors improved the effectiveness of a health risk appraisal. The tailored feedback significantly enhanced the impact of the health risk information on fat reduction. Two other studies were conducted in the Netherlands (Brug et al., 1996; Brug, Steenhuis, Van Assema, Gianz \& De Vries, in press). The first of these studies demonstrated that computer-tailored nutrition education was significantly more effective in motivating people to change their diet wards recom mendations than general nutrition education (Brug et al., 1996). Significant differences between subjects who received computer-tailored feedback and subjects who received general feedback, were found for changes in fat consumption, and attitudes and intentions towards increasing fruit and vegetable intake. In the second study, differences in impact between two computer-tailored interventions were investigated, an intervention in which computer-tailored dietary feedback was provided and a computer-tailored intervention in which dietary feedback plus psychosocial information was given. It was concluded that extensive psychosocial information was not essential for computer-tallored feedback to be effective but respondents who received the comprehensive feedback appreciated the feedback significantly more (Brug et al., in press).

In the present study, the impact of computer-tailored intrition education was compared to general nutrition information. The present study contributes to our further understanding of the potential of personalized computer-generated feedback by studying the impact of computer-tailored nutrition education beyond the short term. Furtiemore, the impact of ipsative feedback letters, tailored to changes in attitudes, intentions and dietary factors that subjects made after initial computer-tailored feedback, was assessed.

It was hypothesized that computer-tailored feedback would be more effective in stimulating participants to reduce their consumption of fat and increase their consumption of fruit and vegetables than general feedback. It was further hypothesized that ipsative computer-taillored feedback would significantly enhance the longer term dietary changes.

\section{Methods}

A randomized trial was conducted to study the impact of computer-tailored nutrition education as compared to general nutrition information. Participants were recruited through advertisements in 35 local newspapers in various Dutch regions, and in two national newspapers, and through appeals on local radio stations. Registration of participants was stopped after 800 subjects had enrolled. Participants were randomly assigned to one of three study groups (Figure 11:1) and received a screening questionnaire at their 
home addresses with whïch data were collected on dietary intake, self-rated intake, and psychosocial factors.

Based on their answers on the screening questionnaire, the first two groups received a computer-tailored nutrition education letter. The third group received a letter with general nutrition information. All participants were surveyed again with self-administered written questionnaires approximately four weeks after the first feedback. The first group recieved a second, ipsative feedback letter based on their answers to this first posttest questionnaire. All participants were again surveyed approximately four weeks after participants in Group 1 had received their second feedback letter (second posttest).

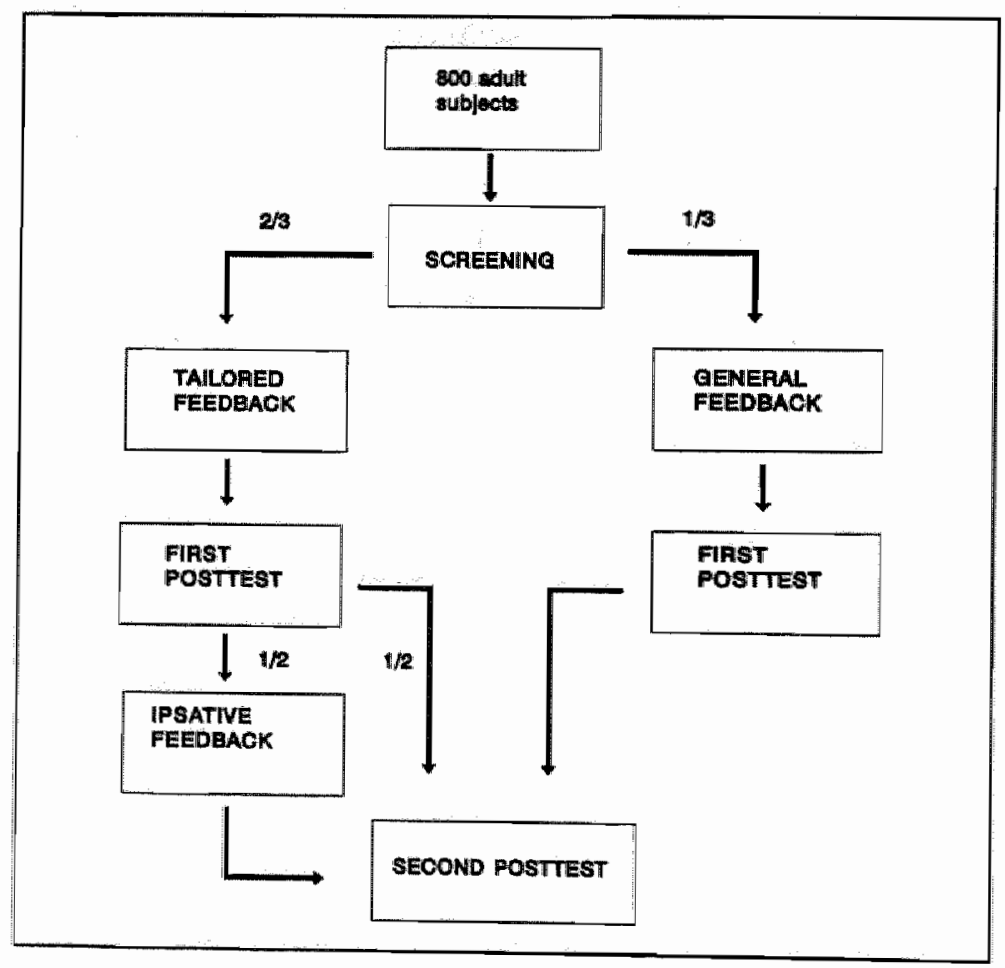

Figure 11:1. Study design 


\section{The questionnaires and intervention}

For providing subjects with computer-tailored nutrition education, three related elements are necessary: a screening instrument to assess variables on which the tailored feedback will be based, a message source file with feedback messages tailored to all possible screening results, and a computer program that selects specific feedback messages for each individual subject from the source file based on the screening results (see Chapter 8, figure 8:1).

The screening questionnaire

A 69-item self-administered written questionnaire was used to survey participants at baseline. The questionnaire took about fifteen minutes to complete. The questionnaire consisted of questions about the participants' sex, age, height, weight and education, a food-frequency questionnaire with which it is possible to assess consumption of fat, fruit and vegetables in a relative valid and reliable way, and questions to assess a number of psychosocial variables. Specific information about the validity of the food-frequency questionnaire has been published elsewhere (Brug, Lechner et al., 1995; Van Assema, Brug et al., 1992). From the food-frequency questionnaire a fat score can be computed that ranges between 12 and 60 which can be used to rank subjects according to absolute fat intake and to detect changes in fat consumption over time (Van Assema, Brug et al., 1992). For fruit and vegetable consumption the number of servings per day could be computed (Brug, Lechner et al., 1995).

In the second part of the questionnaire the subjects were asked to assess their personal intake levels of fat, fruit and vegetables and to compare their intake levels to that of others of their age-sex group. Further, they were asked about their attitudes toward reducing fat intake and increasing fruit and vegetables intake on 7-point very bad - very good scales, and about self-efficacy expectations towards the beforementioned dietary changes on 7-point very difficult - very easy scales. Finally, intentions, past and present efforts to change fat, fruit and vegetable consumption were assessed on 7-point definitely not - definitely so scales. The psychosocial questions were derived from questionnaires used in earlier research on psychosocial determinants of fat intake (Brug, Van Assema, Kok et al., 1994; Van Assema et all., 1993) and of fruit and vegetable intake (Brug, Lechner et al., 1995). 


\section{Posttest questionnaires}

Both posttest questionnaires were similar to the baseline questionnaire. Questions about the participants" sex, age, education, and other background factors were removed for the posttests and additional questions were included about the participants' reactions to the nutrition information letters.

\section{The message source file}

The message source file consisted of 223 different feedback messages. Different dietary feedback messages were written for various categories of dietary behavior for fat, fruit, and vegetables. For example for fat, the source file included messages for subjects eating more fat than is recommended but less than most of their peers, for subjects eating more fat than is recommended as well as more than most of their peers, and for subjects who were eating according to the recommendations for fat. The messages were also tailored to the way participants rated their own consumption: Messages for subjects who had high fat scores but thought that their fat consumption was low, differed from those for subjects who were aware of their high fat consumptions. Further messages were included that addressed six different important dietary fat sources in the Dutch diet (milk and milk products, meat and meat products, spreads, cheese, hot snacks, and sweet snacks), for which low fat alternatives for high fat choices were suggested. Participants received only information about fat sources that were salient in their personal diet. Fat scores of 22 for women and 25 for men were used as operationalizations of the upper levels of the Dutch recommended intake of $35 \%$ energy from fat. Fruit and vegetables messages were included for subjects eating less than the recommended amount of fruit and vegetables and subjects eating according to recommendations. One serving of vegetables per day and two pieces of fruit per day were used to operationalize the Dutch recommendations (200 grams of vegetables and two pieces of fruit per day). Messages also included suggestions on when and how to eat more fruit and vegetables. Subjects were advised to change their dietary behaviors that were not in accordance with recommendations and to sustain and if possible further improve their dietary behaviors that already met the recommendations.

Further messages were included in the source file that addressed possible negative outcome beliefs and messages intended to sustain positive outcome expectancies of fat reduction and increasing fruit and vegetable consumption. These messages were only included in the tailored letters for participants with negative attitudes. For subjects with low self-efficacy expectations, messages were selected from the source file with sugges- 
tions on how to eat less fat or more fruit and vegetables in various 'high risk" situations (when eating out, when eating alone, at parties, when in a hurry, etc.).

Ipsative feedback messages

A separate message source file was created with messages for the second, ipsative tailored feedback letters. Messages were included that addressed fat, fruit and vegetable consumption at the first posttest as compared to consumption at baseline. The messages differed according to the consumption levels as compared to the recommendations and according to changes that were made between baseline and first posttest. Specific tailored messages were written for participants who reduced their fat consumption or increased their fruit and/or vegetable intake between baseline and first posttest, for participants who increased their consumption of fat or decreased their fruit and vegetable intake, and for participants who did not change their consumption. Finally, messages that addressed (changes in) intentions were included. Furthermore, messages with information about the most important dietary fat sources and their low-fat alternatives, similar to those included in the initial tailored feedback, were included in the ipsative feedback source file.

\section{The tailoring computer program}

A computer program was written in Turbo Pascal (Borland International Inc., 1990) which linked individual screening results to specific feedback messages from the source file. The program consisted mainly of a number of so-called 'IF-THEN statements' which were the decision rules for the selection of specific feedback messages from the source file for individual subjects based on their answers on the screening questions. The computer program further regulated the production of personal feedback letters from the selected messages.

\section{Procedure}

In all groups participants received personal letters mailed to their home addresses after they completed and returned their baseline questionnaires. All letters were printed on identical paper that was designed for the tailored nutrition education letters. The participant's name was printed in the letter's introduction and in the final paragraph of the tailored letters. In the tailored letters as well as the general nutrition information letters, illustrative cartoons and recipes for low fat meals were included. The initial tailored letters consisted of four to eight pages. The general nutrition information letters were five pages long. Half of the participants who received computer-tailored feedback received a second, 
ipsative computer-tailored feedback letter tailored to the changes in intentions and diet between baseline and first posttest within two weeks after they completed the first posttest questionnaire. The ipsative feedback was printed on identical paper and was between two and four pages long. Approximately four weeks after these participants received the ipsative feedback, a final posttest questionnaire was send to all participants. Other respondents did not receive any contact between the first and second posttests.

\section{Statistics}

Analysis of variance was used to test for baseline differences between the three study groups in order to detect possible confounding variables and to detect differences in baseline scores between subjects who participated in the entire experiment and subjects who dropped out before the final posttest.

Chi-square tests were used to study differences in the participants' reactions to the nutrition information letters between the three study groups. Descriptive statistics were used to describe the reactions of the participants to the ipsative feedback letters.

Analyses of co-variance were used to test for differences between the study groups in mean posttest intake of fat, fruit and vegetables adjusted for baseline intake levels. T-tests were conducted to study differences in intake within study groups between baseline and both posttests. Differences with $\mathrm{p}<.05$ were considered as statistically significant, except for the T-tests, where a p-value of .01 was used because of the relatively large number of T-tests that were conducted.

\section{Results}

\section{Participants and respons-rate}

The baseline questionnaire was completed and returned by 762 subjects. The first posttest questionnaire was returned by 704 subjects. The final posttest questionnaire was returned by 646 subjects, who therefore completed the entire experiment. All analyses were conducted among these participants. Mean age (SD) was 44 (14) years. A majority of participants ( $82 \%$ ) was female. Forty-two percent of the study population had a college degree, which indicates that the study population was relatively highly educated.

\section{Differences at baseline}

No significant differences between the study groups in age, education, body mass index, or sex distribution were found. At baseline no differences in mean intake of fat, 
fruit and vegetables or in attitudes and intentions were found between the three study groups. No difference in drop-out rates between the three study groups were found and no significant differences between subjects who completed the experiment and those who dropped out after completing the baseline questionnaire were found in socio-demographics, mean dietary intake, and intentions.

Table 11:1

Participants' reactions to, and the subjective impact of, the tailored letters $(\%$ yes)

\begin{tabular}{|c|c|c|}
\hline & $\begin{array}{l}\text { Taillored feedback } \\
\qquad(n=426)\end{array}$ & $\begin{array}{l}\text { General information } \\
\qquad(\mathrm{n}=220)\end{array}$ \\
\hline Have you read the letter? & 99 & $93^{* *}$ \\
\hline Have you saved the letter? & 85 & 80 \\
\hline Have you discussed the letter with others? & 71 & $45^{\circ-}$ \\
\hline \multicolumn{3}{|l|}{ As a result of the nutrition information... } \\
\hline ... have you changed your opinion about your diet? & 62 & $26^{\circ-}$ \\
\hline ... have you changed your diet? & 56 & $19^{\circ *}$ \\
\hline .... have you reduced your fat intake? & 55 & $18^{* *}$ \\
\hline ... have you increased your fruit intake? & 20 & $13^{*}$ \\
\hline ... have you increased your vegetable intake? & 29 & $18^{* *}$ \\
\hline ... do you intend to change your diet? & 69 & $46^{* *}$ \\
\hline
\end{tabular}

"significant difference, $\mathrm{p}<.05$

-significant difference, $\mathrm{p}<.01$

Reactions to the first nutrition information letters

The respondents' reactions to the nutrition information they received after the screening is shown in Table 11:1. Respondents who received a tailored letter were more likely to have read the letter and to discuss it with others. They more often reported changing their diet, their opinion about their diet, or intending to change their diet as a result of the nutrition information letter they received. 
The respondents' opinions of the nutrition information letters is shown in Table $11: 2$. Respondents who received tailored feedback letters rated their letters as more interesting, more personally relevant, and containing more information that was new to them. The general information letters were rated as more credible.

Table 11:2

Participants" opinions of the feedback letters (mean scores)

\begin{tabular}{lcc}
\hline Range $=-3$ (very negative) to 3 (very positive) & $\begin{array}{c}\text { Tailored feedback } \\
(\mathrm{n}=426)\end{array}$ & $\begin{array}{c}\text { General feedback } \\
(\mathrm{n}=220)\end{array}$ \\
\hline How interesting was the tailored letter? & 1.73 & $0.79^{-*}$ \\
How personally relevant was the nutrition information & 1.15 & $-0.17^{-*}$ \\
letter? & & $-1.60^{-*}$ \\
How much of the information was new for you? & -0.44 & $1.98^{-*}$ \\
How credible was the information? & 1.49 & 2.60 \\
How difficult or easy to understand was the information? & 2.51 & \\
\hline
\end{tabular}

- significant difference, $\mathrm{p}<.01$

\section{Reactions to the ipsative feedback}

A large proportion of respondents who received ipsative feedback were positive about these feedback letters. Ninety-nine percent of the respondents in the ipsative feedback group reported reading the ipsative letter, $84 \%$ said they saved the letter, whille $65 \%$ stated having discussed the letter with other people. Equally large proportions found the ipsative letter interesting $(71 \%)$, personally relevant $(68 \%)$, and reported having changed their diet as a result of the nutrition information $(73 \%)$.

\section{The impact of tailored feedback}

Table 11:3 presents the mean fat, fruit and vegetable intake at baseline, first posttest and final posttest for the three experimental conditions. 


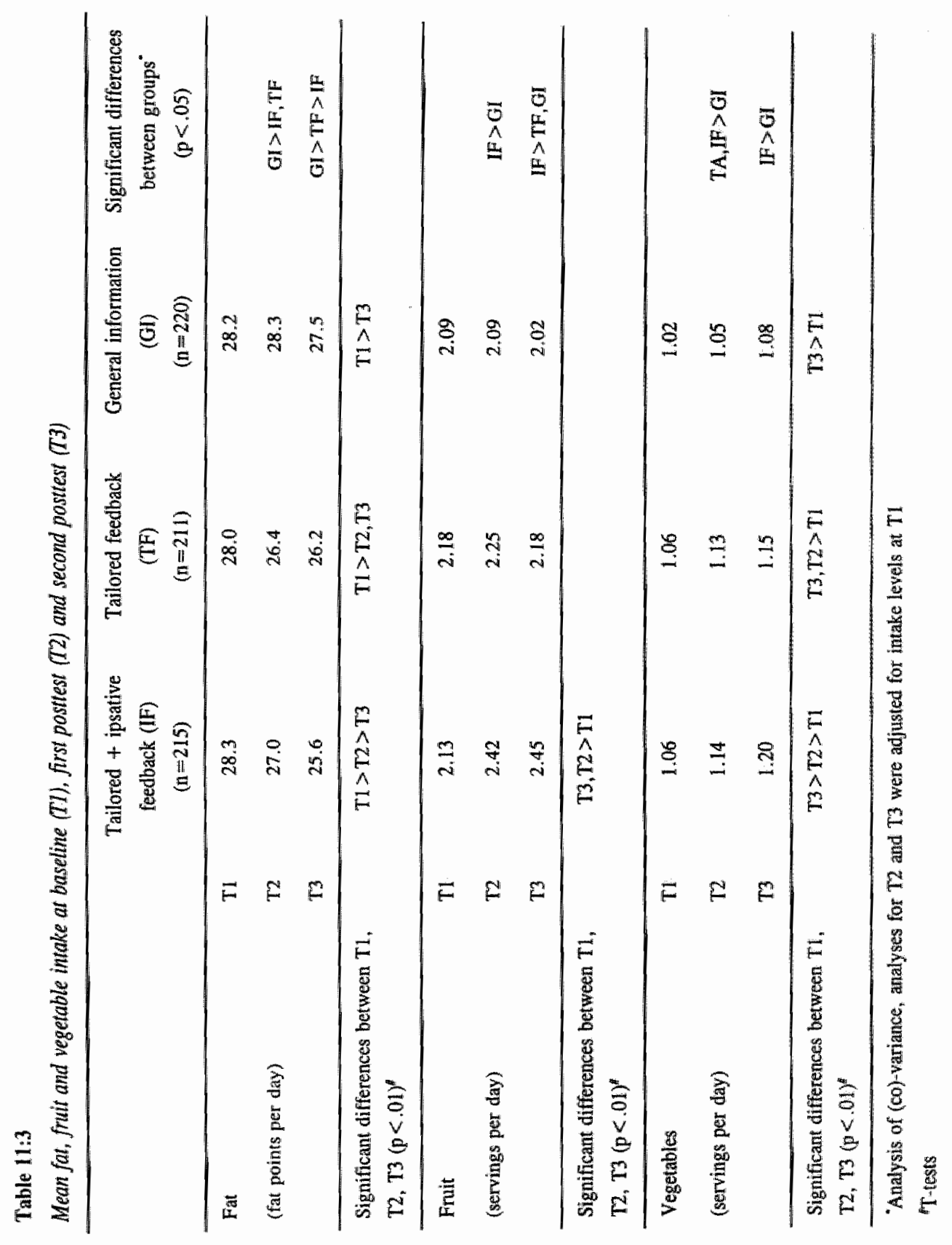


In all three study groups a significant reduction in mean fat intake and an increase in mean vegetable consumption was found between baseline and the final posttest. An increase in mean fruit intake between baseline and posttest was only found among respondents in the ipsative feedback group.

At the first posttest, respondents who received tailored feedback had significantly lower mean fat scores and higher vegetable intake than respondents in the general information group.

At the second posttest, respondents who received ipsative feedback had significantly lower mean fat scores than respondents in both other groups. Respondents who had received the initial tailored feedback but no ipsative feedback, had significantly lower mean fat scores than respondents in the gemeral information group. Mean fruit intake was significantly higher among the ipsative feedback group as compared to both other groups and respondents who received ipsative feedback had a significantly higher mean vegetable intake than respondents in the general information group.

\section{Discussion}

A significant impact of computer-generated personalized feedback on fat reduction and increasing fruit and vegetable intake was found. Furthermore, a second feedback letter, tailored to (a lack of) changes that respondents made in intake and intention after they had received their first tailored letter, led to a further reduction in fat and increase in vegetable consumption. The results are in line with earlier studies on the impact of computer-tailored nutrition education (Brug et al., 1996; Campbell et al., 1994; Kreuter \& Strecher, 1996). Respondents who received tailored feedback were also more positive about the feedback they received: They perceived their feedback to be personally relevant and interesting. This might explain the higher impact of tailored feedback as compared to general information. Since subjects have a limited capacity to process information, it is important to provide them with the information that is worth the processing effort (Rudd \& Glanz, 1990). Furthermore, personally relevant feedback is less likely to contain redundant information. Subjects are therefore more likely to have attention for the information that is provided to them. Attention to the message is an essential prerequisite for effective health messages (McGuire, 1985).

Respondents who received general information judged the information they received to be more credible than respondents who received tailored feedback. This might be explained by the fact that many respondents in the tailored group who received a message 
to reduce their fat intake because it was higher than recommended, perceived their personal fat intake to be low or moderate. This discrepancy between their self-assessed fat intake and their actual fat score, which was presented to them in their personal feedback letter, may have caused the relatively low mean credibility score among respondents in the tailored groups. Additional analysis showed that respondents with a relatively large discrepancy between their self-rated fat intake and fatscore indeed rated their feedback as significantly less credible than other subjects $(F=5.14, p=.02)$.

Ipsative feedback, which informed the respondents about possible progress they made towards the recommendations after they had received an initial feedback letter, proved to significantly enhance the longer term impact of tailored feedback. Feedback, or knowledge about the results of one's performance, is regarded as an important determinant of motivation to change or to maintain changes made in the past. Feedback has been found to have this positive effect, especially in combination with goal-setting (Locke \& Latham, 1990). In the present study, respondents were motivated to change their diet by, among other things, suggesting specific aims for fat reduction and increasing fruit and vegetable intake. The positive impact of the ipsative feedback letters suggests that a fare number of respondents adopted these suggestions as personal goals. A limitation of the study is that subjects who did not receive ipsative computer-tailored feedback were not provided with some sort of alternative intervention activity or equivalent control for the amount of contact or attention.

In earlier studies on the impact of computer-tailored nutrition education, respondents were derived from, for example, worksites (Brug et al., 1996) or general practices (Campbell et al., 1994). In these earlier studies, employees or patients did not have to register before being provided with a screening questionnaire. In the present study, subjects were recruited through advertisements in local newspapers. People who were interested in participating, had to register by calling a telephone number before they received a screening questionnaire. This procedure may have consequences for the generalizebility of the results, since a specific group of subjects may have enrolled in the present study. Nevertheless, mean intake of fat, fruit and vegetables was comparable to consumption levels found in an earlier study in which the same instruments to assess food consumption were used (Brug et al., 1996). This indicates that the slection procedure in the present study did not result in specific healty or unhealthy eating study population but the fact that women were over-represented in the present study is probably the results of the selection procedure. 
The changes in consumption that were found between baseline and final posttest were reasonably large for fat as well as fruit intake. Mean fat score decreased with approximately $10 \%$ between baseline and final posttest among respondents who received ipsative feedback. The increase in fruit intake in this group was about $15 \%$. These changes do certainly seem to be relevant from a public health perspective. A $10 \%$ reduction in fat intake among the general Dutch population has been the goal of a multi year government sponsored national intervention in the Netherlands (Riedstra et al., 1993). Computertailored feedback may be a useful intervention tool in reaching that goal.

The results of the present study confirm and extend earlier findings that computergenerated individualized nutrition education is more effective in inducing dietary change than general nutrition information. Furthermore, the results suggest that ipsative feedback enhances the impact of computer-tailored nutrition education. 


\section{General Discussion}

\section{Introduction}

In the final chapter of this thesis the different studies that have been described in the preceding chapters will be integrated. In doing so, I hope to make clear that this "book" is useful in that it brings together a number of related studies and that the integration of these studies is more than the separate chapters of which the majorty was, or will be, published as research articles in different scientific journals. Therefore, the different studies will be discussed in relation to each other and, hopefully, it will become clear why each study logically followed from the findings of the preceding one. Furthermore, conclusions will be drawn based on the integrated results and about the generalizibility of the research findings.

In this thesis the motivation for, and the development and evaluation of computertailored nutrition education has been presented. The different studies that have been described, followed the pattern of the Model for Planned Health Education Interventions (see General Introduction, figure 1; Green \& Kreuter, 1991) in three parts: problem analysis, psychosocial determinants, and the interventions. This final chapter consists of three paragraphs that reflect the three parts of the thesis.

\section{Problem Analysis}

In the first part of the thesis a literature study has been described in which a number of studies on the association between diet and cardiovascular disease risk and cancer risk were reviewed. Based on this review, it was concluded that certain specific dietary factors are related to (prevention of) cardiovascular disease and certain cancers (Willett, 1994) which are the most important chronic diseases in the Netherlands in terms of montality (Stuurgroep Toekomstscenario's Gezondheidszorg, 1994). More specifically, there are strong indications based on scientific research that consumption of large amounts of saturated fat is associated with cardiovascular disease risk (Shrapnel et al., 1992). The strongest epidemiologic evidence for an association between diet and cancer risk has been found for the preventive effect of consumption of fruit and vegetables (Block, 1991).

Before the 1970 's, dietary advice for the general public in Westernized countries has been aimed at helping people to meet certain recommended daily requirements in times of 
scarcity in order to prevent nutritional deficiencies. In the last decades, dietary advice has gradually been revised to stimulating people to be prudent by restricting intake of especially fat in times of abundance (Nestle, 1995). More recently, the recommendation to eat more of certain food products or food components, i.e. to eat more fruit, vegetables and dietary fiber, has again received more attention from nutrition educators (Havas et al., 1994). Although the associations between these dietary factors and chronic disease risk have been studied in more detail and the results of these studies have given us more insight in the specific associations between fat, fruit and vegetable consumption on the one hand and risk for coronary heart disease and cancer on the other hand, the essence of the issue, and therefore the practical implications for nutrition educators, has remained the same: eat less fat and more fruit and vegetables. Therefore, implementation of the recommendations to eat less (saturated) fat and plenty of (fresh) fruit and vegetables are now the most important goals for nutrition education aimed at primary prevention of chronic diseases (Willett, 1994). A substantial proportion of the Dutch population eat less fruit and vegetables and more (saturated) fat than is recommended in the Dutch dietary guidelines (Hulshof et al., 1994; Voedingsraad, 1986a). Because of these substantial discrepancies between the general Dutch diet and dietary recommendations, there are opportunities for nutrition educators to contribute to primary prevention of coronary heart disease and cancer by stimulating and helping the Dutch public to change their diets towards the recommendations.

\section{Determinants of Fat, Fruit and Vegetables}

An important consideration for health educators is that someone's health behavior is directly influenced by a number of psychosocial factors that are referred to as psychosocial determinants of behavior. When these psychosocial factors can be changed, the related (health) behavior will change. In this behavior change process a number of distinctive stages can be distinguished. There are different theoretical determinant models and stages of change models that have been used to predict and describe health behavior (change) (for reviews, see Glanz \& Eriksen, 1993; Glanz \& Rudd, 1993; Kok, Schaalma, De Vries, Parcel \& Paulussen, in press). In this thesis, the Attitude - Social influences self-Efficacy (ASE-) model (De Vries et al., 1988; Kok et al., 1991), which is very similar to the Ajzen's Theory of Planned Behavior (Ajzen, 1991), and the Transtheoretical Model (Prochaska et al., 1992) were used as a framework to study which psychoso- 
cial factors are important determinants of (changing) consumption of fat. fruit and vegetables in the Netherlands.

The ASE-model implicates that behavior is a result of behavioral intention. Three psychosocial factors have been identified that predict (health-related) behavioral intention: attitudes, social influences, and self-efficacy. A person's attitude towards a specific behavior is a reflection of the most important consequences that person expects from performing the behavior. Social influence is a result of social norms relevant to the behavior, support from others to perform or refrain from the behavior, and whether important others perform or refrain from the behavior themselves (modeling). Selfefficacy expectations are a reflection of a person's beliefs whether he can perform the desired behavior in different situations. The ASE-model implicates that a person's health behavior can be changed, by changing attitudes, social influences and self-efficacy expectations (De Vries et al., 1988).

\section{Attitudes}

At the start of the research project that is described in this thesis, hardly any reports on determinant studies on fruit and vegetable consumption had been published. In our studies into the determinants of fruit and vegetable consumption, which are described in chapters 5 and 6 of this thesis, we found that attitudes were a significant predictor of consumption of salads and boiled vegetables but not of fruit intake. Nevertheless, attitudes were significantly less positive among subjects in the lowest consumption tertile as compared to subjects in the highest consumption tertile for fruit (Brug, Lechner et al., 1995). Further analyses to assess differences in specific attitudinal beliefs between 'high' and 'low' consumers showed that for consumption of boiled vegetables, consumers in the highest intake tertile had more positive beliefs about general healthfulness, about taste. and less often thought that boiled vegetables contain high amounts of pesticide residues. Respondents in the highest consumption tertile for salads had more positive beliefs about taste, health consequences, vitamin content, digestibility, and pesticide residues as compared to the lowest consumption tertile. For fruit consumption, there were differences in beliefs about health consequences and taste between the highest and the lowest consumption tertile. Interventions aimed at stimulating fruit and vegetable consumption through attitude change should focus on changing these beliefs.

Stafleu and colleagues (1991) published a review of studies investigating the psychosocial determinants of different aspects of fat consumption. The authors concluded that attitudes had most frequently been examined as predictors of fat consumption and in most 
of these studies reasonable correlations between attitudes and intentions or behavior were found. Relatively high and significant associations between attitudes and behavior for fat consumption were also found in the studies described in this thesis.

According to Stafleu et al. (1991), the most important attitudinall belief related to fat consumption was "liking". People who like (the taste) of high fat food products are inclined to eat those products. Beliefs about health consequences were also important but of a lesser extent than beliefs related to taste. Other significant beliefs related to fat consumption and fat reduction, were beliefs about low-fat meals being expensive and more difficult to prepare. These beliefs should be addressed in nutrition education aimed at attitude change towards low fat diets.

\section{Social influences}

The associations between social influences and fat consumption are generally found to be smaller as compared to attitudes (Stafleu et al., 1991). Although, in a study recently reported by Paisley and colleagues, subjective norm appeared to be the strongest predictor of intention to make a number of specific dietary changes aimed at fat reduction (Paisley, Lloyd, Sparks \& Mela, 1995), in general social norms have been found to be poor predictors of dietary behaviors (Staflen et al., 1991). Therefore, two other forms of social influences were investigated in our studies: modeling, which was operationalized as the perceived behavior of important others, and social stimulation. Behavior of important others proved to be an important correlate of fat consumption: Subjects with relatives and close friends who they perceived to eat a lot of fat were more likely to have high fat intakes themselves. Furthermore, results from secondary analyses that are not described in the thesis but were published elsewhere (Brug, Van Assema et al., 1995) revealed that social support, especially from their partner, was a significant predictor of intention to reduce fat consumption among men. A similar finding was reported based on a study conducted in the UK in which the respondents' spouses were identified as having the strongest influence on their food choices (Paisley et al., 1995). In a study conducted in Norway, social norms of different social groups (partners, parents, friends and coworkers) on respondents" food choices were investigated (Øygard \& Klepp, 1996). Social norms of partners were identified as the strongest social norm on healthy eating patterns for both men and women and social norms of friends. were significantly associated with women's food choices. However, the contribution of social norms of partners to the total explained variance of a healthy eating score in a stepwise regression analysis was small. 
In a study conducted in the U.S., encouragement from family and friends to eat fruit and vegetables was not significantly associated with consumption (Krebs-Smith et al., 1995).

In our studies, social influences (modeling and social support) proved to be significantly associated with consumption of salads but not with consumption of boilled vegetables or fruit. The association with fruit and vegetable consumption was weaker for social influences as compared to attitudes or self-efficacy expectations (Brug, Lechner et al., 1995).

The fact that social influences have repeatedly been found to be relatively weak predictors of dietary behavior might be contradictory to what one would expect, since dietary behavior is often social behavior. It has been proposed that the reason for the relatively small predictive power of social influences could be due to the way social influences are measured (Stafleu et al., 1991). In determinant research often selfadministered questionnaires or telephone interviews are used to collect data. Since social influences might be mainly subconscious, asking people about the influences they experience might not be a valid way to assess social influences. Furthermore, in our individualized society it might not be socially desirable to admit that others influence one's own dietary behavior. Experiences from the studies described in this thesis support this presumption: The questions on social stimulation were often given a neutral answer and respondents often wrote remarks on the questionnaires indicating their doubts about the relevance of these questions. Nevertheless, because of the clear resemblance in consumption patterns between family members that has been found in studies conducted in the Netherlandls (Feunekes, 1996; Stafleu, Van Staveren, De Graaf, Burema \& Hautvast, 1994), and the predictive power of modeling that was repeatedly found in this thesis, there are indications that social influences might be more important than has been concluded in research on social norms as assessed with questionnaire items (Stafleu et al., 1991). It should be concluded that, although social influences are potentially important ideterminants of dietary behavior, it is still unclear how these social influences should be measured and how these social influences should be addressed in health education interventions.

\section{Self-efficacy expectations}

The association between self-efficacy expectations and dietary behavior has been studied less frequently as compared to the other determinants. In the studies described in chapter 2 and 6 of this thesis, self-efficacy was significantly associated with fat consump- 
tion and self-efficacy expectations were the strongest correlate of intention to consume frixit, sallads and boiled vegetables.

In their review, Stafleu et al. (1991) concluded that the number of studies on selfefficacy and diet are too few to draw conclusions about the importance of self-efficacy as a determinant of dietary behavior. The studies on self-efficacy in relation to dietary behavior have shown inconsistent results. In a study by Sparks et al. (1992), perceived control, which is similar to self-efficacy expectations (Ajzen, 1991), was of less significance as a determinant of consumption or intention to eat wholemeal bread and biscuits than attitudes were. However, Shannon et al. (1990), concluded that self-efficacy was at consistent determinant of eating behavior and of changes in eating behavior over time. Sheeshka et al. (1993) found a relatively strong and significant association between selfefficacy and the intention to adopt healthy eating practices. Raats et al. (1993) found inconsistent results for the association between perceived control and intention to use different kinds of milk. The inconsistencies in the reliation between self-efficacy or perceived control and intention to perform a specific dietary behavior might be attributed to different causes. First, different dietary behaviors were studied and relations between selfefficacy expectations and one specific dietary behavior are not necessarily predictive of self-efficacy - behavior relations for other dietary behaviors. A second reason for the inconsistencies might be the different ways in which self-efficacy has been measured in the various studies. For example, Raats et al. (1993) used a single questionnaire item to measure perceived control in a general matter while Sheeshka et al. (1993) used 11 items to measure self-efficacy in specific "high risk" situations. According to Bandura (1986), in order to increase its predictive power, self-efficacy should be assessed in relation to specific behaviors in specified situations. Furthermore, if self-efficacy is measured in relation to changing dietary behavior towards a specific dietary recommendation with which the subjects have no experience, relations with behavioral intention might be different than for "habitual' dietary behaviors.

Some specific situations that were perceived to be difficult to eat fruit or vegetables were identified. People with diets low in fruit and vegetables were least confident to manage to include fruit and vegetables in their diet when in lack of time, in weekends and when alone. For fat reduction, weekends, seeing other people eat, parties, and going out for dinner were identified as situations in which people found it difficult to reduce their consumption of fat. These situations should be taken into account in designing health messages aimed at fat reduction. 


\section{Habit}

A possibly important predictor of dietary behavior that was not addressed in this thesis is 'habit'. It has been argued that behavior performed repeatedly over a long period of time, like dietary behavior, becomes habitual (Ajzen, 1991). In such situations, the 'reasons' for practicing a certain behavior might not be of relevance anymore. Therefore, habitual behavior may be less well predicted by attitudes, social influences, and/or selfefficacy expectations (Triandis, 1977). It has been proposed to include habit as an independent variable in determinant modeis. A first reason for not including habit in our studies is a practical one: Habit is usually operationalized as "prior behavior". In the studies reported in this thesis, dietary behavior was measured in a retrospective way: respondents were asked what they had eaten during the weeks before administering the food frequency questionnaire. Therefore, operationalizations of behavior and prior behavior would be the same. Furthermore, Ajzen argued that prior behavior itself is a reflection of internal and external factors like attitudes, social norms and perceived behavioral control (Ajzen, 1991). A further argument to not include habit as a possible independent determinant of dietary behaviors is the impossibility to change prior behavior. Therefore, habit, defined as prior behavior, is not a suitable target for nutrition education. Nevertheless, habitual dietary behaviors might be very difficult to change and it is important to keep this in mind when setting specific goals for nutrition education interventions.

\section{Awareness}

In recent stages of change models like the Transtheoretical Model (Prochaska \& DiClemente, 1992), the concept of awareness of risk behavior has been recognized as important in adopting preventive behavior. The Transtheoretical Model suggest a framework for understanding readiness to adopt healthy behavior. A central construct in this model is stages of change: five separate stages through which people may progress toward long-term positive health behaviors. People may be in precontemplation (not (yet) considering the desired behavioral change), contemplation (considering change), and preparation (actually planning change), action (actively changing), or maintenance (maintaining desired behaviors). In the Transtheoretical Model, awareness of risk behavior is seen as essential in the transition from pre-contemplation to contemplating changing the risk behavior (Prochaska \& DiClemente, 1992). The essential role of awareness of personal 'risk behavior' in the earlier stages of change has been further specified in the so-called 'precaution adoption process' as described by Weinstein (1988). He 
argues that there are three levels of awareness of risk behavior. People who have reached the first level of awareness have heard about the risk (behavior), they are aware of the association between behavior and risk. In relation to fat consumption this would mean that people are aware of the fact that too much fat is bad for health. At the second level of awareness, people are aware that (a lot of) other people participate in the risk behavior: They know that other people eat too much fat. At the third level of awareness people realize that they take part in the risk behavior themselves: They realize that their personal fat intake is too high. According to the model, only after this third level of awareness of risk behavior has been reached, people will contemplate changing their risk behavior (Weinstein, 1988).

The determinant studies described in chapters 2,3 and 7 , revealed that a large proportion of the Dutch people are unrealistic about their personal dietary habits and especially underestimate their dietary 'risk behavior': They think that they do not eat too much fat and that they eat enough fruit and vegetables while they are not meeting the recommended intake levels. This high prevalence of misconception of personal dietary intake is important in two ways:

In the first place, coherent with Weinstein's precaution adoption process, misconception of personal dietary intake levels was shown to be a barrier for nutrition education. People who think that their diet is adequate were less likely to intend to change their diet towards the recommended intake levels: Underestimation of fat consumption proved to be a significant predictor of no intention to reduce fat intake among women in one of the studies described in chapter 2 of this thesis (Brug, Van Assema, Kok et al., 1994) and this finding was replicated in a predominantly male sample (Brug \& Kok, 1995). Secondly, misconception of fat consumption might also have implications for the usefulness of theoretical models like the ASE-model that are often used to predict dietary behavior. The fact that awareness of personal risk behavior has not been emphasized in the ASE-model as determinant of behavior or behavioral change might be explained by the fact that the model has been used in particular to predict and explain more overt behaviors like for example smoking (De Vries et al., 1988; De Vries \& Backbier, 1995). Since everybody will be aware of the fact whether he or she smokes or not, awareness of participating in risk behavior is not an issue. There might be lack of awareness about the risky consequences of smoking but it seems hardly possible that people are unaware about their smoking behavior. For dietary behavior things are less obvious. Consumption of fat, for example, is not one behavior, but is the results of consumption of numerous food 
products that can be prepared in various ways and eaten in many combinations. This makes the assessment of one's own fat intake difficult.

Our study showed that among subjects who are unrealistic about their fat intake levels, determinants like attitudes, social influences and self-efficacy expectations - that have repeatedly been found to be important predictors of human behavior - were not associated with dietary intake. As long as subjects do not know how much fat they eat and think of their fat intake as coherent with recommended intake levels, their attitudes, perceived social influences, and self-efficacy expectations reflect what they think they eat and are less strongly related to what they actually eat. This might result in the phenomenon that has been found repeatedly among the Dutch population (Brug \& KoK, 1995) and also in a study reported in this thesis (Chapter 2; Brug, Van Assema, Kok et al., 1994): Although people have positive attitudes towards low fat diets, perceive positive social influences towards eating low fat diets, and have high self-efficacy expectations in relation to eating low fat diets, they continue to eat too much fat. The implication is that, in agreement with Weinstein's model, psychosocial determinants of dietary behavior that are often targeted in nutrition education campaigns will only become relevant after people have become aware of their dietary intake levels.

The phenomenon that people overestimate the adequacy of their personal diet was also found in relation to fruit and vegetable consumption although to a lesser extent (Brug \& Lechner, 1995; Brug, Glanz \& Kok, in preparation). Furthermore, the lack of predictive power of the attitudes, social influences, and self-efficacy expectations among unrealistic subjects was also replicated in relation to fruit and vegetable consumption (Lechner, Brug \& De Vries, in preparation). However, the problem with misconception related to fruit. and vegetable consumption might be somewhat different from fat since fat is a nutrient and fruit and vegetables are food products. Food products are much easier to recognize than nutrients and one's intake of certain food products is therefore easier to assess than nutrient intake especially when that nutrient is present in such a large number of different food items as is the case for fat. This presumption is supported by research reported on by Krebs-Smith et al. (1995). In their study on psychosocial correlates of fruit and vegetable consumption they found that subjects who wrongly estimated their consumption to be adequate are often not familiar with the recommendations for desirable intake level. This implies that misconception of fruit and vegetable consumption might be caused by unawareness of desirable intake levels and not by difficulties in assessing one's own intake. The fact that people in the Netherlands less frequently show misconception of fruit consumption, for which the recommended consumption is straightforward (two pieces per 
day), than for vegetable consumption, for which the recommendation is more complicated (200 gramis per day), supports this hypothesis (Brug \& Kok, 1995).

Dietary behavior might be one of the most difficult health related behaviors for people to make self-assessements about. Nevertheless, the role of awareness of personal health behavior might not be restricted to dietary behavior. Physical exercise, safe sex practices, safe driving are just a few examples of health related behaviors for which it might also be difficuit to estimate the adequacy of one's own behavior. It may be recommendable to take a possible role of misconception of risk behavior into account in future determinant studies aimed at explaining these behaviors and in future interventions aimed at stimulating people to act more prudent.

\section{Stages of change}

Apart from the implication that awareness of dietary intake levels should be reached before subjects will theoretically leave the precontemplation stage of dietary behavioral change and other psychosocial factors become important predictors of dietary change, there are indications that the relative importance of attitudes, social influences and selfefficacy expectations might also differ between the various stages of change (De Vries \& Backbier, 1995). In order to find out which of the psychosocial factors should be influenced in which stage of dietary change in order to motivate people to adopt healthier diets, differences in dietary intake, perceived dietary intake levels, attitudes, social influences and self-efficacy expectations between respondents in the different stages of change were studied (Chapters 4 and 7). Similar patterns were found for fat, fruit and vegetables. The results showed that attitudes and social influences tended to become more positive from precontemplation to preparation and action while self-efficacy expectations were lowest among subjects contemplating or preparing dietary changes. It was concluded that for people to start contemplating changes they not only have to be aware of the need for personal changes but should also have a positive attitudes towards the required changes. Furthermore, when people start to contemplate and prepare to change their diet, they might become aware of possible difficulties in making the changes which may result in lower self-efficacy expectations. Only when they think that they can overcome these difficulties, people will actually start changing their diet. 


\section{Implications for Nutrition Education}

Based on the determinant studies, it is concluded that interventions for fat reduction and stimulating fruit and vegetable consumption should be aimed at making people aware of their present dietary behavior, creating more positive attitudes towards the recommended dietary changes and increasing self-efficacy expectations. These intervention goals are stage-specific. Therefore, interventions should be tailored to stages of change. Subjects in precontemplation should first be made aware of their dietary risk behaviors. These subjects should be offered an easily accessible opportunity to assess their consumption of fat, fruit and vegetables and to compare their intake to dietary recommendations. Only when people know their intake levels, will they be able to decide whether the recommended dietary changes are of personal relevance. But awareness of personal dietary intake levels is not sufficient to make people start to contemplate to eat less fat and more fruit and vegetables. A second step in the behavior change process towards contemplation can be stimulated by giving people information about the positive consequences of changing their diet towards the recommended intake levels in order to create more positive attitudes. Messages about the possibilities to adopt a good tasting diet with less fat and more fruit and vegetables, and messages about the positive health consequences of the recommended changes should be communicated.

Chances are high that when people are aware of the need to change and have positive attitudes towards recommended changes, they will contemplate dietary change. Before people will actually start to change their diet they must be sufficiently confident that they will be able to make the required changes. Information that enhances people's selfefficacy towards fat reduction and increasing fruit and vegetable intake should be made available to people in contemplation. Especially practical information should be given about how to make the required changes in a relatively easy way and about how to cope with situations in which it might be difficult to eat less fat and more fruit and wegetables. Situations in which people eat alone or when they have lack of time are circumstances in which people have difficulties to adopt or maintain healthier eating patterns. Therefore, information about healthy cooking and healthy eating that requires little time and effort might stimulate people to actually change their diet. Furthermore, people should be provided with information that enables them to identify the most important fat sources in their diet and to select low fat alternatives. 
A so-called computer-tailored nutrition education instrument was developed in the course of this project. With this intervention tool individual subjects could be provided with information about their personal consumption levels as compared to their peer group average intake levels and recommended intake levels. Furthermore, information could be given that was hailored to the subjects' personal attitudinal beliefs and self-efficacy expectations. The computer-tailored feedback proved to have a significantly greater impact on changes in consumption, intentions and/or attitudes than general mutrition information. It was argued that with individualized feedback, misconception about personal dietary behavior could be reduced so that subjects would start to contemplate dietary changes. By presenting additional information, like suggestions on how to reduce personal dietary risk behaviors and information about pros and cons of dietary behaviors and dietary changes, we tried to motivate subjects to go further in the behavior change process to preparation and action. Furthermore, because the feedback letters were tailored to personal dietary intake and personal beliefs, the letters were made relevant for subjects in all possible stages of dietary change. Subjects in precontemplation who were not aware of their dietary risk behavior(s) received information about their dietary intake and were made aware of the discrepancy between their intake data and their self-rated consumption patterns. For subjects in precontemplation who were aware of, for example, their high fat intake, information about the positive consequences of fat reduction was included to motivate them to start contemplating fat reduction. For subjects who were, or started, contemplating change, the additional suggestions on how to reduce their consumption of fat was meant to help them make actual plans to start to change and to realize these changes.

The first two experiments on the impact of computer-tailored nutrition education that were described in this thesis, were conducted in worksite settings. The workplace has several advantages for implementing healthy diet promoting activities (Glanz \& SeewaldKlein, 1986; Glasgow \& Terborg, 1988; Heimendinger et al., 1990; Green \& Kreuter, 1991). The workplace offers the opportunity to communicate with individuals on a regular basis over extended periods of time. This is especially useful for computer-tailored health education where participants have to be screened before a tailored letter can be provided. When more than one tailored letter is planned based on different screening moments, a setting where participants can be repeatedly reached over a longer period of time is even more convenient. Furthermore, the workplace facilitates reaching population groups who 
would otherwise not come into contact with nutrition education, e.g. men and subjects from lower socio-economic groups. This was confirmed in the experiments: The experiment that was conducted among employees of the Royal Shell Laboratory showed that a large proportion of male employees were willing and motivated to participate in computer-tailored nutrition education and that the majority of the participants was positive about the computer-tailored feedback letters they received. In the experiment among employees of the Regional Home Care organization we found that participants with lower education were more satisfied with the computer-tailored intervention than higher educated participants. Workplace programs have proven to be easily accessible, especially when part of the participation in health promotion activities can take place during working hours (Breslow, Fielding, Herrman \& Wilbur, 1990). When companies would be willing to allow employees to fill. in their screening questionnaire during work time, participation might be further improved. A further advantage of implementing healthy diet promoting programs at the workplace is the possibility to implement regulations and to supply measures in addition to nutrition education, in order to create a complete health promotion program (Green \& Kreuter, 1991). Computer-tailored health education offers good opportunities to be used in combination with other health promoting activities. The tailored intervention might even be used as a means to refer to other health promotion activities that are implemented at the worksite. Finally, healthy diet promoting programs at the workplace offer the possibility of encouragement from the company management or from peer workers to participate in the interventions, thus creating a positive social environment for dietary behavioral change (Biglan \& Glasgow, 1991). Explicit encouragement is sometimes intensified through incentives offered to successfully participating subjects. The long term beneficial effect of incentives in health promotion is, however, doubtful (Green \& Kreuter, 1991). In the experiments that we conducted within worksites, encouragement from the company management was used by announcing the project through company newsletters in which the program was described and in which it was made clear that the company was actively participating in the project and wanted to encourage all employees to participate by filling in the screening questionnaire they received. Furthermore, the introductory letters that accompanied the screening questionnaires as they were sent to the employees were printed on company paper and signed by a representative of the company management or health department.

Respondents for the final experiment were recruited in a different manmer. In advertisements and editorials in local and regional newspapers, people were asked to participate in research aimed at improving nutrition education in the Netherlands. In 
contrast with the worksite experiments, people had to enlist before they received a screening questionnaire. Almost inevitably, this must have resulted in a stronger selection. bias than in the worksite experiments where a random sample of subjects were provided with a questionnaire without having to enlist first. The recruitment procedure was chosen for the third experiment in order to test the impact of tailored nutrition education in a different setting with another realistic way of enlisting that could also be used in other than research circumstances.

The tailored intervention proved to result in significant changes in fat, fruit and vegetable consumption. Fat reduction was consistently and significantly larger among subjects who received tailored feedback as compared to subjects who received general nutrition information in both experiments in which tailored information was compared to general feedback. Although some significant differences in intake, intentions or attitudes were found according to feedback condition for finit and vegetables, no consistent difference in fruit or wegetable intake were found between tailored and general information described in Chapter 9. The more consistent tailoring impact on fat as compared to fruit and vegetables might be explained by the fact that fat consumption is more complex and more difficult to assess. This was confirmed by the larger proportions of misconception of personal intake for fat. Since one"s personal fat intake is difficult to assess and reducing fat intake requires knowledge about important fat sources in one"s diet and low fat alternatives, personalized information for fat might be more relevant for fat as compared to fruit and vegetables for which it is easier to assess the adequacy of intake as soon as the recommended intake levels are known. This hypothesis was confirmed in a study by Krebs-Smith et al. (1995) that showed that awareness of recommendations was strongly associated with increased intake of fruit and vegetables.

Theory on behavior change states that psychosocial determinants of behavior should be influenced as a prerequisite for behavior change. Nevertheless, tailored feedback with psychosocial information did not result in a significantly larger impact on targeted dietary changes than tailored feedback without additional psychosocial information. Earlier studies have shown that only giving personalized risk feedback does not motivate people to change their risk behavior (Bowen et al., 1994; Kreuter \& Strecher, 1996). This might seem contradictory to the results of our second experiment. But the tailored feedback without psychosocial information that was provided in this experiment was more than 'risk information'. Additionally to feedback about their fat, fruit and vegetable intake as compared to certain normative values, respondents were also provided with, for example, information about their personal dietary fat sources, low fat alternatives for their high fat 
choices, and suggestions on how to include more fruit and vegetables in their diet, based on their present eating patterns. This information, although solely based on dietary intake data, could have improved self-efficacy expectations and outcome expectations by providing respondents with practical skills to make changes and information on what consequences these suggested changes would have for their diet. Although we assessed, for example, self-efficacy at both pretest and posttest, these data are difficult to compare. Psychosocial factors were all assessed in relation to behavior change. For example, selfefficacy was assessed with questions about how easy or difficult subjects thought reducing their fat intake or increasing their fruit and vegetable intake would be. Since substantial proportions of subjects reported to have changed their diets between pretest and posttest, posttest assessments of psychosocial factors were made as related to further changes for many subjects. The feedback letters might indeed have resulted in desirable changes in psychosocial factors that were not detected at posttest. Subjects might for example have increased their self-efficacy expectations because of the feedback they received and higher self-efficacy might have resulted in dietary changes. At posttest self-efficacy to change the diet even further would be assessed in that case. Consequently, comparisons of assessments of psychosocial factors between baseline and posttest should be interpreted with caution.

In the final experiment in which tailored feedback was again compared to general information, respondents in the experimental group received computer-generated feedback letters tailored to their dietary intake, intentions, attitudes, self-efficacy expectations and self-rated behavior. Half of the respondents in the experimental group received additional ipsative feedback tailored to changes in behavior and intentions after the first feedback letter. Respondents in the control group received a single general nutrition information letter in a similar format as the tailored letters. Computer-tailored nutrition education had a significant greater impact on fat reduction and increases in fruit and vegetable intake than general information. Ipsative computer-tailored feedback had an additional significant impact on fat and finit intake. The results confirm that computer-generated individualized feedback can be effective in inducing dietary changes towards recommended intake levels. The resuits further indicate that ipsative feedback might increase the longer-term impact of computer-tailored nutrition education. Because respondents who received additional psychosocial information in the experiment described in Chapter 9 found their feedback more interesting, it was decided to include some psychosocial information in the tailored intervention used in the last experiment. Nevertheless, screening of attitudes and self- 
efficacy was less specific in the final experiment, and therefore, the psychosocial information was less personalized and less comprehensive.

In Chapter 8 of this thesis, increased attention and less redundant information by means of personalization were suggested as possible reasons why computer-tailored nutrition education might be more successful than general nutrition information. Based on the data on differences in appreciation between the tailored letters and general feedback letters, some provisional conclusions about these mechanisms can be drawn. Tailoring feedback to personal characteristics seems to increase attention and usage of the feedback, since people who received tailored feedback more often read, saved and discussed their feedback letter. Tailoring might also work because of personalization. People who received tailored feedback thought that the feedback was of more personal relevance. Kreuter and Strecher (1996) suggested that this personalization might simply be the respondent's name in the feedback but in the studies described in this thesis the respondents' names were also printed on the general feedback letters. Therefore, it can be concluded that personalization beyond addressing respondents with their name might be a mechanism that enhances the impact of nutrition information. Finally, according to goal setting theory (Locke \& Latham, 1990), information about one's performance in changing behavior is expected to positively influence performance especially in combination with goal setting. Large proportions of subjects who received tailored feedback reported that they intended to change their diet because of the feedback they received (goal-setting). Subjects who received a second feedback letter further improved their diets, which supports the hypothesis that feedback about performance can motivate people to reach their goal.

\section{General Conclusion}

It can be concluded that underestimation of dietary risk behavior is an important barrier to preventive dietary changes. Furthermore, underestimation of dietary risk behavior should be taken into account when using psychosocial models to explain dietary behavior (change), like the attitude, social influences, self-efficacy model and the Transtheoretical Model. Computer-tailored nutrition education is a means to apply insights about awareness of dietary behavior, psychosocial determinants of dietary behavior and stages of change in dietary behavior to stimulate people to change their diet towards dietary recommendations. It can be concluded that tailored nutrition education is more effective in inducing dietary changes, especially fat reduction, than general nutrition 
information. Additional personalized psychosocial feedback is not an essential element of the computer-tailored nutrition education intervention that was tested in this thesis. 


\section{References}

Ajzen, I. (1988). Attitudes personality and behavior. Milton Keynes: Open University Press.

Ajzen, I. (1991). The theory of planned behavior. Organizational Behavior and Human Decision Processes, 50, 179-211.

Ajzen, 1., \& Fishbein, M. (1980). Understanding attitudes and predicting behavior. Englewood Cliffs, NJ: Prentice Hall.

Ajzen, I., \& Madden, T. J. (1986). Prediction of goal-directed behavior. Attitudes, intentions and perceived behavioral control. Joumal of Experimental Social Psychology, 22, 435-474.

Anti, M., Marra, G., Armelao, F., Bartoli, G. M., Ficarelli, R., Percesepe, A., De Vitis, I., Maria,

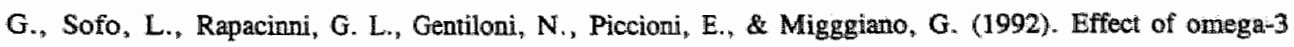
fatry acids on rectal mucosal cell proliferation in subjects at risk for colon cancer. Gastroenterology, 103, 883-891.

Armstrong, B. K., Mann, J. L., Adelstein, A. M., \& Eskin, F. (1975). Commodity consumption and ischemic heart disease mortality, with special reference to dietary practices. Joumal of Chromic Disease. 36, 673-677.

Bandura, A. (1986). Social foundations of thought and action. A social cognitive theory. Englewood Cliffs, NJ: Prentice Hall.

Baranowski, T. (1992). Beliefs as motivational influences at stages in behavior change. International Quarterly of Community Health Education, 13, 3-29.

Baranowski, T., Domel, S., Gould, R., Baranowski, J., Leonard, S., Treiber, F., \& Mullis, R. (1993). Increasing fruit and vegetable consumption among 4th and 5th grade students: Results from focus groups using reciprocal determinism. Journal of Nutrition Education, 25, 114-120.

Basen-Enquist, K. \& Parcel, G. S. (1992). Attitudes, norms, and self-efficacy: A model of adolescents' HIV-related sexual risk behavior. Health Education Quarterly, 19, 263-277.

Benito, E. (1992). Overview of dietary recommendations on diet and cancer. In E. Benito, A. Giacosa, \& M. J. Hill (Eds.), Public education on diet and cancer (pp. 3-12). Dordrecht, the Netherlands: Kluwer Academic Publishers.

Bierman, E. L., \& Chait, A. (1988). Nutrition and diet in relation to hyperlipidemia and atherosclerosis. In M. E. Shills, \& V. R. Young (Eds.), Modem nutrition in health and disease (7nd ed, pp. 72-107). Philadelphia: Lea \& Fehiger.

Biglan, A., \& Glasgow, R. E. (1991). The social unit: An important facet in the design of cancer control research. Preventive Medicine, 20, 292-305.

Block, G. (1991). Vitamin C and cancer prevention: The epidemiologic evidence. American Joumal of Clinical Nutrition, 53, 270s-282s.

Block, G. (1993). Dietary guidelines and the results of food consumption surveys. American Journal of Clinical Nutrition, $53,356 \mathrm{~s}-357 \mathrm{~s}$.

Block, G., Patterson, B., \& Subar, A. (1992). Fruit, vegetables, and cancer prevention: A review of the epidemiological evidence. Nutrition and Cancer, 18, 1-29.

Bolton-Smith, C., Woodward, M., \& Tunstall-Pedoe, H. (1991). The Scottish Heart Health Study. Dietary intake by food frequency questionnaire and odds ratios for coronary heart disease risk. II. The antioxidant vitamins and fibre. European Journal of Climical Nutrition, 46, 85-93.

Borland International Inc. (1990). Turbo Pascal. Scotts Valley, Ca: Borland. 
Bowen, D. J., Fries, E., \& Hopp, H. P. (1994). Effects of dietary fat feedback on behavioral and psychological variables. Iournal of Behawioral Medicine, 17, 589-604.

Breslow, L., Fielding, J., Herrman, A. A., \& Wilbur, C. S. (1990). Workplace health promotion: Its evolution and the Johnson \& Johnson experience. Preventive Medicine, 19, 13-21.

Brug, J., Debie, S., Van Assema, P., \& Weijts, W. (1995). Psychosocial determinants of fruit and vegetable consumption among adults. Results of focus group interviews. Food Quality and Preference, $\underline{6}$, 99-107.

Brug, J., Glanz, K., \& Kok, G. Do eating practices and psychosocial factors differ across stages of change for fruit and vegetable intake? Manuscript submitted for publication.

Brug, J., Hospers, H.J., \& Kok, G. Differences in psychosocial factors and fat consumption between stages of change for fat reduction. Psychology \& Health, in press.

Brug, J., \& Kok, G. (1995). Misconceptie van consumenten over eigen vetconsumptie [Consumers' misconception about their own fat consumption]. Voeding, 56, 11-14.

Brug, J., \& Lechner, L. (1995). Nederlanders overschatten hun groente- en fruitconsumptie [The Dutch overestimate their fruit and vegetable consumption]. Voeding, $\underline{56}, 20-23$.

Brug, J., Lechner, L., \& De Vries, H. (1995). Psychosocial determinants of fruit and vegetable consumption. Appetite, 25, 285-296.

Brig, J., \& Van Poppel, G. (1993). Voeding en kanker: Chemopreventieve voedingsbestanddelen [Nutrition and cancer: Chemopreventive substances]. Nederlands Tildschrift voor Geneeskunde, 137, 799 803.

Brug, J., Riedstra, M., Pruyn, J. F. A., \& Löwik, M. R. H. (1993). Effecten van de derde landelijke Let op Vet campagne [The effects of the third Fat Watch campaign]. Voeding, 54, 8-10.

Brug, J., Riedstra, M., Van der Feen de Lille, J. C. J. F., Pruyn, J. F. A., \& Aarnink, E. J. M. (1993). Drie jaar landelijke Let op Vet campagne [Three years Fat Watch campaign]. TNO-report V 931.390. Zeist, the Netherlands: TNO Nutrition Institute.

Brug, J., Steenhuis, I.H.M., Van Assema, P., \& De Vries, H. (1996). The impact of a computertailored nutrition intervention. Preventive Medicine, 25, 236-242.

Brug, J., Steenhuis, I.H.M., Van Assema, P., Glanz, K., \& De Vries, H. Computer-tailored nutrition education: Differences between two interventions. Health Education Research, in press.

Brug, J., Van Assema, P., \& Kok, G. (1995). Psychosocial determinants of dietary fat intake and intention to change. Emahrungs-Umschau, 42 (Beiheft), 150-152.

Brug, J. "Van Assema, P., Kok, G., Lenderink, T., \& Glanz, K. (1994). Self-rated dietary fat intake: Association with objective assessment of fat, psychosocial factors and intention to change. Iournal of Nutrition Education, 26, 218-223.

Brug, J., Van Assema, P., Lenderink, T., Kok, G., \& Glanz, K. (1994). Misconception of fat consumption: Causes and implications. Paper presented at the 122nd Anmual Meeting of the American Public Health Association. Abstract Book, pp. 383.

Burling, T. A., Marrotta, J., Gonzälez, R., Moltzen, J. O., Eng, A. M., Schmidt, G. A., Welch, R. L., Ziff, D. C., \& Reilly, P. M. (1989). Computerized smoking cessation program for the worksite: Treatment outcome and feasibility. Journal of Consulting and Clinical Psychology, 57, 619-622. 
Burnett, K. F.. Magel, P. E. Harrington, S., \& Taylor, C. B. (1989). Computer-assisted behavioral health counseling for high school students. Journal of Counseling Psychology, 36, 63-67.

Butrum, R. R., Clifford, C. K., \& Lanza, E. (1988). NCI dietary guidelines: Rationale. American Joumal of Clinical Nutrition, 48, 888-895.

Cameron, M. E., \& Van Staveren, W. A., (Eds.). (1988). Mamual on Methodology for food consumption studies. Oxford: Oxford University Press.

Campbell, M., DeVellis, B. M., Strecher, V. J., Ammerman, A. S., DeVellis, R. F., \& Sandler, R. S. (1994). Improving dietary behavior: The effectiveness of tailored messages in primary health settings. American Journal of Public Health, 84, 783-787.

Carroll, K. K., Braden, L. M., Bell, J. A., \& Kalamegham, R. (1986). Fat and cancer. Cancer, 58 , 1818-1825.

Curry, S.J., Kristal, A.R., \& Bowen, D.J. (1992). An application of the stage model of behavior change to dietary fat reduction. Health Education Research, $I_{x}$ 97-105.

Davidson, S., Passmore, R., Brock, J. F., \& Truswell, A. S. (1979). Human nutrition and dietetics. Edinburgh: Churchill Livingstone.

Dawber, T. R. (1980). The Framingham study; the epidemiology of atherosclerotic disease. Cambridge, MA: Harvard University Press.

De Vries, H., \& Backbier, E. (1994). Self-efficacy as an important determinant of quitting among pregnant women who smoke: The $\varnothing$ pattern. Preventive Medicine, 23, 167-174.

De Vries, H., Backbier, E. Kok, G., \& Dijkstra, M. (1995). The impact of social influences in the context of attitude, self-efficacy, intention and previous behavior as predictors of smoking onset. Journal of Applied Social Psychology, 25, 237-257.

De Vries, H., Dijkstra, M., \& Kuhlman, P. (1988). Self-efficacy: The third factor besides attitude and subjective norm as a predictor of behavioral intentions. Health Education Research, 3, 273-282.

De Vries, H., Weijts, W., Dijkstra, M., \& Kok, G. (1992). The utilization of qualitative and quantitative methods for health education program planning, implementation and evaluation: a spiral approach. Health Education Ouarterly, 19, 101-115.

DiClemente, C. C., Fairhurst, S. K., Velasquez, M. M. Prochaska, J. O., Velicer, W. F., Rossi, J. S. (1991). The process of smoking cessation: An analysis of precontemplation, contemplation and preparation stages of change. Journal of Consulting and Clinical Psychology, 59, 295-304.

Doll, R. (1989). The prevention of cancer: Opportunities and challenges. In T. Heller, B. Davey, L. Bailey (Eds.). Reducing the risk of cancers (pp. 14-25). London: Hodder \& Stoughton.

European Community Commission. (1994). Notities over Europa; Europa tegen Kanker [Reports on Europe; Europe against Cancer]. Brussel: Bureau for Official Publications of the EC.

Evans, M. G., The problem of analyzing multiplicative composites. American Psychologist, 46, 6-15.

Evans, R. 1., Rozelle, R. M., Mittelmark, M. B., Hansen, W. B., Bane, A. L., \& Havis, J. (1978). Deterring the onset of smoking in children: Knowledge of immediate physiological effects and coping with peer pressure and parent modeling. Journal of Applied Social Psychology, 8, 126-135.

Feunekes, G. I. J. (1996). Food, fat, family and friends: Studies on the impact of the social environment on dietary intake. (Thesis). Wageningen, the Netherlands: Landbouwumiversiteit Wageningen 
Fraser, G. E. (1994). Diet and coronary heart disease: Beyond dietary fats and low-density-lipoprotein cholesterol American Journal of Clinical Nutrition, $59,1117 \mathrm{~s}-1123 \mathrm{~s}$.

Gemson, D. H., \& Sloan, R. P. (1995). Efficacy of computerized health risk appraisal as a part of a periodic health examination at the worksite. American Journal of Health Promotion, 2 , 462-466.

Gerster, H. (1991). Potential role of betancarotene in the prevention of cardiovascular disease. International Joumal of Vitamin and Nutrition Research, 61, 277-291.

Gey, K. F. Puska, P., Jordan, P., \& Moser, U. K. (1991). Inverse correlation between plasma vitamin $\mathrm{E}$ and mortality from ischemic heart disease in cross-cultural epidemiology. American Joumal of Clinical Nutrition, 53, 326s-334s.

Giovannuci, E., Rimm, E. B., Stampfer, M. J., Colditz, G. A., Ascherio, A., \& Willetr, W. C. (1994). Intake of fat, meat, and fiber in relation to risk of colon cancer in men. Cancer Research, 54, 23902397.

Glanz, K., \& Eriksen, M. P. (1993). Individual and community models for dietary belhavior change. Journal of Nurrition Education, 25, 80-86.

Glanz, K., Kristal, A. R., Sorensen, G., Palombo, R., Heimendinger, J., \& Probart, C. (1993). Development and validation of measures of psychosocial factors influencing fat- and fiber-related dietary behavior. Preventive Medicine, 22, 373-387.

Glanz, K., Patterson, R. E., Kristal, A. R., DiClemente, C. C., Heimendinger, J., Linnan. L., \& McLerran, D. F. (1994). Stages of change in adopting healthy diets: Fat, fiber, and correlates of autrient intake. Health Education Ouarterly, 21, 499-519.

Glanz, K., \& Rudd, J. (1993). Views of theory, research, and practice: A. survey of nutrition education and consumer behavior professionals. Journal of Nutrition Education. 25, 270-273.

Glanz, K. \& Seewald-Klein, T. (1986). Nutrition at the workplace: An overview. Journal of Nutrition Education $18,1 \mathrm{~s}-11 \mathrm{~s}$.

Glasgow, R. E., \& Terborg, I. R. (1988). Occupational health promotion programs to reduce cardiovasicular risk. Journal of Consulting and Clinical Psychology, 56, 365-373.

Godin, G., \& Shephard, R. J. (1990). Use of attitude-behavior models in exercise promotion. Sponts Medicine, 10, 103-121.

Goldbohm, R. A., Van den Brandt, P. A., Brants, H. A. M., Van 't Veer, P., Al, M., Sturmans, F., \& Herrnus, R. J. J. (1994). Validation of a dietary questionnaire used in a large-scale prospective cohort study on diet and cancer. European Journal of Clinical Nutrition, 48, 253-265.

Goldbohm, R. A., Van den Brandt, P. A., Van 't Veer, P., Brants, H. A. M., Dorant, E., Sturmans, F. \& Hermus, R. J. J. (1994). A prospective cohort study on the relation between meat consurnption and the risk of colon cancer. Cancer Research, 54, 718-723.

Goodwin, P. J., \& Boyd, N. F. (1987). Critical appraisal of the evidence that dietary far intake is related to breast cancer risk. Joumal of the National Cancer Institute, 79 , 473-485.

Graham. S. (1986). Hypothesis regarding caloric intake in cancer development. Cancer 58, 1814-1817.

Green, L. W., \& Kreuter, M. W. (1991). Health promotion planning; an educational and environmental approach, Mountain View, CA: Mayfield. 
Greene, G. W., Rossi, S. R., Richards-Reed, G., Willey, C., \& Prochaska, $\mathbb{~ I . ~ O . ~ ( 1 9 9 4 ) . ~ S t a g e s ~ o f ~}$ change for reducing dietary fat to $30 \%$ of energy or less Ioumal of the American Dietetic Association, 24 , $1105-1110$.

Grubbe, J. W., Morgan, M. \& McGee, S. T. (1986). Attitudes and normative beliefs as predictors of smoking intensions and behaviors: A test of three models. British Joumal of Social Psychology, 25, 81-93.

Halliwell, B. (1994). Free radicals and antoxidants: A personal view. Nutrition Reviews, 52, 253-265.

Harper, R. (1963). Some attitudes to vegetables, and their implications. Nature, 200, 14-18.

Havas, S., Heimendinger, I., Reynolds, K., Baranowrki, T., Nicklas, T. A., Bishop, D., Buller, D., Sorensen, G., Beresford, S. A. A., Cowan, A., \& Damron, D. (1994). 5 a day for better health: A new research initiative. Joumal of the American Dietetic Association, 94, 32-36.

Heimendinger, J., Thompson, B., Ockene, J., Sorensen, G., Abrams, D., Emmons, K., Varnes, J., Eriksen, M. P., Probart, C., \& Himmelstein, J. (1990). Reducing the risk of cancer through worksite intervention. Occupational Medicine, 5, 707-723.

Hertog, M. G. L. (1991). Mogelijke rol van non-nutritieve stoffen in de voeding bij de preventie van. kanker [The role of non-nutritive food components in the prevention of cancer]. Voeding, 52, 101-106.

Hertog, M. G. L., Feskens, E. J. M., Hollman, P. C. H., Katan, M. B., \& Kromhout, D. (1993). Dietary antioxidant flawonoidis and risk of coronary heart disease: The Zutphen Elderly Study. The Lancet. 342, $1007-1011$.

Higgins, M., \& D'Agostino, R. (1990). Obesity and cardiovascular disease. In Y. Oomura, S. Tarui, S. Inoue, \& T. Shimazu (Eds.) Progress in obesity research (pp. 381-384). London: John Libbey.

Hill, M. J. (1994). Dietary fat and cancer. ECP News 27. Brussels: European Cancer Prevention Organization.

Hulshof, K. F. A. M. (1993), Assessment of variety clustering and adequacy of eating patterns. (Thesis). Maastricht, the Netherlands: University of Limburg.

Hulshof, K. F. A. M., Löwik, M. R. H., \& Kistemaker, C. (1994). Voeding na vijf jaar opnieuw gepeild [A new surveillance of the Dutch diet, after tive years]. Voeding, 55, 28-32.

Hulshof, K. F. A. M., Läwik, M. R. H., Kistemaker, C., Hermus, R. J. J., Ten Hoor, F., \& Ockhuizen, Th. (1993). Comparison of dietary intake data with guidelimes: Some potential pitfalls. Journal of the American College of Nurrition, $12,176-185$.

Hulshof, K. F. A. M., Lowik, M. R. H., Kok, F. J., Wedel, M., Brants, H. A. M., Hermus ${ }_{i}$ R. J. J., \& Ten Hoor, F. (1991). Diet and other life-style factors in high and low socio-economic groups. Europear. Journal of Clínical Nutrition, $45,441-450$.

Hunter, D. J., \& Willett, W. C. (1989). Human epidemiological evidence on the nutritional prevention. of cancer. In T. E. Moon \& M. S. Micozzi (Eds.), Nutrition and cancer prevention: Investigating the role of micronutrients. New York: Marcel Dekker.

Hyner, G. C.. Petri, C. J., Melby, C. L., Duda, J. L., \& Huddy, D. G. (1987). The effects of different health risk appraisal feedback on health-related behaviors in a worksite population. Health Education Research, 2, 161-164.

Janz, N., \& Becker, M., (1984). The Health Belief Model: A decade later. Health Education Quarterly, 11. $1-47$. 
Kellerman, S. T., Felts, W. M., \& Chenier, T. C. (1992). The impact on factory workers of health risk appraisal and counseling in health promotion. American Joumal of Preventive Medicine, $8,37-42$.

Knekt, P., Aroma, A., Maatela, J., Aaran, R. K., Nikkari, T., Hakama, M., Hakulinen, T., Peto, R., \& Teppo, L. (1991). Vitamin E and cancer prevention. American Journal of Clinical Nutrition, 53 . 283s-286s.

Kok, G. (1985). Een model van gedragsverandering door voorlichting (A model for behavioral change through public edvication]. Nederlands Tildschrift voor de Psuchologie, 40, 71-76.

Kok, G. (1994). Let op Vet campagne vooral zinvol voor de buren [Fat Watch campaign especially useful for the people next door]. Tiijdschrift Gezondheidswoprlichting, 11, 2-5.

Kok, G., De Wries, H.., Mudde, A. N., \& Strecher, V. J. (1991). Planned health education and the role of self-efficacy: Dutch research. Health Education Research, 6, 231-238.

Kok, G., Schaalma, H., De Vries, H., Parcel, G., \& Paulussen, Th. (in press). Social psychology and health education. In W. Stoebe \& M. Hewstone (Eds.), European review of social psychology: Vol. 7. New York: Wiley,

Krebs-Smith, S. M., Heimendinger, J., Patterson, B. H., Subar, A. F., Kessler, R., \& Pivonka, E. (1995). Psychosocial factors associated with fruit and vegetable consumption. American Joumal of Health Promotion, 10, 98-104.

Kreuter, M. W., \& Strecher, V. J. (1996). Do tailored behavior change messages entuance the effectiveness of health risk appraisal? Results from a randomized trial. Health Education Research, 11, 97 105.

Kris-Etherton, P. M., Volz-Clarke, P., Clark, K., \& Dattilo, A. M., (Eds.). (1990). Cardiovascular disease: Nutrition for prevention and treatment. The American Dietetic Association.

Kritchevsky, D. (1986). Diet, nutrition, and cancer: The role of fiber. Cancer, 58, 1830-1836.

Kritchevsky, D. (1995). The effect of over- and undernutrition on cancer. European Journal of Cancer Prevention, 4, 445-451.

Kromhout, D., Bosschieter, E. B., \& De Lezenne Coulander, C. (1985). The inverse relation between fish consumption and 20-year mortality from coromary heart disease. The New England Medical Journal, $312,1205-1209$.

Kromhout, D., Menotti, A., Bloemberg, B., Aravanis, C., Blackburn, H., Buzina, R., Dontas, A. S., Fidanza, F., Giampaoli, S., Jansen, A., Karwonen, M., Katan, M., Nissinen, A., Nedieljkovic, S. Pekkanen, J., Pekkarinen, M., Punsar, S., Răsänen, L., Simic, B., \& Toshima, H. (1995), Dietary saturated and trans fatty acids and cholesterol and 25-year mortality from coronary heart disease: The Seven Countries Study. Preventive Medicine, 24, 308-315.

Krueger, R. A. (1988). Focus groups; a practical guide for applied research. Newbury Park, CA: Sage Publications.

Lackey, C. J., Kolasa, K. M., \& Homer, R. D. (1992). Nutrition education in a community cholesterol screening program. Health Values, 16, 39-47.

Larsson, B. (1990). Obesity, fat distribution and cardiovascular disease. In Y. Oomura, S. Tarui, S. Inoue, \& T. Shimazu (Eds.), Progress in obesity research (pp. 375-379). London: John Libbey.

Leaf, A. (1992). Health claims: Ornega-3 fatty acids and cardiovascular disease. Nutrition Reviews, 50 , $150-154$. 
Lechner, L., Brug, I., \& De Vries. Misconception of fruit and vegetable consumption: Interpretation and consequences. Manuscript submitted for publication.

Lechner, L., \& De Vries, H. (1995). Starting participation in an employee fitness program: Attitudes, social infiuences and self-efficacy. Preventive Medicine, 37, 627-633.

Linscheer, W. G., \& Vergroesen, A. J. (1988). Lipids. In M. E. Shills, \& V. R. Young (Eds.), Modern nutrition in health and disease (7nd ed, pp. 1283-1297). Philadelphia: Lea \& Fehiger.

Lloyd, H. M., Paisley, C. M., \& Mela, D. J. (1993). Changing to a low fat diet: Attitudes and beliefs of UK consumers. European Journal of Clinical Nutrition, 47, 361-373.

Locke, E.A., \& Latham, G.P. (1990). A theory of goal setting and task performance. Englewood Cliffs, NY: Simon \& Schuster.

Löwik, M. R. H., Brussaard, J. H., Hulshof, K. F. A. M., Kistemaker, C., Schrafsma, G., Ockhuizen, Th., \& Hermus, R. J. J. (1994). Adequacy of the diet in the Netheriands in 1987-1988 (Dutch Nutrition Surveillance System). International Journal of Food Sciences and Nutrition, 45, 1s-62s.

Mariswa, L. F., Magadia, N. E.., Weisburger, J. H., \& Wynder, E. L. (1975). Promoting effect of bile acids on colon carcinogemesis after incra rectal installation of MNNG in rats. Journal of the National Cancer Institute, 55, 1093-1097.

Martin-Moreno, J. M., Willett, W. C., Gorgojo, L., Banegas, J. R., Rodriguez-Artalejo, F., Fernandez-Rodriguez, J. C., Maisonmeuve, P., \& Boyle, P. (1994). Dietary fat, olive oil intake and breast cancer. International Journal of Cancer, $58,774-780$.

McGuire, W. J. (1985). Attitudes and attitude change. In G. Lindzey, \& E. Aronson (Eds.), Handbook of sociall psychology: Vol II. Special fieids and application (pp. 233-246). New York: Random House.

Meeker, M.C. (1988). A review of the validity and efficacy of the health risk appaisal instrument. Joumal of Manipulative and Psychological Therapeutics, 11, 108-113.

Mensink, R. P., Zock, P. L., \& Katan, M. B. (1994). Vet, vetzuren en coronaire hartziekten [Fat, fatty acids and coronary heart disease]. Hart Bulletin, 25, 111-115.

Milner, J. A. (1989). Mechanisms for nutritional inhibition of carcinogenesis. In T. E. Moon \& M. S. Micozzi (Eds.), Nutrition and cancer prevention: Investigating the role of micronutrients (pp. 13-32). New York: Marcel Dekkier.

Mudde, A. N., De Vries, H., Willemsen, M. C., \& Van Assema, P. (1994). Development and utilization of a self-help manual for community smoking cessation interventions. In $R$. Richmond (Ed.), Interventions for smokers: An intemational perspective (pp. 293-322). New York: Williams \& Williarns.

National Research Council (1989). Diet and health: Implication for reducing chronic disease risk. Washington, DC: National Academic Presss.

Nestle, M. (1995). Dietary guidelines tor the 21st century: New Approaches. Journal of Nutrition Education, 27, 272-275.

Nederlandse Hartstichting. (1995). Hart-en vaatziekten in Nederland [Cardiovascular disease in the Netherlands]. Den Haag, the Netherlands: Nederlandise Hartstichting.

Netherlands Bureau for Food and Nutrition. (1992). Praktische Voedingsmiddelen Gids [Practical Food Compositions Table]. Den Haag, the Netherlands: Netherlands Bureau for Food and Nustrition.

Nunnally, J. C. (1967). Psychometric theory. New York: McGraw-Hill. 
Ossendorp, S. J. M., Ypma, E. B., Van Leeuwen, F. E., \& Rookus, M. A. (1993). Vet en het risico op borstkanker [Fat and breast cancer risk]. Voeding, 54, 16-20.

Dygard, L., \& Klepp, K. I. (1996). Influences of social groups on eating patterns: A study among young adults. Journal of Behavioral Medicine, 19, 1-15.

Paisley, C., Lloyd, H., Sparks, P., \& Mela, D. J. (1995). Consumer perceptions of dietary changes for reducing fat intake. Nutrition Research, 15, 1755-1766.

Patterson, B. H. Block, G. (1988). Food choices and the cancer guidelines. American Joumal of Public Health, 78, 282-286.

Patterson, B. H., Block, G., Rosenberg, W. F., Pee, D., \& Kahle, L. L. (1990). Fruit and vegetables in the American diet: Data from the NHANES II survey. American Journal of Public Health, 80, 14431449.

Petty, R. E., \& Cacioppo, J. T. (1986). The elaboration likelihood model of persuasion. Advances in Experimental Social Pswcthology, 19, 123-205.

Potter, J. D. (1995). Risk factors for colon neoplasia: Epidemiology and biology. European Journal of Cancer, 31, 1033-1038.

Prochaska, J. O. (1992). A transtheoretical model of behavior change: Implications for diet interventions. In M. Henderson, D. Bowen, \& $\mathbb{K}$. De Roos (Eds.), Promoting dietary change in communities: Applying existing models of dietary change to population-based inierventions (pp. 37-50). Seattle, WA: Fred Hutchinson Cancer Research Center.

Prochaska, J. O., \& DiClemente, C. C., (1992). Stages of change in the modification of problem behaviors. Progress in Behavior Modification, 28, 184-218.

Prochaska, J. O., DiClemente, C. C., \& Norcross, J. C. (1992). In search of how people change: Applications to addictive behaviors. American Psychologist; 47, 1102-1114.

Prochaska, J. O., DiClemente, C. C., Velicer, W. F. \& Rossi, J. S. (1993). Standardized, individualized, interactive, and personalized self-help programs for smoking cessation. Health Psychology, 12, 399405 .

Produktschap voor Groenten en Fruit. (1994). De Nederlandse consumptie van groemten, fruit, noten en vruchtesappen. Voedselconsumptiepeiling 1992 [Consumption of vegetables, fruit, nuts and fruit juices in the Netherlands. Dutch National Food Consumption Survey 1992]. Den Haag, the Netherlands: Produktschap voor Groenten en Fruit.

Raats, N. M., Shepherd, R., \& Sparks, P. (1993). Attitudes, obligations and perceived control: Predicting milk selection. Appetite, 20, 239-241.

Riedstra, M.. Brug. J., Hardeman, W., Pruyn, J. F. A., \& Löwik, M. R. H. (1993). Drie jaar landelijke Let op Vet campagne: Wat is er gebeurd [Three years national Fat Watch campaign: What are the effects]. Voeding, 54, 4-7.

Riedstra, M., Hardernan, W., Pruyn, J. F. A., Aarnink, E. J. M., Van der Feen de Lille, J. C. J. F., \& Jonkers, R. (1992). De effecten van de tweede landelijke Let op Vet campagne, gehouden in 1992. Consumentenonderzoek. [The effects of the second national Fat Watch Campaign; consumer research]. TNO-report V 92.453. Zeist, the Netherlands: TNO Nutrition Institute.

Rohan, T. E., \& Bain, C. J. (1987). Diet in the etiology of breast cancer. Epidemiologic Reviews, 9. $120-145$ 
Rose, D. P. (1986). Dietary factors and breast cancer. Cancer Surveys, 5, 671-688.

Rosenstack, I. M. (1990). The Health Belief Model: Explaining health through expectancies. In $\mathrm{K}$. Glanz, F. M. Lewis, \& B. K. Rimer (Eds.) Health beharior and health education: Theory, research and practice (pp. 39-62). San Francisco, CA: Jossey Bass.

Rudd, J., \& Glanz, K. (1990). How individuals use information for health action: Consumer information processing. In K. Glanz, F. M. Lewis, \& B. K. Rimer (Eds.), Health behavior and health education: Theory, research and practice (pp. 115-139). San Francisco, CA: Jossey Bass.

Ruwaard, D., \& Kramers, P. G. N., (Eds.). (1993). Volksgezondheid Toekomst Verkenning [Exploring the future public health]. Den Haag, the Netherlands: SDU.

Shannon, B., Bagby, R., Wang, M. Q., \& Trenker, L. (1990). Self-efficacy: A contributor to the explanation of eating behavior. Health Education Research, 5, 395-407.

Sheeshka, J. D., Woolcott, D. M., \& MacKinnon, N. J. (1993). Social cognitive theory as a framework to explain intentions to practice healthy eating behaviors. Journal of Applied Social Psychology, 23, 1547-1573.

Shepherd, R., \& Farleigh, C. A. (1986). Attitudes and personality related to salt intake. Appetite. I. 343-354.

Shrapnel, W. S., Calvert, G. D., Nestel, P. J., \& Truswell, A. S. (1992). Diet and coronary heart disease. The Medical Joumal of Australia, 156, $9 \mathrm{~s}-16 \mathrm{~s}$.

Skinner, C. S., Seigfreid, J. C., Kegler, M. C., \& Strecher, V. J. (1994). The potential for computers in patient education. Patient Education and Counseling, 22, 27-34.

Skinner, C. S., Strecher, V. J., \& Hospers, H. (1994). Physicians" recommendations for marmmography: Do tailored messages make a difference? American Journal of Public Health, 84, 43-49.

Sorensen, G., Grasgow, R. E., \& Corbetr, K. (1990). Involving worksites and other organizations. In N. Bracht (Ed.), Health promotion at the community level (pp. 158-184). Newbury Park, CA: Sage Publications.

Sparks, P., Hedderley, D., \& Shepherd, R. (1992). An investigation into the rellationship between perceived control, attitude variability and the consumption of two common foods. European Journal of Social Psychology, 22, 55-71.

Sporny, L. A., \& Contento, I. R. (1995). Stages of change in dietary fat reduction: Soclal psychological correlates. Journal of Nutrition Education, 27, 191-199.

SPSS Inc. (1988). Statistical Package for the Social Sciences. Chicago, LL: SPSS.

Stafleu, A., De Graaf, C., \& Van Staveren, W. A. (1991). A review of selected studies assessing social-psychological determinants of fat and cholesterol intake. Food Quality and Preference, 3, 183-200.

Stafleu, A., Van Staveren, W. A., De Graaf, C., Burema, I., \& Hautvast, J.G. (1994). Family resemblance in energy and cholesteroll intake: A study among three generations of women. Preventive Medicine, 23, 474-480.

Steenhuis, I. H. M., Brug, J., Van Assema, P., Imbos, Tj. (1996). The validation of a test to measure knowledge about the fat content of food products. Nutrition and Health, 10, 331-339.

Stewart, D.W., \& Shamdasani, P. N. (1990). Focus groups; theory and practice. Newbury Park, CA: Sage Publications. 
Strecher, V. J., Kreuter, M., Den Boer, D. J., Kobrin, S., Hospers, H. J., \& Skinner, C. S. (1994). The effects of computer-tiallored smoking cessation messages in family practice settings. The Joumal of Family Practice, $39,262-270$.

Strecher, V. J., Rimer, B. K., \& Monaco, K. D. (1989). Development of a new self-help guide "Freedom from smoking for you and your family". Health Education Quarterly, 16, 101-112.

Stuurgroep Toekomstscenario's Gezondheidszorg. (1994). Kanker signaleringsrapport 4 [Cancer registration repon 4]. Rijswijk, the Netherlands: Stuurgroep Toekomstscenario"s Gezondheidszorg.

Subar, A.F., Ziegler, R.G., Patterson, B.H., Ursin, G., \& Graubard, B. (1994). U.S. dietary patterns associated with fat intake: The 1987 National Health Interview Survey. American Journal of Public Health, 84, $359-366$.

Sulls, J., \& Wills, T. A., (Eds.). (1991). Social comparison: Contemporary theory and research. Hillsdale, NJ: Lawrence Eribaum Associates.

Svenson, O. (1981). Are we all less risky and more skillful than our fellow drivers? Acta Psychologica, 47. 143-148.

Swanborn, P. G. (1996). De Fishbein/Ajzen-theorie in de kritiek [The Fishbein/Ajzen model: Some critical remarks]. Nederlands Tiidschrift voor de Psychologie, 51, 35-46.

Thomas, P. R., (Ed.). (1993). Improving America's diet and health: From recommendations to action. Washington, DC: National Academy Press.

Thornton, J. R. (1981). High colonic PH promotes colorectal cancer. The Lancet, 1(8229), 1081-1083.

Triandis, H. C. (1977). Interpersomal behavior. Monterey, CA: Brooks/Cole.

Tuorila, H. (1987). Selection of milks wilh varying fat contents and related overall liking, attitudes, norms and intentions. Appetite, 8, 1-14.

Tuorila-Ollikainen, H., Lahteenmäki, L., \& Salovaara, H. (1986). Attitudes, norms, intentions and hedonic responses in the selection of low salt bread in a longitudinal choice experiment. Appetite, $I, 127$. 139.

US Department of Agriculture, US Department of Health and Hurman Services. (1985). Nutrition and your health: Dietary guidelines for Americans (2nd ed.). Washington, DC: US Governmental Printing Office.

US Departments of Agriculture and Health and Human Services. (1990). Nutrition and your health: Dietary guidelines for Americans. Home and Garden Bulletin, No. 232.

US Department of Agriculture. (1992). USDA's Food Guide Pyramid. Home and Garden Bulletin, 249.

Van Assema, P. (1993). The development, implementation and evaluation of a community health project. (Thesis). Maastricht, the Netherlands: Universitaire Pers.

Van Assema, P., Brug, J., Dolders, M., Kok, G., \& Steenhuis, I. (1996). Misconceptie van vetconsumptie: Een kwalitatief onderzoek naar oorzaken en beïnvloedingsstrategieèn [Misconception of fat consumption: A qualitative study on the causes and possible solutions]. Tiidschrift Sociale Gezondheidszorg, 74, $347-355$.

Van Assema, P., Brug, J., Kok, G., \& Brants, H. A. M. (1992). The reliability and validity of a Dutch questionnaire on fat consumption as a means to rank subjects according to individual fat intake. European Journal of Cancer Prevention, 1, 375-380. 
Van Assema, P., De Vries, H., \& Kok, G. (1992). Kankerpreventieonderzoek door middel wan focusgroepinterviews [Cancer prevention research by means of focus group interviews]. Gedrag en Gezondheid, 20, 10-22.

Van Assema, P., Pieterse, M., Kok, G., Eriksen, M., \& De Vries, H. (1993). The determinants of four cancer related risk behaviors. Health Education Research, 8, 461-472.

Van Assema, P., Steenbakkers, M., Kok, G., Eriksen, M., \& De Vries, H. (1994). Results of the Datch community project 'Healthy Bergeyk'. Preventive Medicine, 23, 394-401.

Van Beurden, E., James, R., Dunn, T., Tyler, C. (1990). Risk assessment and dietary counselling for cholesterol reduction. Health Education Research, 5, 445-450.

Van den Brandt, P. A., Van 't Veer, P., Goldbohm, R. A., Dorant, E., Volovics, A., Hermus, R. J. J., \& Sturmans, F. (1993). A prospective cohort study on dietary fat and the risk of post menopausal breast cancer. Cancer Research, 53, 75-82.

Van der Weijden, M. (1995). Groot deel bevolking eet te weinig groente en fruit [Large proportion of population eat to little fruit and vegetables]. Voeding, 56(5), 10-13.

Van 't Veer, P. (1990). Dietary habits and breast cancer (thesis). Maastricht, The Netherlands: Rijksuniversiteit Limburg.

Velicer, W. F., DiClemente, C. C., Prochaska, J. O., \& Brandenburg, N. (1985). Decisional balance measure for assessing and predicting smoking status. Journal of Personality and Social Psychology, 48 , 1279-1289.

Velicer, W. F., Prochaska, J. O., Bellis, J. M., DiClemente, C. C., Rossi, J. S., Fava, J. L., \& Steiger, J. H. (1993). An expert system intervention for smoking cessation. Addictive Behaviors, 18, 269 290.

Voedingsraad [Dutch Nutrition Council]. (1982). Voeding in relatie tol coronaire hartziekten [Diet in relation to coronary heart disease]. Den Haag, the Netherlands: Voedingsraad.

Voedingsraad [Dutch Nutrition Council]. (1986a). Het advies Richtlijnen Goede Voeding [Dietary recommendations]. Den Haag, the Netherlands: Voedingsraad.

Voedingsraad [Dutch Nutrition Council]. (1986b). Voedingsfactoren en het ontstaan van kanker [Dietary factors and the development of cancer]. Den Haag, the Netherlands: Voedingsraad.

Voedingsraad [Dutch Nutrition Council]. (1991). Nader advies inzake de richtlijn m.b.t. de vetconsumptie uit het advies Richtliinen goede voeding 1986 [Further advice in respect to the recommendadtion for fat of 1986]. Den Haag, the Netherlands: Voedingsraad.

Voorlichtingsbureau voor de Voeding. (1993). Zo eet Nederland, 1992 [This is how the Dutch eat, 1992]. Den Haag, the Netherlands: Voorlichtingsburean woor de Voeding.

Wagner, J. L., Winett, R. A., \& Walbert-Rankin, J. (1992). Influences of a supermarket intervention on the food choices of parents and their children. Jounnal of Nutrition Education, 24, 306-311.

Wargowich, M. J. (1992). Fish oil and colon cancer. Gastroenterology, 103, 1096-1101.

Weinstein, N. D. (1988). The precaution adoption process Health Psychology, I, 355-386.

Welsch, C. W. (1987). Enhancement of mamary rumor genesis by dietary fat: Review of potential mechanisms. American Joumal of Clinical Nutrition, 45, 192-202.

Willett, W. C. (1989). The search for the canses of breast and colon cancer Nature, 338, 389-394,

Willert, W. C. (1994). Diet and Health: What should we eat? Science, 264, 532-537. 
Willett, W. C., \& Ascherio, A. (1994). Trans fatry acids: Are the effects only marginal. Americant Journall of Public Health, 84, 722-724.

Willett, W. C., Hunter, D. J., Stampfer, M. J., Colditz, G., Manson, J. E., Spiegelman, D., Rasner, B., Hennekensi, C. H., \& Speizer, F. E. (1992). Dietary fat and fiber in relation to risk of breast cancer. Joumal of the American Medical Association, 268, 2037-2044,

Willetr. W. C., Morris, J. S., Pressel, S., Taylor, J. O., Polk, B. F., Stampfer, M. J., Rosner, B., Schneider, K., \& Hames, C. G. (1983). Prediagnostic serum selenium and risk of cancer. The Lancet, $11(8342), 130$.

Willett, W. C., Starnpfer, M. I., Colditz, G. A., Rosner, B. A., \& Speizer, F. E. (1990). Relation of meat, fat, and fiber intake to the risk of colon cancer in a prospective study among women. New England Journal of Medicine, 323, 1664-1672.

Winett, R. A., Wagner, J. L., Moore, J. F., Walker, W. B., Hite, L. A., Leahy, M., Neubauer, T., Arbour, D., Walberg, J., Geller, E. S., Mundy, L. L.x \& Lombard, D. (1991). An experimental evaluation of a prototype public access nutrition information system for supermarkets. Health Psuchology, 10, 75-78.

Ziegler, R. G. (1989). A review of the epidemiologic ewidence that carotenoids reduce the risk of cancer. Journal of Nutrition, 119, 116-122. 


\section{Summary}

There is a large body of evidence from epidemiological research that a high intake of (saturated) fat and a low intake of fruit and vegetables is associated with increased risk for cardiovascular disease and certain cancers. Furthermore, nationwide food consumption surveys in the Netherlands have shown that more than half of the Dutch population eat more fat and less fruit and vegetables than is recommended by health authorities.

In order to stimulate the Dutch public to change their diet towards the recommendations, a number of nutrition education interventions have been implemented in the Netherlands. The best known interventions were the nationwide 'Fat Watch' campaigns, aimed at fat reduction. Although these campaigns were successful in reaching a large proportion of the Dutch population, the positive effect on motivation to reduce fat intake was disappointing.

The discrepancies between the Dutch diet and the dietary recommendations and the fact that only a very small proportion of the Dutch people intend to change their diet towards healthier choices, was reason to study why people eat too much fat and too little fruit and vegetables. Based on these determinant studies a nutrition education intervention was developed, implemented and evaluated.

\section{Determinant studies}

In this thesis, the Attitude - Social influences - self-Efficacy (ASE) model, which is very similar to the Ajzen's Theory of Planned Behavior, and the Transtheoretical Model were used as a framework to study which psychosocial factors are important determinants of (changing) consumption of fat, fruit and vegetables in the Netherlands.

The ASE-model implicates that behavior is a result of behavioral intention. Three psychosocial factors have been identified that predict (health-related) behavioral intention: attitudes, social influences, and self-efficacy. A person's attitude towards a specific behavior is a reflection of the most important consequences that person expects from performing the behavior. Social influence is a result of social norms relevant to the behavior, support from others to perform or refrain from the behavior, and whether important others perform or refrain from the behavior themselves (modeling). Selfefficacy expectations is a reflection of a person"s beliefs whether he can perform the desired behavior in different situations. The ASE-model inplicates that a person's health behavior can be changed, by changing attitudes, social influences and self-efficacy expectations.

From earlier studies it had become clear that the majority of people in the Netherlands are convinced that eating a low fat diet is good for health and tastes good, is easy to 
adopt and maintain, and that important others like family and friends do not discourage them to eat low fat diets. Based on this information one could conclude that the conditions for fat reduction in the Netherlands were favorable. But what also came forward from these earlier studies was that only a very small minority of the Dutch population had the intention to reduce their fat intake. In ASE terms: The Dutch public had positive attitudes towards low fat diets, expected positive social-influences towards low fat diets and had high self-efficacy expectations towards low fat diets, but they did not intend to adopt a low fat diet.

Before people will start to consider changing a specific behavior, they should be aware of the fact that they perform that behavior. In recent stages of change models like the Transtheoretical Model, the concept of awareness of risk behavior has been recognized as important in adopting preventive behavior. In the Transtheoretical Model, five stages are distinguished in the process of behavior change: People move from precontemplation (not (yet) considering the behavioral change of interest), through contemplation (considering change), and preparation (actually planning change), to action (actively changing) and maintenance (sustaining the desired changes in behavior). Relapse to previous stages is possible and movement through the stages can involve a cycling and recycling process. Awareness of risk behavior is seen as essential in the transition from precontemplation to contemplating changing the risk behavior. The essential role of awareness of personal 'risk behavior' in the earlier stages of change has been further specified in the so-called Precaution Adoption Process as described by Weinstein. He argued that there are three levels of awareness of risk behavior. People who have reached the first level of awareness have heard about the risk (behavior), they are aware of the association between behavior and risk. In relation to fat consumption this would mean that people are aware of the fact that too much fat is bad for health. At the second level of awareness, people are aware that other people participate in the risk behavior: They know that other people eat too much fat. At the third level of awareness people realize that they participate in the risk behavior themselves: They realize that their personal fat intake is too high. According to the model, only after this third level of awareness of risk behavior has been reached, people might consider changing their risk behavior.

In order to study the role of awareness of dietary fat intake as a possible factor in the process of dietary behavior change, data from 1507 adult subjects gathered among inhabitants of two Dutch cities were analyzed. Objective assessments of dietary fat intake were compared to self-rated, or subjective, dietary fat intake. A majority of the respondents had an unrealistic view of their own fat intake. Men were more often unrealistic 
than women. Underestimation of fat intake was especially prevalent. Self-rated dietary fat intake, and not objectively assessed fat intake, proved to be a significant correlate of intention to reduce fat consumption. Psychosocial determinants of fat intake were stronger correlates of self-rated fat intake than of objectively assessed fat intake. It was concluded that a large proportion of the Dutch people are unrealistic about their personal dietary habits and especially underestimate their dietary "risk behavior": They think that they do not eat too much fat and that they eat enough fruit and vegetables while they are not meeting the recommended intake levels. Underestimation of fat consumption proved to be a significant predictor of intention to reduce fat intake. Misconception of fat consumption also had implications for the usefulness of theoretical models like the ASE-model. Our study showed that among subjects who are unrealistic about their fat consumption levels, psychosocial factors like attitudes, social influences and self-efficacy expectations, that are regarded as predictors of human behavior, were not associated with dietary intake levels. The implication is that, in conformation with Weinstein's model, psychosocial determinants of dietary behavior that are often targeted in nutrition education campaigns will only become relevant after people have become aware of their dietary intake levels.

A further study was conducted to investigate what might be the determinants of misconception of personal dietary intake levels. Possible correlates of misconceptions of personal fat consumption were studied among a random sample of the Dutch population $(n=989)$ in order to give recommendations for strategies to reduce misconception. Multiple regression analyses were used to identify significant correlates of misconception. The way respondents compared their fat intake to that of others was the most important determinant of misconception of fat intake. Furthermore, a large majority of respondents reported believing their fat intake to equal to $(32 \%)$ or lower than $(48 \%)$ comparable others, indicating an optimistic bias in self-assessment of fat intake. Sex, age, knowledge about fat contents of food products, whether the respondents" thought that only overweight people had high fat diets, and whether respondents reported having reduced their fat intake in the past and the belief that the general Ducth diet used to be higher in fat in the past, were other significant correlates of misconception of fat intake in multiple regression analysis, but these variables contributed only modestly to total variance explained. In order to reduce misconception of fat intake, intervention materials should be developed and implemented that enable people to easily assess their personal fat intake in comparison to recommended intake levels and their peer group average fat intake in order to help people to make more realistic assessments of their own fat intake levels. 
Because hardly any studies on psychosocial determinants of fruit and vegetable consumption had been published at the start of the studies described in this thesis, an explorative study was conducted, using focus group interviews as method for data collection, to identify relevant beliefs related to fruit and vegetable consumption among Dutch adults.

Six different general issues were identified as being important in relation to fruit and vegetable consumption. Satisfaction, and especially taste, perceived health consequences, social influences, skills and barriers, habit, and lack of awareness were brought forward during the interviews as determinants of fruit and vegetable consumption. The results of this preliminary study was used to dewellop a questionnaire to be used in a telephone survey to study psychosocial determinats of fruit and vegetable intake in a quantitative way.

This telephone survey was conducted among an adult Dutch population $(n=367)$ based on the ASE model. Self-efficacy and attitudes were consistently and significantly associated with consumption of boiled or otherwise heated vegetables, of salads, and of fruit. Furthermore, respondents reporting low consumption of these food groups had lower selfefficacy expectations and less positive attitudes than subjects with relatively high consumption of fruit and vegetables. It was concluded that mutrition education aimed at stimulating fruit and vegetable consumption should focus especially on changing attitudes and self-efficacy expectations.

The Transtheoretical Model was used to study which specific determinants should be changed in different stages of change for fat reduction and increasing fruit and vegetable intake. Data on fat consumption, self-rated fat intake, attitudes, social support, selfefficacy, and stages of change were collected among a sample of 507 adults. Analyses of variance were used to study differences in these factors between stages of change. Attitudes and social support were most positive among subjects in preparation and action. Self-efficacy expectations were lowest among subjects in contemplation and preparation. Fat consumption was highest among precontemplators but no substantiall differences between other stages were found.

In order to study differences between stages of change for fruit and vegetable intake, data were collected using a self-administered survey, as part of the baseline assessment for a nutrition intervention study. Subjects were 739 Dutch adults aged 18 years and older. Significant differences were found between stages of change in dietary intake, attitudes, self-efficacy, and social comparison. Differences in attitudes were largest 
between precontemplation and contemplation and differences in intake and self-efficacy were most marked between pre-action stages and action/maintenance.

It was concluded that subjects in different stages of change differ in psychosocial factors that are regarded as important determinants of behavioral change. Based on these differences it is recommended to develop stage-tailored nutrition education. Messages to influence attitudes about the benefits of less fat and more fruits and vegetables are likely to affect people in precontemplation, and self-efficacy information to increase confidence in overcoming barriers to changes in consumption is likely to be effective with persons in contemplation and preparation stages. A majority of subjects who were classified in maintenance based on their self-rated intake, consumed more fat or less fruit and vegetables than is recommended. These subjects might better be considered as precontemplators who are unaware of their dietary risk behavior and should be encouraged to re-evaluate their intake levels which might stimulate them to contemplate changing their diet.

\section{Intervention studies}

In order to make people aware of what they eat and to further motivate them to adopt healthy diets, a nutrition education instrument was developed with which respondents could be provided with personalized dietary feedback. Respondents completed written questionnaires with which consumption levels of fat, fruit and vegetables, as well as selfrated intake, attitudes, perceived social influences, self-efficacy expectations, and motivation to change could be assessed. Based on these assessments, respondents were provided with computer-generated personalized feedback in which their consumption of fat, fruit and vegetables was compared to their peer group average intake levels and to recommended intake levels, and information was given about the most important dietary fat sources and low fat alternatives. Additional feedback was provided, tailored to the respondents' personal attitudes, perceived social influences, self-efficacy expectations and motivation to change.

The impact of this so-called computer-tailored nutrition information on changes in fat, vegetable, and fruit consumption was tested in a randomized trial among 347 employees of the Royal Shell Laboratory in Amsterdam. Respondents in the experimental group received computer-generated feedback letters tailored to their personal dietary behavior, attitudes, perceived social influences, self-efficacy expectations, and awareness levels. Respondents in the control group received general nutrition information letters printed in a font size and on paper that was identical to the tailored letters. 
Respondents in the experimental group decreased their fat consumption significantly more than respondents in the control group between baseline and posttest. A significant effect of tailoring was also found for changes in attitudes and intentions towards reducing fat intake and increasing fruit and vegetable consumption. Furthermore, respondents in the experimental group were more satisfied with the nutrition information they received and more often reported changing their diet or intention as a result of the information. It was concluded that computer-tailored nutrition information is a promising means of stimulating people to change their diet toward dietary recommendations.

In a second experiment; the impact of two computer-tailored nutrition education interventions was compared in a randomized trial among 315 subjects with a pretestposttest control group design. Respondents in both study groups received feedback tailored to their consumption of fat, fruit, and vegetables. Respondents in the experimental group received additional psychosocial feedback tailored to their attitudes, perceived social support and self-efficacy expectations towards reducing their fat consumption and increasing their consumption of fruit and vegetables. A significant reduction in fat consumption and increase in consumption of fruit and vegetables were found in both the experimental group and the control group between pretest and posttest. Respondents in the experimental group more often indicated that the feedback they received was interesting and easy to understand. Respondents in the control group more often reported having reduced their fat consumption because of the feedback they received. No significant differences in consumption of fat, fruit and vegetables were found at posttest between the experimental group and the control group. These results confirm that tailored feedback can be effective in inducing dietary changes. The results do not support the hypothesis that additional psychosocial information is an essential component of effective tailored feedback but additional psychosocial feedback might contribute to a more positive evaluation of tailored feedback.

In the final experiment, the longer term impact of individualized computer-generated nutrition information and the additional effects of ipsative feedback on (maintaining) changes in intake of fat, fruit and vegetables was studied in a randomized trial. Respondents in the experimental group received computer-generated feedback letters tailored to their dietary intake, intentions, attitudes, self-efficacy expectations and self-rated behavior. Half of the respondents in the experimental group received additional ipsative feedback tailored to changes in behavior and intentions after the first feedback letter. Respondents in the control group received a single general nutrition information letter in a similar format as the tailored letters. Computer-tailored nutrition education had a 
significant greater impact on fat reduction and increases in fruit and vegetable intake than general information. Ipsative computer-tailored feedback had an additional significant impact on fat and fruit intake. The results confirm that computer-generated individualized feedback can be effective in inducing dietary changes towards recommended intake levels. The results indicate that ipsative feedback might increase the longer-term impact of computer-tailored nutrition education."

The conclusions of the thesis are as follows: Underestimation of dietary risk behavior is an important barrier to preventive dietary changes. Furthermore, underestimation of dietary risk behavior should be taken into account when using psychosocial models to explain dietary behavior (change), like the attitude, social influences, self-efficacy model and the Transtheoretical Model. Computer-tailored nutrition education is a means to apply insights about awareness of dietary behavior, psychosocial determinants of dietary behavior and stages of change in dietary behavior to stimulate people to change their diet towards dietary recommendations. It is further concluded that tailored mutrition education is more effective in inducing dietary changes, especially fat reduction, than general nutrition information. 


\section{Samenvatting}

De Ontwikkeling en Evaluatie van Geautomatiseerde

Voedingsvoorlichting-op-Maat

Uit epidemiologisch onderzoek is gebleken dat het eten van te veel (verzadigd) vet en te weinig groente en fruit gerelateerd is aan een hogere kans op het krijgen van hart- en vaatziekten en bepaalde vormen van kanker. Daarnaast kan op basis van voedselconsumptieonderzoek worden geconcludeerd dat veel mensen in Nederland meer vet en minder groente en fruit eten dan door deskundigen wordt aanbevolen.

In Nederland zijn de laatste jaren een aantal activiteiten ontplooid om vooral de vetconsumptie te doen dalen. Deze campagnes, zoals bijvoorbeeld de 'Let op Vet' campagnes, hebben zich met name gericht op het vragen van aandacht voor de 'vetboodschap' en op het beïnvloeden van attitudes ten aanzien van minder vet eten. Hoewel deze campagnes een behoorlijk bereik hadden, was de proportie van mensen die van plan waren om minder vet te gaan eten na de campagne niet gestegen.

De discrepantie tussen de voedingsgewoonten en de aanbevelingen voor een gezonde voeding in Nederland en het tegenvallende effect van massamediale campagnes op die voedingsgewoonten, was reden om onderzoek te doen naar de redenen van mensen om (te) veel vet en (te) weinig groente en fruit te eten. Op basis van deze determinantenstudies werd een voedingsvoorlichtingsinterventie ontwikkeld, geïmplementeerd en geevalueerd.

\section{Determinantenstudies}

Het zogenaamde Attitude, Sociale invloed, Eigen-effectiviteit (ASE)-model en het Transtheoretisch Model werden gebruikt als theoretisch kader om de belangrijkste determinanten van (veranderingen in) consumptie van vet, groente en fruit in kaart te brengen. Het ASE-model gaat er van uit dat de motivatie (de intentie; ben ik het van plan?) om gezond gedrag te vertonen (dus bijvoorbeeld om minder vet of meer fruit te gaan eten) wordt bepaald door drie factoren: de attitude, de sociale invloeden, en de eigen-effectiviteitsverwachtingen ten aanzien van het gezonde gedrag. Hierbij is de attitude een afweging van voor- en nadelen die de betrokkene van het gezonde gedrag verwacht (Levert het me wat op?). De sociale invloeden worden bepaald door de sociale norm ten aanzien van het gezonde gedrag (Wat vinden anderen er van?), in hoeverre de sociale omgeving het gezonde gedrag daadwerkelijk actief ondersteund (Krijg ik hulp?), 
en of mensen in de directe omgeving zelf het gezonde gedrag vertonen (Wat doen anderen?). De eigen-effectiviteit, ten slotte, is de inschatting die de betrokkene maakt of hij of zij in staat is om het gedrag in gezonde richting te veranderen (Kan ik het wel?). Een belangrijke implicatie van het ASE-model is dat iemands gedrag kan worden veranderd door zijn of haar attitude, ervaren sociale invloeden en/of de eigen-effectiviteitswerwachtingen te beïnvloeden.

Uit eerder onderzoek was gebleken dat mensen in Nederland in meerderheid weten dat minder vet eten goed is voor de gezondheid, en dat zij minder vet eten goed vinden smaken. Verder zijn zij er van overtuigd dat eten met minder vet vrij eenvoudig te realiseren en wol te houden is, en men geeft in ruime meerderheid aan voldoende kennis te bezitten over vetarm eten. Ook geeft een meerderheid aan dat men door familie en vrienden zeker niet wordt belemmerd om minder vet te eten. Op basis van deze informatie kon worden geconcludeerd dat in Nederland de voorwaarden aanwezig waren voor een vermindering van de vetconsumptie. Wat echter ook duidelijk naar voren kwam was dat vrijwel niemand van diezelfde Nederlanders wan plan was om de eigen vetconsumptie te verlagen. In termen van het ASE-model: De respondenten hadden een positieve attitude ten aanzien van eten met weinig vet, ze hadden een positieve inschatting van hun eigeneffectiviteit en de sociale invloeden ten aanzien van weinig vet te eten, maar hadden toch niet de intentie om minder vet te gaan eten. Iets soortgelijks treedt op met betrekking tot groente- en fruitconsumptie. Mensen vinden in het algemeen groente en fruit lekker en gezond, de meeste mensen voelen zich door hun omgeving gesteund om voldoende groente en fruit te eten, en denken goed in staat te zijn om voldoende groente en fruit tot zich te nemen. Toch eten de meeste Nederlanders te weinig groente en fruit en is een meerderheid niet van plan om meer te gaan eten.

Voordat een gedragsverandering wordt overwogen, dus voordat er sprake kan zijn van intentie, is het noodzakelijk dat degene die de gedragsverandering overweegt, zich ervan bewust is het te veranderen gedrag te vertonen. Voordat iemand bijvoorbeeld zal overwegen te stoppen met roken, moet die persoon weten dat hij rookt. Iedereen weet echter van zich zelf of hij rookt of niet. Bewustwording van het eigen ongezonde gedrag is met betrekking tot 'stoppen met roken' dus geen relevante factor en is mede daarom niet in onderzoek met het ASE-model benadrukt. Roken is echter op een aantal punten een principieel ander gezondheidsrisicogedrag dan het eten van vet $\mathrm{en}$, in mindere mate, het eten van groente en fruit. Roken is een zeer zichtbaar gedrag en in de gezondheidsvoorlichting wordt het beschouwd als een gedrag met twee mogelijkheden: Je doet het wel of je coet het niet. Daarom is de voorlichtingsboodschap ook eenduidig: stoppen met 
roken. Eten echter, bestaat uit een diversiteit van handelingen. Zo wordt de vetconsumptie bepaald door het eten van verschillende voedingsmiddelen die in een veelheid van combinaties kunnen worden geconsumeerd en op zeer veel verschillende manieren kunnen worden bereid. Aan vetconsumptie liggen dus meerdere gedragingen ten grondslag en is het niet eenvoudig om het niveau van de eigen vetconsumptie te kunnen beoordelen. Mede hierdoor is ook de voorlichtingsboodschap ten aanzien van vet niet eenvoudig. Stoppen met vet is niet gewenst, en minder vet eten kan op zeer veel verschillende manieren worden ingevuld.

Het begrip "bewustzijn van risicogedrag' heeft een duidelijke fundering in de sociaalpsychologische inzichten over hoe en waarom mensen hun gedrag veranderen. Het Transtheoretische Model, ook wel het 'Stages of Change' model genoemd, is in dit kader belangrijk. Het model geeft aan dat gedragsverandering niet een discreet éenstaps proces is maar dat hierin ten minste vijf verschillende fasen zijn te onderscheiden: precontemplatie, contemplatie, voorbereiding, actie, en gedragsbehoud. Mensen in precontemplatie overwegen niet om hun gedrag te veranderen, mensen in contemplatie overwegen dit wel maar hebben nog geen concrete plannen. Als die plannen wel worden gemaakt komt men in de voorbereidingsfase waarna bij werkelijke (pogingen tot) gedragsverandering de actiefase optreedt. De behoudsfase begint als de gedragverandering gedurende langere tijd is volgehouden.

In de eerste fase, precontemplatie, is de verandering van gedrag niet aan de orde, het wordt niet overwogen. In deze fase zijn mensen zich vaak niet bewust van hun risicogedrag. In wat een aanvulling op het fasenmodel kan worden gezien heeft Weinstein bewustzijn van risicogedrag verder gespecificeerd als een eerste essentiêle stap in het proces van gedragsverandering van precontemplatie naar contemplatie. Hierbij wordt onderscheid gemaakt tussen drie stadia van bewustzijn. Het eerste stadium is bereikt wanneer mensen zich bewust zijn van het risicogedrag als zodanig: Men weet dat te vet eten slecht is. In het tweede stadium is men zich er van bewust dat er (veel) mensen in hun omgeving het risicogedrag vertonen: Men weet dat er in het algemeen te veel vet wordt gegeten in Nederland. In het derde stadium, tenslotte, is men zich er ook van bewust zelf het risicogedrag te vertonen: Men weet van zichzelf dat men te veell vet eet. Het model zegt dat alleen als mensen dit derde stadium van bewustzijn hebben bereikt, zij gemotiveerd kunnen worden om hun 'risicogedrag' te veranderen. Pas dan zullen factoren als attitudes, sociale invloeden en eigen-effectiviteitsverwachtingen relevant worden om te bepalen of men het gedrag ook werkelijk zal veranderen. 
Om de roll van bewustzijn van eigen consumptie in het proces van verandering van vetconsumptie te bestuderen, werd bij 1507 inwoners van twee Nederlandse gemeenten een voedselfrequentielijst afgenomen waarmee de vetconsumptie op een objectieve manier kan worden geschat, en werd aan de respondenten gevraagd om hun eigen vetconsumptie te beoordelen op een schaal van heel laag tot heel hoog. Vervolgens werd gekeken in hoeverre de vetconsumptie die werd geschat met de objectieve methode overeen kwam met de eigen inschatting van de respondenten. Uit het onderzoek bleek dat ongeveer de helft wan de mannen en iets meer dan een derde van de vrouwen hun vetconsumptie onderschatten.

De eigen inschatting die mensen van hun vetconsumptie maakten bleek, in tegenstelling tot de schatting van het werkelijke vetconsumptieniveau, significant gecorreleerd te zijn aan intentie om minder vet te gaan eten: Respondenten die hun vetconsumptie onderschatten hadden significant minder vaak de intentie om minder vet te gaan eten dan respondenten die hun vetconsumptie realistisch inschatten. Bij mensen die hun vetconsumptie onderschatten bleken attitudes, sociale invloeden en eigen-effectiviteitsverwachtingen geen samenhang te vertonen met vetconsumptie. Geconcludeerd werd dat de eigen inschatting die mensen maken van hun vetconsumptie slechts weinig samenhang toont met de hoeveelheid vet die ze werkelijk eten en dat vooral mensen die relatief veel vet eten hun consumptie onderschatten. Daamaast werd geconcludeerd dat onderschatting van vetconsumptie een belangrijke barrière is in motivatie om de vetconsumptie te verlagen. Tot slot werd geconcludeerd dat misconceptie van de eigen vetconsumptie belangrijke consequenties heeft voor de bruikbaarheid van het ASE-model. Bij mensen die onrealistisch zijn over hun vetconsumptie, zijn attitudes, sociale invloeden en eigen-effectiviteitsverwachingen geen determinanten van vetconsumptie. De implicatie is dat, conform het model van Weinstein, deze psychosociale factoren waarop voedingsvoorlichting vaak is gericht, pas relevant worden als mensen zich bewust zijn van hun eigen consumptieniveaus.

Een volgende studie werd uitgevoerd om na te gaan wat mogelijke oorzaken zijn van misconceptie van de eigen consumptie. Op basis van focusgroepinterviews werden een aantal mogelijke oorzaken van misvattingen over de eigen vetconsumptie geinventariseerd. Gebrek aan kennis over vet in voedingsmiddelen en/of de aanbevolen hoeveelheden voor vet, onrealistische vergelijking van de eigen vetconsumptie met die van anderen, het idee

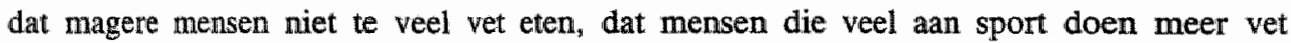
mogen eten, dat zolang men geen lichamelijke klachten ervaart de vetconsumptie niet te hoog zal zijn, en dat vroeger veel meer vet werd gegeten in Nederland, kwamen uit de 
interviews naar voren als mogelijke oorzaken van misconceptie. Daarnaast bleek dat wanneer men dacht al minder vet te zijn gaan eten, de huidige vetconsumptie als laag werd ingeschat. De manier waarop mensen hun eigen vetconsumptie inschatten in vergelijking met anderen bleek de sterkste samenhang te vertonen met misconceptie van vetconsumptie. Mensen die denken dat hun vetconsumptie lager was dan die van vergelijkbare anderen waren meer geneigd hun vetconsumptie te onderschatten. Ook bleek dat bijna de helft van de respondenten hun eigen vetconsumptie lager of veel lager inschatte dan die van vergelijkbare anderen terwijl maar $8 \%$ dacht dat hun eigen vetconsumptie hoger was. Dit duidt op een duidelijke optimistische bias in de eigen inschatting van de vetconsumptie. De overige mogelijke voorspellers, waaronder kennis over vet in voedingsmiddelen, bleken slechts een bescheiden samenhang te vertonen met misconceptie van vetconsumptie. Mensen met meer kennis over vet schatten hun vetconsumptie nauwelijks realistischer in dan mensen met minder kennis. Mogelijk is het zo dat ook woor mensen met relatief veel kennis over de vetgehaltes van verschillende voedingsmiddelen, het "berekenen" van de eigen vetinname op basis van deze kennis moeilijk is. Geconcludeerd werd dat persoonlijke feedback over de eigen vetconsumptie in vergelijking tot de aanbevelingen en de vetinname van vergelijkbare anderen een manier zou kunnen zijn om mensen meer bewust te maken van hun vetconsumptie en hen zo te motiveren hun vetinname te verminderen.

\section{Interventiestudies}

Om mensen bewust te maken van hun eigen consumptie van vet, groente en fruit en hen verder te motiveren om minder vet en meer groente en fruit te gaan eten, werd een voedingsvoorlichtingsinterventie ontwikkeld waarmee aan respondenten persoonlijke feedback over hun voeding kon worden gegeven. Respondenten vulden schriftelijke vragenlijsten in waarmee de consumptie en de eigen inschatting van vet, groente en fruit kon worden gemeten, alsmede attitudes, ervaren sociale invloeden, eigen-effectiviteitsverwachtingen en motivatie ten aanzien van het eten van minder vet en van meer groente en fruit. Op basis van de antwoorden op deze vragenlijst kregen respondenten persoonlijke brieven waarin zij informatie kregen over hun eigen consumptieniveau vergeleken met het gemiddelde van hun seksegenoten en met de aanbevolen hoeveelheden. Daarnaast was het ook mogelijk om op deze wijze persoonlijke informatie te geven over voor- en nadelen van het eten van minder vet en van meer groente en fruit en om suggesties the geven hoe men de eigen vetconsumptie kan verlagen en hoe men meer groente en frult tot zich kan nemen. Deze vorm van voedingsvoorlichting werd woedingsadvies-op-maat genoemd. 
Om na te gaan of dit advies-op-maat mensen kan motiveren en helpen om minder vet en meer groente en fruit te gaan eten en welke soort persoonlijke feedback hierwoor belangrijk is, zijn drie experimenten uitgevoerd.

Het eerste experiment werd uitgevoerd bij 347 werknemers van het Koninklijke Shell Laboratorium in Amsterdam die willekeurig werden verdeeld over twee onderzoeksgroepen. De ene helft kreeg het advies-op-maat in de vorm van een persoonlijke brief, terwij» de andere helft van de deelnemers een algemeen voedingsadvies $\mathrm{kreeg}$, ook in de vorm van een persoonlijke brief die wat betreft briefpapier, lay-out en illustraties gelijk was aan het advies-op-maat. Het bleek dat werknemers die het voedingsadvies-op-maat kregen significant minder vet waren gaan eten dan werknemers die een algemeen voedingsadvies kregen. Een significant effect van het advies-op-maat werd ook gevonden voor veranderingen in attitudes en intenties ten aanzien van minder vet en van meer groente en fruit eten. Daarnalast waren de respondenten die een advies-op-maat kregen gemiddeld meer tevreden over de informatiebrieven die zij ontvingen en gaven vaker aan hun mening over hun voedingsgewoonten of hun voedingsgewoonten veranderd te hebben naar aanleiding van de informatie die zij ontvingen. Op basis van dit experiment werd geconcludeerd dat voedingsvoorlichting-op-maat een veelbelovende manier is om mensen te stimuleren om hun voedingsgewoonten in de richting van de aanbevelingen te veranderen.

Met een tweede experiment werd onderzocht welke adviezen-op-maat essentieel waren om mensen te motiveren hun voeding te veranderen. Twee vormen van advies-op-maat, een uitgebreid advies en een beperkter advies, werden hiervoor vergeleken. In het uitgebreide advies werd ingegaan op de consumptie van vet, groente en fruit, en op attitudes, sociale inwloeden en eigen-effectiviteitswerwachtingen met betrekking tot het eten van minder vet en meer groente en fruit. In de beperkte versie werd alleen ingegaan op de consumptiegegevens. Het experiment werd uitgevoerd bij 315 werknemers van de Stichting Thuiszorg in Zuid-Limburg die willekeurig werden verdeeld in twee onderzoeksgroepen. De eerste groep kreeg het uitgebreidere advies, de tweede groep het beperkte advies. In beide groepen daalde de vetconsumptie en steeg de consumptie van groente en fruit significant. Ex werd echter geen verschil in consumptie van vet, groente en fruit gevonden tussen de twee groepen. Wel vonden de mensen die uitgebreid advies kregen hun advies-op-maat brieven significant interessanter en geloofwaardiger dan de mensen die de beperkter advies-op-maat brief kregen. De resultaten bevestigden dat advies-opmaat effectief kan zijn om mensen te stimuleren han voeding te veranderen. Informatie over psychosociale determinanten van vet, groente en fruit lijkt niet noodzakelijk voor een 
effectief advies-op-maat maar draagt waarschijnlijk wel bij tot een betere waardering van het advies.

In het laatste experiment werd onderzocht wat de effecten van een voedingsadvies op langere termijn waren en of een tweede adviesbrief deze effecten op termijn kan verbeteren. Voorlichting-op-maat had een significant groter effect op de gewenste veranderingen in voeding (minder vet, meer groente en fruit) dan algemene voorlichting. Het effect op de vetconsumptie was ook nog aanwezig bij een tweede nameting, ruim twee maanden nadat de respondenten hun voorlichting-op-maat brief hadden ontvangen. Respondenten die in de tussentijd een tweede persoonlijke voorlichtingsbrief kregen die inging op (de afwezigheid van) veranderingen naar aanleiding van de eerste brief, hadden bij de tweede nameting een lagere vetconsumptie en een hogere fruitconsumptie dan respondenten die eenmalig voedingsvoorlichting-op-maat kregen. De resultaten bevestigden dat voedingsvoorlichting-op-maat effectief kan zijn om mensen te motiveren hun voedingsgewoonten te veranderen en dat feedback over de voortgang van die veranderingen dit effect kan versterken.

De conclusies van het proefschrift zijn als volgt: Misvattingen over het eigen voedingsgedrag kunnen een effectieve voedingsvoorlichting in de weg staan. Daarnaast moeten misvattingen over het eigen voedingsgedrag in ogenschouw genomen worden bij het gebruiken van modellen die gedrag of gedragswerandering proberen te verklaren zoals het ASE-model en het Transtheoretisch Model. Voorlichting-op-maat lijkt een geschikte methode om, door mensen bewust te maken van hun persoonlijke voedingsgedrag en informatie te geven die aansluit bij hun persoonlijke gedrag en gedragsdeterminanten, mensen te motiveren hun voeding te veranderen in de richting van aanbevelingen voor een gezonde voeding. Geconcludeerd kan worden dat voorlichting-op-maat hierin effectiever is dan algemene schriftelijke voedingsvoorlichting. 


\section{Curriculum Vitae}

Johannes (Hans) Brug was born on June 21, 1963 in Apeldoorn. In 1982 he graduated at the Christian Lyceum Dr. W.A. Visser 't Hoofd in Leiden and received a vwo diploma. That same year he started his university training at the Agricultural University in Wageningen. He received his MSc. diploma in Human Nutrition in 1989. After graduation he worked for 18 months at the TNO Nutrition Institute in Zeist at the Department of Epidemiology. In 1991 he was granted a fellowship from the Dutch Cancer Society which enabled him to specialize in nutrition education research in order to study the possibilities of nutrition education aimed at primary prevention of chronic diseases. From 1994 he has been employed as research associate at the Department of Health Education and Promotion, Maastricht University, in which period the studies described in this thesis were conducted. 


\section{Acknowledgements}

I would like to express my gratitude for helping me to realize this dissertation to the Dutch Cancer Society for its financial support and (in alphabetical order) to:

Patricia van Assema

Jack Berben

Karen Glanz

Harm Hospers

Gerjo Kok

Ingrid Steenhuis

Hein de Vries

Astrid Weij 
Appendix

Examples of Feedback letters
A: Tailored feedback letter
B: General nutrition information letter 
Geachte mevrouw Jansen,

U heeft onlangs een vragenlijst over voeding ingevuld. Met de antwoorden die u toen op onze vragen heeft gegeven, is door mij voor u een voedingsadvies samengesteld. Dit voedingsadvies is voor u persoonlijk van belang. Het advies houdt rekening met uw persoonlijke eetgewoonten en ideeën over voeding.

Voeding is van groot belang voor uw gezondheid. Met deze brief proberen wij $u$ wat meer te vertellen over uw eigen voeding en geven wij $u$ suggesties hoe $u$ beter kunt eten. Om gezonder te eten hoeft $u$ niet uw hele voeding te veranderen. Met een paar eenvoudige aanpassingen kunt u al een eind op weg zijn.

In deze brief komen de onderwerpen vet, groente en fruit ter sprake. Niet te veel vet, en voldoende groente en fruit zijn belangrijke onderdelen van een gezond eetpatroon. Uw persoonlijke eetgewoonten zullen worden vergeleken met adviezen van deskundigen.

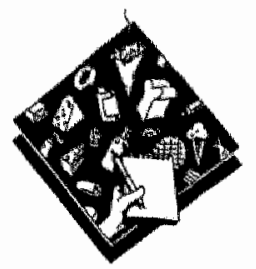

Uit ons onderzoek blijkt dat $u$ waarschijnlijk meer vet eet dan door deskundigen wrordt aanbevolen. $U$ eet ook meer vet dan de meeste andere vrouwen. U heeft 33 vetpunten. Eén vetpunt is ruim $3 \mathrm{gram}$ vet per dag. $\mathrm{U}$ zou niet meer, en liefst minder, dan 23 vetpunten moeten hebben. In de grafiek hieronder staat dat weergegeven.

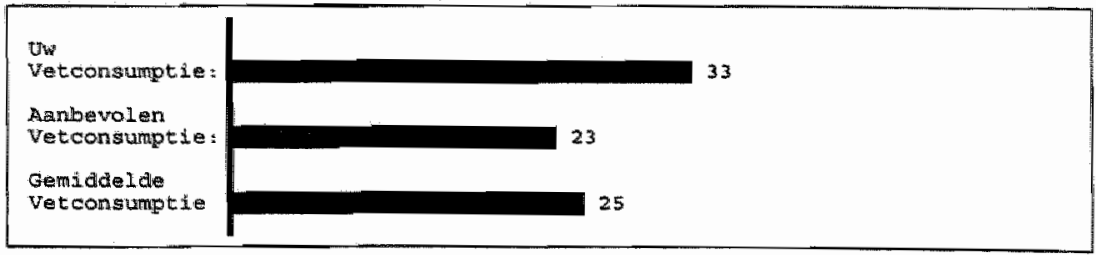


Te veel vet eten is niet goed voor de gezondheid. Uit onderzoek is gebleken dat mensen die weel vet eten meer kans hebben op bijwoorbeeld overgewicht, hartklachten, en suikerziekte. Ook wie keurig op gewicht is en daarom denkt onbekommerd te kunnen eten, moet op vet letten. Slanke mensen hebben een vrijwel even grote kans om hart- en vaatziekten te krijgen. Je wordt misschien niet dik van vet eten maar je vaten kunnen wel dichtslibben. Andere mensen denken dat ze meer vet nodig hebben omdat ze veel aan sport doen. Mensen die veel aan sport doen kunnen echter beter meer koolbydraten eten. Koolhydraten zitten in aardappels, brood, fruit, rijst en spaghetti. Koolhydraten zijn een veel betere brandstof tijdens sport.

\section{UUGGESTIES OM MINDER VET TE GAAN ETEN}

Hieronder volgen één of meer belangriike vetleveranciers in uw voeding:

-Broodbeleg

-Tussendoortjes

\section{BROODBELEG}

\section{VLEESWAREN}

$U$ eet vrij veel brood met vleeswaren. Zelfs de magerder vleeswaren bevatten nog behoorlijk veel vet. $U$ kunt in plaats van vleeswaren eens wat vaker zoet beleg op uw brood doen. Wist $u$ dat 1 gram vet ongeveer drie keer zoveel calorieën bevat als 1 gram suiker?

\section{TUSSENDOORTJES}

Een belangrijk deel van uw vet komt door de tussendoortjes die us eet. U eet vrij veel tussendoortjes die vet zijn. Als u trek heeft tussen de maaltijden door kunt $\mathbf{u}$ ook iets eten dat niet vet is, bijwoorbeeld fruit, een stuk ontbijtkoek, of een boterham.

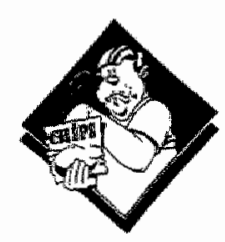

\section{NOTEN EN ZOUTJES}

Noten, chips, en andere zoutjes zijn vaak vet. Minder vette knabbels zijn popcorn, zoute stokjes, krenten en rozijnen, en japanse zoutjes. Probeer minder vaak vette noten en zoutjes te eten. 


\section{GEBAK, GROTE KOEKEN EN CHOCOLADE}

$U$ eet vrij vaak gebak, grote koeken of chocolade. Bijna alle soorten gebak zijn vet. Alleen vruchtenvlaai is niet zo vet. Het beste is om slechts af en toe gebak te eten. Bewaar het voor echt speciale gelegenheden. De grote koeken zoals gevulde koek, kokosmakronen en dergelijke zijn ook vaak erg vet. Er zijn echter ook minder vette soorten.

Vette koeken zijn bijwoorbeeld: kokosmakroon, gevulde koek, gevulde speculaas, cake, en stroopwafel.

Minder vette koeken zijn bijvoorbeeld: ontbijtkoek, eierkoek, en evergreen.

Als $u$ in plaats van een vette koek een minder vette koek neemt scheelt dit al snel meer dan 5 gram vet. Chocolade is altijd vet. Probeer dit niet te veel te eten.

\section{KOEKJES}

Uit ons onderzoek blijkt dat u vrij veel koekjes eet. Dit is een belangrijke bron van vet in uw voeding. Wat minder koek zou daarom goed zijn.

Sommige soorten koek zijn minder vet, andere zijn heel erg vet. Probeer de minder vette soorten te kiezen.

Vette koekjes zijn bijvoorbeeld: speculaas, chocoladebiscuit, bastognekoek, bokkepootje, sprits.

Minder vette koekjes zijn bijvoorbeeld: ontbijtkoek, biscuit, en rozijnenbiscuit.

\section{MOET ALLES ANDERS?}

Als $u$ het voorgaande hebt gelezen denkt u misschien: 'Moet ik dat allemaal veranderen?' Nee, u hoeft natuurlijk niet alles in één keer te doen. Maar probeer gewoon met éen stap te beginnen. Kies uit het bovenstaande één of twee veranderingen die u makkelijk lijken en begin daar mee. 
U denkt dat het niet makkelijk is om minder vet te gaan eten. De meeste mensen hebben vooral moeite om minder vet te eten bij tussendoortjes of bij speciale gelegenheden.

Het is ook best moeilijk om minder vet te eten op feestjes, wanneer je bij anderen gaat eten, of in restaurants. $U$ hoeft natuurlijk ook niet altijd op vet te gaan letten. U kunt af en toe eens een maaltijd of een avond 'vrij af' nemen. Maar als u liever bij bijzondere gelegenheden ook wat meer op vet let, volgen hier nog een paar tips.

\section{UIT ETEN}

Wanneer mensen uit eten gaan, vinden zij het vaak moeilijk om minder vet te eten. In restaurants weet je vaak niet hoeveel vet er in gerechten zit. Probeer niet te hongerig te zijn als u uit eten gaat, dan is de verleiding om voor zware en vette maaltijden of gerechten te kiezen minder groot. Eet bijvoorbeeld nog iets lichts voordat $u$ naar het restaurant gaat.

Wist $\mathbf{u}$ dat gerechten met vis in het algemeen minder vet bevatten dan gerechten met vlees? Heldere soepen bevatten in het algemeen minder ver dan gebonden of crèmesoepen.

\section{BIJ ANDEREN ETEN}

Wanneer $u$ bij vrienden of kennissen gaat eten en $u$ wilt niet te vet eten, kunt $\mathrm{u}$ dit van te voren natuurlijk met uw vrienden bespreken. Zeg gewoon dat u bezig bent op vet te letten. De meeste mensen hebben hier wel begrip voor omdat zij zelf ook al wel eens geprobeerd hebben om minder vet te eten.

\section{FEESTJES}

Als u weet dat u naar een feestje gaat en $u$ toch wilt letten op minder vet eten, kunt $u$ hier bijvoorbeeld al de rest van de dag rekening mee houden. Probeer die dag weinig vette dingen te eten, dan kunt u zich tijdens het feestje wat extra's veroorloven. Probeer niet met honger naar een feestje te gaan want dan is de verleiding extra groot om daar veel vette dingen te gaan eten.

\section{TUSSENDOORTJES}

Wanneer $\mathrm{u}$ tussen maaltijden door honger krijgt, is de verleiding groot om vette tussendoortjes te eten. Zorg dat u niet te veel van dit soort tussendoortjes in huis hebt. De verleiding om ze te eten is dan kleiner. Als u vaak tussen maaltijden door honger krijgt, kunt u proberen om tijdens de maaltijden iets meer te eten. 


\section{GROENTE EN FRUIT}

Groente en fruit zijn heel belangrijk voor een gezond voedingspatroon. Groente en fruit zijn een belangrijke bron van vitamines. Uit wetenschappelijk onderzoek is gebleken dat mensen die (ruim) voldoende groente en fruit eten minder kans hebben om hart- en vaatziekten en bepaalde vormen van kanker te krijgen.

\section{EET U WEL VOLDOENDE GROENTE?}

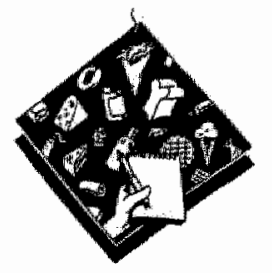

U eet:

gemiddeld iedere dag groente

De aanbeveling is: $\quad 150-200$ gram groente per dag

In onze vragenlijst hebben wij a gevraagd om aan te geven hoe vaak u groente en rauwkost eet. Daaruit bleek dat $\mathbf{u}$ in ieder geval dagelijks groente eet. Dat is een heel gezonde gewoonte. Ga daar wooral mee door.

\section{EN DAN NOG FRUIT, HOEVEEL EET U?}

\section{FRUIT, ECHT GEZONDHEIDSVOEDSEL}

Fruit is echt gezondheidsvoedsel. Fruit is, net als groente, rijk aan vitamines en vezels. Mensen die veel fruit eten, hebben meer weerstand. Het eten van fruit zorgt voor een betere stoelgang, fruit is licht verteerbaar en

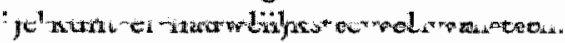

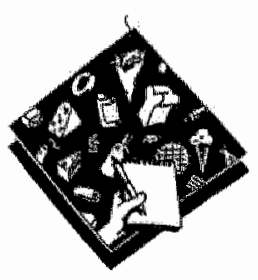

U eet: $\quad$ meer dan 1 stuk fruit per dag

De aanbeveling is: 2 stuks fruit per dag

$U$ denkt dat u vrij weinig fruit eet. Uit de vragenlijst blijkt echter dat $u$ waarschijnlijk voldoende fruit eet. Ga zo door! Deskundigen doen de aanbeveling om minstens twee stuks fruit per dag te nemen. Dagelijks fruit hoort bij een gezonde voeding. 
Ik hoop mevrouw Jansen, dat u deze informatie over uw voeding interessant hebt gevonden. Deze brief heeft u misschien een beter beeld gegeven van uw eigen voedingsgewoonten.

Met vriendelijke groet,

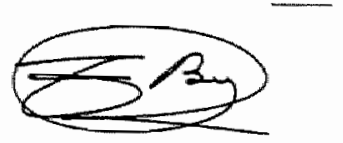

Ir. J. Brug, voedingskundige

Deze persoonlijke voorlichting is mogelijk gemuakt door een subsidie van de Nederlandse Kankerbestrijding.

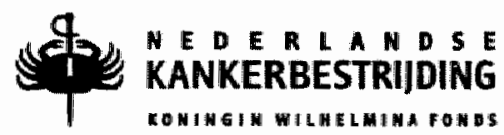

- 1994 Vakgroep Gezondheidsvoorlichting (GVO), Rajkswniversiteit Limburg, Maastricht. Tekst: Ir J. Brug en dr P. Van Assema. Software constructie: J. Berben.

Alle rechten op dit advies op maat berusten bij de Rijksuniwersiteit Limburg Het advies op math is alleen bedoeid roor persoonlijk gebruik. 


\section{RECEPTEN OM MINDER VET TE ETEN}

De recepten zijn voor 2 personen.

\section{MET VLEES}

Varkensvlees a la Piperi

$200 \mathrm{~g}$ varkensvlees, $10 \mathrm{~g}$ plantadardige (dieet) margarine, $1 / 2$ blikje tomatenpuree, 1 ui, 1 rode paprika, 1 groene peper, 1 teentje knoflook, 1 eetlepel ketjap, peper

Snijd de ui klein. Was de paprika, verwijder de pitjes uit de peper en snijd beiden in reepjes. Snijd het vlees in blokjes. Verhit de margarine. Fruit hierin de ui, paprika, en peper. Knijp het teentje knoflook hierbij fijn. Laat het geheel 5 minuten sudderen. Voeg de tomatenpuree toe. Voeg vervolgens het vlees, de ketjap, wat peper en een kopje water toe. Breng het geheel zachtjes aan de kook en laat het 30 minuten pruttelen.

Per persoon: $240 \mathrm{kcal}, 16 \mathrm{~g}$ vet

\section{ZONDER VLEES}

\section{Stamppot prei}

$600 \mathrm{~g}$ aardappelen, zout, $400 \mathrm{~g}$ prei, $20 \mathrm{~g}$ plantaardige (dieet) margarine, 2 theelepels kerrie, 2 dl melk, nootmuskat

Schil de aardappelen en kook ze in weinig water met zout gaar. Maak de prei schoon en snijd ze in ringen. verwarm de margarine en voeg de prei, wat zout en de kerrie toe en stoof de groente in 10 minuten gaar. Verwarm de melk. Maak van de gare aardappelen met de hete melk en nootmuskaat een puree. Schep de prei erdoor. Serveer eventueel met parmezaanse kaas.

Per persoon: $450 \mathrm{kcal}, 10 \mathrm{~g}$ vet 
Geachte mevrouw Jansen,

U heeft onlangs een vragenlijst over voeding ingevuld voor een onderzoek van de Rijksuniversiteit Limburg. Omdat u meedoet aan dat onderzoek ontvangt u deze brief. In de brief staan een aantal adviezen over gezonde voeding. Deze adviezen zijn gebaseerd op aanbevelingen van de Nederlandse Voedingsraad.

\section{WAAROM GEZONDE VOEDING?}

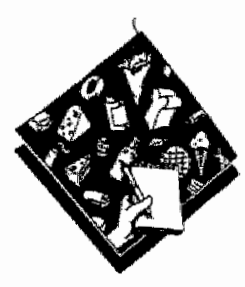

MINDER VET

Voeding is van groot belang voor uw gezondheid. Door gezond te eten krijgt uw lichaam alle voedingsstoffen die het nodig heeft. Van sommige voedingsstoffen krijgen we echter vaak te veel binnen. In Nederland wordt vooral te veel vet gegeten. Er zijn echter ook voedingsmiddelen waar we best wat meer van zouden kunnen eten. Uit onderzoek blijkt dat wij in Nederland gemiddeld meer groenten en fruit zouden moeten eten.

Vet is nodig in onze voeding. Maar te veel vet is op den duur schadelijk voor onze gezondheid. Door te veel vet te eten is de kans op overgewicht en hoge bloeddruk groter. Ook hebben mensen die te veel vet eten een grotere kans op het krijgen van hart- en vaatziekten, suikerziekte, en bepaalde vormen van kanker. Ook wie keurig op gewicht is en daarom denkt onbekommerd te kunnen eten, moet op vet letten. Slanke mensen hebben een vrijwel even grote kans om hart- en vaatziekten te krijgen. Je wordt misschien niet dik van vet eten, maar je vaten kunnen wel dichtslibben. Andere mensen denken dat ze meer vet nodig hebben orndat ze veel aan sport doen. Mensen die veel aan sport doen kunnen echter beter meer koolbydraten eten. Koolhydraten zitten in aardappels, brood, fruit, rijst en spaghetti. Koolhydraten zijn een veel betere brandstof tijdens sport. Van de tien Nederlanders eten er ongeveer zeven te veel vet. De meeste mensen weten echter helemaal niet dat zij zelf te veel vet eten. 
Gemiddeld eten de Nederlanders 105 gram vet per dag terwijl 75 gram al voldoende is. Voor de meeste mensen is het daarom belangrijk dat ze minder vet gaan eten.

Met een paar eenvoudige aanpassingen kunt $\mathrm{u}$ dagelijks al minder vet eten. Eeri paar tips:

\section{MELKPRODUKTEN:}

- Kies halfvolle of magere melk, karnemelk en magere yoghurt in plaats van volle melkprodukten.

\section{BROODBELEG:}

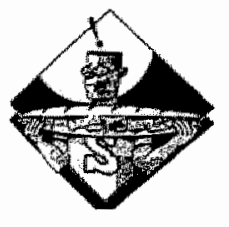

- Smeer (dieet-)halvarine in plaats van margarine of boter op brood.

- Probeer eens $20+$ of $30+$ dieetkazen in plaats van volvette kaas.

- Kies voor magere vleeswaren voor op brood. Magere vleeswaren zijn bijwoorbeeld achterham, rookvlees en kipfilet.

- Kies wat vaker jam of appelstroop op brood in plaats van kaas of vlees.

\section{DE WARME MAALTTJD:}

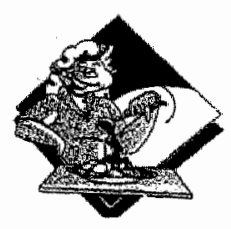

- Gebruik bij het koken zo weinig mogelijk vet of olie.

- Kies voor mager vlees bij de maaltijd, bijvoorbeeld kip, rosbief, hamlappen, varkensfilet of tartaar.

- Kies eens wat vaker vis in plaats van vlees. Vooral vis als kabeljauw, schol en tong zijn mager.

- Gebruik zo weinig mogelijk jus en maak de jus minder vet door deze an te lengen met water.

\section{TUSSENDOORTJES:}

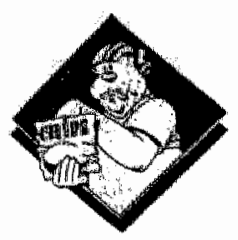

Tussendoortjes zoals snacks, noten en zoutjes en gebak en koekjes zijn een belangrijke bron van vet. Eet hier niet te veel van, bewaar het voor speciale gelegenheden. Als $\mathrm{u}$ behoefte heeft aan een tussendoortje neem dan een stuk fruit, of een boterham. Andere niet vette tussendoortjes zijn bijvoorbeeld rozijnen, japanse zoutjes, ontbijtkoek en popcorn. 
Groenten en fruit is echt gezondheidswoedsel. Groenten en fruit zijn de belangrijkste bron van vitamines en voedingsvezel. Uit wretenschappelijk onderzoek zijn aanwijzingen gevonden dat mensen die veel groenten en fruit eten minder kans hebben op het krijgen van hart- en vaatziekten en kanker. In Nederland wordt minder groente en fruit gegeten dan door het Voorlichtingsbureau voor de Voeding wordt aanbevolen. De aanbeveling is om dagelijks 200 gram groente en 2 stuks fruit te eten.

\section{GOED VOOR DE LIJN}

Groenten en fruit bevatten slechts zeer weinig caloriëen en nauwelijks vet. Je kunt daarom bijna niet te veel groente en fruit eten en als je meer groente en fruit gaat eten word je daar niet dikker van. Groente of fruit kan ook heel goed gegeten worden in plaats van vette tussendoortjes en dat kan helpen om af te vallen.

\section{WANNEER GROENTE EN FRUIT?}

DE BROODMAALTIJD:

Veel mensen eten alleen groente bij de warme maaltijd en fruit soms als tussendoortje. Probeer eens iets anders! Groente en fruit zijn ook heerlijk bij de broodmaaltijden. Probeer eens rauwkost of fruit op brood, bijvoorbeeld pindakaas met komkommer of banaan, kaas met sla, tomaat, of stukjes appel, vleeswaren met augurk. Het is niet alleen lekker, maar het maakt de broodmaaltijd ook gezonder.

\section{DE WARME MAALTIJD}

Fruit is niet alleen een lekker en licht tussendoortje maar hoort ejgenlijk ook bij de warme maaltijd. Fruit kan natuurlijk op veel verschillende manieren worden verwerkt als toetje. Gewoon een appel of sinaasappel toe is een verstandige keuze. Of doe eens een banaan of appel door de vla of yoghurt.

Ik hoop dat deze informatie $u$ kan helpen bij het kiezen voor gezonde voeding met minder vet, en meer groente en fruit.

Met vriendelijke groet,

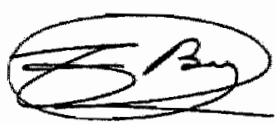

Ir. J. Brug, voedingskundige 


\section{RECEPTEN OM MINDER VET TE ETEN}

De recepten zijn voor 2 personen.

Spaghetti met tonijnsaus

$200 \mathrm{~g}$ spaghetti, 1 wi, 1 blikje tonijn in water (naturel), 1 takje peterselig, 1 eetlepel olie, 1 blikje gepelde tomaten, 1 dl bouillon, paprikapoeder, italiaanse kruiden, peper.

Kook de spaghetti volgens de aanwijzingen op de verpakking. Maak de uien schoon en snijd ze fijn. Laat de tonijn in een zeef of vergiet uitlekken en verdeel het in stukken. Was de peterselie en knip de takjes fijn. Verhit de olie en fruit hierin de uien. Voeg de tomaten, bouillon, en paprika poeder en italiaanse kruiden toe en kook de saus een paar minuten op een zacht vuur. Voeg de tonijn toe. Verhit de saus en voeg naar smaak peper toe. Strooi tot slot de peterselie erover en serveer de saus apart van de spaghetti.

Per persoon: $480 \mathrm{kcal}, 8 \mathrm{~g}$ vet

\section{Champignonrijst}

$150 \mathrm{~g}$ rijst, $250 \mathrm{~g}$ champignons, 1 ui, $10 \mathrm{~g}$ plantdardige (dieet) margarine, $1 / 4$ liter bouillon, $50 \mathrm{~g}$ geraspte oude kaas of parmezaanse kaas, peper

Snijd de ui fijn en fruit deze in een grote pan in de margarine. Breng tegelijkertijd in een andere pan de bouillon aan de kook. Snijd de champignons in plakjes en voeg deze samen met de rijst toe aan de ui. Fruit het geheel enkele minuten onder voortdurend omscheppen. Voeg de bouillon toe en laat het geheel ongeveer 20 minuten zachtjes doorkoken. Voeg de kaas en peper naar smaak toe.

Per persoon: $400 \mathrm{kcal}, 15 \mathrm{~g}$ vet 
